\title{
Results of highly selective vagotomy
}

Citation for published version (APA):

Busman, D. C. (1983). Results of highly selective vagotomy. [Doctoral Thesis, Maastricht University]. Rijksuniversiteit Limburg. https://doi.org/10.26481/dis.19830624db

Document status and date:

Published: 01/01/1983

DOI:

$10.26481 /$ dis. $19830624 \mathrm{db}$

Document Version:

Publisher's PDF, also known as Version of record

\section{Please check the document version of this publication:}

- A submitted manuscript is the version of the article upon submission and before peer-review. There can be important differences between the submitted version and the official published version of record.

People interested in the research are advised to contact the author for the final version of the publication, or visit the DOI to the publisher's website.

- The final author version and the galley proof are versions of the publication after peer review.

- The final published version features the final layout of the paper including the volume, issue and page numbers.

Link to publication

\footnotetext{
General rights rights.

- You may freely distribute the URL identifying the publication in the public portal. please follow below link for the End User Agreement:

www.umlib.nl/taverne-license

Take down policy

If you believe that this document breaches copyright please contact us at:

repository@maastrichtuniversity.nl

providing details and we will investigate your claim.
}

Copyright and moral rights for the publications made accessible in the public portal are retained by the authors and/or other copyright owners and it is a condition of accessing publications that users recognise and abide by the legal requirements associated with these

- Users may download and print one copy of any publication from the public portal for the purpose of private study or research.

- You may not further distribute the material or use it for any profit-making activity or commercial gain

If the publication is distributed under the terms of Article $25 \mathrm{fa}$ of the Dutch Copyright Act, indicated by the "Taverne" license above, 


\section{Results of highly selective vagotomy}

Proefschrift

ter verkrijging van de graad van doctor in de geneeskunde aan de Rijksuniversiteit Limburg te Maastricht, op gezag van de rector magnificus Prof.Dr. H.C. Hemker, volgens besluit van het College van Dekanen in het openbaar te verdedigen in de aula van de universiteit

Tongersestraat 53 op vrijdag 24 juni 1983 des namiddags te vier uur

door

Dick Cornelis Busman geboren te 's-Gravenhage 
Promotors: Prof.Dr. J.M. Greep, surgeon

Prof.Dr. P.J. Brombacher, clinical biochemist

Referents: David Johnston, Professor of Surgery, Leeds

Prof.Dr. H. van Houten, surgeon, Rotterdam

Prof.Dr. J. Flendrig, physician, Maastricht

Dr. J.D.K. Munting, surgeon, Heerlen. 
To the memory of my parents 



\section{List of contents}

Chapter 1 Introduction page

1.1 - introduction 1

1.2 - purpose of the study 2

1.3 - design of the study 3

1.4 - - patient selection and indications for operation 3

1.5 - nomenclature 4

1.6 - recurrence rate: what does it mean? 5

1.7 - overview of the contents

\begin{tabular}{l|l} 
Chapter 2 & Natural history and epidemiology
\end{tabular}

2.1 - natural history 9

$\begin{array}{lll}2.2 & - \text { epidemiology } & 10\end{array}$

2.3 - evolution of the operative treatment 11

\begin{tabular}{l|l} 
Chapter 3 & Surgical anatomy and physiology
\end{tabular}

\begin{tabular}{lll}
\hline 3.1 & - anatomy & 13
\end{tabular}

3.2 - physiology 19

$\begin{array}{lll}3.3 & \text { - the rationale of operative treatment } 20\end{array}$

Chapter 4 Patients and methods

$\begin{array}{lll}4.1 & \text { - description of patients } & 23\end{array}$

$\begin{array}{lll}4.2 & \text { - statistical methods } & 28\end{array}$

\begin{tabular}{l|l} 
Chapter 5 & Technical aspects of the operation
\end{tabular}

5.1 - preoperative management 33

5.2 - technique of operation 33

$\begin{array}{lll}5.3 & \text { - adaptations } & 37\end{array}$

5.4 - management of complicated duodenal ulcer 38

$\begin{array}{ll}5.5 & \text { - postoperative management } 39\end{array}$

5.6 - early modifications 40

\begin{tabular}{l|l} 
Chapter 6 & Quality control testing
\end{tabular}

\begin{tabular}{lll}
\hline 6.1 & - introduction & 41 \\
6.2 .1 & - intraoperative tests & 42 \\
6.2 .2 & - postoperative tests & 42 \\
6.3 & - discussion & 43
\end{tabular}


\begin{tabular}{l|l} 
Chapter 7 & Visick grading and follow-up
\end{tabular}

7.1 - Visick grading

7.2 - follow-up

\begin{tabular}{l|l} 
Chapter 8 & Results
\end{tabular}

8.1.1 - Visick grading

8.1.2 - recurrences

8.2 .1 - mortality

8.2.2 - complications

8.2 .3 - side effects and sequelae

\section{\begin{tabular}{l|l} 
Chapter 9 & HSV for complicated duodenal ulcer
\end{tabular}}

$\begin{array}{lll}9.1 \text { - introduction } & 63\end{array}$

$\begin{array}{lll}9.2 & \text { - diagnosis } & 63\end{array}$

$\begin{array}{lll}9.3 & - \text { technique } & 65\end{array}$

9.4 - follow-up 65

9.5 - postoperative complications 65

$\begin{array}{lll}9.6 & \text { - results } & 65\end{array}$

$\begin{array}{lll}9.7 & - \text { discussion } & 67\end{array}$

$\begin{array}{lll}9.8-\text { conclusion } & 68\end{array}$

Chapter $10 \mid$ Acid secretion studies

\begin{tabular}{lll}
\hline 10.1 - introduction & 69
\end{tabular}

$\begin{array}{lll}10.2 & - \text { performance of the tests } & 71\end{array}$

$\begin{array}{lll}10.3 & \text { - results } & 71\end{array}$

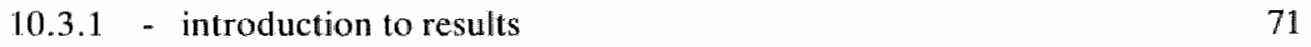

$\begin{array}{lll}10.3 .2 & \text { - results of Basal Acid Output } & 72\end{array}$

10.3.3 - results of Peak Acid Output 82

$\begin{array}{ll}10.4 \text { - conclusions } & 92\end{array}$

10.5. - discussion 93

10.5.1 - discriminative analysis 93

10.5.2 - acid secretion in the course of time 94

Chapter 11 Gastrin

\begin{tabular}{llr}
\hline 11.1 & - introduction & 99 \\
11.2 & - methods & 99 \\
11.3 & - results & 100 \\
11.4 & - discussion & 102 \\
11.5 & - conclusion & 105
\end{tabular}


Chapter $12 \mid$ Vitamin $B_{12}$

$\begin{array}{lll}12.1 & \text { - introduction } & 107 \\ 12.2 & - \text { materials and methods } & 107 \\ 12.3 & \text { - results } & 108 \\ 12.4 & \text { - discussion } & 110\end{array}$

Chapter 13 Metabolic parameters

13.1 - introduction 113

$\begin{array}{ll}13.2 \text { - results } & 113\end{array}$

13.2 .1 - weight 113

13.2.2 - haemoglobin 116

13.2 .3 - erythrocyte sedimentation rate 117

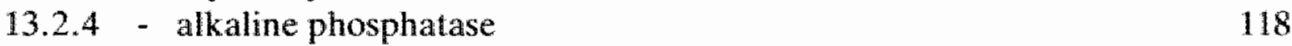

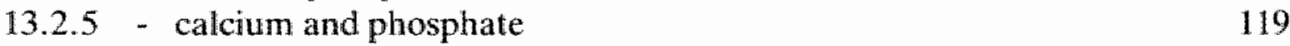

$\begin{array}{lll}13.2 .6 & \text { - iron and total iron binding capacity } & 120\end{array}$

Chapter 14 Blood group and family history

\begin{tabular}{lll}
\hline 14.1 - introduction & 123
\end{tabular}

14.2 - materials and methods 124

14.3 - results 124

- gastric acid secretion and blood group 125

- hypersecretion 125

- age at onset of disease 126

$\begin{array}{lll}14.4 \text { - discussion } & 128\end{array}$

- influence of hypersecretion $\quad 129$

- influence of age at onset of disease $\quad 129$

- influence of family history 130

Chapter 15 Recurrences: an analysis

15.1 - introduction 131

15.2 - characteristics of patients with and without a recurrence 131

$\begin{array}{lll}15.3 & \text { - recurrence rate } & 132\end{array}$

15.4 - peak acid output and recurrence 136

15.5 - hypersecretion and recurrence 137

$\begin{array}{ll}15.6 \text { - discussion } & 140\end{array}$ 
Chapter $16 \mid$ Special observations

16.1 - anecdotal observations 147

16.2 - periodicity 149

16.3 - appendix 149

16.3.1 - case reports of patients with a recurrence 149

16.3.2 - localisation of the recurrent ulcers 156

16.3.3 - pathology of the resected specimens 157

Chapter 17 Summary and conclusions

17.1 - summary and conclusions 159

17.2 - final remarks 162

$\begin{array}{lr}\text { Samenvatting en conclusies } & 165\end{array}$

$\begin{array}{ll}\text { List of abbreviations } & 171\end{array}$

$\begin{array}{lr}\text { References } & 173\end{array}$

$\begin{array}{lr}\text { Acknowledgements } & 187\end{array}$

$\begin{array}{ll}\text { Curriculum vitae } & 189\end{array}$ 


\section{Chapter 1}

\section{Introduction}

\subsection{Introduction}

This study deals with the application of a relatively new operation in surgery: highly selective vagotomy (HSV).

The operation was first performed on man in 1969 by Johnston ${ }^{160}$ and Amdrup ${ }^{8}$ although a similar technique was performed by Holle from $1964^{136}$ who added and still adds a standard pyloroplasty to it, which is probably an essential difference.

In the hospital where the present study was done - De Wever-Ziekenhuis, Heerlen, the Netherlands - HSV has gradually replaced partial gastrectomy as the operation of choice for the treatment of duodenal ulcer.

In spite of several renowned disadvantages of partial gastrectomy, vagotomy (whether truncal or selective) has never gained such a wide popularity either in the Netherlands or in this hospital in comparison with for example the United Kingdom or the United States. Conditions changed, however, when the suspicion grew that late stomach cancers appeared to be related to a preceding partial gastrectomy, which has now been established.

At the same time the new vagotomy seemed extremely promising and harmless in several reports from well known centres.

The introduction of highly selective vagotomy started in the De Wever-Ziekenhuis in 1974. It is a general hospital; health care is the main task and science is an appreciated but not dominating principle. Time is very important in such a hospital which must be financially almost completely self-reliant. There is no special staff and little money for scientific programmes. No extra care is devoted to some procedures or operations above others. It may be that the population of patients is different from that attending specialised centres. One of the consultant surgeons (J.D.K.M.) started the operation early in 1974 after being taught the technique by professor David Johnston in Leeds" General Infirmary. Initially the operation was practised by this consultant only, but gradually as the experience grew, as well as confidence in it, it became the operation of choice; initially only in elective cases, later also for complicated cases: bleeding, perforation and stenosis.

From 1976 HSV was the standard operation for duodenal ulcer and was performed increasingly by senior residents (comparable to registrars in the UK). At the conclusion of the study, Ist Jully 1982 , over half ( $64 \%$ ) of all HSV's had been performed by trainees. All patients who underwent this operation for duodenal ulcer in the period of study have been included. The only HSV's omitted were those done for gastric, prepyloric and pyloric ulcers, a small minority. As shown in table I HSV was not the only operation performed for duodenal ulcer. The reasons why HSV was not applied exclusively were:

- some surgeons continued to prefer in the beginning other operations, which in their hands had satisfying results.

- in some elderly patients, not fit to undergo a prolonged procedure, an emergency truncal vagotomy and pyloroplasty was performed. 
- for the sake of teaching sometimes a partial gastrectomy was preferred to a HSV in the early years when both operations still seemed equivalent.

Table I demonstrates the operations performed for uncomplicated and complicated duodenal ulcer in the years of study. Operations where only a simple suture was done have been omitted in the figures. Several of these patients underwent a definitive procedure later.

table 1.

operations performed for duodenal ulcer

\begin{tabular}{lc|ccc}
\hline year & numberofoperations & HSV & BlBII & $\begin{array}{c}\text { Truncal vagotomy } \\
\text { and pyloroplasty }\end{array}$ \\
\hline 1973 & 49 & 0 & 28 & 21 \\
1974 & 42 & 18 & 21 & 3 \\
1975 & 40 & 21 & 17 & 2 \\
1976 & 54 & 41 & 13 & 0 \\
1977 & 55 & 45 & 10 & 0 \\
1978 & 46 & 41 & 4 & 1 \\
1979 & 31 & 28 & 3 & 0 \\
1980 & 38 & 35 & 2 & 1 \\
1981 & 39 & 33 & 0 & 6 \\
\hline
\end{tabular}

It is apparent that the proportion of HSV's is steadily increasing. With the knowledge of a decreasing incidence of duodenal ulcer it is interesting to compare these figures with those reported by Suy $\left(1962^{342}\right)$ over a 14 year-period (1946-1960) when 1591 partial gastrectomies were done for duodenal ulcer in the same hospital; this is an average of 114 cases per year. This difference in the number of cases coming to operation most probably reflects a similar decrease in incidence of the disease ${ }^{248,254}$, 291,329

Moreover it can be appreciated from this report by Suy why partial gastrectomy was not easily replaced by vagotomy: the reoperation rate in the period 1946-1960 was $2.2 \%$ and the mortality $1.9 \%$ for all cases and $1.2 \%$ for elective cases.

The number of operated cases has further come down after 1978 since the introduction of cimetidine (Tagamet $($ ).

\subsection{The purpose of this study}

The purpose of this study is to show the results of HSV applied in routine conditions as described, supported by as many relevant details as possible and with a nearly complete follow-up.

This study will probably not demonstrate the intrinsic value of the method with near exclusion of the influence of the individuals, both patients and surgeons, but it is equally important to know what the average result is of this operation if applied on a relatively large scale, under routine conditions. 
The study was prospective since a protocol comprising preoperative and postoperative requirements was set out beforehand. This was not importantly changed during the period of study; slight modifications will be discussed in the respective chapters. The technique of the operation was standardised as much as possible for a quickly evolving operation ${ }^{12}$.

The protocol required:

preoperatively:

- routine history taking and complete physical examination.

- measurement of height and weight.

- estimation of blood group, rhesus factor, haemoglobin ( $\mathrm{Hb}$ ), ESR and serum alkaline phosphatase (AP), calcium (Ca) and phosphate (P), iron (Fe) and total iron binding capacity (TIBC).

- serum vitamin $B_{12}$ and basal serum gastrin values were obtained in increasing numbers from the moment the isotope laboratory in the hospital was able to determine them.

- acid secretion tests, both in basal state and after stimulation.

- adequate examination with X-ray and oesophago-gastro-duodenoscopy.

postoperatively:

routine follow-up examinations after $1 / 2$ year, 1 year and yearly thereafter

- the weight was to be taken on every follow-up date.

- all blood parameters ( $\mathrm{Hb}, \mathrm{ESR}, \mathrm{AP}, \mathrm{Ca} \& \mathrm{P}, \mathbb{F e} \& \mathrm{TIBC}$, basal gastrin and vitamin $B_{12}$ ) every whole year with the exception of gastrin which was determined at $1 / 2$ year follow-up as well.

- acid secretion tests were to be performed $1 / 2$ year, 1 year and 5 years after operation.

- X-ray and / or endoscopic examinations: only in case of symptoms suggestive of a recurrence.

\subsection{Patient selection and indications for operation}

The patients were not selected favourably or unfavourably towards HSV.

Most patients were sent from medical specialists from the same hospital who had no influence on the type of operation performed.

The most common indication was intractable duodenal ulcer. Usually there was a considerable history during which on repeated occasions X-ray studies were performed as well as one or more gastroduodenoscopies. Early in this series the diagnosis of duodenal ulcer was proved only with X-ray studies, later endoscopy was more relied on.

In many patients the diagnosis of recurrent duodenal ulcer was established by both methods. In all patients a recurrent duodenal ulcer had been proved. To understand the indication correctly: the indication was such that a gastric resection would have been justified, it was not "HSV-adapted". Only very recently has there been a tendency that patients are proposed for HSV only and not for resection, which could 
mean that in the future the indication will become easier: "HSV-adapted". If a change in indication had taken place in this series after some time of favourable experience with this operation a shorter length of history would have been expected in the patients operated upon more recently. In an attempt to check this a comparison was made of the average length of history between the first and the second half of the series. There was no difference at all.

Nevertheless one can speculate that two factors of opposed direction will come into force in the future ${ }^{254}$ possibly have already been in force:

- operating earlier than in the past since HSV proved to be a relative harmless procedure with gratifying results as many reports demonstrate: $80-90 \%$ good or excellent results and a low mortality and complication rate and few serious sequelae.

- the influence of better and more potent conservative treatment than available in the past - drugs like cimetidine, carbenoxolone, DeNol $B$, ranitidine - reducing the number of operations ${ }^{282}$. The timing of operation might be influenced, if still necessary in spite of medical treatment ${ }^{22}$.

Several reports suppose that for many patients surgical treatment might just be postponed ${ }^{346}$. It is reasonable however to state that for others operation will be avoided by these conservative treatments. It is difficult to prove these trends in such a versatile disease with its unpredictable natural history.

Possibly patients will be selected in the future on the base of intractability in spite of cimetidine treatment or the need for and fatigue from permanent drug use.

Certainly for the time being there will be a higher percentage of complications coming to operation after long-term medical treatment 248,282 . This trend is also perceivable in this material.

\subsection{Nomenclature}

In spite of modern trends and recommendations for uniform nomenclature ${ }^{10,360}$ many names are in use for this operation. HSV was chosen in this study. This term was proposed by a pioneer group (Johnston, Leeds ${ }^{160,286}$ ) and appears to be a logical extension of the predecessors: truncal vagotomy and selective vagotomy (selective gastric vagotomy). This operation is certainly more selective since it is intended to be confined to the acid secreting part of the stomach.

However any modification or extension of this type of vagotomy is expressed in superlatives which are soon lacking.

Probably it is also language dependant which name is best applicable. Ultraselective vagotomy was used by Grassi et al ${ }^{99}$ and supraselective vagotomy by Hollender and others.

SPV - selective proximal vagotomy - is mostly used in German speaking countries and appreciated by some as a mnemonic for Save Pylorus Vagotomy ${ }^{3 / 3}$.

The best alternatives are PGV - proximal gastric vagotomy -, which provides a good topographical description of the operation and PCV, parietal cell vagotomy, describing the intended denervation of the acid producing cells.

Other varieties are PSV, proximal selective vagotomy, acido-secretive vagotomy (Grassi $1973^{49}$ ) and, as Holle ${ }^{136}$ stated, the operation is probably best described by: selective vagovasosympathectomy of the proximal stomach. But evidently this will 
never become very popular.

In Keen's "Operative Surgery and Management" (1981 ${ }^{173}$ ) Johnston again recommends the use of HSV, if anatomical landmarks are used in the dissection and $\mathrm{PCV}$ if the dissection is guided by pH-metric mapping of the parietal cell mass. SPV should be used for operations where a pyloroplasty is added ${ }^{136}$.

All these arguments appear to be semantic. However, it does have practical consequences; one tends to abbreviate the names of this operation both in speaking and in writing; there can easily be confusion with other medical abbreviations especially when less popular terms are used. In a country where PGV is the commonly used name HSV might not be understood and may be confused with e.g. herpes simplex virus, $\mathrm{PCV}$ with packed cells volume. Some computer systems for searching literature do not recognise either HSV or PCV.

Uniformity about the name of the operation will not be expected soon, if ever. Here highly selective vagotomy is preferred, since it has become the most popular term in the Netherlands. Moreover, the first thesis about HSV in the Netherlands (Geurts, $1975^{88}$ ) HSV was translated as "Hoog Selectieve Vagotomie" with the advantage of the same abbreviation but with the disadvantage of being a germanism.

\subsection{Recurrence rate, what does it mean?}

Any method of treatment including operation does have inherent restrictions and probably failures ("method failures"). But even a theoretically ideal method will have failures when applied in practice ("surgeon failures" in the case of an operation).

Therefore the question of the recurrence percentage cannot be answered straightforwardly without further comment.

Moreover the time interval after operation should be defined. In fact the question is debatable theoretically.

\section{Method failure}

How many recurrences can be expected after a complete HSV?

In case of an ideal operation this figure should approach $0 \%$. However, there is a possibility that a complete HSV is a perfect operation for the vast majority of patients, but not for all of them due to anatomical or physiological variations. It is not mere speculation that a complete HSV is in principle not possible if the parietal cell mass extends into the part of the antrum that is innervated by the last branch of the terminal fibres of the nerve of Latarjet, which must be saved during the operation ${ }^{10 \%, 287,288}$. Moreover, other factors influencing the stomach could predominate over the vagus nerve, for example gastrin or other humoral agents ${ }^{93,157}$, the sympathicus ${ }^{207,2018}$, the mucosal blood supply $8,146,192,247,252,277$ etc. These options can explain why after several years nobody can report $0 \%$ recurrence rates and, even if this is the case, occasional recurrences will still develop some time later. How many years are needed until the answer is mature? Nevertheless the intrinsic cure rate of an operation will be approached by several unbiased series with the lowest recurrence rates. This figure will probably be below $5 \%$ for highly selective vagotomy, as it is for the other vagotomies ${ }^{47,} 157,172,273,305,328$. 


\section{Surgeon failure}

A second very important question is what will happen when HSV is applied on a large scale, performed by "the average" surgeon? What is the chance that the majority of surgeons performing HSV's routinely produce satisfactory results?

There will always be variations in results between apparently good and bad vagotomists as is the case with other forms of treatment but the problem is not so acute with other operations for duodenal ulcer: if a gastroenterostomy is badly performed there can be leakage or stenosis but, if functioning, it is a gastroenterostomy with a certain intrinsic value for cure or recurrence.

There is little more variation with partial gastrectomy: the extent of resection required was dependent on general opinion and this varied with time and country but the performance of the operation as intended was generally not the reason why it could fail (unless the resected part was grossly overestimated): the result of operation was "in the pot". With vagotomy (whether truncal, selective or highly selective) it is much more critical: the concept of operation is clear: performance of a complete vagotomy - but the difficult point is the achievement of this goal.

If only $10 \%$ of vagal fibres remain intact after an intended vagotomy the result could soon be nihil ${ }^{51,76,343}$, or even worse than before the operation ${ }^{343}$.

This study probably better reflects the answer to the question of the application by the average surgeon than do the results of expert vagotomists, whose results are equally necessary to know the intrinsic value of the method.

Both gastric resection and any kind of vagotomy have their limits and are possibly not suitable to the same extent for all duodenal ulcer patients ${ }^{277}$. An additional proof is a combination of both procedures (truncal vagotomy and antrectomy) which seems to be most capable in curing the disease and this operation has been done by many equally imperfect surgeons generally resulting in lower recurrence rates than in either of them individually ${ }^{47},{ }^{268}$. Does this mean that there are different duodenal ulcers, most of them sensitive to either method but some less sensitive to either gastrectomy or to vagotomy?

\section{Paticnt failure}

Another bias not often discussed is the possibility of local, geographical or individual susceptibilities.

It is not unreasonable to assume that almost everybody could develop a peptic ulcer provided the circumstances contribute unfavourably enough. Something similar may be true for development of a recurrence after operation. As long as there is acid an ulcer is possible. Probably it is a matter of overshooting to do an operation which prevents ulcers absolutely since this will most certainly have many disadvantages (e.g. a total gastrectomy).

The knowledge about duodenal ulcer is extensive but still very fundamental data are lacking. The cause of the disease is largely unknown, probably it is multifactorial. Many contributions have been written in an endeavour to unravel this problem. Among incriminated factors ${ }^{32}$ are blood group ${ }^{98}$, stress, diet, cigarette smoking, alcohol and drug use, social class, prolession, hereditary ${ }^{110}$, psychosomatic, environmental, geographical ${ }^{348}$ and pathogenetic factors contributing to an imbalance 
between aggressive forces and defence mechanisms ${ }^{348}$; hyperfunction of the vagus nerve, hypersecretion, humoral factors, dysregulation of different factors, sympathetic inffuence $^{31,49,222,243}$, attenuation of defence systems, defective feedback mechanism. and gastric mucosal blood flow 223, 262.323.

Of course several of these factors could be of important influence and not all duodenal ulcers need to have the same aetiology. There must be difference in exposure to risk factors which influence the results of operation as it does influence the prevalence of duodenal ulcer disease.

Since it is known that disease patterns vary in different parts of the world it is clear that for that reason there will be variation in treatment results and thus in the number of recurrences, which is the exponent of failure with $\mathrm{HSV}$.

In short: the virulence of the causing or contributing agents can be different.

In still another way the concept of "recurrence rate" can prove confusing: it is hardly ever defined in terms of follow-up, number of recent cases and, most important, time relationship. Yet everybody intuitively appears to feel what recurrence rate is and all operations used for duodenal ulcer seem to bear a more or less fixed recurrence rate. It will be argued in several chapters $(8,15)$ that it is - perhaps surprisingly - not that simple.

Probably most reported results are a mixture of method failures and surgeon failures. This net result is probably the most important for the society and the patients. An operation that is only perfect in the hands of few is a bad operation but an operation, good in the hands of many is a good operation.

\subsection{Overview of the contents}

In the short time of its existence an extensive literature has been accumulated about HSV and related subjects.

It is neither possible, nor is it intended, to review this completely or to discuss all aspects of the disease and the operation comprehensively.

The following chapters ( 2 and 3 ) have been written in order to introduce the reader concisely into general questions concerning duodenal ulcer, its treatment and specifically HSV. Thereafter (chapter 4 ) the patients in this study are described. The technical aspects of the operation with the management pre-and postoperatively will be described in chapter 5 .

In chapter 6 quality control testing is discussed.

The principles of grading of the results and the follow-up will be explained in chapter 7.

The results of operation and the influence of complications before operation are dealt with in chapter 8 and 9 , followed by the results of laboratory parameters (chapter 10 to 13).

A special chapter has been devoted to hereditary factors as represented by the blood group, rhesus factor and the family history (chapter 14). Several of the preceding results will be analysed there according to these factors.

Recurrences will be analysed in chapter 15 and special, sometimes anecdotal observations have been collected in chapter 16 , together with the short case histories of all patients who developed a recurrence.

Finally, chapter 17 summarises all chapters and contains some final remarks. 


\section{Chapter 2}

\section{Natural history and epidemiology}

\subsection{Natural history}

Nobody really knows why a duodenal ulcer develops and why it does or does not heal; neither do we know why it causes pain or discomfort in many people but not in others.

If at endoscopy an ulcer is seen in the duodenal bulb and next to this ulcer a similar one is punched out by biopsying, the latter will soon heal, but the former will not (Wormsley, ranitidine symposium, Amsterdam 1982). The above and similar statements demonstrate that duodenal ulcer is not an easily intelligible disease in spite of many endeavours. This mystery is even greatly enhanced by the natural history of the disease. It is not the same in all patients and is even not the same in the same patient; its behaviour is versatile.

Undoubtedly there are people affected only once in their life by a DU which may heal spontaneously or which may perforate or bleed. Most patients, however, sulfer from chronic, recurrent disease often with an episodic character.

It is not very likely that the disease will "burn out" after many years. Krause (1963

${ }^{202}$ ) found in his accurate long-term follow-up study of patients who were admitted for the first time between 1925 and 1934, that only $6.5 \%$ of the men and $10.9 \%$ of the women were symptomfree after more than 25 years. In $70 \%$ an operation would have been justified in the course of that period.

Usually pain is the leading symptom, often visceral in character and difficult to describe. The pain is usually located in the epigastrium, and comes and goes, is usually temporarily relieved by food or milk and may be aggravated in stressful circumstances; in many however this relation is not evident at all.

In the majority, pain recurs when the stomach is empty i.e. in the early morning and is relieved only by food or milk. Often pain is accompanied by hearlburn, flatulence, nausea or vomiting.

The period of stomach trouble may last days, weeks or months and seems continuous in some. It may occur once or more frequently each year often in the same season. Probably many circumstances are of influence for recurrence of ulcer symptoms, and modification of the disease. The severity of the attacks may change as well.

Complications (bleeding, perforation, stenosis) can occur in anybody at any moment even without premonitory symptoms, but once such a complication has taken place such a patient seems to be prone to the same complication once more. A perforation or bleeding may be the first and only symptom in patients who were never aware of any ulcer.

Often the presence of a more aggressive ulcer diathesis is assumed when a complication occurs. At the other hand the risk of bleeding in duodenal ulcer disease increases with the length of ulcer history and the incidence may approach $100 \%$ if one waits long enough ${ }^{116}$.

The perforation rate seems to be rather constant and proportional to the total number 
of duodenal ulcer patients ${ }^{341}$. This rate has often been used as an index of prevalence of the disease, since those cases are usually recorded by hospital admission ${ }^{329}$. If the recurrent ulcer is located near the pylorus and causes shrinking in healing or oedema at the time of inflammation, obstruction may become apparent, the third complication of duodenal ulcer. The rate of each complication may differ in different parts of the world and even within a country, since the factors causing them are unknown ${ }^{348}$.

Intractability is often called the fourth complication: a subjective term in a dual sense: both doctor and patient dependent. Those are the patients coming to elective operation; it depends on the patient, the doctor, the available drugs, the available surgical treatment how large this group will be; the environment and even fashion both play a role.

The consequence of this complicated picture of the natural history is that one has to be careful in comparing results of treatment between different populations.

It is understandable that the variability in occurrence of symptoms, of severity, of complications rate, of ulcer recurrence, etc. will be reflected in a similar way in the results of a certain treatment; it is very improbable that this will be the same in all populations.

Controlled clinical trials are therefore necessary to demonstrate the superiority of a certain treatment above another, but even the results of this kind of study cannot be transposed to other circumstances unless more data are available.

It could be that for example in a area in mid England the pathogenesis of DU disease is different from that in the part of the Netherlands where the patients studied here are living. Supposing that vagal hyperfunction is the dominant factor in the pathogenesis in mid England (which in fact is not known) the result of a controlled clinical trial could result in a clear superiority for TV and D over partial gastrectomy. However it is possible that this does not hold true for the presently described population which might contain more gastrin dependent sufferers (which is not known either) ${ }^{213}$. If a similar trial was to be held here the results could be the reverse. Time and again surgeons have recognised the fact that not all duodenall ulcer patients are the same and that treatment (including surgical treatment) should be adapted to the individual patient ${ }^{70,136,154,268,277}$, but this has not led to uniform conclusions.

\subsection{Epidemiology}

Most fascinating and confusing are historical and epidemiological data: one century ago duodenal ulcer was largely unknown ${ }^{32,253,346 . ~ H o w e v e r, ~ t h e r e ~ a r e ~ e a r l i e r ~}$ descriptions but they are incidental ${ }^{116}$. The incidence of perforations is often used as an index of the disease since a perforation came more easily to light than an ulcer which could not be proved at that time, unless by autopsy ${ }^{341}$. With the increase of the industrialisation the number of duodenal ulcers increased sharply as measured by the reported perforation rates. Susser et al $\left(1962^{341}\right)$ conclude in an excellent review of the matter that duodenal ulcer cannot be regarded simply as a disease of civilisation but it could accompany the phase of early urbanisation ${ }^{348}$. The present tendency of decline of duodenal ulcer in the western world could be understood since the population has become adapted on a large scale to the stresses of the modern society. In other parts of the world it does not seem connected to modern society life ${ }^{348}$. 
It is estimated that $5-10 \%$ of the population is suffering at some time in their life from peptic ulcer disease ${ }^{116}$.

This decline (which is perceived increasingly) affects age groups differently. The decade of birth seems to bring about a certain risk during lifetime for developing ulcers and perforations (cohort phenomenon). One consequence of this is that the age at which the frequency of duodenal ulcer is highest is changing over the years. At times it was predominantly a disease affecting young men, at other times elderly people. That gastric ulceration is a different entity is illustrated in a pattern unequal to that of duodenal ulcer ${ }^{32,59,110}$. The decline was confirmed by several authors already before the introduction of $\mathrm{H}_{2}$ receptor antagonists: a $35 \%$ decline for the preceeding decade has been reported. ${ }^{110}, 116,253,254,291.329$.

Introduction of $\mathrm{H}_{2}$ receptor antagonists (1977) has further brought down the number of operations for duodenal ulcer. Is the decline real or is peptic ulcer disease taking another face ${ }^{253}$ ? What does happen in the third world? According to the above theory it should be increasing, but reality could prove to be entirely different ${ }^{58,346 .}$ 348.

The future incidence of duodenal ulcer and the role of surgery is still unpredictable. Peptic ulcer remains a mysterious disease.

Recently Thompson $\left(1982^{346}\right)$ commented that it seems ironic that the greatly decreased need for surgery for duodenal ulcer coincides with the firm establishment of a safe and effective operation (highly selective vagotomy).

\subsection{Evolution of the operative treatment}

In about a century of peptic ulcer disease several operations have been devised and evolved with differing success.

One of the first procedures employed was simple gastroenterostomy which seemed quite effective initially, but the number of failures increased and partial resection of the stomach gained wider acceptance ${ }^{277}$. This procedure was first successfully employed about a century ago (in 1881) by Billroth treating gastric cancer.

Due to the feared high incidence of anastomotic ulcers in B-I variety many preferred B-II which sometimes was the only feasible alternative in very difficult ulcers. Vagotomy gained interest after Dragstedt's publication of supradiaphragmatic vagotomy for duodenal ulcers ${ }^{75}$. This seemed a successful treatment but in many cases gastric retention and consequently stasis and gastric ulceration was the main problem after operation. Therefore he switched to abdominal vagotomy which enabled inspection of the pyloric region and addition of a drainage procedure ${ }^{76}$. Gradually many surgeons preferred the vagotomy and drainage procedure to partial gastrectomy because of the safety, speed and simplicity of operation and good results.

However, others were not convinced about the superiority of vagotomy and continued with their first choice - partial gastric resection.

Both operations do have their own advantages and problems. Of course mortality and complication rates were very important but also postoperative sequelae occurred in a certain percentage of cases which could continue lifelong, sometimes crippling 
the patient ${ }^{94,172,268}$. Both operations had their failures such as recurrent or new ulcers. There was much wariety in the extent of the resection which made it difficult to make a fair comparison with vagotomy. As recurrent ulceration after partial gastrectomy was considered a principal failure attributed to a still too large amount of residual acid production, larger resections have been tried.

Visick promoted the use of the measured radical gastrectomy as a standard operation for gastric and duodenal ulceration leaving only a measurable and measured 3 inch small gastric remnant in situ ${ }^{352}$. He described excellent results and introduced the grading of patients during a continuous follow-up. Disadvantages of truncal vagotomy not attributable to any drainage procedures considered necessary were related to the denervation of other abdominal organs and of the antrum ${ }^{94}$.

A logical solution appeared to be selective vagotomy of the stomach whereby only the stomach was denervated and the extra-gastric nerve supply was preserved ${ }^{277}$. How attractive in theory, this operation has not gained wide popularity in spite of good results. The clinical trials devised to compare the relative benefits of different operations for peptic ulcer have greatly prepared the way for an even more selective type of operation: HSV which means division of the nerves to the acid secreting part of the stomach while preserving the nerve supply to the antrum and pylorus (at the same time probably preserving defence factors mediated via the antrum ${ }^{305}$ ).

Griffith and Harkins $\left(1957^{108}\right.$ ) have been credited to be the first to apply this method on dogs and Johnston in Leeds and Amdrup in Copenhagen were the first to apply the method on a large scale on men. However, Holle developed a similar procedure and applied it from 1964, called selective proximal vagotomy, but added a pyloroplasty, "appropriate to form and function" 132,316 .

In fact he used a whole scale of operations for peptic ulcer trying to tailor the operation to the requirements of the individual patient. In many instances in addition to a SPV a small part of the stomach (proximal, midpart or distal) was resected depending on the localisation of the ulcer and the secretory pattern ${ }^{133}, 134,136$.

Several controlled clinical trials have compared the results of HSV with and without pyloroplasty and most of them have demonstrated that a drainage procedure is unnecessary in HSV and only adds disadvantages $172,219,271,312,359,316$. As mentioned before the present HSV is more than a vagotomy as the blood supply to the lesser curvature part of the proximal stomach is completely interrupted as well, as is the sympathetic nerve supply.

Many things in medicine have to be redone and rediscovered before they are practically used: the same is true for HSV. In fact the first HSV-like procedure was described in 1920 even before the vagotomies performed and described by Latarjet ${ }^{34,} 220,358$. 


\section{Chapter 3}

\section{Surgical anatomy and physiology}

\subsection{Anatomy}

One of the first good descriptions of the vagus nerve supply of the stomach was given by Latarjet ${ }^{220}$ in 1922 who after experiments on dogs applied a total vagal denervation of the stomach including the antrum and pylorus. He intended to denervate the stomach vagally but he realised that many sympathetic fibres to the stomach were severed as well in the same procedure. He recognised the distinct and the more or less constant nerve supply by the vagus nerve in contrast to the then firmly held belief that the stomach was autonomically innervated via an external plexus. He denied the existence of such a plexus for the stomach.

Latarjet outlined the anatomy that we still recognise as the essential one (figure 1): the left (anterior) vagus nerve branches at the level of the distal oesophagus into the principal anterior nerve of the lesser curvature (later called nerve of Latarjet) and the gastrohepatic nerve, supplying the liver and gallblaclder and from which duodenal pyloric fibres branch off supplying the pyloric region and first part of duodenum. He stressed that the nerves that were later to be named after him never reached the pylorus. The right (posterior) vagus branches into the principal posterior nerve of the lesser curvature and fibres going to the coeliac plexus. From this plexus according to Latarjet fine fibres accompany the right gastroepiploic artery and some of them branch off to the stomach at the greater curvature side ${ }^{281}$.

Latarjet already experimented on total vagotomy of the stomach with and without a drainage procedure. He realised that not adding a drainage procedure caused a delay of gastric emptying of many hours. The six patients with gastric and juxtapyloric ulcers he treated with total gastric vagotomy all underwent a gastrojejunostomy but for other diseases ("gastropathies without apparent lesion") he omitted this in some cases.
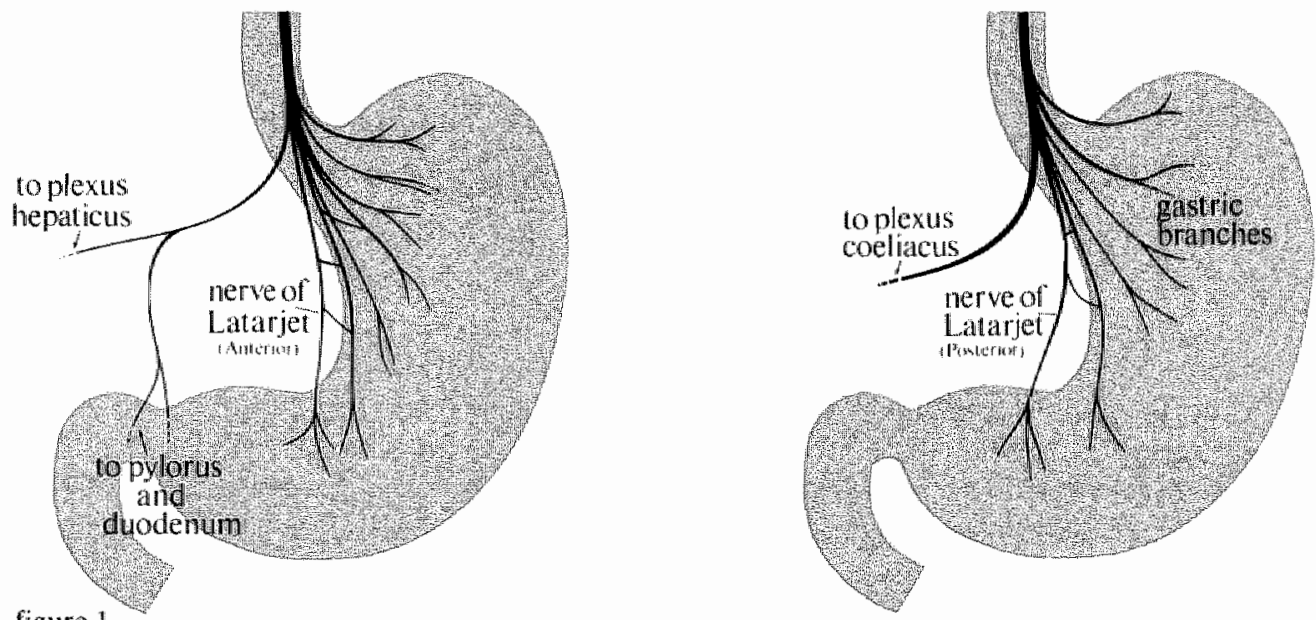

figure 1

schematic drawing of the vagal nerve supply of the stomach; left: anterior side, right: posterior side 
McCrea ${ }^{245}$ in 1924 confirmed Latarjet's description in general. He was, however, surprised that Latarjet never found an anterior or posterior external gastric plexus, which McCrea thinks may or may not be present depending on the number of intercommunication and the opinion of the observer as to what constitutes a plexus. He separated in his description branches - originating at the level of the cardiooesophageal junction from the anterior main vagal trunk - going to the left and supplying the proximal stomach, and branches going to the right: to the porta hepatis and to the antrum; he found communications between the latter and the branches to the proximal stomach.

McCrea demonstrated also that at a higher level both the right and the left vagus supply the whole stomach as they intermingle in an ever present thoracic oesophageal plexus.

Mitchell ${ }^{258}$ in 1940 similarly described the vagal anatomy. He found a radiating course of the gastric branches ( 4 to 10) from both vagal trunks, the one situated most to the right being usually the heaviest. He proposed the term: greater gastric nerve (anterior or posterior), but admitted this to be as clumsy as principal nerve of the lesser curvature. Therefore most reports use "Latarjet's nerve".

Jackson ${ }^{149}$ in 1948 studied the vagus nerves in relation to the oesophagus and to the stomach and confirmed this outline of vagal anatomy. In his study on 50 cadavers he found many variations in the branching pattern and multiplicity of trunks and demonstrated that truncal vagotomy, whether sub-or supradiaphragmatic, often (in $30 \%$ ) will be incomplete if only one anterior and one posterior main trunk is cut. Moreover he explained why truncal vagotomy above the diaphragm is more difficult to accomplish completely than below, since above the diaphragm multiple trunks are more likely to occur on the less accessible posterior side. This was confirmed clinically in 1977 by Taylor $e t$ al who found on reoperation for incomplete vagotomy, that an intact posterior trunk was the most common finding ${ }^{343}$.

However, in only 28 out of 50 cases Jackson found an anterior principal nerve of Latarjet and only in 19 cases a posterior principal nerve. He speculated about the possibility of vagal fibres reaching the greater curvature via the hepatic and gastroduodenal artery to the distal right side as Latarjet did and via the splenic vessels to the proximal left side, but postulated these of minor importance basing this conclusion on the result of insulin tests.

Striking however is the difference in most clinical publications where ususally one main stem is seen (Latarjet's nerve) with a number of side branches supplying the rest of the stomach, compared with the pictures of McCrea, Jackson and Mitchell, who found that there are a number of branches ( 3 to 10$)$ originating from the main anterior vagal stem at the level of the cardio-oesophageal junction (and equally posteriorly).

This explains perhaps that Holle assumes the existence of a "caudal proximal and distal ventral borderline" nerve, being two parallel radiating branches. Holle's descriptions are based on an anatomical study by Loeweneck ${ }^{231}$ who found a similar distribution of the vagal branching off towards the lesser curvature as the other 
authors did, but who stressed more the radiating course of the branches coming high from the main stem. He studied in detail the rami antrales (analogues to the nerve of Latarjet) and found in his study on 50 cadavers that only in $14 \%$ was there one common bundle from where both antrum, corpus and fundus were innervated. This, however, is adopted as the "classical" picture, found in almost every report about HSV technique.

In $24 \%$ however Loeweneck found one or more isolated rami antrales without communications with corpus or fundus fibres. In $50 \%$ rami antrales having communications with branches to the fundus of the stomach were found and in $12 \%$ there was an isolated ramus antralis with some fibres to the corpus.

Only McCrea found a nerve similar to that mentioned by Holle when he described one antral nerve running in the lesser omentum and another just along the line of attachment of the lesser omentum going to the incisura angularis.

Recently (1980), Hollender et al ${ }^{140}$, published a review of the anatomical literature on the subject, adapted to their 10 year experience with super-selective vagotomy. They refer to one principal nerve of the lesser curvature and their illustration resembles the usual pattern, comparable to figure 2 .

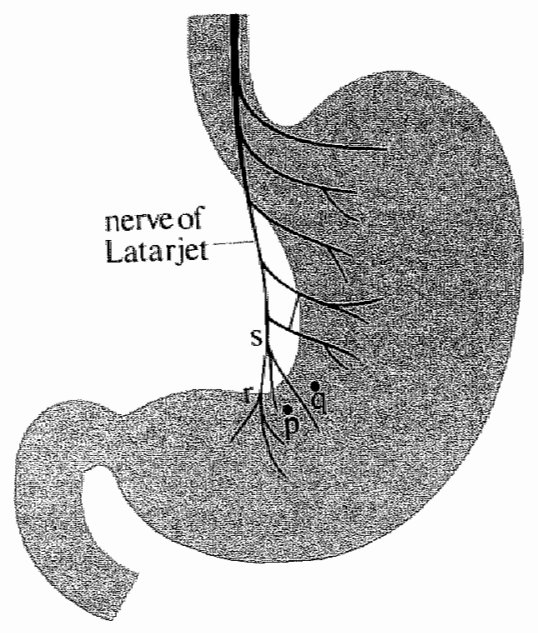

figure 2

classical representation of anterior vagal nerve supply

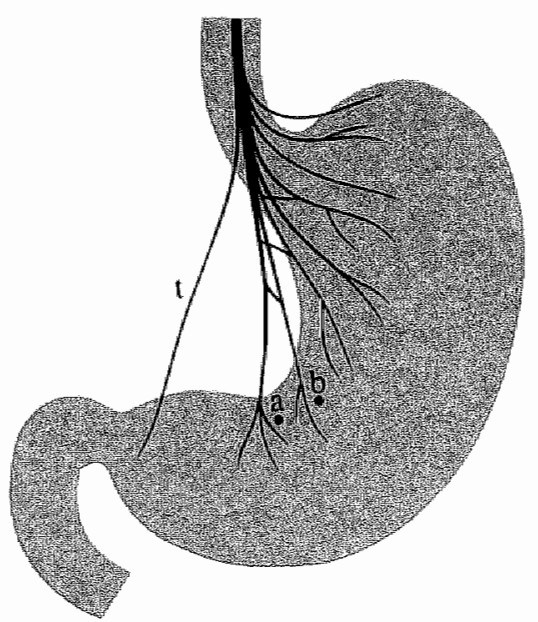

figure 3

alternative representation of anterior vagal nerwe supply

The discussion about the exact anatomy, however variable it may be is not purely academic.

If the usually used picture (figure 2) is adopted as the most common representation, the only problem that can arise is how far distally the dissection should be started (at point p or q), but the one main stem is to be preserved. In case, however, Loeweneck's presentation is more real an additional problem is that there could be more main stems. One of the "main stems" being less visible could be overlooked and the surgeon could be satisfied preserving what he thinks is the only main stem (see figure 3: starting at $b$ in stead of a). 
It is even more complicated knowing that sometimes there are additional isolated branches to the pylorus and/or the antrum running in the lesser omentum and coming off from the principal anterior nerve or from the external gastric plexus (t in figure $3)$.

The significance of the existence of an external plexus in the proximal stomach is that if one major branch is not cut it can convey stimuli via the connections in the plexus to many branches cut off from their main nerve supply.

Morever if an intramural plexus exists as postulated by Jackson any branch left influences a larger part of the stomach than corresponding to the macroscopical anatomical distribution of that branch. Additionally stimuli can be spread further via Auerbach's myenteric plexus.

These studies show that there are many intercommunications between left and right vagus at the level of the oesophagus and more distally between the anterior and posterior vagal trunks. Moreover, whether called, "plexus" or not, there are many communications between anterior gastric branches among each other and equally for posterior branches and even between anterior and posterior nerves.

As Jackson has proved, at the level of the oesophagus above the diaphragm there can be communicating vagal branches running under the muscular coat for some distance. Probably this occurs below the diaphragm as well 313,314 . This would mean that even if the oesophagus has been cleared of all visible fibres circumferentially at a certain level, there could be fibres underneath or in the muscular coat originating from a higher level $112,142,209,244$, still supplying nerve twigs that have already been interrupted on the outside.

That is probably the reason why about six cm of the oesophagus should be bared, as demonstrated by clinical experience ${ }^{115,142,209,244}$. It appears improbable that such submuscular nerve fibres have already submerged and reach the gastro-oesophageal junction without coming out again. Some surgeons, however, make a superficial circumferential cut around the oesophagus after having completed $5-7 \mathrm{~cm}$ skeletonisation in order to divide longitudinal nerve fibrils that run to the cardia ${ }^{313}$, 314

Another important detail is the presence or existence of the so-called crow's foot. Is there a crow"s foot and if so should it be considered the end-twigging of the main stem of the nerve of Latarjet, which implies that it should be preserved in HSV? (point $r$ in figure 2).

Should a triple branching somewhat more proximal (point s) be called so, which means that one or two "loes" of the crow's foot should be preserved and the other ones cut? 281 . Using this concept the dissection of the lesser curvature is started to the left of the crow's foot ${ }^{95}, 125,255$, but some surgeons save only the most to the right positioned toe and sever the one or two left ones ${ }^{101,281 .}$

Others 173,286 use the word "crow's foot" to describe the vascular branching accompanying the nerve of Latarjet. Johnston ${ }^{173}$ denies the existence of a neural crow's foot and refers to a crow's foot of veins.

Several different HSV techniques have been compared with respect to the descriptions of the distal innervation and the operative procedures for starting the dissection. The order of mention is arbitrary and no attempt at completeness has been made. 
Hedenstedt: ${ }^{127}(1980)$

the entire lesser curvature is skeletonised proximal to an anatomical point immediately adjacent to the entrance of the rami antrales (the so-called crow's foot).

Korompai: ${ }^{200}$ (1979)

the corpus antrum border is determined anatomically by the nerve of Latarjet; by PCV this nerve and everything to the patient's right is left intact.

Wastell: ${ }^{361}$ (1977)

the dissection is such that the last wisible major branch of the ant. and post. nerve of Latarjet is preserved.

Ahonen: ${ }^{6}$ (1979)

in group I the distal extent of the dissection is determined by the distribution of the nerves of Latarjet. The end point of denervation is located where the terminal branches of the nerves pass at right angles into the antral wall, from $6-8 \mathrm{~cm}$ from the pylorus.

Hill: ${ }^{130}(1978)$

thus beginning $7-8 \mathrm{~cm}$ from the pylorus just proximal to the toe of the crow"s foot, the tumnel is entered etc.

De Miguel: ${ }^{255}$ (1977)

initially only $5-6 \mathrm{~cm}$ of the distal stomach were left with vagal innervation, which invariably meant severing one or more of the terminal branches of the nerwes of Latarjet. Later, fearing that such an extensive denervation might interfere in some cases with normal gastric emptying, all the terminal branches of the nerve of Latarjet were preserved, which meant retaining vagal innervation to $8 \mathrm{~cm}$ or more of the distal stomach.

Goligher: ${ }^{95}$ (1974)

the ant. nerve of Latarjet is usually clearly discernible in the lesser omentum parallel to and about 1,5-2,0 $\mathrm{cm}$ from the lesser curvature of the stomach, where it fans out into branches rather like the digits of a crow's foot. According to Johnston and Wilkinson (1970) originally the dissection was started just to the left of the crow's foot, which usually meant about $7 \mathrm{~cm}$ from the pyloroduodenal junction. Andrup and Jensen, using pH-metry started the separation at that point on the lesser curve which was usually $3-4 \mathrm{~cm}$ higher up than the crow's foot. More recently most surgeons in Britain, including Goligher himself, have tended to adopt this latter starting point (without mapping).

Johnson: ${ }^{156}(1977)$

normally the denervation of the lesser curve is started arbitrarily at the first or second branch of the vascular crow's foot.

Grassi: ${ }^{101}(1975)$

where it divides into a number of terminal branches " usually three. The dissection begins with the most proximal branches and proceeds upward allong the lesser curvature.

Salaman: ${ }^{310}(1978)$

the procedure starts in the region of the incisura, where a trifurcation of vessels is usually seen. The pyloric and middle branches are not disturbed but the most proximal branch is clipped and divided.

Johnston: ${ }^{160}(1970)$

the dissection begins near the incisura and proceeds upward, the lesser curve is then separated from the lesser omentum within which the nerves of Latarjet run downwards to the antrum.

Christiansen: ${ }^{50}(1981)$

the corpus antrum border is determined anatomically by the nerve of Latarjet. By PCV this nerve and everything to the patient's right is left intact.

Rossi: ${ }^{305}(1980)$

dissection of the ant. leaf of the gastrohepatic ligament is begun at the left of the crow's foot, approximately $7 \mathrm{~cm}$ from the pylorus.

Braasch: ${ }^{41}(1980)$

a standard technique is used that emphasises dissection of the serosa of the lesser curvature of the stomach to permit division of the ant. and post. vagal branches to within $6 \mathrm{~cm}$ of the pylorus. 
Pendower: ${ }^{281}(1981)$

both these patients had four branches of the ant. merve of Latarjet where it crosses the lesser curve (the crow"s foot) instead of the usual three. The author routinely divides the first branch, but in these patients acid secretion was not abolished until the second branch was also divided.

Hallenbeck: "15 (1976)

initially POV was performed by separating the lesser omentum from the stomach, beginning proximal to the pyloras, preserving the ant, and post. nerves of Latarjet to the gastric antrum.

Poppen: ${ }^{289}$ (1981)

the starting point of denervation is the middle of the crow's foot (group I); in group III only the most distal branch of the ant. nerve of Latarjet is saved.

Poppen: ${ }^{288}(1978)$

the patients were grouped according to the type of mucosat found at the point on the minor curwature where the most distally located visible branch of the ant. nerve of Latarjet intersects the stomach wall.

Johnston: ${ }^{173}(1981)$

the anterior nerve of Latarjet is identified, and the position of its terminal branches noted. The nerve is rendered more obvious if the assistant exerts traction on the greater curvature. There is a crow's foot arrangement of large veins (not nerves) in the region of the incisura and the major terminations of the nerve of Latarjet accompany the veins that form the "toe" of the foot. The anterior part of the dissection begins just proximal to the point where these nerves pass across the musculature of the antral region. Hollender: ${ }^{40}(1980)$

the crow's foot termination of the Latarjet's anterior nerve in the living subject is an almost constant surgical landmark. Dissection is begun immediately to the left of this point which can lead to sectioning the left diwisional branch.

Sawyers: ${ }^{313}(1977)$

the antral=parietal cell border is determined anatomically by the entrance of the branches of the ant. nerve of Latarjet on to the gastric antrum (crow's foot).

Evidently this problem has not been solved; many authors do not mention a crow's foot in their description of operative techniques but refer to the main branch of Latarjet's nerve or just to Latarjet's nerve. Others do mention it but without defining it.

On the other hand it is not certain whether the distal level where the dissection starts is that imporiant since there is a wide variation of opinions with possibly similar results. Ahonen published a nice study ${ }^{6}$ comparing the results of HSV using anatomical landmarks as a starting point with $\mathrm{pH}$-metric defined borders and found no difference in gastric secretion and clinical results although the mapping technique meant more distal dissection.

De Miguel similarly observed no appreciable difference between the first group of patients with only $5-6 \mathrm{~cm}$ of distal stomach left innervated and the following group in which all terminal branches of Latarjet's nerve were preserved (average $9 \mathrm{~cm}$ ) ${ }^{255}$. Others ${ }^{151,286}$ came to a similar conclusion, but sometimes the level was found to be critical $^{281}$.

It is remarkable further that in spite of Jackson's observations of the nerves of Latarjet failing to reach the antrum in a high proportion of cases, this has almost never been mentioned in descriptions of details of operation in clinical studies. Only Hill ${ }^{346}$ used this as an argument for a quicker operation: anterior HSV and posterior truncal vagotomy. In the present material no special study was made about the termination of Latarjet's nerve but although a crow's foot like aspect of the terminal branches of Latarjet's nerve sometimes is apparent it is certainly not the 
most common picture. The term "crow's foot" is better avoided for the terminal branching of the nerves of Latarjet, and it is preferable to use the main stem of Latarjet"s nerve as the anatomical landmark for starting the dissection. It is often discernible from its terminal branches being the thickest and entering the antrum at about a right angle, but in a number of cases this stem fans out in several branches of equal size; it can be difficult then to recognise a main stem. In such a case it depends on the distance to the pylorus and the angle of entering which one(s) is (are) 1o be severed.

\subsection{Physiology}

The stomach possesses a great number of functions as one of the first stations in the alimentary tract.

The stomach can be divided into two rather differing parts: a proximal part: the corpus and the fundus, and a distall part: the antrum and the pylorus ${ }^{74}$.

The proximal part has the power of receptive relaxation, which means the possibility of adapting to volume without increasing pressure. Further, the gastric pacemaker is situated here for the automatic peristalsis of the stomach which is independent of the external nerve supply. It initiates a contraction wave three times per minute. The power of this wave is probably dependent on the nerve supply, mainly the vagus nerve.

Histologically this part contains mucous cells, producing a protective layer continuously, oxyntic or parietal cells, which are able to secrete $\mathrm{HCl}$ against a very high concentration gradient, and chiefcells, which produce pepsinogen that is to be activated by the secreted $\mathrm{HCl}$. The parietal cells are also responsible for the production of intrinsic factor, necessary for the absorption of vitamin $\mathbf{B}_{12}$.

The acid is of importance in sterilising the contents of the stomach. Further it could be important for the absorption of iron. The vagus stimulates the muscle power and mediates the receptive rellaxation. It influences the acid production and is involved in many reflex mechanisms influencing secretion and motility.

The distal segment of the stomach is motorically the emptying mechanism. By its forceful movements the chyme is thoroughly mixed and propelled to the duodenum in close cooperation with the pylorus and duodenum. Many still unknown factors are hereby involved. The motor function is dependent on the wagal nerve supply; if this is damaged a pronounced delay in emptying occurs, as in truncal and selective vagotomy.

The antrum has a regulating role by means of hormones. The G-cells of the antrum produce gastrin under the influence of certain stimuli (distension, food). Gastrin in turn stimulates via the blood stream the parietal cells to acid production and it is regulated via a feed-back mechanism by the very acid it stimulates.

Many other factors play a role, like composition of the food, volume of the contents, other humoral agents, psychological factors and probably the sympathetic nervous system.

The digestion of protein is commenced in the stomach by the proteolytic capacity of the activated pepsin. 
Carbohydrate digestion under the influence of salivary amylase continues in the stomach, while the chyme is mixed. Part of its contents can already be absorbed by the stomach, like alcohol, drugs and water.

Traditionally the gastric secretory process is divided into three phases, depending on where the stimuli come from.

The three phases are: cephalic, gastric and intestinal phase. The cephalic phase is influenced by the wagus nerve; the gastric and intestinal phases are mediated mainly by humoral agents, gastrin being the best known ${ }^{20,331}$. Gastrin, histamine and acetylcholine are considered as the three main physiological stimulants of gastric acid secretion. All seem to act at separate and specific receptors on the parietal cell, but potentiating interactions occur ${ }^{331}$. Histamine probably exerts the most central role. The interrelationships are rather complicated. Kay ${ }^{180}$ stated in 1970 that there was only one good explanation for the reduced production of gastric acid after a vagotomy in spite of maximal stimulation with histamine: histamine needs a certain background level of acetylcholine for its action. The production of gastric acid can be restored to preoperative levels by adding a cholinergic drug - like mecholyl. Probably intracellular secondary effectors are released by these three agents.

It is not unlikely that prostaglandin will prove to play an important role ${ }^{111,257,323}$. Many important questions, however, are still unsolved.

\subsection{The rationale of operative treatment}

This concise anatomical and physiological background offers a modest idea about the effects of and objections to several operations. Why a certain operation works is often not well understood at the moment of practice, but retrospectively a rational foundation can usually be given.

Why gastro-enterostomy can cause a longstanding cure for DU is probably based on quick deviation of the food after ingestion. The food is only in contact with the stomach for a short time thereby decreasing stimulation of acid, pepsin and gastrin secretion. Disadvantages are: a high jejunal ulcer rate, side-effects due to every drainage procedure and by-passing of the pylorus: diarrhoea, dumping, bilious vomiting. Moreover there is an increased risk of developing carcinoma of the stomach ${ }^{263}$. At present this operation has given way to other more effective procedures.

Partial gastrectomy is elfective by removing the gastrin producing source as well as a part of the acid and pepsin producing cell mass. Disadvantages: more demanding procedure, higher mortality rate, and the objections inherent in the loss of the pylorus, including the risk of late carcinoma ${ }^{80,113,189,295}$.

Truncal vagotomy works by eliminating the stimulating influences of the vagus on the gastric juice production, although not abolishing it. However, the motility and emptying of the stomach are also disturbed and a gastro-jejunostomy or a kind of pyloroplasty should be added.

Moreover many intra-abdominal organs are denervated, such as the liver, gallbladder, pancreas, the whole small gut and a part of the colon. Thus it removes the possible protective factors of gastric or extra-gastric origin transmitted by vagal pathways. 
An important advantage is the relative safety and simplicity of the procedure alt hough the simplicity should not be overestimated (Nyhuss) ${ }^{71}$. 273 . A logical successor could be: selective gastric vagotomy: vagal denervation of the stomach only, but still at drainage procedure is needed. HSV seems to be a natural next step, since we know that it works; it confers only few disadvantages. No drainage procedure or disturbance of pyloric function is needed $5,13,72,212,289,361$, but the motor disability of the proximal stomach is immediately evident, though this tends to improve with time. HSV in itself, and in comparison to other operations, is in many aspects a very interesting physiological test which has boosted much new scientific work and understanding, resulting in more questions to be resolved and understood than before ${ }^{180}$. The concept of HSV is denervating the acid secreting part of the stomach and preserving the antrum and pylorus innervation with a number of regulating and inhibiting mechanisms ${ }^{286}$

The question that arises is: is HSV effective enough in all cases and, if not, what factors are determinant?

As discussed already there is the possibility that HSV even if performed perfectly well solves the problem in only $90 \%$ of the patients. Another possibility is that the method is perfect, but that this is seldom achieved in all cases. Many investigations have been done to substantiate this, among them several intra-operative tests to check the completeness of the denervation.

Perhaps it is more useful to say that a new equilibrium is set between aggressive and defensive factors which normally constitute health but which can equally be disturbed by external influences giving rise to the original disease for which the operation was done. The question then arises how severe a recurrence is and how much risk one is allowed to take to ban this hazard. Extreme circumstances probably can produce a recurrence after whatever therapy (except total gastrectomy).

Nevertheless it is possible that a treatment can be found that is almost independent from aetiological and pathogenetic factors, because it influences in a favourable way the hypothetical final common pathway giving rise to the ulcer.

The dilemma is as so often in medicine: what price can be afforded to pay for the benefit of near absolute cure.

Even if a treatment is discovered which almost excludes a recurrence ("super HSV") it could mean that other and perhaps worse sequelae ensue which are not directly related to the gastrointestinal tract: myocardial infarction, nervousness (see chapter 16), suicide etc. ${ }^{249}$.

Although it seems attractive to search for answers to all possible questions on the base of a theoretical background, it may be dangerous to believe too much in that; the observer risks seeing only what he believes and does not dare to believe or document what he sees (Wangensteen ${ }^{358}$ ). Often in the history of science a theory was true until something else - sometimes the opposite - became more true. 


\section{Chapter 4}

\section{Patients and methods}

\subsection{Patients and characteristics}

In the period of study - from 1st January 1974 until Ist January 1982 - 262 patients with duodenal ulcer were treated with HSV either electively or for complications. As many characteristics of all patients as were recorded have been presented in table A (p. 29-31), as well as subdivided in men and women. These characteristics are discussed below.

It should be noted that for a number of characteristics the total number of patients is not equal to 262. From the missing patients that particular detail was not recorded. The percentages were calculated disregarding these patients.

The significance of the differences between men and women has been indicated in the table.

From the 262 patients 223 were operated on electively, 25 semi-electively ( 11 for stenosis and 14 for bleeding that had stopped in the previous days) and 14 in the acute situation ( 4 for bleeding, 10 for perforation). See also chapter 9 about preoperative complications.

A similar table but with a subdivision in patients with or without a recurrent ulcer after operation will be presented in chapter 15 (table B).

Sex

There were 214 men $(81.7 \%)$ and 48 women $(18.3 \%)$, a ratio of $4.5: 1$. This is similar to what most series report at present ${ }^{171}$, but differs from the $9: 1$ ratio reported by Suy ${ }^{342}$ in the large series from this hospital about three decades ago.

\section{Height}

The average height of the patients was: $174 \mathrm{~cm}$ (sd 9), median $174 \mathrm{~cm}$; for men 176 $\mathrm{cm}$ ( $\mathrm{sd} \mathrm{8)}$, for women $164 \mathrm{~cm}$ (sd 6).

\section{Weight}

The mean weight for all patients was $70.8 \mathrm{~kg}$, for men 73.1 , for women $63.7 .16 \%$ of the patients stated that they had lost weight due to their disease prior to operation. Their weight, however, did not differ significantly from those who did not lose weight, neither for men nor for women. This will be extensively discussed in the chapter about metabolic consequences (chapter 13 ).

\section{Nationality}

Almost all patients were of Dutch origin including a single patient born in Germany, but living for a long time in the Netherlands. There were ten (3.8\%) foreign workers, all men. 
or distribution will be extensively dealt with in chapter

40.9 years; for men 40.2 and for women 44.1 , which gram of the age distribution is presented in figure 1.

Im the date of operation and the length of ulcer history. y not very accurate.

0 years; for men 29.4, for women 32.4. This difference isee figure 2 .

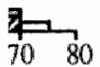

years)

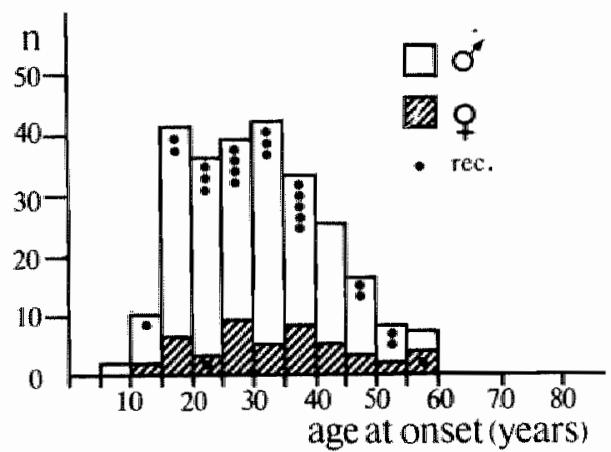

figure 2

istory for all patients was 9.9 years; for men 9.7 , for 3 . 


\section{Periodicity}

The periodicity of the complaints is often a striking feature of duodenal ulcer disease, if present. Sometimes it is not so clear and very often not present at all, although it might have been in the past. In many histories of patients who underwent a HSV there was continuous pain for a considerable period prior to operation but a more or less episodical course in the years before.

This means that in many cases it is difficult to attach the predicate "episodic character" at the moment of history taking. Thus it is difficult to delineate exactly how many were negative, or positive. Especially positivity does have more value in this respect, since positive findings are often volunteered by the patients in contrast to characteristics which are absent. In some instances it had evidently not been recorded. The figures should not be considered absolute, but if this characteristic should make any clear difference in any respect it would certainly come out statistically if the positive group was compared with the negative one. It was positive in $34 \%$ of the patients and more so in men $(37 \%)$ than in women. It will be dealt with more extensively in chapter 16 .

\section{Length of follow-up}

The average length of the follow-up was 50.4 months (sd 25), ranging from 6-99 months, with no difference between men and women.

\section{Nervousness}

Although duodenal ulcer has often been related with stress not all patients expressed this in their behaviour. A number however demonstrated nervousness to a grossly greater degree than normal. Although very difficult to measure, the distinction from other patients was clinically quite obvious. In this material $30 \%$ demonstrated this nervousness enough for it to be recorded and few did indeed have quite peculiar behaviour. 15 patients $(5,7 \%)$ had a history of psychiatric treatment.

\section{Intoxications}

Smoking:

Four catogories were distinguished but in 40 patients (15.2\%) no data were available.

1. nil-sporadically $15.2 \%$

2. less than 10 cig. daily $\quad 14 \%$

3. 10-25 cig. daily $42 \%$

4. more than 25 cig. daily $28.8 \%$

This means that $85 \%$ of the patients were smokers. This is in agreement with other reports ${ }^{249}$.

\section{Alcohol use}

Patients were again subdivided into four categories but in 59 patients $(22,5 \%)$ no data were recorded. 
1. nil to sporadically $\quad 53 \%$

2. litule $\quad 36.5 \%$

3. intuch $7.4 \%$

4. abuse, very much $3 \%$

These categories are of course arbitrarily estimated.

Drinking much alcohol means here more than 3-6 units of alcohol daily. In some patients there was a very heavy use at the weekends but almost no intake on working days.

\section{Drugs}

Most patients uised one or more antacids and tranquillisers which is expected in such a group (preoperatively). The use of cimetidine before operation was especially noted. The first patient having used cimetidine was operated on in 1978. Later almost every patient who came to operation had used cimetidine for some time, totalling $44 \%$ of all patients in this series.

\section{Employment}

There could be a relation of inability to work with severity of disease but in a time of increasing unemployment it is difficult to interpret the data concerning employment. In 18 patients no data were recorded. The remainder can be distributed as follows:

- not applicable (school, studying) 7 (2.9\%)

- at work $171(70.1 \%)$

- inability to work (social security) $23(9.4 \%)$.

- retired $4(1.6 \%)$

- housewife $39(16 \%)$

If a housewife was also employed in a job, she was counted there.

\section{Preoperative complications}

There were three rather common complications in duodenal ulcer often precipitating an operalion:

1. bleeding

2. perforation

3. stenosis caused by postpyloric obstruction due to scarring

The distribution of these complications among the patients studied was:

$-49(18.7 \%)$ bleeding

$-24(9.2 \%)$ perforation

- $1(0.4 \%)$ bleeding and perforation

- $9(3.4 \%)$ stenosis

- $2(0.8 \%)$ perforation and stenosis

This is a mixture of acute complications requiring immediate surgery and previous complications having taken place in history. Often more than one bleeding was present in the history, but only in a few instances had it led to emergency operations (chapter 9). 
The surgeons

In this series 19 different surgeons had been operating, 7 consultant surgeons and 12 residents (registrars).

The consultants performed 95 pperations themselves $(36 \%)$ and acted as assistant in 54 operations.

The residents did 167 operations (64\%) and were assisting in 156 cases. Other residents who had not yet performed a HSV themselves assisted at the remainder of the operations.

Most residents had assisted in about $10 \mathrm{HSV}$ 's belore performing their first HSV. Three however did their first HSV after $\mathbb{4} 4$ times of assisting.

There were four consultants involved in teaching; they did 49 of the assistances.

The surgical training in the Netherlands is different from that in other countries. The duration of training is 6 years for specialist registration. HSV was taught and performed from the fourth year onward. The residents in that stage of training are henceforth called "registrars" although this litle does not exist in the Netherlands.

\section{Activity of the ulcer at operation}

The activity of the ulcer was usually recorded in the operation report:

- no ulcer seen and no detectable scarring: 23 patients $(8.8 \%)$

- scarring deformation adhesions: $139(53.3 \%)$

- slight activity: $36(13.8 \%)$

- active ulcer: $62(23.8 \%)$.

In 2 patients nothing was recorded about activity.

As stated before, the indication for operation was a recurrent duodenal ulcer but in 23 cases the diagnosis could not be verified at the time of operation which could mean that the scarring was not visible or palpable.

\section{Additional operations}

The following operations were performed together with the HSV:

-7 cholecystectomies $(2.3 \%)$

-3 liver biopsies (1.1\%)

-4 appendicectomies ( $1.5 \%)$

- 1 hiatal repair $(0.4 \%)$.

\section{Clips}

In 66 patients clips were used for ligation of tissue ${ }^{310}$ but in 37 of them only partially (indicated as $1 / 2$ in the table).

\section{Skeletonising of greater curvature}

As described in the next chapter (operative technique) initially the greater curvature was not opened at all (147 cases) and the whole dissection of the lesser curvature was done from the front as described by Goligher ${ }^{95}$.

Now it is standard to skeletonise the greater curvature (112 patients). 
cm oesophagus dissected

The number of centimeters of oesophagus laid bare varied slightly around $5-6 \mathrm{cms}$. The average was $5,4 \mathrm{~cm}$; the numbers and percentages of the patients having $4,5,6$ or $7 \mathrm{~cm}$ of dissection are indicated in the table.

\section{cm antrum dissected}

Similarly the distance from the point where the dissection started to the pylorus has been recorded (see operative technique, chapter 5). The average was $6,7 \mathrm{~cm}$. (see table).

\subsection{Statistical methods}

The data were tested according to the t-test of Student or the chi-square $\left(\mathrm{X}^{2}\right)$ test, where appropriate. The reader should be warned, that with so many statistical tests as applied in this thesis on the basis of statistical probability (at the $5 \%$ level) one out of twenty tests with statistical significance (at the $5 \%$ level) is significant by chance. It should be noted further that comparing data from the same population - although with differing patients and unequal numbers -at differing time periods (before and at several time intervals after operation) is not strictly correct statistically. Therefore the $t$-test for paired observations has been applied to test the validity of the difference or non-difference found. This is circumscribed in this thesis as "strictly coupled data" or "paired data".

Additionally, coupled values have been employed i.e. only those postoperative values have been used when there was a preoperative value; thereby all postoperative data in each patient had been averaged. For these coupled values-comparisons all preoperative values have been used.

The first way of describing data was maintained, however, since it often occurs in scientific papers ${ }^{89}, 127,144,330$, since it is simpler to demonstrate the data graphically and since comparison between groups (men and women, patients with and without a recurrence) is allowed at each time interval.

More often in the text the procedure is explained to allow the reader to understand all chapters as isolated entities.

Unless defined otherwise, significance has been assumed to be present at the $5 \%$ probability level. The term significance meaning other than statistical significance has been avoided.

It should be noted further that error bars of whatever nature ( $1 \mathrm{sd}, 1 \mathrm{sem}, 2 \mathrm{sem}$ ) are often misleading since they can suggest (significance) what they do no necessarily indicate and are therefore completely omitted.

In some of the comparisons the number of cases to be compared was considered too small to be tested. In that case n.a. (not applied, not applicable) has been indicated. In tables and figures the presence of significance is indicated with an asterisk, the absence with n.s. (not significant); $p$ indicates the level of significance. 
table $A$

Characteristics of all patients with a subdivision in men and women.

The laboratory parameters refer to preoperative values.

Either the number of cases and the percentages are indicated or the average value the standand deviation (sd) and the number of values ( $\mathrm{n}$ ); if the latter is the case the units are given in the second collumn.

The set-up of this table is essentially the same as that of table B (Chapter 15) with a subdivision in patients with and without a recurrence.

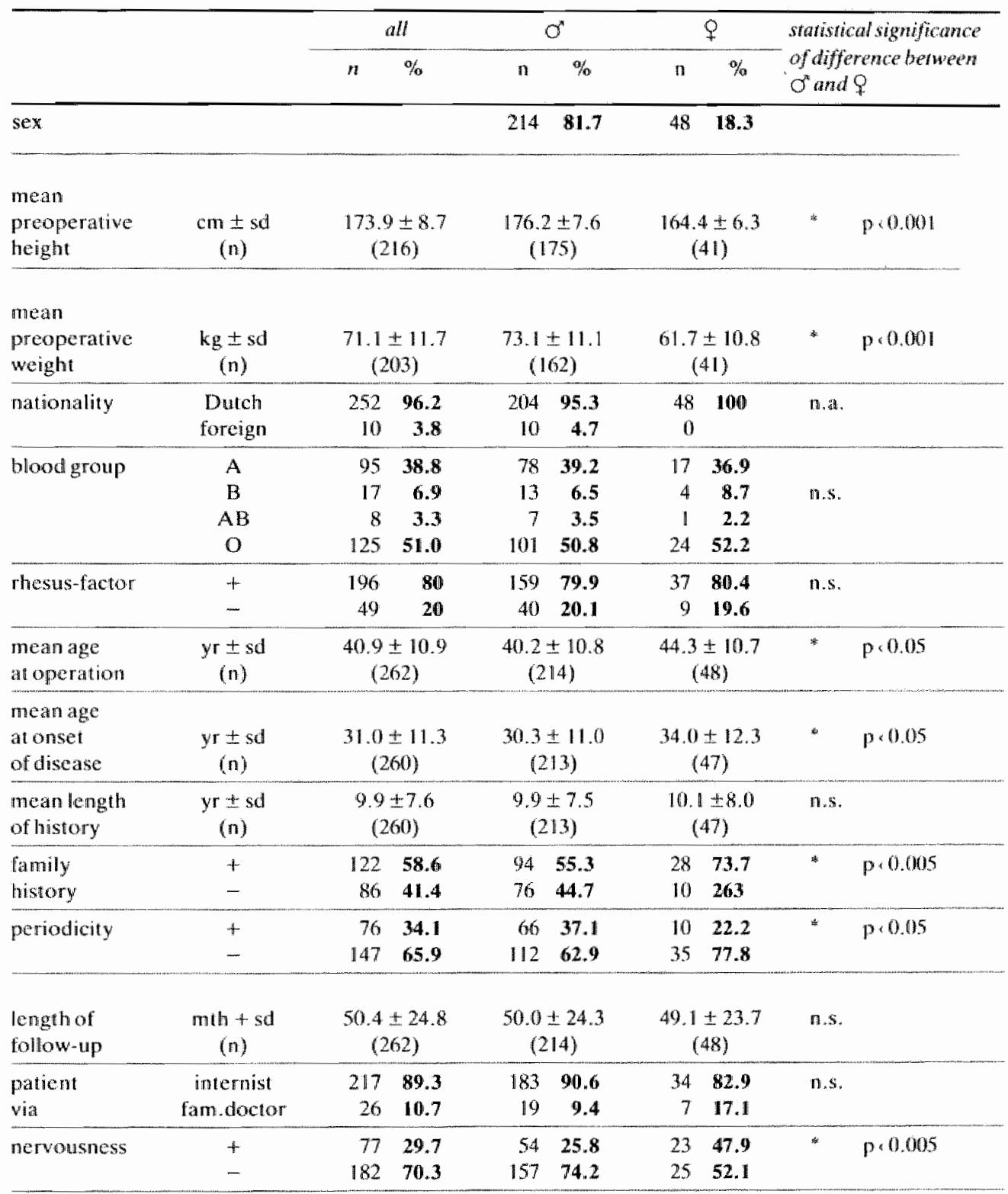




\begin{tabular}{|c|c|c|c|c|c|c|c|c|}
\hline & & \multicolumn{2}{|c|}{ all } & \multicolumn{2}{|c|}{$0^{\pi}$} & \multicolumn{2}{|r|}{$q$} & \multirow{2}{*}{ 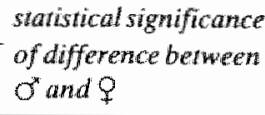 } \\
\hline & & $n$ & $\%$ & $\mathrm{n}$ & $\%$ & n & $\%$ & \\
\hline $\begin{array}{l}\text { history of } \\
\text { psychiatry }\end{array}$ & + & $\begin{array}{r}15 \\
242 \\
\end{array}$ & $\begin{array}{r}5.8 \\
94.2 \\
\end{array}$ & $\begin{array}{r}12 \\
197 \\
\end{array}$ & $\begin{array}{r}5.7 \\
94.3 \\
\end{array}$ & $\begin{array}{r}3 \\
45 \\
\end{array}$ & $\begin{array}{r}6.2 \\
93.8 \\
\end{array}$ & $\mathrm{nis.}$. \\
\hline $\begin{array}{l}\text { srinoking of } \\
\text { cigarettes }\end{array}$ & $\begin{array}{c}- \\
10 \\
10.25 \\
\times 25\end{array}$ & $\begin{array}{l}34 \\
31 \\
93 \\
64\end{array}$ & $\begin{array}{l}15.3 \\
14.0 \\
41.9 \\
28.8 \\
\end{array}$ & $\begin{array}{l}29 \\
25 \\
78 \\
53 \\
\end{array}$ & $\begin{array}{l}15.7 \\
13.5 \\
42.2 \\
28.6 \\
\end{array}$ & $\begin{array}{r}5 \\
6 \\
15 \\
11 \\
\end{array}$ & $\begin{array}{l}13.5 \\
116.2 \\
40.5 \\
29.7 \\
\end{array}$ & n.s. \\
\hline allcohol & $\begin{array}{l}\text { moderate } \\
\text { much } \\
\text { abuse }\end{array}$ & $\begin{array}{r}108 \\
74 \\
15 \\
6\end{array}$ & $\begin{array}{r}53.2 \\
36.4 \\
7.4 \\
3.0 \\
\end{array}$ & $\begin{array}{r}82 \\
68 \\
14 \\
6 \\
\end{array}$ & $\begin{array}{r}48.2 \\
40.0 \\
8.2 \\
3.5 \\
\end{array}$ & $\begin{array}{r}26 \\
6 \\
1 \\
0 \\
\end{array}$ & $\begin{array}{r}78.8 \\
18.2 \\
3.0\end{array}$ & * $\quad p=0.001$ \\
\hline employment & $\begin{array}{c}- \\
+ \\
\text { rejected } \\
\text { retired } \\
\text { housewife }\end{array}$ & $\begin{array}{r}0 \\
171 \\
23 \\
4 \\
39 \\
\end{array}$ & $\begin{array}{r}72.1 \\
9.7 \\
1.7 \\
16.5 \\
\end{array}$ & $\begin{array}{r}7 \\
162 \\
23 \\
4 \\
0\end{array}$ & $\begin{array}{r}3.6 \\
82.6 \\
11.7 \\
2.0\end{array}$ & $\begin{array}{r}0 \\
9 \\
0 \\
0 \\
39\end{array}$ & $\begin{array}{r}18.7 \\
81.3 \\
\end{array}$ & n.a. \\
\hline $\begin{array}{l}\text { preoperative } \\
\text { complications }\end{array}$ & $\begin{array}{c}\text { bleeding } \\
\text { perforation } \\
\text { bt + perf } \\
\text { stenosis } \\
\text { st + perf }\end{array}$ & $\begin{array}{r}177 \\
49 \\
24 \\
1 \\
9 \\
2\end{array}$ & \begin{tabular}{r|}
6.7 .5 \\
18.7 \\
9.2 \\
0.4 \\
3.4 \\
0.8 \\
\end{tabular} & $\begin{array}{r}141 \\
44 \\
20 \\
1 \\
6 \\
2 \\
\end{array}$ & $\begin{array}{r}65.9 \\
20.6 \\
9.3 \\
0.5 \\
2.8 \\
0.9\end{array}$ & $\begin{array}{r}36 \\
5 \\
4 \\
0 \\
3 \\
0\end{array}$ & $\begin{array}{r}75.0 \\
10.4 \\
8.3 \\
6.3\end{array}$ & \\
\hline $\begin{array}{l}\text { preoperative } \\
\text { complications }\end{array}$ & - & $\begin{array}{r}178 \\
84 \\
\end{array}$ & $\begin{array}{l}67.9 \\
32.1 \\
\end{array}$ & $\begin{array}{r}142 \\
72 \\
\end{array}$ & $\begin{array}{l}66.2 \\
33.7 \\
\end{array}$ & $\begin{array}{l}36 \\
12 \\
\end{array}$ & $\begin{array}{l}75.0 \\
25.0 \\
\end{array}$ & n.s. \\
\hline $\begin{array}{l}\text { HSV } \\
\text { performed by }\end{array}$ & $\begin{array}{c}\text { registrars } \\
\text { consultants }\end{array}$ & $\begin{array}{r}167 \\
95 \\
\end{array}$ & $\begin{array}{l}63.7 \\
36.3 \\
\end{array}$ & $\begin{array}{r}139 \\
75 \\
\end{array}$ & $\begin{array}{l}64.9 \\
35.1 \\
\end{array}$ & $\begin{array}{l}28 \\
20 \\
\end{array}$ & $\begin{array}{l}58.3 \\
41.7 \\
\end{array}$ & n.s. \\
\hline $\begin{array}{l}\text { HSV } \\
\text { assistance } \\
\text { by }\end{array}$ & $\begin{array}{l}\text { registrars } \\
\text { consultants }\end{array}$ & $\begin{array}{r}208 \\
54 \\
\end{array}$ & $\begin{array}{l}79.4 \\
20.6\end{array}$ & $\begin{array}{r}174 \\
40 \\
\end{array}$ & $\begin{array}{l}81.3 \\
18.7 \\
\end{array}$ & $\begin{array}{l}34 \\
14\end{array}$ & $\begin{array}{l}70.8 \\
29.2 \\
\end{array}$ & n.s. \\
\hline $\begin{array}{l}\text { activity of } \\
\text { the ullcer at } \\
\text { operation }\end{array}$ & $\begin{array}{c}- \\
\text { scar } \\
\text { slight activity } \\
+\end{array}$ & $\begin{array}{r}23 \\
139 \\
62 \\
36\end{array}$ & $\begin{array}{r}8.8 \\
53.5 \\
23.8 \\
13.9 \\
\end{array}$ & $\begin{array}{r}19 \\
110 \\
54 \\
29 \\
\end{array}$ & $\begin{array}{r}9.0 \\
51.9 \\
25.5 \\
13.7 \\
\end{array}$ & $\begin{array}{r}4 \\
29 \\
8 \\
7\end{array}$ & $\begin{array}{r}8.3 \\
60.4 \\
16.7 \\
14.6 \\
\end{array}$ & n.s. \\
\hline $\begin{array}{l}\text { (semi) } \\
\text { emergency } \\
\text { HSV }\end{array}$ & $\begin{array}{c}- \\
\text { bleeding } \\
\text { perforition } \\
\text { stenosis } \\
\text { semiacute } \\
\text { bleeding }\end{array}$ & $\begin{array}{r}223 \\
4 \\
10 \\
11 \\
14\end{array}$ & $\begin{array}{r}85.1 \\
1.5 \\
3.8 \\
4.2 \\
5.3\end{array}$ & $\begin{array}{r}182 \\
3 \\
9 \\
8 \\
12\end{array}$ & \begin{tabular}{r|}
85.0 \\
1.4 \\
4.2 \\
3.7 \\
\\
5.6
\end{tabular} & $\begin{array}{r}41 \\
1 \\
1 \\
3 \\
2\end{array}$ & $\begin{array}{r}85.4 \\
2.1 \\
2.1 \\
6.2 \\
4.2\end{array}$ & $\mathrm{n} . \mathrm{s}$ \\
\hline $\begin{array}{l}\text { HSV with } \\
\text { additional } \\
\text { procedure }\end{array}$ & + & $\begin{array}{r}226 \\
36\end{array}$ & $\begin{array}{l}86.3 \\
113.7\end{array}$ & $\begin{array}{r}188 \\
26\end{array}$ & $\begin{array}{l}87.8 \\
12.2\end{array}$ & $\begin{array}{l}38 \\
10\end{array}$ & $\begin{array}{l}79.2 \\
20.8\end{array}$ & n.s. \\
\hline clips & $\begin{array}{l}- \\
1 / 2 \\
4\end{array}$ & $\begin{array}{l}195 \\
37 \\
29\end{array}$ & $\begin{array}{l}74.7 \\
14.2 \\
11.1\end{array}$ & $\begin{array}{r}165 \\
28 \\
20 \\
\end{array}$ & $\begin{array}{r}77.5 \\
13.1 \\
9.4 \\
\end{array}$ & $\begin{array}{r}30 \\
9 \\
9 \\
\end{array}$ & $\begin{array}{l}62.5 \\
18.7 \\
18.7\end{array}$ & n.s. \\
\hline $\begin{array}{l}\text { skeletonising } \\
\text { of greater } \\
\text { curve }\end{array}$ & - & $\begin{array}{l}147 \\
112\end{array}$ & $\begin{array}{l}56.8 \\
43.2\end{array}$ & $\begin{array}{r}119 \\
92\end{array}$ & $\begin{array}{l}56.4 \\
43.6\end{array}$ & $\begin{array}{l}28 \\
20\end{array}$ & $\begin{array}{l}\mathbf{5 8 . 3} \\
\mathbf{4 1 . 7}\end{array}$ & n.s. \\
\hline
\end{tabular}




\begin{tabular}{|c|c|c|c|c|c|}
\hline & & $a l l$ & $0^{m}$ & 9 & \multirow{2}{*}{ 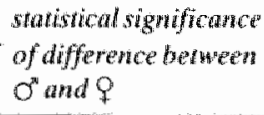 } \\
\hline & & $\%$ & $\%$ & $\%$ & \\
\hline cm of & $4 \mathrm{~cm}$ & 3.5 & 3.8 & 2.1 & \\
\hline oesophagus & $5 \mathrm{~cm}$ & $14456 \ldots$ & $119 \quad 56.7$ & $25 \quad 53.2$ & \multirow{3}{*}{ ns } \\
\hline \multirow[t]{2}{*}{ skeletonised } & $6 \mathrm{~cm}$ & $100 \quad 38.9$ & 8038.1 & $20 \quad 42.6$ & \\
\hline & $7 \mathrm{~cm}$ & 1.6 & 1.4 & $1 \quad 2.1$ & \\
\hline \multicolumn{6}{|l|}{ crry of } \\
\hline $\begin{array}{l}\text { oesophagus } \\
\text { skeletonised }\end{array}$ & $\begin{array}{c}\mathrm{cm} \pm \mathrm{sd} \\
\text { (n) }\end{array}$ & $\begin{array}{c}5.38 \pm 0.58 \\
(257)\end{array}$ & $\begin{array}{c}5.36 \pm 0.57 \\
(210)\end{array}$ & $\begin{array}{c}5.44 \pm 0.55 \\
(47)\end{array}$ & $\mathrm{m}_{\mathrm{n}} \mathrm{s}_{\mathrm{n}}$ \\
\hline \\
\hline of antrum & $5 \mathrm{~cm}$ & $7 \quad 2.7$ & $7 \quad 3.3$ & 0 & \multirow{5}{*}{ n.s. } \\
\hline \multirow{4}{*}{ skeletonised } & $6 \mathrm{~cm}$ & $85 \quad 33.2$ & 7133.8 & $14 \quad 30.4$ & \\
\hline & $7 \mathrm{~cm}$ & $129 \quad 50.4$ & $101 \quad 48.1$ & $28 \quad 60.9$ & \\
\hline & $8 \mathrm{~cm}$ & 34. $\quad 13.3$ & $30 \quad 14.3$ & 8.7 & \\
\hline & $10 \mathrm{~cm}$ & 0.4 & 0.5 & 0 & \\
\hline \multirow[t]{2}{*}{$\begin{array}{l}\mathrm{cm} \\
\text { of antrum } \\
\text { skeletonised }\end{array}$} & $\begin{array}{c}c m \pm s d \\
(n)\end{array}$ & $\begin{array}{c}6.72 \pm 0.80 \\
(256) \\
\end{array}$ & $\begin{array}{c}6.70 \pm 0.82 \\
(210)\end{array}$ & $\begin{array}{c}6.78 \pm 0.57 \\
(46)\end{array}$ & n.s. \\
\hline & & $A \|$ & $0^{x}$ & 9 & \multirow[b]{2}{*}{$* \quad p \cdot 0.000$} \\
\hline $\mathrm{Hb}$ & $\begin{array}{c}\mathrm{mmol} / \mathrm{t} \mathrm{sd} \\
(\mathrm{a})\end{array}$ & $(242)$ & $\begin{array}{c}9.72 \pm 0.70 \\
(199)\end{array}$ & $\begin{array}{c}8.79 \pm 0.76 \\
(43)\end{array}$ & \\
\hline ESR & $\begin{array}{c}m / h \pm s d \\
(n)\end{array}$ & $\begin{array}{c}6.14 \pm 6.62 \\
(227)\end{array}$ & $\begin{array}{c}5.75 \pm 6.71 \\
(186)\end{array}$ & $\begin{array}{c}7.90 \pm 5.94 \\
(41)\end{array}$ & $n . s$ \\
\hline seruma $A D$ & $\begin{array}{c}\mathrm{U} / \pm \mathrm{sd} \\
(\mathrm{n})\end{array}$ & $\begin{array}{c}84.4 \pm 27.6 \\
(181) \\
\end{array}$ & $\begin{array}{c}84.6 \pm 27.8 \\
(149) \\
\end{array}$ & $\begin{array}{c}83.4+27.2 \\
(32) \\
\end{array}$ & n.s. \\
\hline seruma $C a$ & $\begin{array}{c}\mathrm{mmol} / \mathrm{l} \pm \mathrm{sd} \\
(\mathrm{n})\end{array}$ & $\begin{array}{c}2.41 \pm 0.11 \\
(159)\end{array}$ & $\begin{array}{c}2.42 \pm 0.11 \\
(134)\end{array}$ & $\begin{array}{c}2.37 \pm 0.08 \\
(25)\end{array}$ & n.s. \\
\hline serump & $\begin{array}{c}\mathrm{mmol} / \mathrm{I} \pm \mathrm{sd} \\
(\mathrm{n})\end{array}$ & $\begin{array}{c}1.12 \pm 0.20 \\
(159)\end{array}$ & $\begin{array}{c}1.11 \pm 0.20 \\
(134)\end{array}$ & $\begin{array}{c}1.17 \pm 0.18 \\
(25)\end{array}$ & $\mathrm{n} . \mathrm{s}$ \\
\hline serum Fe & $\begin{array}{c}\mu \mathrm{mol} / \mathrm{I} \mathrm{sd} \\
(\mathrm{n})\end{array}$ & $\begin{array}{c}19.8 \pm 6.5 \\
(144)\end{array}$ & $\begin{array}{c}19.4 \pm 6.6 \\
(120)\end{array}$ & $\begin{array}{c}17.5 \pm 5.6 \\
(24)\end{array}$ & $n . s$ \\
\hline serum TIBC & $\begin{array}{c}\mu \mathrm{mol} / \mathrm{t} \mathrm{sd} \\
(\mathrm{n})\end{array}$ & $\begin{array}{c}60.7 \pm 9.7 \\
(144)\end{array}$ & $\begin{array}{c}60.9 \pm 10.0 \\
(120)\end{array}$ & $\begin{array}{c}60.1 \pm 8.3 \\
(24)\end{array}$ & n.s. \\
\hline vilamin $B_{12}$ & $\begin{array}{c}\mathrm{nmol} / \mathrm{l} \pm \mathrm{sd} \\
(\mathrm{n})\end{array}$ & $\begin{array}{c}311.0 \pm 92.8 \\
(110)\end{array}$ & $\begin{array}{c}315.6 \pm 92.8 \\
(95)\end{array}$ & $\begin{array}{c}281.6 \pm 71.8 \\
(15)\end{array}$ & $\mathrm{n} . \mathrm{s}$. \\
\hline serum gastrin & $\begin{array}{c}n g h \pm s d \\
(n)\end{array}$ & $\begin{array}{c}120.3 \pm 64.5 \\
(190)\end{array}$ & $\begin{array}{c}122.0 \pm 66.5 \\
(159)\end{array}$ & $\begin{array}{c}114.3 \quad \pm 53.3 \\
(31) \\
\end{array}$ & n.s. \\
\hline $\mathrm{BAO}$ & $\begin{array}{c}\mathrm{mmol} / \mathrm{h} \\
\text { (n) }\end{array}$ & $\begin{array}{c}6.116 \pm 6.96 \\
(207)\end{array}$ & $\begin{array}{c}6.32 \pm 7.46 \\
(169)\end{array}$ & $\begin{array}{c}5.42 \pm 4.10 \\
(38)\end{array}$ & $\mathrm{n} . \mathrm{s}$ \\
\hline voluane & $\mathrm{ml} / \mathrm{h} \pm \mathrm{sd}$ & $\begin{array}{cl}126 & \pm 92 \\
120 & +23\end{array}$ & $128 \pm 97$ & $117 \pm 70$ & n.s. \\
\hline Acidity & monol/1 $\pm s d$ & $42.9 \pm 23.7$ & $42.8 \pm 23.6$ & $43.1 \pm 24.9$ & n.s. \\
\hline $\mathrm{PAO}$ & $\begin{array}{c}\mathrm{mmol} / \mathrm{h} \pm \mathrm{sd} \\
\text { (n) }\end{array}$ & $\begin{array}{c}56.1 \pm 24.2 \\
(212)\end{array}$ & $\begin{array}{c}57.4 \pm 24.7 \\
(174)\end{array}$ & $\begin{array}{c}50.2 \pm 21.3 \\
(38)\end{array}$ & n.s. \\
\hline volume & $\mathrm{m} \| / 15 \mathrm{~min} . \pm \mathrm{sd}$ & $13\| \pm 5\|$ & $136 \pm 52$ & $110 \pm 41$ & $p \cdot 0.0015$ \\
\hline acidity & $\mathrm{mmol} / \mathrm{s} \mathrm{sd}$ & $\begin{array}{c}108.6 \pm 18.4 \\
(208)\end{array}$ & $\begin{array}{c}107.6 \pm 19.4 \\
(170)\end{array}$ & $\begin{array}{c}112.8 \pm 12.6 \\
(38)\end{array}$ & n.s. \\
\hline MAO & $\begin{array}{c}\mathrm{mmol} / \mathrm{h} \pm \mathrm{sd} \\
(\mathrm{n})\end{array}$ & $\begin{array}{c}34.0 \pm 13.9 \\
(202)\end{array}$ & $\begin{array}{c}35.0 \pm 14.3 \\
(168)\end{array}$ & $\begin{array}{c}29.0 \pm 10.3 \\
(34)\end{array}$ & $\| 9,0.015$ \\
\hline
\end{tabular}




\section{Chapter 5}

\section{Technical aspects of the operation}

\subsection{Preoperative management}

Patients are operated generally electively the day after admission. On admission the presence of the protocol data is checked and if data are missing additional examinations are done, sometimes resulting in double blood determinations. History is taken and a complete physical examination done and recorded. If necessary the physician is consulted again for special problems.

On the day before operation the patient receives a laxative and is shaved, if necessary, from nipples to pubis (not inclusive). From midnight the patient is kept fasting.

All patients receive anticoagulant prophylaxis, either coumarine derivates or subcutaneous heparin twice daily, starting before operation. If coumarine derivates are given the thromboplastin time is measured initially daily and later less frequently and the dose is adjusted as necessary. $75 \%$ got heparin prophylaxis, $22 \%$ acenocoumarol (Sintrom mitis (i)). $3 \%$ of the patients started on heparin but continued with acenocoumarol.

In the operation theatre the patient is positioned supine on the operating table in $20^{\circ}$ anti-Trendelenburg position. In some cases - depending on the build of the patient a slight convex curve under the upper abdomen is given by flexing the operating table for better presentation of the upper abdomen which is thus stretched. A nasogastric tube is introduced by the anaesthetist.

\subsection{Description of the present technique of HSV}

An upper midline incision is always made from above the xyphoid to the umbilicus and if necessary a few centimeters further.

After opening the abdomen inspection and palpation of the abdomen is performed. Special attention is paid of course to the stomach, pylorus, duodenum, nerve of Latarjet and hiatus. The pylorus is checked for patency by bidigital palpation. The presence, localisation and activity of the ulcer are noted and the position of the stomach tube checked or adjusted.

For optimal presentation of the upper part of the stomach and lower part of the oesophagus a curved bladed retractor is inserted in the upper wound margin, and fixed traction is made by a rope of sterile linen attached to this retractor and fixed by the anaesthetist to a bar fixed to the cranial end of the table. Then a small 2-bladed retractor is inserted over unfolded gauzes covering the wound margins.

The retractor is then opened gently but firmly increasing the traction from above. A third midline retractor for the lower wound margin is not usually used.

After the patency of the pylorus has been established, the anterior nerve of Latarjet is identified and the main stem followed until it enters the antrum. The main stem of this nerve is to be preserved and the distance to the pyloric vein of Mayo measured along the lesser curvature of the unstretched stomach. 
This distance is recorded and the point just proximal of its entrance in the stomach wall is marked superficially by electro-cautery. The distance is usually about $6 \mathrm{~cm}$. In case there is a ramification of the terminal Latarjet bundle the thickest is to be preserved and the fibres to the left of it will be cut.

In case the ramifications are of equal size at least one and sometimes two rami should be cut. This is a little arbitrary and depends on the judgement of the operator for assistant if senior) and sometimes it is destined by the centimeter; fibres nearer than $6 \mathrm{~cm}$ to the pylorus are not cut in such a case, but they are severed if the main stem is clearly preserved.

The first step is to skeletonise the greater curvature $12 \%, 156,220,281,303$. The transverse colon or greater omentum is held taut by the assistant and $10-15 \mathrm{~cm}$ of the greater curvature is divided from the gastrocolic ligament laying bare the greater curvature from some centimeters from the pylorus to some distance proximal to the place where the corpus antrum border is thought to be. The gastroepiploic vessels can usually be saved, the skeletonising being done between these vessels and the stomach wall; fine instruments are used as shown in the picture (figure 1). A double-clamp technique is employed, the points of the slightly curved clamps pointing to each other (figure $2^{b}$ ).

\section{figure 1}

instruments used for the dissection, from left to

right clamps according to Hallenbeck

("mosquito"), Leriche, Bengolea, Kantrowitz

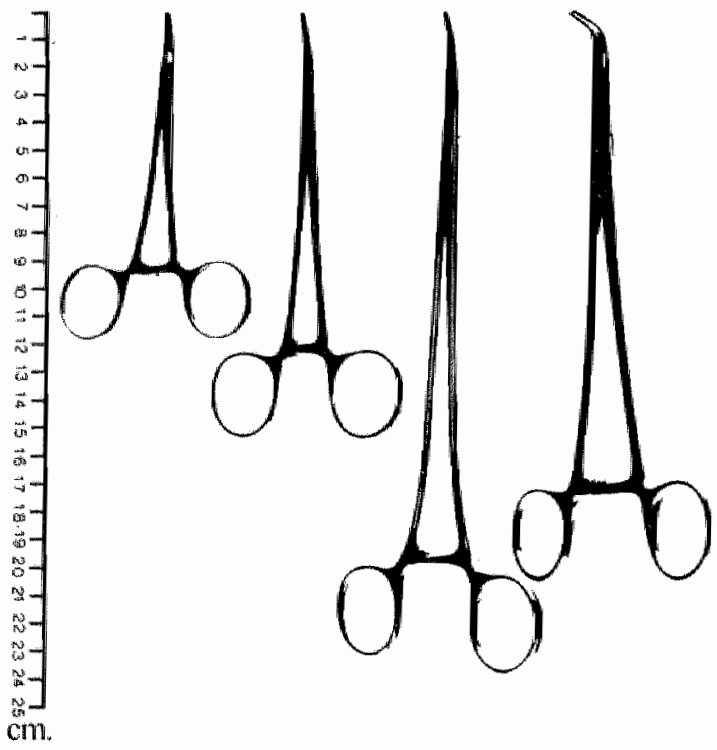

For safety the clamp on the side of the stomach wall is placed first in order not to compromise this wall. All ligatures are done with absorbable polyglactin (Vicryl ${ }^{\circledR}$ ) $2 \times 0$ or $3 \times 0$ depending on the size of tissue.

This being done the omental bursa and pancreas are inspected and adhesions cut if 
necessary until the posterior stomach wall has been freed from the posterior peritoneum.

The posterior nerve of Latarjet is inspected and the starting point marked as described for the anterior side.

Then the pars flaccida of the lesser omentum is cut lo enable two fingers to be introduced. The second and third left hand fingers are placed from posterior near the marked point and present the tissue to be operated on better (figure $2^{\text {a }}$ ). At the transition zone between the stomach and lesser omentum the overlyng peritoneurn is cut between visible vessels and a small curved haemostat (mosquito) - see figure I is used to find its way under the first vessels (and nerves, sometimes clearly visible). The first step often is critical and fearing to damage the main stem or a branch of Latarjet's nerve to be preserved, the start is usually $1 \mathrm{~cm}^{\text {more proximal }}{ }^{8}$. In case of bleeding here it has never been a problem to control. The double-clamp technique is used exactly as described above, starting with the finest haemostats and gradually using longer instruments. After dissecting the anterior blade of the lesser omentum for some distance, the middle layer is treated in the same way. Always $3 \times 0$ absorbable sutures (polyglactin) are used. Diathermy is used also but only if no visible blood vessels are present. The experience is that often the most tiny leashes do bleed. Any bleeding is caught meticulously with fine instruments and cauterised with the scale carefully adjusted so as not to carbonise too much tissue. If the diameter of the bleeding vessel seems to large it is grasped by a fine haemostat and ligated. Always care is taken to stay clearly away from Latarjet's nerve even in case of a slipped ligature and consequent ligation of a blood vessel. In case of some inadvertent haemorrhage in the lesser omentum which is always near to the nerve of Latarjet either anterior or posterior it is a great help to present the tissue where the bleeding is with the fingers of the left hand which can easily stop the bleeding temporarily by compression and prevent annoying ecchymoses.

After dissection of several centimeters the stomach is lifted by the assistant with the aid of the nasogastric tube and the same procedure is started with the posterior leaf of the lesser omentum for some distance. At this stage there is usually an opening between the lesser omentum and the stomach wall of the lesser curvature. If not, this connection is made by cutting some tiny leashes. This opening being made the dissection is aided greatly with the help of two elastic rubber bands: one around the stomach and one around the lesser omentum containing Latarjet's nerve (figure $2{ }^{\circ}$ ). Both rubber bands are stretched carefully not to put undue temsion on the structures. At this stage dissection is usually performed back to the marked distal starting point. After arriving at this point a slight further deviation $(1-1 / 2 \mathrm{~cm})$ is made caudally on the surface of the stomach cutting a few vessels and possibly nerve fibres (Holle ${ }^{136}$ ). The dissection continues proximally leaf by leaf until the greater neurovascular bundle entering the cardia has been cut, clearly exposing the longituclinal oesophagal fibres. Having started the posterior side from behind with identification of the nerve, the dissection can easily be done from the front, but if the exposure is easy enough one can continue the posterior dissection just as on the anterior side. Then His" angle is visualised and palpated and the anterior peritoneal leaf is cut in that direction until the gastrophrenic ligament is reached (figure $2^{c}$ ). Usually fine long haemostats are used (see figure 1) but sometimes a sharply curved clamp (Kantrowitz) is used for 
HSV: different phases of the dissection as explained in the text
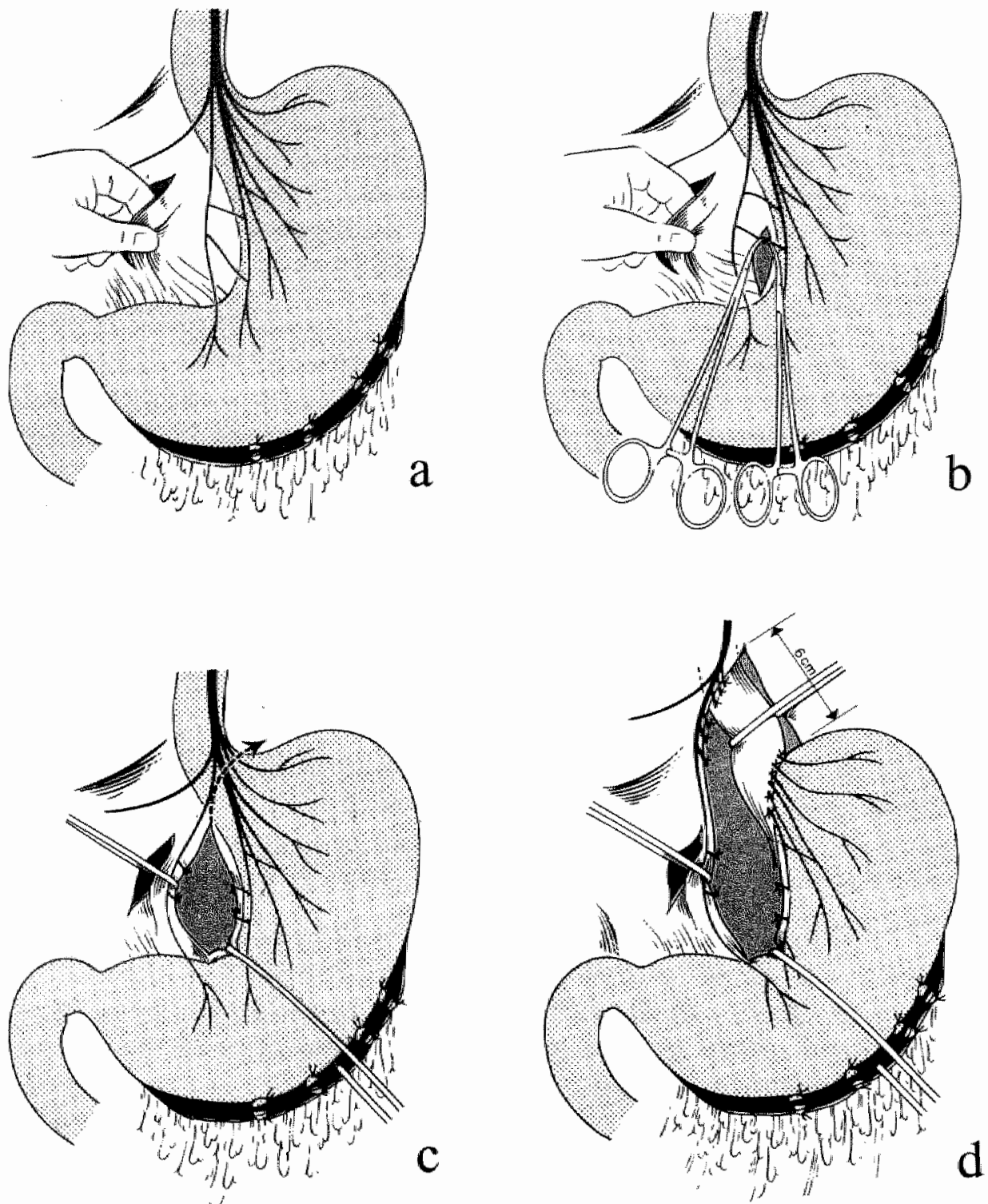

dissection to prevent the tissues from slipping off. Dissection is continued on the next layers until the oesophageal fibres are bared.

The vagal trunks are not exposed; we have never come across them during the procedure as described. After the peritoneum to the left of the cardio-oesophageal angle has been cut, an attempt is made carefully to surround the oesophagus with both index fingers, the right index finger coming from above left, the left index finger coming from below right (keeping to the left of the coeliac trunk). This is a most 
critical procedure which must be done with gentle handling and "feeling". Often a tiny blade pushed upward to the left of the oesophagus through which the glove can be seen shining through must be cut. A third rubber band is then used to encircle the oesophagus for upward traction.

By gentle and correct traction on the oesophagus band and the lesser omentum band the tissues adhering to the oesophagus to be divided can easily be identified. Small steps should be taken (double-clamp technique after dissection with the Kantrowitz clamp), and for fine leashes of tissue diathermy is used.

One should be careful to avoid cutting oesophageal wall fibres which sometimes detach quite easily together with the investing layers. At this stage the anterior, right and posterior side of the oesophagus have been freed of all non-muscular vissue. The intention is to free of all surrounding tissue $6 \mathrm{~cm}$, measured along the left side of the oesophagus (figure $2^{\mathrm{d}}$ ). A good estimate can be made with 3 fingers. Still one side has not yet been freed. For this purpose the traction of the rubber band is released after placing the second and third finger of the left hand under the oesophagus; with the thumb of the same hand the oesophagus is rotated clockwise as seen from above over to the right in order to inspect the more difficult left side.

Sometimes the use by the assistant of a swab on a stick is indispensable to keep omentum away or to stretch tissues.

All tissues and fibres covering the oesophagus muscle fibres are cut. The most difficult part is the angle of His which is hardest to turn and special attention must be paid not to overlook fibres here (called "criminal branches" of Grassi ${ }^{102}$, since leaving nerve fibres intact here often means failure of the operation).

Finally the gastrophrenic blade is cut nearing the spleen.

The distance of oesophagus laid bare $(6 \mathrm{~cm})$ is checked again as well as the haemostasis in unstretched conditions.

The rubber bands are removed and a drain (21-27 F) is placed from behind the oesophagus through the rent in the lesser omentum going under the liver and coming out at the right side of the patient.

The loosened left lobe of the liver is placed between the lesser omentum and the stomach wall if conditions permit easily, preventing adhering of both structures and possibly reinnervation ${ }^{362}$.

Then after a final inspection for haemostasis and the sponge count the abdomen is closed again using a running absorbable polyglactin 0 atraumatic thread for peritoneum and interrupted ligatures of polyglactin 1 for the fascia. The skin is sutured with interrupted silk $3 \times 0$.

\subsection{Adaptations}

This way of operating is suitable to a teaching situation. Many small adaptations can be made:

- in Leeds the covering peritoneal blades of the dissection area are cut with scissors up to the oesophagus right from the start. Possibly it makes dissection easier;

- the fine haemostats can be used for dissecting and clamping; however a warning must be given not to perforate the stomach or oesophageal wall which is quite easy with these instruments; many surgeons probably prefer blunt clamps for dissection. In Leeds, Roberts' clamps are popular; they are not suitable for the double-clamp 
technique since they are too thick and heavy, so a ligature is passed through with the aid of the dissecting clamp and ligated at the side of the nerve ${ }^{173}$.

- An alternative method for securing haemostasis also used in a number of the patients in this series employs haemoclips.

Instead of placing the two clamps on a piece of tissue as described above, haemoclips of the appropriate size can be placed and the tissue cut in between. The method does not work well in very thin bites; the clips sometimes fall off easily by handling the stomach or by hooking in a swab. This method has been described by Salaman 310. Clips were used exclusively in 29 patients $(11.1 \%)$ and partially in $37(14.2 \%)$. In the remainder $(75 \%)$ ligatures were used exclusively.

- Placing a big gauze behind the spleen can make the upper part of the dissection easier by pushing the stomach to the right together with the spleen and preventing tears in small vessels near the spleen when the stomach is stretched.

- A drain can be omitted since no leaking of an anastomosis can happen and haemostasis can be secure. However, it was considered safer to insert a drain routinely in a teaching hospital.

In three instances it was of great help: in one patient the drain suddenly started leaking stomach contents on the second postoperative day; without delay and before peritoneal inflammation ensued the patient was re-laparotomised. There was a local perforation due to necrosis caused by a haemoclip placed in the stomach wall and it was oversutured.

In two other patients there appeared considerable blood loss, coming out from the drain. Re-laparotomy was considered but since the amount of blood could be measured exactly and soon diminished, the conservative approach with appropriate blood replacement prevented reoperation.

- Recently, in December 1982 (Weger et al ${ }^{364}$ ), it was reported that the exposure of the nerves of Latarjet is greatly facilitated by the left hand of the (first) assistant, palm up, posterior to the stomach through a rent in the gastrocolic ligament. No experience with this technique was obtained in this study.

The duration of operation from the incision to the dressing in elective cases was seldom less than two hours in this series. The operation time has not been included in this study, however. Other authors report operating times of 90 - 180 minutes.

Meticulous technique is to be stressed as the mainstay of the operation. In a teaching hospilal where relatively inexperienced surgeons have performed the majority of operations and will probably continue to do so, this time will probably not be reduced quickly, but individual surgeons will increase their speed with growing experience. Some surgeons use a stapler technique with Surgiclip (B) M11 (Autosuture), which is disposable and they claim a much quicker operation. Three to four disposables are needed for one HSV. It was not used in this series.

\subsection{Operation for complications}

In case of a complication such as haemorrhage, perforation or stenosis the intended HSV as described is preceded by the appropriate procedure as described earlier by Johnston ${ }^{163}$. 
In summary: in case of bleeding duodenal ulcer the duodenum is opened longitudinally just distally to the pylorus. The bleeding point is underrun and ligated with atraumatic polyglactin 0 ; if possible the edges of the ulcer are approximated to cover it. The duodenotomy is then closed longitudinally or transversely.

In one case the bleeding point could not been reached and the incision was extended through the pylorus and distal antrum.

The bulb was heavily deformed but then the bleeding could be found in a huge ulcer crater. After underrunning the incision was closed as described by Johnston ${ }^{170}$ with a continuous through and through catgut thread, followed by atraumatic and fine interrupted seromuscular stitches (polyglactin). The healing was uneventful. No side effects have been observed.

In case of a perforation a simple suture with interrupted atraumatic polyglactin 0 is performed and the perforation is covered further by an omental patch.

In case of postpyloric stenosis $68,77,163$ a small gastrotomy is performed near the greater curvature in the proximal part of the antrum just large enough to admit the index finger.

The incision is positioned there not to hamper the innervation of the antrum. The size of the stenotic orifice is palpated bidigitally by the inside and the outside index finger. Usually the stenosis does not allow the finger to pass through; in such cases metal Hegar dilators of increasing size are used to probe and to dilate the stenosis. Often it is difficult at operation to locate the narrowing exactly due to deformation and scarring, but preoperative diagnosis of postpyloric obstruction is of great help. In one case a rigid $6 \mathrm{~cm}$ choledochoscope was used to define the location of the ulcer and the course of the duodenum. This was done to be sure not to dilate a scarred pylorus and to prevent a false passage.

In two cases the softer oesophageal bougies were of great help in overcoming the obstruction. It was aimed to dilate so much that the PIP-joint of the index finger could pass. Often the index finger is used for additional dilatation.

In the one case of dilatation with the index finger the duodenum ruptured and was oversutured transversely. The perforated place was covered with an omental patch and the patient's recovery was uneventful ${ }^{77}$.

5.5 Postoperative management

A bladder catheter is not usually introduced before operation but if so it is removed immediately after operation.

The patient can return to the ward on the day of operation. The next day the nasogastric tube is removed and the patient is allowed to drink. If no problems occur the drip is removed in the course of the day and fluids are allowed freely. The patient is encouraged to get out of bed.

On the second day, the drain is retracted a few $\mathrm{cm}$ and in the absence of increased production it is removed a few hours later.

The patient can start eating light food and is mobilised as much as possible. From the third day onwards food will be less restricted and the patient is usually moving around freely. Generally the patient is dicharged on the 10 th postoperative day after removal of the stitches.

The vast majority have very little, if any, trouble in the reconvalescence period. 
Often they experience some dysphagia which may persist for some weeks but invariably disappears.

No insulin tests were performed at all and no intraoperative tests were performed to check the completeness of the section of the vagal nerves. This subject will be discussed extensively in the next chapter.

\subsection{Early modifications}

The technique of operation was slightly different in the beginning.

1. The dissection started at a measured distance from the pylorus, initially $8 \mathrm{~cm}$, later 7 , and still later $6 \mathrm{~cm}$, provided that the nerve of Latarjet was not included in the dissection.

This means that too little of the antrum (or corpus) was dissected compared with the present method. In contrast: in the description in this chapter the nerves to be saved are determined first and then the distance is measured so that this is the calse.

The transition from this original method to the present one has been very gradual. Initially the ramification was saved completely later occasionally one branch was cut and now usually 1 or 2 branches are cut provided one major branch is preserved.

The influence of this is not clear. A comparison of the results of the two extreme groups has been attempted but they can not be compared clinically since the oldest group has a much longer follow-up and several other factors are different, for example opening of the greater curvature. In $13.3 \%$ the starting point was $8 \mathrm{~cm}$, in $50.4 \% 7 \mathrm{~cm}$, in $33.2 \% 6 \mathrm{~cm}$, and in $2.7 \% 5 \mathrm{~cm}$. However there are many reports which demonstrate that it is better to stay on the safe side and that there is not much difference in starting at 6 or $8 \mathrm{~cm}$ (see chapter 3 ).

The matter however is controversial.

2. The greater curvature was not skeletonised in the beginning. This means that the posterior side was not visualised. All layers were then dissected one by one from the front, keeping close to the stomach wall. Probably no posterior nerve damage has occurred since this coincided with the time the $8 \mathrm{~cm}$ distance was kept and thus the distance to the nerves was not particularly critical.

Skeletonisation of the greater curvature occurred in $43,2 \%$ of the patients. 


\section{Chapter 6}

\section{Quality control tests}

\subsection{Introduction}

The use of a quality control test, if reliable, would be of great benefit to the quality of the operation. There is, however much controversy about the kind of test to be used, about the reliability, about the timing of some tests and about the criteria. Theoretically, one should distinguish between a complete and an adequate vagotomy (in this case: HSV) ${ }^{172}$. A complete vagotomy is a vagotomy where all vagal fibres influencing the acid secretion (thought to be influencing the development of a recurrence) have been cut. An adequate vagotomy is a vagotomy resulting in freedom from complaints and not leading to a recurrence. This, in fact, is a retrospective conclusion and it is not known after how many years one is allowed to make this statement. An adequate vagotomy is not necessarily complete, but even a complete vagotomy is not necessarily adequate. This needs further explanation: the difficulty is, that theoretically a complete vagotomy should exist, but what is the infallible criterion for assessing this? Completeness is the result of testing!

Adequacy of vagotomy is a matter of judgment of the clinical results, but theoretically and in reality it exists. There could be patients with a complete vagotomy (a kind of "laboratory" diagnosis) which proves to be inadequate since in spite of the "completeness" of the vagotomy recurrences develop. This is identical to the "method failures" discussed in the introduction.

In fact adequacy of the operation is the most important criterion, but when can it be established? Furthermore, what is the consequence (for example to the technique of operation) if adequacy should turn into inadequacy, after any time period? Practically it is only possible to assess a "defined" completeness.

6.2 Principally, two methods can be distinguished: intraoperative and postoperative tests. Both have advantages and disadvantages.

\section{Intraoperative tests}

advantages

disadvantages
- they can direct the surgeon immediately to perfect his technique by guiding where the vagotomy is incomplete

- usually a gastrotomy is necessary enhancing the danger of contamination

- prolonging the procedure

- special anaesthetic requirements 


\section{Postoperative tests}

advantages

disadwantages
- no gastrotomy or prolongation of the procedure

- if incompleteness is discovered they do not change the result for the patient (unless the consequence would be: reoperation) his chances have been fixed by the operation

- discomforl for the patient

A good review of the matter was presented by Kronborg in $1976^{210}$, who also wrote a thesis about the evaluation of the insulin test (1972).

\section{In short}

\subsection{1 intraoperative tests:}

1. electrical stimulation test (Burge test, Vagorec ${ }^{186}$ ) principle: testing the motoric vagal function assuming a close correlation with the secretory function

2. leucomethylene blue staining (Lee ${ }^{221}$ ) principle: the dye turns nerve fibres blue (several studies about the usefulness have been disappointing, as many other fibres appear to stain as well ${ }^{176}$ )

3. $\mathrm{pH}$ measurements (Grassi ${ }^{101}$, Amdrup \& Jensen ${ }^{8}$ ) principle: monitoring the gastric mucosa with a $\mathrm{pH}$ electrode under pentagastrin stimulation searching for acid areas

4. congo red staining (Kusakari ${ }^{211,372}$ ) principle: the dye turns black in the presence of acid; the use of an endoscope is required during operation.

\subsection{2 postoperative tests:}

1. insulin test (Hollander ${ }^{137}$ ) principle: injection of insulin induces hypoglycaemia causing a central vagal stimulation which can be measured by gastric secretion.

Many criteria have been devised, but the Hollander criterion is the most popular one: it is positive if an increase of the acidity of the stomach juice is obtained of more than $20 \mathrm{mmol}$ above the basal level in 2 consecutive specimens. If there is basal anacidity, only $10 \mathrm{mmol}$ acidity is required for a positive response, meaning incompleteness. This is a qualitative criterion with an "all or none" outcome, slightly modified by division into early ( 45 minutes) and late ( $>45 \mathrm{~min}$.) positivity.

2. pentagastrin test (histamine test) (Kay ${ }^{179}$ ) principle: the maximum acid production is to be measured both before and after operation. The percentage reduction should be a measure of completeness.

3. alkali titration test ${ }^{70}$

principle: the acid in the stomach is neutralised by a measurable amount of bicarbonate until neutrality is reached. A telemetric $\mathrm{pH}$ capsule is required.

4. sham feeding test (Richardson ${ }^{299}$ ) principle: the gastric secretion is measured during sham feeding and after pentagastrin. The advantage appears to be that no preoperative test is required. 


\subsection{Discussion}

Reliability of any test is of course the most important precondition. There are a number of controversies: - is a quality control test necessary? - which test should be done? - when should a certain test be done (postoperatively)? - which are the criteria, and for what? - what is the reliability?

The insulin test is the most widely adopted test for completeness of the vagotomy. As stated before, in this series no intraoperative testing was done since the technique adopted was judged to be firmly established. The results obtained by using anatomical landmarks for the extent of dissection were similar to those obtained with $\mathrm{pH}$-metric mapping out ${ }^{9}$. Postoperatively no insulin tests were performed, but histamine/ pentagastrin tests were carried out. At the introduction of the HSV protocol the results of histamine/pentagastrin tests were considered more or less comparable to the results of the insulin tests. The controversy whether the acid output data with histamine/pentagastrin do have a discriminatory ability for the development of a recurrence has not yet been solved. The comparability with the results of the insulin test is still debatable.

The reasons no insulin test were instituted were:

- no absolute reliability

- controversy about the value of the outcome

- insulin tests are not without danger ${ }^{279}, 355$

- controversy about the timing of the insulin test

- insulin testing would not abolish a histamine/pentagastrin test and hence would increase the discomfort for the patient.

The insulin test itself is still in discussion: the reliability, the criteria and the timing: should it be done after $7-10$ days ${ }^{47}, 158,161,172,235,14$ days ${ }^{89}$, within one or three months ${ }^{92}$, after 6 months ${ }^{25}$, or after 1 year? ${ }^{354}$. After some time a conversion takes place from negative to positive, abolishing the value of the outcome ${ }^{92,162,226,235,}$ 3(x)

Many authors use it as a quality control test and consider it reliable, although not absollutely so $25,30,137,180,182,204,235,288,313,304,330$. Others have used it but are disappointed with the outcome, since a proportion of the patients with assessed complete vagotomies did develop a recurrence ${ }^{127.151,345}$, and many found other gastric secretion parameters (BAO, PAO or MAO with histamine or pentagastrin) to be equally reliable or even better $21,61,83,91,109,123,127,177,203,207,212,244,272,274$. $320,345,354$.

Some workers even do not find any relation at all between the results of insulin tests and the development of a recurrence $277,146,348$.

In contrast: others can almost titrate the "degree" of completeness ${ }^{30,4(\%)}, 2(4), 330$. Those in favour of the insulin test maintain that it is the best available, taking into account the restrictions on its use ${ }^{158}$.

Indeed theoretically it should be perfect: it is almost the only test assumed specifically to stimulate the vagus.

The histamin and pentagastrin tests measure the vagus action indirectly since the vagal tone facilitates the secretion of acid elicited by these stimulants.

However many authors speculate on the basis of their results, that insulin also brings 
about a sympathetic reaction, a release of gastrin and other substances, which could give rise to a false positive result $207,208,235,243,272$. Moreover false negative results occur in a number of cases.

Some other arguments about the value of the insulin test are equally impressive:

- the Hollander criterion, which is still the most commonly used, cannot be very reliable since it is based on a comparison with $B A O$ acidity, the most versatile parameter. Several authors ${ }^{82,83.177,178}$ demonstrated that the Hollander criterion is the worst of all among the possibilities of the insulin test parameters. But even all other criteria and modifications have not been proved to be convincingly better.

- the correlation between the result of the insulin test and intraoperative quality testing is disappointing. Geurts ${ }^{89}$ found two weeks after HSV $45 \%$ positive tests in his patients who had all been operated on with the help of $\mathrm{pH}$-metry.

Gillespie ${ }^{91}$ found, that only 20 of 47 non-operated patients had an early positive insulin test. Hedenstedt ${ }^{127}$ reported that all recurrences in his HSV series had a negative insulin test.

- Hollander, $19500^{356}$ : "the insulin test cannot be used to prognosticate clinical resuits of vagotomy".

$1948^{138}$ :" a positive response (insulin test) does not imply of necessity that the surgeon failed to interrupt the gastric vagi completely".

Perhaps Makey's conclusion (1979 ${ }^{238}$ ) is the closest to reality, namely that the reduction of acid production in the group of patients with a recurrence is less than in those without recurrence, but for the individual no reliable predictions can be made. A similar conclusion was drawn from the results of 229 patients in the present series (Busman and Munting, 1982 ${ }^{44}$ ), and by others ${ }^{109,274,345}$. 


\section{Chapter 7}

\section{Visick grading and follow-up}

\subsection{Visick grading}

It has become customary to assess the results of stomach surgery with a grading originally described by Visick in 1948. He followed up almost all his patients who underwent a gastric resection for peptic ulceration and devised a scale for classifying the results.

Grade I: no gastric symptoms (fullness after extra large meal allowed)

Grade II: no pain, mild occasional symptoms only, easily controlled by care (including: rest, limitation of size of meal and rejection of certain articles of diet).

Grade III : mild symptoms not controlled by care; this grade is subdivided into III-S: satisfactory and III-U: unsatisfactory.

Grade IV: not improved (failures).

In his concept a satisfactory result is covered by grade I to III-S. Later a modified Visick classification was adopted and used in most reports. (Goligher $1978^{96}$ ). In Goligher's grading the subdivision in grade III - satisfactory and unsatisfactory has disappeared. His modified Visick grading is as follows:

1. Excellent, absolutely no symptoms, perfect result.

2. Very good, patient considers result perfect, but interrogation elicits mild occasional symptoms, easily controlled by minor adjustment to diet.

3. Satisfactory, mild or occasional symptoms, not controlled by care, causing some discomfort but patient and surgeon satisfied with result which does not interfere seriously with life or work.

4. Unsatisfactory, moderate or severe symptoms or complications which interfere considerably with work or enjoyment of life; patient or doctor dissatisfied with the result. Includes all cases with proved recurrent ulcer and those submitted for further operation even though the latter may have been followed by considerable symptomatic improvement.

In a similar grading employed by Poppen ${ }^{289}$ the use of drugs is mentioned.

Visick stressed that no surgeon should do his own grading and he and others have accomplished this; he described vividly the set up of his gastric follow-up clinic where a surgeon together with a physician and sometimes a radiologist - all unaware what kind of operation had been performed - interviewed each patient attending and classified him as objectively as possible.

Unfortunately in the present study this was not done so; it was simply not feasible in practice under the conditions described. The grading was given by the author on the basis of the written reports of the doctors who had seen the patients. The vast majority of patients were seen at least once personally by me so I was able to check their present and preceding wellbeing and compare it with the standard grading.

In general there is no difficulty in grading patients Visick 1 or Visick 4 , grade 1 being perfect, grade 4 the complete failures: recurrences or failures with no improvement 
at all compared to the preoperative condition. When minor complaints are present which can be easily relieved the patient is classified into grade 2 .

Grade 3 patients do have more severe symptoms which result usually in visiting the family doctor and being prescribed drugs. Compared to grade 2 the symptoms of this group of patients are more severe and/or more frequent or prolonged.

Sometimes the distinction is not easy. A criterion could be the need of taking drugs but this is not always correct.

People in this decade tend not to accept even minor discomfort and seem to be more eager to use drugs in combating discomfort instead of adapting their way of life. Antacid drugs are easily available and many patients are acquainted with the drugs they used before operation and have kept some in case they might need them.

Few of the patients classified in grade 2 sometimes took drugs but they were in no way restricted in their activities and they could have easily managed without.

Even taking cimetidine is not an absolute criterion for classification because

- family doctors sometimes prescribe it as the first drug for minor complaints which could be managed by care alone.

- patients having had experience with cimetidine have kept some in store or ask for it easily since they have confidence in it on the base of their previous experience.

Many consider it as a simple antacid drug.

Some of the patients told us at follow-up interview that they took cimetidine occasionally when feeling discomfort, because one or two of the tablets abolished it. Therefore patients only occasionally taking drugs can sometimes be classified in grade 2 .

A similar problem arises if a patient has had no trouble at all during the year preceding the follow-up interview except "one or two weeks in February" which were bad. Some of these patients have not taken any drugs or other measures, whereas others have.

In short, the increasing medical consumption causes bias for the grading. It is felt that Visick's grades III-S and -U have been spread over grade 2 and 3: the original III-S patients are now in grade 2 and the III-U patients in grade 3 or occasionally in grade 4 . In other words the grade 3 patients do have a moderate result: much better than being called a failure but definitely not good or excellent. In practice there are lew debatable cases.

Another problem appears to be the rising unemployment rate and thus the failing criterion of resumption of work. This rate is extraordinarily high in this part of the country where there used to be a coalmining industry with a large influence on circumferential industries. The last coalmine was closed down in 1974 and the absence of replacing industries has caused a high unemployment rate and an easy access to social security.

Recurrences are by definition graded Visick 4 .

It has been customary in the literature to maintain this grade whatever the patients' condition later: "once a recurrence, always a recurrence".

\subsection{Follow-up}

In the follow-up scheme the patients were due for an interview and examination 6 and 12 months after operation and once yearly thereafter. 
After discharge from the hospital there were usually several visits to the surgical outpatient department (OPD) before the real scheduled follow-up started.

There was no special gastric follow-up clinic; all patients were seen on a normal surgical outpatient basis by the surgeon or resident in charge.

At each follow-up interview they were questioned about pain, heartburn, flatulence, diarrhoea, symptoms of dumping (defined as faintness, sweating or fatigue after food), tollerance of food and meals, taking drugs, satisfaction about the operation compared with preoperative condition; visits to the family doctor, etc.

Relevant parameters were checked according to a fixed scheme as set-out in chapter 1. At 6 months after operation the weight and serum gastrin were checked and a gastric secretion test was performed. At one year after operation the weight was checked as well as Hb, ESR, AP, Fe, TIBC, Ca, P, serum gastrin and serum vitamin $\mathrm{B}_{12}$; again a gastric secretion test was performed. The gastric secretion test was repeated after 5 years. Each whole year the weight and the blood parameters were again checked.

110 Patients (almost $45 \%$ ) abandoned their follow-up at some time; there was no routine call-up of those patients.

It was known already that many patients dropped out because they feared invasive examinations and possibly feared being persuaded when they attended the outpatient department. Their serious objections against proposed examinations were always honoured.

There have been two call-ups of all patients already operated on at that time. The first was in 1979. The results hereof were reported in Hamburg in June 1980 (XI International Congress of Gastroenterology) and in September 1980 in Lisbon (6th world congress CICD).

The second and most extensive call-up was done recently at the beginning of 1982 . All these patients were interviewed and examined by the author.

The follow-up for this study was concluded in 1st July 1982. Recently, the results in 229 of the patients have been published in the British Journal of Surgery ${ }^{44}$. 66 Patients, $60 \%$ of those who had abandoned their follow-up, responded to call-up and could be interviewed and examined. From the remainder (44 patients) reliable information could be obtained from the records of their family doctors. Additional information was received from a questionnaire sent to these patients, which sometimes slightly modified the grading made possible by the general practitioners. Moreover virtually all patients had come several times to the OPD before ceasing to attend. Usually the information from the family doctors or the answers in the questionnaire confirmed the unchanged condition at a previous follow-up visit. All patients who had moved to another town could be traced and information about them obtained. Finally, information about 3 patients was lacking. They were considered as lost to follow-up; however in no instance was medical information requested concerning these patients which is customary in this country if they were being considered for reoperation elsewhere.

Moreover there is some indirect information about them to make us confident in believing that they were not operated upon and that they had no recurrence.

Patient no. 34 was arrested and detained in prison for a long time somewhere in the country. Only once was some information received via the questionnaire but he still 
had some stomach problens at that time.

Patient no. 63 persisted in complaining after his operation and was rejected for employment ("afgekeurd") and received social security payments.

He was a foreign worker and went back to Marocco to join his family. He still gets paid while residing there provided he has an examination each year by a doctor who must send this report to the Netherlands in order to continue the payment. One could predict the outcome: he continues to have trouble but only once (in Marocco) was a gastroscopy performed: no ulcer was demonstrated.

Patient no. 98 moved to another address in the same village but never responded to a call-up; his family doctor has not seen him in his office for three years. This was considered too unreliable for grading and he was considered lost for follow-up; before being lost he was in grade 2 .

This means that three of 262 patients have been lost which is $1,5 \%$.

Not counting the deceased patients this suggests a $99 \%$ complete follow-up (259 of 262). Up till now 8 patients have died since operation: 7 from non-related causes. Four patients died from myocardial infarction, respectively $4,3,2 \frac{1}{2}$ years and $31 / 2$ months after operation ( 3 men and I woman).

Two patients died from cerebral metastases secondary to bronchial carcinoma 2 and 5 years postoperatively. One patient died 4 years after HSV because of peritonitis due to perforated diverticulitis; this was verified by postmortem examination. All these patients had a good or excellent result until their death.

One patient died on the second postoperative day and will be discussed under mortality.

By convention these deceased patients are counted as lost for follow-up although they were all seen regularly before their death.

This results in 11 of 262 patients which is $4 \%$. In other words the follow-up has been complete in $96 \%$ of the patients. The deceased patients appear in the dynamic Visick grading tables as long as they lived (see chapter 8 ). 


\section{Chapter 8}

\section{The results}

\subsection{Visick grading and recurrences.}

Ideally a perfect operation should cure the disease, have no mortality and minimal morbidity, should have no side effects related to the operative procedure and should prevent recurring of the disease.

Different operations meet these requirements incompletely and some can cure to a high extent with little chance of recurrence but at the expense of something else, be it a certain mortality, morbidity or side effects.

HSV appears to approach the ideal probably most of all but it does not provide absolute protection against recurrence.

\subsubsection{Visick grading}

The patients were classified according to the above discussed convention (chapter 7). The average follow-up was 50.4 months (sd 25 , range $6-99 \mathrm{~m}$.)

The date of reference is the 1st July 1982 and the results are presented in table I, $81 \%$ had a good or excellent result; $11 \%$ were unsatisfactory.

One could speculate that emergency operations are disturbing the real picture. Even if they are left out, however, the figures are very similar (table II).

Similarly other operations performed at the same time as the HSV, like cholecystectomy, appendicectomy, hiatal repair, could constitute a disadvantage for HSV as such. But, equally, if these operations are not counted, still no important change is perceivable (table III).

table I

static Visick grading

on $1 / 782$ in or $(n=251)$

\begin{tabular}{cc|c} 
Wisick & & \\
1 & 57.4 & 80.9 \\
2 & 23.5 & \\
3 & 8.0 & \\
4 & 11.1 & \\
\hline
\end{tabular}

table II

static Visick grading without emergency HSV's on $1 / 7 / 82$ in $\%(1-237)$

Visick

$\begin{array}{lr}1 & 56.8 \\ 2 & 23.3 \\ 3 & 8.8 \\ 4 & 11.0\end{array}$

table III'

static Visick grading without other operations

on $1 / 7182$ in $\%(n=217)$

Visick

\begin{tabular}{|c|c|c|}
\hline 1 & 57.6 & $80 ?$ \\
\hline 2 & 22.6 & \\
\hline 3 & 8.7 & \\
\hline 4 & 11.1 & \\
\hline
\end{tabular}


It is clear, however, that this is a static and retrospective grading.

It shows the last grading of all patients at the date mentioned. The time interval between operation and this last grading date is different for all patients ranging from 6 months to 99 months. In general this is meant when it is stated that (for example) $1 / 2-8$ years results after HSV are given. As Visick ${ }^{352,353}$ clearly demonstrated this method of presentation does not reveal very much for several reasons:

1. It fails to explain the proportion of recent cases included.

2. It does not give a survey of changing of grading since operation.

3. Tonly reports the proportion of patients who were failures at the time of their last examination (1st July 1982) except recurrences who remain in Visick 4.

4. It does not give credit to the fact that many recurrences in the past subsequently run a benign course and appear to be just unfortunate incidents in patients otherwise satisfied with the result.

Therefore the grading was adapted into a prospective one. The moment of reference is the date of operation. All patients were graded at all interval dates considering their actual condition at that time and in the period preceding that date. The principle of remaining in grade 4 for ever after a recurrence was abolished and everyone regraded if necessary. In this way a more dynamic picture of the results (which are of course not static) can be obtained. This is called "dynamic" Visick grading. It means that healing of the ulcer and disappearance of the complaints can be indicated as well as the development of a second or third recurrence. The results are shown in table IV and figure 1.

table IV

dynamic Visick grading on 1/7/82 in \%

\begin{tabular}{crrrrrrrr}
\hline Visick & \multicolumn{1}{c}{$1 / 2$} & 1 & 2 & 3 & 4 & 5 & 6 & vearsafier operation \\
\hline 1 & 69.5 & 67.1 & 63.7 & 64.6 & 62.9 & 61.2 & 65.6 \\
2 & 20.5 & 21.9 & 24.5 & 22.5 & 21.2 & 27.6 & 26.2 \\
3 & 5.0 & 6.5 & 6.6 & 6.7 & 8.6 & 6.1 & 1.6 \\
4 & 5.0 & 4.5 & 5.2 & 6.2 & 7.3 & 5.1 & 6.6 \\
$\mathrm{n}=$ & 259 & 246 & 212 & 178 & 1.51 & 98 & 61
\end{tabular}

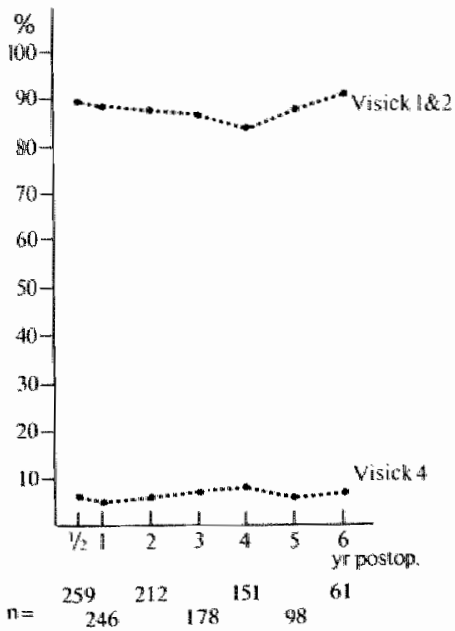


These results show that they are more or less constant. This way of fluent grading has been done before, ${ }^{7,44,352}$, but sometimes without the principle of regrading ${ }^{7}$. In this way of presentation $90 \%$ of the patients remain continuously in grade 1 or 2 . About 5-6\% remain failures each year (about half of them being temporary failures) and it is not necessarily the same patients who constitute this percentage.

- Although revealing more in addition to the classic grading there is still one drawback to this method: the population of patients at each grading moment differs: all patients have completed the 1/2-year follow-up, fewer the 1-year period etc. (the number of patients at each interval date have been indicated in figure 1).

Therefore all patients with a complete follow-up to 5 years, which is a fixed group, were considered apart. See table V and figure 2 . This results in an outcome simillar to

table $\mathrm{V}$

dynamic Visick grading in a fixed group

on $1 / 782 \mathrm{in} \% \mathrm{H}=98$

\begin{tabular}{rrrrrrrr}
\hline Visick & \multicolumn{1}{c}{$1 \%$} & \multicolumn{1}{c}{1} & \multicolumn{1}{c}{2} & \multicolumn{1}{c}{3} & \multicolumn{1}{c}{4} & \multicolumn{1}{c}{5} & yearsafteroperation \\
\hline 1 & 77.6 & 76.5 & 64.3 & 63.3 & 64.3 & 61.2 & \\
2 & 14.3 & 17.4 & 27.6 & 26.5 & 22.5 & 27.6 \\
3 & 4.1 & 2.0 & 1.0 & 6.1 & 6.1 & 6.1 \\
4 & 4.0 & 4.1 & 7.1 & 4.1 & 7.1 & 5.1 \\
\hline
\end{tabular}

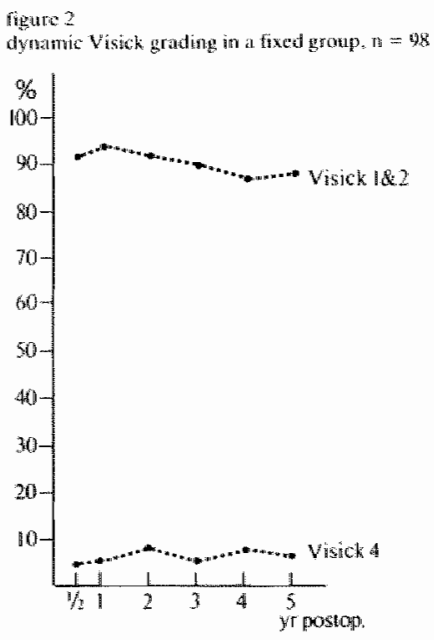

that in the foregoing presentation. The patients who proved to be definite failures and required reoperation ( 3 patients) and patients who needed an operation for other reasons ( 2 stenoses) cannot be considered after their reoperation as being in the follow-up for HSV but nevertheless they have been included and were graded permanently as a failure. The three patients with a recurrence, who needed reoperation all underwent a $B$ I partial gastrectomy. The pathological findings of the resected specimens are presented in chapter 16 (appendix). 
Not all grade 4 patients had a recurrence; in some no recurrent ulcer could be demonstrated although they did not improve after operation. Several of them often needed cimetidine but in two cases neither cimetidine nor antacids gave any relief at all, which makes the gastric origin of their complaints doubtful.

It is interesting to see how the static grading changes depending on the moment the grading is applied. In this series it was investigated how the static Visick grading would have been exactly 1,2, etc. years ago (with consequently a diminishing number of patients to be judged and also a decreasing number of recurrences). The results are shown in table VI. In figure 3 the percentages of grade 4 and grades 1 +2 have been plotted for each year including 1982 . The resulting figure 3 resembles the graph of the dynamic Visick grading (figure 1) but is in fact completely different, even when a similar regrading of patients with a recurrence would have been applied, as illustrated in figure 4 (the table with the numerical data has not been presented here).

\section{table VI}

static Visick grading in $\%$

\begin{tabular}{|c|c|c|c|c|c|c|c|c|}
\hline Visick & & $1 / 7 / 81$ & on $1 / 7 / 80$ & on 117179 & on $117 / 78$ & \multicolumn{2}{|c|}{ on $1 / 7 / 77$} & on 117176 \\
\hline 1 & 60.9 & \multirow{2}{*}{82.7} & \multirow{2}{*}{81.9} & \multirow{2}{*}{85.1} & \multirow{2}{*}{90.2} & 75.6 & \multirow{2}{*}{93.5} & $75.7]$ \\
\hline 2 & 21.8 & & & & & 17.9 & & $21.6]^{9 / .3}$ \\
\hline 3 & 5.4 & & 8.5 & 4.8 & 1.6 & 0 & & 0 \\
\hline 4 & 11.8 & & 9.6 & 9.9 & 8.2 & 6.4 & & 2.7 \\
\hline$n=$ & 230 & & 195 & 167 & 126 & 81 & & 38 \\
\hline
\end{tabular}

figure 3

static Wisick grathing

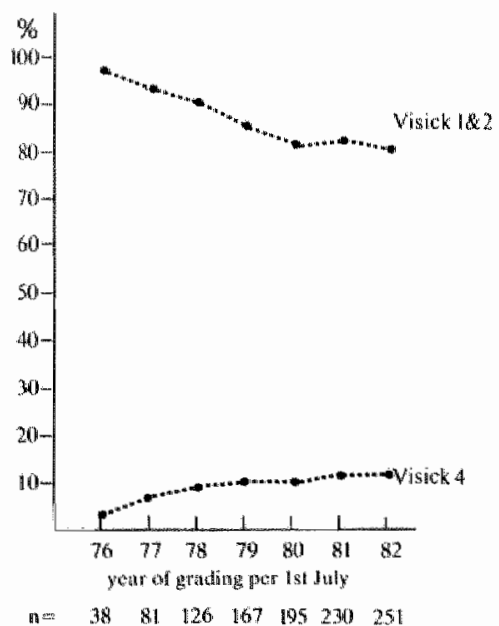

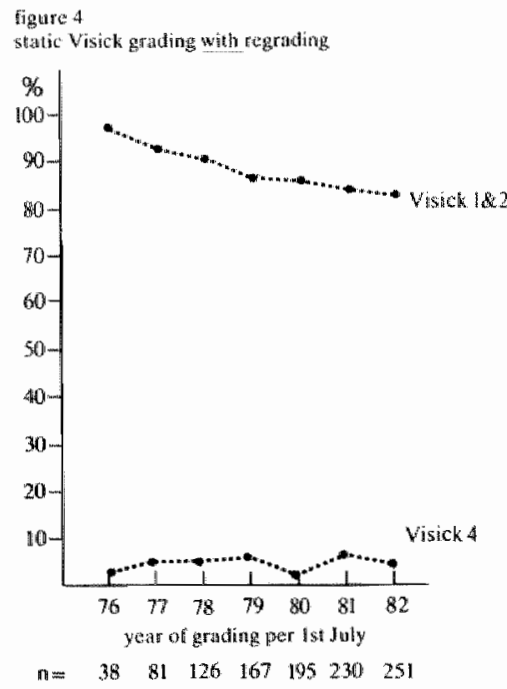


The main differences are: the number of patients in figure 4 are growing from left to right in contrast to figure 1, representing the dynamic Visick grading. Further, at each grading moment in figure 4 the patients have all lengths of follow-up possible at that date in contrast to the dynamic grading data, which are plotted on the base of their follow-up time.

The main concordance is that both graphs (figures 1 and 4) show a fairly constant number of grade 4 patients.

table VII

dynamic Visick grading without regrading in \%

\begin{tabular}{|c|c|c|c|c|c|c|c|c|c|c|c|c|c|c|}
\hline Visick & & $1 / 2$ & 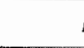 & & & 2 & 3 & & 4 & & 5 & $\theta$ & 6 & yr postop. \\
\hline $\begin{array}{l}1 \\
2\end{array}$ & $\begin{array}{l}69.5 \\
20.5\end{array}$ & 90 & $\left.\begin{array}{l}67.1 \\
22.0\end{array}\right]$ & 89 & $\left.\begin{array}{l}63.2 \\
24.5\end{array}\right]$ & 87.7 & $\left.\begin{array}{l}64.0 \\
21.3\end{array}\right\} 85.3$ & $\left.\begin{array}{l}60.9 \\
19.9\end{array}\right]$ & 80.8 & $\begin{array}{l}57.1 \\
23.5\end{array}$ & 80.6 & $\left.\begin{array}{l}62.3 \\
19.7\end{array}\right]$ & 82 & \\
\hline 3 & 5.0 & & 6.1 & & 6.1 & & 5 & 7.3 & & 5.1 & & 0 & & \\
\hline 4 & 5.0 & & 4.8 & & 6.1 & & 9.5 & 11.9 & & 14.3 & & 18.0 & & \\
\hline
\end{tabular}

กigures

dybatnic Visick gridding withonr regending

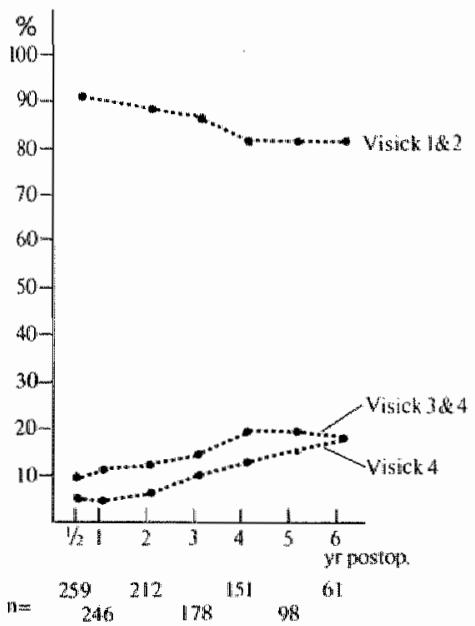

Finally table VII and figure 5 show how the dynamic Visick grading figures and graph would change if no regrading had been permitted. The conclusions of these artificial comparisons are that recurrences are mainly responsible for the number of Visick 4 patients (failures) and that with regrading the proportion of failures at each period is about the same whether in prospect or in retrospect.

\subsubsection{Recurrences}

Patients who have a recurrence after operation are considered as failures of the applied treatment. Nevertheless in this series few patients remained failures in the real sense and more than $50 \%$ had a recurrence demonstrated once but fared very well both before and after that seemingly isolated event. As discussed above it is doubtful whether these patients must be counted for ever as failures ${ }^{16}$, 50. Several other authors also mentioned the relatively benign course of many recurrences ${ }^{141}$, $19,266,322$ 
Many recurrent ulcers appeared in conditions related to severe stress ${ }^{353}$. Most of the recurrences healed quickly, usually with a short course of cimetidine ${ }^{55}$; in a few cases no treatment at all was given, since the ulcer had become symptomless or had healed very soon after demonstration ${ }^{266}$.

In other words: highly selective vagotomy appears to have modified and mollified the natural history of disease in many of those where it did not prove to be $100 \%$ successful.

This benign course is in contrast to the behaviour of recurrences after other operations, which are relatively resistant to treatment ${ }^{332}$.

It should be noted, however, that most patients who developed a recurrent ulcer in this series had not experienced the use of cimetidine before operation, since this drug was not available at that time.

It might be imagined that they would have been cured easily with cimetidine before operation, but this is not the general experience. A short course (4-6 weeks) of cimetidine is known to constitute inadequate treatment for unoperated patients, since in $90 \%$ the ulcer recurs within 1 year $104,118,198$.

This was not the case however in most of the patients described.

Reoperation was proposed by us to several patients but this was refused. It would seem that these patients were not hampered so much by their occasional complaints or recurrence as to undergo a second operation.

Some patients evidently tried to use their pretended suffering in order to get an casier job or rejection for work and access to social security payment.

Adding up all the permanent and temporary failures as is done in the retrospective Visick grading and as is done in the statement: "this series has a recurrence rate of $9.2 \%$ " may give a distorted picture of HSV results. Nevertheless recurrences were considered failures and looked at separately in this study in order to try and find associations and correlations with other factors (chapter 15).

Each re-appearance of an ulcer after operation is considered as a recurrence, whether duodenal (truly "recurrent"), pyloric or gastric. An overview of the localisation of the recurrent ulcers found is given in chapter 16.3 .2 .

There were 24 recurrences recorded in 22 men and 2 women, a ratio of $11 / 1$ in spite of an unfavourable reputation of women as regards the results of gastric surgery ${ }^{94}$ 129. 353 . The propontion of recurrences was much lower in women compared with men: $2 / 48(4.1 \%)$ for women and $22 / 214$ (10.3\%) for men (n.s.). This has been found recently by other authors ${ }^{229}$. One reason why this has come to light only recently might be that several studies have left out women - always in the minority - for reasons of uniformity $313,339,361$.

The diagnosis of recurrent ulcer was proved by endoscopy in $79 \%$ of the patients and by barium meal examination in $46 \%$; in most cases both examination techniques were used, leaving little room for doubt. This explains the overlapping diagnosing proportion of each technique; in $25 \%$ both examinations were positive; in $54 \%$ the recurrence was proven only by endoscopy and in $21 \%$ the $\mathrm{X}$-ray was definitely positive but endoscopy failed to reveal the ulcer, or the patients refused endoscopy. These 
examinations were not carried out routinely in all patients after operation but only in the presence of symptoms, even when these were only slight.

Sometimes ( $n=20$ ) an $X$-ray examination was requested in a patient without symptoms. An ulcer was never found ${ }^{354}$. Asymptomatic ulcers could have been missed therefore but are also missed in healthy people not attending doctors. In all patients who had an ulcer proved, a repeat examination was done later. It had always healed at that time, in some cases without any treatment 173,266.

The mean age of the patients with a proved recurrence was 41.9 years (sd 8.3 ); this was not significantly different from the patients without a recurrence $(40.8$ years, sd 11.1). The length of history of the recurrence group ( 8.9 years, sd 6.8) was slightly shorter than the non-recurrence group (10.0 years, sd 7.7 ) but not significantly so. Had this difference been significant it could mean a more aggressive ulcer diathesis. The average time interval before recurrence was 33.3 (sd 23.4) months, and a detailed list of the time since operation before recurrence in all these patients is shown in chapter 15 .

The average time interval for consultants' patients was 35 (sd 24) months (range 3-86 months) and for registrars' 30 (sd 23) months (range $4-56$ months).

$82 \%$ of the recurrences appeared within 4 years after operation, but there were two recurrences after 82 en 85 months respectively.

It is very interesting on whose account the recurrences have been found.

As stated in chapter 4 , the majority of operations were performed by registrars during their surgical training; 167 of the 262 operations $(64 \%)$ were performed by them, whereas the consultants performed the other $95(36 \%)$. The assistances at the operations of the registrars were done in 45 cases $(27 \%)$ by consultants. The other assistances were done by other trainees, in 25 cases (15\%) being senior, in 97 cases $(58 \%)$ being junior to the surgeon who performed the operation.

table VIII

daita of patients operated on by consultants and registrars

\begin{tabular}{|c|c|c|c|c|c|c|c|c|c|c|}
\hline & $\begin{array}{l}\text { Ho. of } \\
M V^{\prime} V_{B}\end{array}$ & 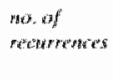 & 营, & $\begin{array}{l}\text { follow-itps } \\
\text { timsc } \\
\text { (enth) }\end{array}$ & 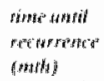 & $\begin{array}{l}\text { prepps. } \\
\text { iteighs } \\
\left(k_{i g}\right)\end{array}$ & 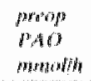 & 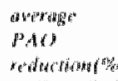 & 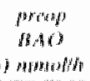 & 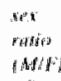 \\
\hline 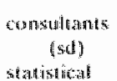 & 95 & $16 x$ & 16.8 & $\begin{array}{c}67 \\
(23)\end{array}$ & $\begin{array}{r}35 \\
0.47\end{array}$ & $\begin{array}{r}71.2 \\
(13.9)\end{array}$ & $\begin{array}{c}54.2 \\
(24.4)\end{array}$ & $\begin{array}{c}46.2 \\
(29.8)\end{array}$ & $\begin{array}{l}6.2 \\
(8.2)\end{array}$ & 3.75 \\
\hline $\begin{array}{l}\text { sigraflicance } \\
\text { registars }\end{array}$ & 167 & 8 & 4.16 & 42 & $\begin{array}{c}01.5 \\
30\end{array}$ & 71.8 & 5.5 & Ant & $6,8.8$ & $\begin{array}{l}18.4 \\
4.46\end{array}$ \\
\hline
\end{tabular}

The total recurrence rate was 24 out of 262 , which is $9.2 \%$. The recurrence rate for consultants was $16.8 \%$ and for registrars $4.8 \%$ (table VIII). This difference is significant. As will be demonstrated in table B in the special chapter (15) devoted to "recurrences" there was no difference in the proportion of assistances by a consultant between patients who did develop a recurrence and those who did not.

To state that registrars scored better than their teachers is misleading for a number of reasons:

- the follow-up period of the consultants' patients was longer $(67$ compared to 42 months) 
- three consultants not involved in teaching HSV technique and only occasionally performing the operation contributed 4 recurrences from 10 operations

- in the initial period of HSV only consultants were operating in order to get enough experience for teaching; the recurrence rate in that period was high; these were the patients with the longest follow-up and thus the best chance of recurrence.

Even if the data are corrected for the "occasional surgeons" and for the first 25 patients in the introduction period, there still remains a balance in favour of the registrars:

$8.3 \%$ compared with $4.8 \%$ (see table IX). Nevertheless there is a difference in followup time.

table ix

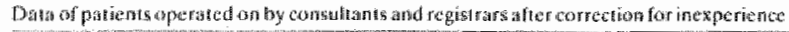

\begin{tabular}{|c|c|c|c|c|c|c|c|c|c|c|}
\hline & 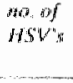 & 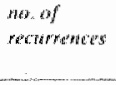 & ws & $\begin{array}{l}\text { foldowrtap } \\
\text { Bigne } \\
\text { (minh) }\end{array}$ & 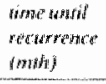 & $\begin{array}{l}\text { preopy. } \\
\text { hiterging } \\
\text { rkgj }\end{array}$ & $\begin{array}{l}\text { Preop. } \\
\text { PAC } \\
\text { mmolith }\end{array}$ & 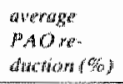 & $\begin{array}{l}\text { preqpe } \\
B, 4 Q \\
\text { mmollth }\end{array}$ & $\begin{array}{l}\text { seth } \\
\text { ratso } \\
\text { (AHF) }\end{array}$ \\
\hline 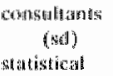 & 60 & 5 & $\mathbb{1} 3$ & $\begin{array}{c}58 \\
(21)\end{array}$ & $\begin{array}{l}28 \\
189\end{array}$ & $\begin{array}{c}70.9 \\
(13.5)\end{array}$ & $\begin{array}{c}57.1 \\
(239)\end{array}$ & $\begin{array}{l}44.5 \\
(32.8)\end{array}$ & $\begin{array}{l}6.6 \\
(7.919\end{array}$ & 3.611 \\
\hline 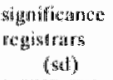 & 167 & 8 & $\begin{array}{l}10.4 \\
4.4\end{array}$ & $\begin{array}{c}* \\
42 \\
(21)\end{array}$ & $\begin{array}{c}n+3 \\
30 \\
(21)\end{array}$ & $\begin{array}{l}10.8 \\
71,1 \\
(10,6)\end{array}$ & $\begin{array}{c}n .6 \\
54.8 \\
(24.1)\end{array}$ & $\begin{array}{l}17.5 \\
46 . i \\
(20.6)\end{array}$ & $\begin{array}{l}17.5 \\
6.1 \\
(6.1 .)\end{array}$ & $\begin{array}{l}40 . s_{8} \\
4.96\end{array}$ \\
\hline
\end{tabular}

It shouid be realised, however that the follow-up time is influenced unfavourably by recent cases. Registrars have performed $96 \%$ of the HSV's in the last 2 years, and if these operations had not been counted, the difference in follow-up time would not have been significant.

Further one can speculate that this outcome is biased by an unequal distribution of unfavourable cases towards the consultants. $21 \%$ of all patients with a recurrence had a history of psychiatric treatment; all but one were operated upon by consultants. A similar unfavourable distribution could apply for extremely obese patients.

However, the average weight at the time of operation was equal in both groups, but there were a few very heavy patients in the consultants' series as might be appreciated from the larger spreading.

A number of other possible factors have been listed in the foregoing tables, but apart from the details already discussed, there was no significant difference.

Further attempts to analyse why patients with a recurrence have got this recurrence will be found in the different chapters dealing with different subjects (acid secretion, gastrin, etc.).

There will be a special chapter devoted on the subject later (chapter 15).

\subsection{Mortality, complications and side effects}

Almost every operation devised for curing duodenal ulcer has caused a number of sequelae and side effects.

Moreover a certain mortality and complication rate appears to be associated with the procedure employed. It is clear that this should be as low as possible 2660 .

\subsubsection{Mortality}

There was one postoperative death in this series. The patient, a 23 year Maroccan labourer died suddenly from an unknown cause on the second postoperative day 
after an uneventful HSV operation. He developed hyperthermia and convulsions and died within hours. Unfortunately post mortem examination was refused by the family. The most probable explanation was an intracerebral catastrophe - probably haemorrhage - which was thought to be unrelated to HSV per se but could have occurred after any operation/anaesthesia or even spontaneously.

Thus the mortality rate was $1 / 262=0.4 \%$. The reported mortality in the world is $0.3 \%{ }^{168}$ and this has been confirmed by many reports.

This mortality is the lowest of all operative treatments known for duodenal ulcer ${ }^{145}$. The conclusion is that HSV appears to be a very safe operation, even in the hands of relatively inexperienced surgeons.

\subsubsection{Complications during or after operation}

The complications have been divided into early and late ones.

table 1

Complications of 262 HSV's

\begin{tabular}{|c|c|c|c|}
\hline \multirow[t]{9}{*}{ early } & - local perforation & 4 & \\
\hline & - pulmonary & 13 & \\
\hline & thromboemibolic & 2 & \\
\hline & - wound infection & 12 & \\
\hline & - bleedimg & 2 & \\
\hline & - ileus & 1 & \\
\hline & - fever of unknown origin & 2 & \\
\hline & - neurapraxida of Latarjef nerve & 1 & \\
\hline & & 37 & $(14 \%)$ \\
\hline \multirow[t]{6}{*}{ late } & - incisional hernia & 5 & \\
\hline & - persisting suture sinus & 5 & \\
\hline & - ileus & 3 & \\
\hline & - ossification in scar: & 5 & \\
\hline & - pyloric stenosis & 2 & \\
\hline & & 20 & $(7.5 \%)$ \\
\hline
\end{tabular}

Early complications: appearing during operation or within 1 month.

- local perforation: 4 cases

three of these perforations occurred during the HSV procedure. One patient had a perforation of the lower oesophagus during the procedure of clearing it of nerve fibres. The perforation was sutured immediately and covered with the fundus of the stomach. The recovery was uneventful.

One patient had a perforation during the dissection of the lesser curvature which was repaired immediately. The lesser omentum in that patient was abnormally thick $(11 / 2 \mathrm{~cm})$; the recovery was also uneventful.

One patient operated on for stenosis had a perforation of the duodenum during the dilatation; it was sutured transversely and covered with omentum. He recovered without problems and never had any complaint after operation.

One patient had to be reoperated upon on the second postoperative day because of 
sudden signs of peritonitis.

The drain - still in place - started discharging intestinal contents which were perceived immediately and laparotomy was performed without delay. Although fearing a lesser curvature necrosis - a specific HSV complication ${ }^{35,256,251,319}$ - it turned out to be caused by a wrongly placed haemoclip (in the stomach wall) which had caused a very localised necrosis. The perforation was sutured and the abdomen lavaged. The patient recovered without further problems.

- pulmonary complications

13 patients developed pulmonary infections, atelectasis or infected spulum, requiring antibiotics, physiotherapy and supportive drug treatment. Their stay in hospital was never prolonged.

- there were two thromboembolic complications in spite of anticoagulant prophylaxis.

One patient probably had a pulmonary embolism and another developed an axillary thrombosis after having a phlebitis.

Both patients had subcutaneous heparin as prophylaxis. There was no permanent incapacity due to these complications.

- woundinfections (superficial) 12 patients ( $4.5 \%$ )

no dehiscence of the abdominal wall occurred. In 4 cases persisting suture sinuses resulted and in one case an incisional hernia developed. A wound infection usually prolonged the stay in the hospital for some days.

- bleeding

in two cases there was significant postoperative haemorrhage requiring blood transfusions. Thanks to the routinely introduced drain the actual blood loss could easily be monitored. In one patient 5 pints of blood were necessary, in the other two. Undoubtly this complication could have been attributed to insufficient haemostasis or a slipped ligature (in both patients all vessels were ligated), however it should be added that in both patients an additional procedure had taken place. In one case a cholecystectomy had been performed as well, in the other the HSV was performed after oversuturing a perforation. It is not certain whether the bleedings resulted from the HSV or from the other procedures.

- in one patient a mechanical bowel obstruction developed a few days after operation; she could be managed conservatively and recovered uneventfully. She never had obstructive symptoms later.

- two patients had fever $\left(39^{\circ} \mathrm{C}\right)$ without any known cause for some days. It recovered spontaneously and did not prolong their hospital stay. 
- one patient had a neurapraxia of one (or both) nerve(s) of Latarjet, which was already suspected during the procedure. Shortly after operation he developed symptoms indicating difficulty in emptying of the stomach, although the obstruction was not absolute. Initially he was managed conservatively and will be discussed further under "late complications".

Late complications: complications coming to light more then one month after HSV. Table 1.

- during follow-up all patients were examined for the presence of incisional hernia. Five cases were found but none of them had complaints about the hernia (1.9\%). One of these patients also had ossification in the scar and a repeatedly draining suture sinus with abcess formation. He was operated on, and the "ossification" turned out to be an infiltrated suture granuloma, which was removed, and the hernia was repaired.

In the other four patients no operation for that cause ensued.

- there were 5 suture sinuses; ultimately they resolved in the course of months. Since the use of absorbable polyglactin for closure of the fascia this complication was not seen anymore.

- there were three late cases of ileus (mechanical bowel obstruction). One patient was reoperated twice elsewhere for massive adhesions and bands, respectively twelve and sixteen months after HSV. He never experienced stomach problems again after his HSV and there was no sign of recurrence during these reoperations. 2 patients were admitted for bowel obstruction respectively 9 months and 36 months after operation. The latter could be managed non-operatively, but the first needed operative division of the adhesions.

- in 5 patients ossification of part of the scar was found; they only had minor complaints about it.

- two patients had to be operated on for stomach outlet obstruction, 6 and 10 months after their HSV operations. One patient, a foreign labourer of Tunisian nationality already had gastric emptying problems immediately after operation, complaining of frequent eructations, epigastric fullness and (occasionally) vomiting. 10 days postoperatively an X-ray examination was performed, which showed a dilated stomach emptying slowly. A neurapraxia of one or both nerves of Latarjet was suspected and domperidon (Motilium $\left({ }^{B}\right)$ was prescribed which improved the symptoms slightly. The patient was discharged home but did not improve and ultimately was reoperated 6 months after operation; a Heineke-Mikulicz pyloroplasty was performed. He had no emptying problems therealter but rather the reverse: he developed diarrhoea and dumping and remained a failure for that reason.

The second patient with obstruction symptoms was operated elsewhere 10 months after operation for a severely deformed bulb region with emptying problems. $\mathrm{He}$ underwent a gastric resection with Billroth I anastomosis. 
It is difficult to compare the complications here to the rate of other operations or with other series, since a number of the listed complications are usually not mentioned in other series.

The majority of the complications, however, were only a temporary draw-back and have been overcome completely. The complications specifically associated with HSV were:

- local stomach/duodenum perforation

- perforation of the oesophagus

- pyloric stenosis

- postoperative bleeding; the doubt about the origin of the bleeding has already been discussed.

The other complications are not specifically related and are associated only with being operated upon. Perhaps pulmonary complications do have some relation with HSV as such since the operative trauma in the upper abdomen could predispose to pulmonary problems.

Thus HSV brought about very few complications associated with the nature of the procedure 172 .

There were no cases of lesser curve necrosis; there was no rupture of the spleen in this series and no postoperative perforation of the oesophagus.

The conclusion appears warranted that HSV as such brought about very few lasting complications. Even the general complications were relatively "benign" 266 .

\subsubsection{Side effects and sequelae due to the operation}

In general the sequelae affecting the quality of life after stomach operations can be divided in several categories: those caused by a drainage procedure, by a reduction of the gastric capacity, by the vagotomy itself, or by removing or bypassing the natural sphincter.

It is not always possible to assess the exact cause of the consequences of a previous operation, but a number of problems are well known and have been proved to be attributable to an operative procedure ${ }^{94,268}$ :

epigastric fullness,

carly satiety.

dysphagia,

hearburn,

acid brash/reflux, diarrhoea

dumping,

size and number of meals,

nausea/vomiting,

metabolic consequences.

Both partial gastric resection and truncal vagotomy were notorious for their eventual postoperative sequelae (especially diarrhoea, dumping and bilious vomiting) which in a number of cases were so severe that the patients were more incapacitated by these causes than by their ulcers. The "Albatross-syndrome" indicates patients, crippled by gastric surgery and forever "hanging around their doctor's neck", searching for relief ${ }^{172}$.

Many sophisticated operations have been devised to combat these sequelae ${ }^{185,294}$. This complex of symptoms, which was unpredictable, has long been considered the price for ulcer cure. Selective Vagotomy and drainage was devised to obviate some of these sequelae and probably would have been succesful to a certain extent if HSV had not been introduced as a more dominant competitor ${ }^{326}$. 


\section{Side effects and sequelae in the patients studied}

In many patients symptoms similar to those they had before operation recurred at times after operation, often to a greatly diminished degree. The presence and frequency of these symptoms were expressed in the Visick grading, but symptoms of this kind were not considered side effects of the operation.

The difference between new symptoms (possible side effects) and recurrence of the original disease to some degree was sometimes difficult. Very few patients had a different pattern of symptoms after operation than before; for example: it was exceptional that patients complained about heartburn when they had not experienced this before operation.

Some patients mentioned here had several symptoms usually at the same time, for example: regurgitation and nausea.

This means that adding all figures and examples here would exaggerate the proportion of patients affected.

- Dysphagia has been recorded as a rather common complaint after operation, but it always disappeared quickly, in the course of several weeks ${ }^{324,340}$.

- About a quarter of the patients experienced epigastric fullness or early satiety after a meal as a consequence of the diminished receptive relaxation of the stomach. In general this disappeared completely within half a year, but still some mentioned on questioning some inability to enjoy a full-size meal. However, this was never experienced as severe.

- There were no serious cases of diarrhoea or dumping following HSV in the series; less then $3 \%$ had episodes of this nature, but never severe.

- Heartburn was mentioned in $15 \%$ of the cases, usually much less than before operation and thus in fact no side effect ${ }^{26 \%}$. In less than $1 \%$ it was a reason for being graded Visick $3 / 4$.

- Tolerance of food was always better than before operation. Most patients had some kind of intolerance for certain foods before operation, but in the majority of cases this improved. A great number of operated patients did not experience any need to restrict their diet. Some, however, continued to have the same intolerance as before operation. A new intolerance not present before operation was exceptional.

- Nine patients demonstrated symptoms of oesophageal reflux after operation, in five of them this reflux was demonstrated by $X$-ray or endoscopy. A hernia was not always present. In three of these patients symptoms of this kind had already been present before operation, but were probably masked by the ulcer symptoms. Three patients also developed a recurrence.

Not counting the patients with a recurrence the reflux caused two patients to be graded Visick 3 and 4 respectively.

On the other hand, ten patients had either a hiatal hernia or reflux demonstrated before operation. One patient had a hiatal repair at the time of the HSV. All these patients never had any complaints after operation. Reflux symptoms are not 
reported to be a common sequel of $\mathrm{HSV}^{18,41,64,65,266,276,321,344,357,370 .}$

- Nausea and vomiting could be side effects of the operation if a (relative) outlet obstruction had occurred, and were usually accompanied by pronounced eructations. They were, however, not frequent complaints and were recorded only in 9 patients at some time.

- In two patients they turned out to be symptoms of gastric outlet obstruction. Reoperation for pyloric stenosis was carried out as reported earlier.

- In one patient who had a proved recurrence they were only present at the time of that recurrence.

- In one patient they turned out to be symptoms of non-gastric origin (spastic colon) and disappeared completely after treating this.

- In two patients they were present at times both before and after operation. Both had a history of psychiatric treatment and probably the nausea and vomiting were not of gastric origin. Both patients had $\mathrm{X}$-ray and endoscopic examinations after operation never demonstrating a recurrence.

- In one patient they were considered to be the symptoms of oesophagitis which was proved after operation. Two more patients were suspected of gastric outlet obstruction shortly after operation. In both, the symptoms disappeared suddenly spontaneously after $1 / 2$ - 1 year.

Interestingly both had been diagnosed as having pyloric stenosis before operation, but at the operation a sufficient patency of the pylorus was judged to be present and gastrotomy and dilatation were omitted.

There were 2 exceptional but striking side effects which to the author's knowledge have not been described before in relation to HSV. Ten patients complained after operation of pain in their left shoulder when using apparently a too large meal, possibly caused by irritation of the left hemi-diaphragm. Two patients clearly demonstrated the psychosomatic nature of their ulcer disease. At follow-up they spontaneously mentioned being without further complaints but they sometimes felt very nervous (sweating, trembling, subjective feeling) in situations when they would have experienced stomach ache before operation, resembling symptom shift. Several other patients mentioned that they felt more nervous and insecure in general after operation.

These patients and their symptoms will be discussed extensively in chapter 16. Possible metabolic consequences are discussed in chapter 13.

The conclusion is that the incidence and severity of side effects associated with HSV are in general of minor importance as reported in the literature.

Nevertheless some side effects remain, but it should not be forgotten that the normal, healthy population already exhibits a certain number of "side effects" although a gastric operation has never been performed or no ulcer has ever been demonstrated $183,267,311$.

Comparisons should not be attempted with a "standard population", more healthy and symptom free than the normal population. 


\section{Chapter 9}

\section{HSV for complicated duodenal ulcer}

\subsection{Introduction}

There are three common complications in duodenal ulcer disease:

haemorrhage, perforation and postpyloric stenosis (commonly denominated as pyloric stenosis). They always appear in a certain proportion in studies of patients with duodenal ulcer. These proportions, however, appear to vary in differing populations ${ }^{53}$.

Among other factors, the proportion of each complication in a series of operated cases is influenced by the attitude of the physicians and surgeons treating such patients. In case of a rather conservative approach the rate may be accordingly lower.

Nevertheless in a certain population the rate of each complication seems to be rather constant, especially so with the perforation rate, which has been used as a yardstick to estimate the prevalence of duodenal ulcer in a population ${ }^{329,341}$.

The estimated figures published for the frequency of the respective complications among the patients coming to operation are differing, however.

$\begin{array}{lll}\text { For stenosis: } & 4-30 \% & 77,116,128,163,172,214,365 \\ \text { for perforation: } & 5-15 \% & 116,181 \\ \text { for bleeding: } & 9-25 \% & 128,214,342\end{array}$

In this series the number of HSV's performed in an emergency or semi-emergency situation is not a good measure of the incidence of those complications in the area, since other methods of operative treatment have been applied as well, especially in the first years.

Later, as confidence in HSV increased, almost all complications were treated with HSV after the appropriate additional procedure.

Nevertheless, a special chapter has been devoted to preoperative complications to demonstrate whether this group of patients fared as well as the group without those complications.

\subsection{Diagnosis}

The diagnosis of stenosis was - apart from the proof of a duodenal ulcer - based mainly on clinical grounds: repeated and continuing vomiting, inability to take adequate meals, loss of weight, dilated stomach on $\mathrm{X}$-ray with very slow emptying (not quantified) and on endoscopy a narrowing of the pyloric channel not permitting the scope to pass into the bulb. At operation the diagnosis was confirmed by bidigital palpation and after gastrotomy by calibrating with the finger and with Hegar dilators. Unfortunately the calibre measured was not recorded systematically.

However in two patients the pyloric region at operation appeared to be normal as judged by bidigital palpation: their stomachs were not grossly dilated at that time (after several days of decompression by nasogastric tube) and gastrotomy and dilatation were omitted.

Both patients had moderate to severe complaints postoperatively for a considerable 
time due to difficulties in emptying. One of these became suddenly symptomfree, after more then 1 year of trouble, the day the dose of his anti-arrhythmic Isoptin (B) (verapamil) was halved.

The second patient also complained for about 1 year and was ready to undergo a pyloroplasty, when his complaints subsided spontaneously and he became symptomfree.

The diagnosis of perforation was confirmed at operation in the cases involved. The patients with a perforation managed conservatively in the past were diagnosed on clinical grounds, but had an ulcer and deformity proved after improving clinically. At operation later, adhesions of the omentum in the bulb region were usually present.

The diagnosis of bleeding was made by endoscopy and was confirmed at operation in the acute cases. In the semi-acute cases the bleeding ulcer had been demonstrated by endoscopy and in all cases clinical evidence of haemorrhage had been present (shock, drop in $\mathrm{Hb}$, melaena, haematemesis).

Bleedings in the past were usually demonstrated by the presence of haematemesis and/or melaena with demonstration of a duodenal ulcer.

In fact two kinds of preoperative complications have been considered together here: those complications having taken place in the past and those which gave rise to an emergency operation. When considering all complications together, whether recent or past, the figures in this series are:

\begin{tabular}{llcl}
50 & bleedings & $(19.1 \%)$ & \\
27 & perforations & $(10.3 \%)$ & \\
11 & stenoses & $(4.2 \%)$ & \\
\hline 88 & & $33.5 \%$ & in 262 patients
\end{tabular}

There were three patients with 2 differing complications (bleeding + perforation, stenosis + perforation $(2 \mathrm{x}))$.

This means that 85 of the patients in this series $(32.4 \%$ ) had a complication at some time in their history of disease.

In the 11 patients with stenosis the obstruction was the main indication for operation, which took place as a semi-emergency procedure after several days of supportive treatment and decompressive therapy (drugs, i.v. fluids and nasogastric tube). Of the 27 patients with a perforation 13 were managed conservatively in the past and 4 only had the perforation oversutured. In 10 patients a HSV was performed during the same emergency procedure as oversuturing and covering with an omental patch.

Acute bleeding was treated acutely in 4 cases: three times by duodenotomy and underrunning of the bleeding point followed by a HSV and once without duodenotomy because the bleeding had apparently stopped. In 14 cases the operation took place semi-acutely one to several days after the bleeding had been proved. No duodenotomy was required in any of these cases. 
Some patients had several complications before their HSV, mainly repeated haemorrhages, managed non-operatively. Two patients had a perforation in the past and a stenosis, the last being the indication for operation. One patient had a perforation in the past and a bleeding, the latter being the indication.

9.3 Technique

An excellent description of the techniques of treating complicated duodenal ulloer has been given by Johnston ${ }^{163,170}$.

A concise description of the techniques used in this series has been written in chapter 5 about operative technique.

\subsection{Follow-up}

Although the proportion of acute complications treated with HSV following some other appropriate procedure is increasing in more recent years, the average length of follow-up is little different from the main group.

The follow-up time for the acute and semi-acute cases was 40.7 months, as compared to 50.4 months for all patients. The difference is significant, however.

\subsection{Postoperative complications}

One of the advantages of HSV is that the alimentary canal does not have to be opened and hence a lower complication rate can be expected.

The overall complication rate has been discussed in chapter 8 .

Among the patients with a complication in 22 the alimentary canal was breached and the peritoneum potentially soiled: in 10 patients by perforation, in 9 cases by gastrotomy for dilatation of the obstruction and in 3 cases by duodenotomy for bleeding.

When these are taken together 4 postoperative complications resulted $(18.2 \%)$. After gastrotomy and dilatation: no complications.

After perforation: 1 superficial wound infection and 1 postoperative haemorthage, managed conservatively, requiring 5 units of packed cells.

After duodenotomy for bleeding: 1 superficial wound infection and 1 pneumonia. This complication rate does not differ substantially from the overall complication rate. In all patients with a potentially soiled peritoneum the abdominal cavity was routinely lavaged with warm saline after closing the alimentary tract.

There was no mortality among the patients with a complication.

\section{Results}

Results of the patients with a recent or past complication, treated with HSV.

Of all "complicated" cases the number, the sex distribution, the number of recurrences known at 1 st July ' 82 , the average age at operation, the age at the onset of the disease, the length of history, the blood group distribution and the Visick grading at 1st July 82 are given in the tables (1-8). 


\section{Stenosis}

There were $\mathbb{1}$ patients with this indication for operative treatment in this series. They were operated upon after several days of conservative treatment with i.v. fluids and a nasogastric tube for decompression and lavage.

The results are indicated in table 1 . In two patients no gastrotomy \& dilatation was performed since at operation no obstruction was judged to be present.

\section{Perforation}

10 Patients were operated on acutely for perforation; after oversuturing of the perforation with heavy atraumatic polyglactin an omental patch was fixed on the perforation site.

17 Patients had a perforation in the past.

The results are shown in table 2 . The patients are subdivided into those who had the perforation in the past and those who had an acute perforation. Moreover both categories have been added in the table.

\section{Haemorrhage}

Three categories have been subdivided:

- acute operations for severe haemorrhage (4)

- semi-acute operations, one to several days after admission for bleeding which who had stopped or continued slowly but still warranted operative treatment (14)

- one or more bleedings in the past (32)

In table 3 all bleeding categories are represented as well as the collective outcome.

In tables 4 and 7 the results of all patients who had their HSV in connection with the acute complication have been collected. In table 5 these results have been extended with the results of the patients with a semi-acute operation for bleeding.

In tables 6 and 8 all patients who ever had a complication, whether acutely, semiacutely or in the past, are taken together. Since three patients had 2 different complications a correction has been made in this table to prevent counting them twice.

Complicated duodenatilued

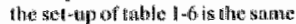

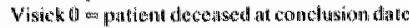

no 0 intumber of castest

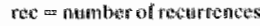

\begin{tabular}{|c|c|c|c|c|c|c|c|c|c|c|c|c|c|c|c|c|}
\hline \multirow{4}{*}{$\begin{array}{l}\text { bable } 1 \\
\text { stenosis }\end{array}$} & \multirow[t]{2}{*}{$n$} & \multirow[t]{2}{*}{ 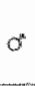 } & \multirow[t]{2}{*}{9} & \multirow{2}{*}{ ried } & \multirow{2}{*}{$\begin{array}{c}\text { age } \\
\text { at operomon } \\
(y)\end{array}$} & \multirow{2}{*}{$\begin{array}{c}\text { wgere of } \\
\text { onset of } \\
\text { distrase (yo) }\end{array}$} & \multirow{2}{*}{$\begin{array}{c}\text { Length of } \\
\text { Alstory } \\
\text { (yr) }\end{array}$} & \multicolumn{4}{|c|}{ blowd gmouplo } & \multicolumn{5}{|c|}{$\begin{array}{c}\text { regraded } \\
\text { Vissick grad hing }\end{array}$} \\
\hline & & & & & & & & $A$ & $B$ & $A A$ & 0 & $\theta$ & 1 & 2 & 3 & 4 \\
\hline & & & & & & & & & & & & & & & & \\
\hline & 11 & 8 & 3 & $19 y$ & 520 & 40.5 & 11.5 & 2 & 0 & 0 & 9 & 1 & 7 & 3 & 0 & 0 \\
\hline
\end{tabular}

\begin{tabular}{|c|c|c|c|c|c|c|c|c|c|c|c|c|c|c|c|c|c|}
\hline perloration & neclate & 10 & 9 & 1 & $1\left(0^{\circ}\right)$ & 443 & 40.5 & 8.2 & 1 & i & 0 & 8 & 0 & 6 & 2 & 0 & 2 \\
\hline & in past & 17 & 14 & 3 & $2\left(0^{\circ}\right)$ & 45,3 & 35.3 & 5 & 13 & 0 & 1 & 3 & 1 & 8 & 7 & 1 & (1) \\
\hline & all & 27 & 28 & 4 & $3\left(0^{\circ}\right)$ & 449 & 39.1 & 9,0 & 14 & I & 1 & 11 & 1 & 14 & 9 & I & 2 \\
\hline
\end{tabular}




\begin{tabular}{|c|c|c|c|c|c|c|c|c|c|c|c|c|c|c|c|c|c|}
\hline \multirow{4}{*}{$\begin{array}{l}\text { fable } 3 \\
\text { bleteding }\end{array}$} & & \multirow[t]{2}{*}{$n$} & \multirow[t]{2}{*}{$\sigma^{m}$} & \multirow[t]{2}{*}{$q$} & \multirow[t]{2}{*}{ 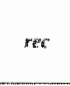 } & \multirow{2}{*}{$\begin{array}{c}\text { agge } \\
\text { ar operafuch } \\
\text { oyrd }\end{array}$} & \multirow{2}{*}{ 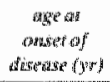 } & \multirow{2}{*}{ 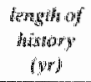 } & \multicolumn{4}{|c|}{ blood grets } & \multicolumn{5}{|c|}{ 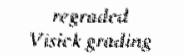 } \\
\hline & & & & & & & & & $A$ & 8 & $A$ & 0 & 0 & 1 & 2 & 7 & 4 \\
\hline & incute & 4 & 3 & 1 & 0 & 81,8 & 366 & 5.01 & 3 & 0 & 0 & If & 0 & 2 & 2 & il & a \\
\hline & seminacute & If & 12 & 2 & $1(\infty)$ & 42.6 & 31.5 & 11.01 & 道 & 0 & 1 & 0 & $\sharp$ & 9 & 3 & a & 1 \\
\hline & in past & 32 & 30 & 2 & $1\left(\omega^{x}\right)$ & 41.4 & 29.7 & 18.9 & 8 & 0 & 0 & $2 y$ & H & 21 & 5 & 4 & 1 \\
\hline & all & 50 & 45 & 5 & $2\left(0^{*}\right)$ & 4.7 & 新 & 111.1 & !s & $\theta$ & 1 & 3 & 2 & $x^{2}$ & 10 & 4 & 2 \\
\hline
\end{tabular}

Nation 4

allacute operations

(st. $\| 1$, perf $10, b]+$

$25 \quad 20 \quad 5 \quad 2\left(0^{\circ}, 9\right) \quad 47$

38. 1

9.1

$6 \quad 1 \quad 0 \quad 18 \quad$ | $15 \quad 7 \quad 0 \quad 2$

hatyle 5

all arete and

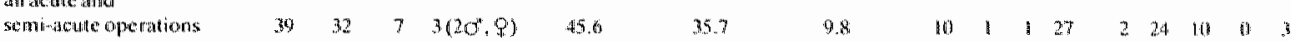

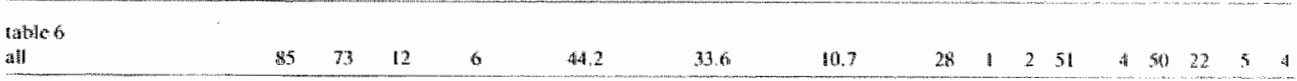

\begin{tabular}{|c|c|c|c|c|c|c|c|c|}
\hline \multirow[t]{2}{*}{ table 7} & \multicolumn{3}{|c|}{ blood group } & \multicolumn{3}{|c|}{$\begin{array}{l}\text { regraded Kisiol } \\
\text { grading }\end{array}$} & \multicolumn{2}{|c|}{$\begin{array}{l}\text { Sratho Whick } \\
\text { grading }\end{array}$} \\
\hline & & $n$ & (x) & & $n$ & $(\%)$ & $n$ & $(\%)$ \\
\hline & $A$ & 6 & $(24)$ & $\mathfrak{i}$ & 15 & $(62.5)$ & 15 & $(625)$ \\
\hline all incute? & $\mathrm{B}$ & 1 & (4) & 2 & 7 & $(29.2)$ & 6 & $(25)$ \\
\hline \multirow[t]{2}{*}{ operations } & $A B$ & 0 & $(0)$ & 3 & (1) & $(0)$ & 0) & $(0)$ \\
\hline & 0 & 18 & $(72)$ & 4 & 2 & (8.3) & 3 & $(12.5)$ \\
\hline nables & $\mathrm{A}$ & 28 & $(34,2)$ & 1 & 50 & $(6 \|, 7)$ & 49 & $(60.5)$ \\
\hline all oper:ations & $\mathbf{B}$ & 1 & $(1.2)$ & 2 & 22 & $(27,2)$ & $20]$ & $(24,7)$ \\
\hline for atany & $\mathrm{AB}$ & 2 & $(2$, 래) & 3 & 5 & $(6.2)$ & 5 & $(6.2)$ \\
\hline complication & $a$ & 51 & $(62.2)$ & 4 & 4 & $(4.5)$ & 7 & $(8.6)$ \\
\hline
\end{tabular}

\subsection{Discussion}

In general the patients with a complicated duodenal ulcer appear to be somewhat older at operation than the non-complicated patients. This is especially apparent with postpyloric obstruction, where the mean age is more then 10 years higher. This seems to be a common feature ${ }^{163}$.

This ageing is not caused by a prolonged history, but the age of onset of the disease is on average higher.

A similar but less pronounced higher age at operation is seen with the patients having a perforation. The sex ratio $\left(\sigma^{\prime \prime}: Q\right)$ is $6: 1$, as compared to $4.5: 1$ in the whole series.

\section{Blood group}

The proportion of blood group $\mathrm{O}$ among the patients with a complication is significantly elevated as will be demonstrated also in chapter 14 . Both for stenosis and bleeding this appears to be prominent whereas in the patients with a perforation the results in this series are rather conflicting:

in the patients with an acute HSV there is a preponderance of blood group $\mathrm{O}(\mathrm{O}: 8 \mathrm{x}$, 
$A:(x)$, whereas in the patients with a perforation in the past blood group $A$ is predominant, giving a net result slightly in favour of blood group $A$.

\section{Recurrence}

In 6 of the patients discussed here a recurrent ulcer had occurred before the date of conclusion of this study (1st July 1982).

This is $7.1 \%$ ( 6 out of 85 ) compared to a $10.2 \%$ (18 out of 177) recurrence rate in patients without a complication ever. Even if only emergency operations are considered the recurrence rate is not unfavourable: $8 \%$ (2 out of 25 ) and if semi-acute HSV's for bleeding are included: $7.7 \%$ ( 3 out of 39 ).

\section{Visick grading}

The Visick grading of the patients as given at the conclusion date of this study has been shown in the tables. As explained before a regrading has been employed in these figures.

However, the results without regrading are only slightly different.

The official Visick grading (once a recurrence $=$ always Visick 4 ) is shown in table 7 for the 25 patients operated upon acutely and in table 8 for the whole "complicated" group.

\subsection{Conclusion}

The conclusion appears warranted that performing a HSV in acute conditions for a complication of duodenal ulcer together with the adequate specific procedure leads to results at least equal to those in uncomplicated cases both for recurrence rate, Visick grading, mortality and complication rate $77,163,314$.

In case of a hacmorthage for which operation is judged necessary, a definitive operation is mandatory 117,172 . A HSV can be recommended if the condition of the patient permits the prolonged time compared to other procedures.

In case of a perforation, however, a definitive operation after closing the perforation is optional but should not be done in poor-risk patients or in the presence of purulent peritonitis. In all other cases it can be recommended to perform a HSV in connection with the closure of the perforation irrespective of the length of ulcer history, since for those (the majority) who would otherwise need further treatment (including operation) this treatment has already been given effectively and for those who would remain symptom free - without further operation - no damage has been done.

The dilemma of definitive operation in case of a perforation thus appears to be solved. However, one could consider excluding the patients with an acute perforation (as assessed at laparotomy) not having a history of ulcer disease or having a history of less than 3 months $39,85,103,107,172,174,175,188,314,337$. 


\section{Chapter 10}

\section{Acid secretion studies}

\subsection{Introduction}

Gastric secretion tests were routinely performed in all patients before and after operation but this does not mean that they were always succesful. In a number of patients testing proved impossible, others refused pertinently - most of the refusals were postoperative - and in some the tests were performed inadequately. All preoperative tests ( 4 tests) which did not reach a Peak Acid Output (PAO) of 15 $\mathrm{mmol} / \mathrm{h}$ were left out since Baron et al have demonstrated that the stimulated acid production in duodenal ulcer patients always exceeds $15 \mathrm{mmol} / \mathrm{h}{ }^{25}$.

Three tests were declared invalid since the preoperative acid production was much lower than obtained from postoperative ones. In principle the PAO in a gastric secretion test should be reproducible and should represent the maximum response. Even if the operation had no effect at all, postoperative tests can reach at maximum the same PAO as before operation but never much more.

As a result of this secretory data of 212 patients were obtained preoperatively. All were scheduled to have several tests postoperatively: the first: $1 / 2$ year after operation, the second 1 year and the third 5 years after operation, but for various reasons (refusal of the patient, unpleasant experiences at earlier testing, abandoning of follow-up) tests were not done at all or at a later time and sometimes a test was repeated in between. Therefore there are a considerable number of tests 2,3 and 4 years after operation, which were combined as one intermediate group. The same applies to tests carried out 6 or 7 years after operation which were grouped together with the 5 year tests.

Initially the augmented histamine test according to Kay ${ }^{179}$ was performed. After measuring the basal secretion for 30 minutes an intramuscular injection of histamine (histamin phosphate, $40 \mu \mathrm{g} / \mathrm{kg}$ ) was given, preceded by an antihistamine drug to suppress the non-gastric effects of histamine; during three 15 minute periods the volume and concentration of the acid was measured and the production calculated. When it became clear that pentagastrin was better as a stimulant (since it had less side effects with the same stimulatory power) this drug was introduced and replaced histamine $2,19,77,153,159,163,197,225,237,269,280,314,371$.

Preoperatively $6 \mu \mathrm{g}$ pentagastrin $/ \mathrm{kg}$ body weight was given, postoperatively $10 \mu / \mathrm{kg}$ i. $m$.; this has been reported to be the dose with which the maximum secretory level is reached ${ }^{19,25}$.

At the same time the periods measured were changed: four basal portions of 15 minutes were collected and after stimulation 6 more 15 minute portions were obtained: for the discussion in this section this test is called: PG test type $I$.

Later, from January 1980, another portion to be collected was added: the gastric juice present in the stomach at introduction of the stomach tube: this is portion 0; the test: PG type II. A schematic overview of the three types of test employed is shown in the figure: 


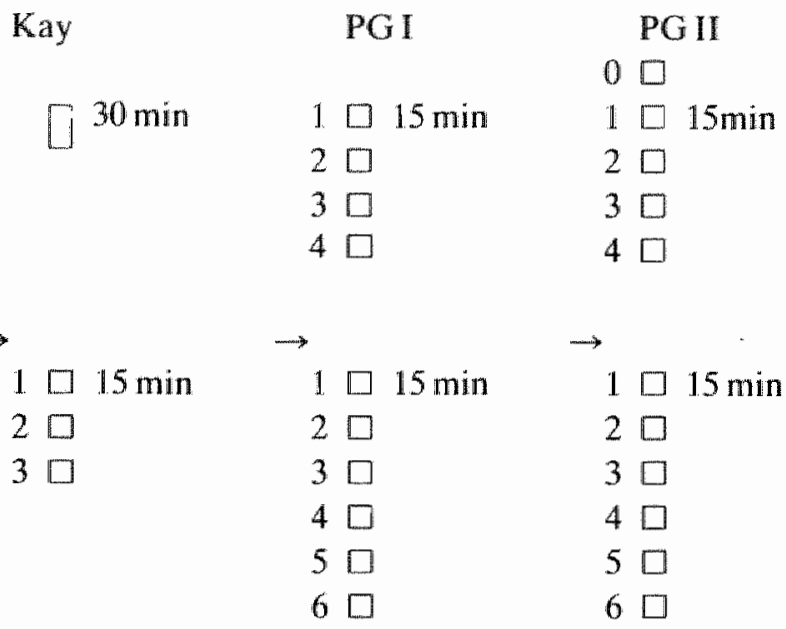

In fact only the PG test II was correct. With the other ones, in both the Kay test and PG test I, a systematic error was made: in both tests the resting contents of the stomach (i.e. the gastric juice present in the stomach at the moment of introduction of the nasogastric tube) was not discarded or measured separately but was included in the first portion so in fact portion of PG test I was equal to portion $0+1$ of PG test II. This also meant that in the case of the histamine test the only basal portion of 30 minutes was not correct but generally too high. Fortunately in the case of PG test I there were three correct portions left and statistically - assuming a steady state of basal secretion - the first portion could be constructed from the other 3 (portion $1=$ portion $(2+3+4): 3)$.

The continued systematic error after introduction of the PG test I made it possible to calculate a correction factor, with which the same mistake in the Kay test could be statistically corrected.

If the uncorrected portion $I$ and portion 2 of the PG test $I$ are added a sample is obtained comparable to the basal 30 minute portion of the histamine test; this was compared to the sum of the corrected portion 1 and portion 2 and the mean value of all available tests calculated. The comparison of the means gave the correction factor and this was applied to the values of the basal portion of the histamine tests. The correction Lactor was 0.7 for the thirty minutes basal period. This all meant that the basal values of these corrected tests - especially the histamine tests - and thus the BAO (basal acid output) were less accurate individually, but statistically correct. Of course this construction of values was less favourable, but it was the only way to use earlier data too.

Another problem was that after stimulation with histamine only three portions of 15 minutes were collected. According to most authors ${ }^{23,153,225,269}$, this should usually be enough to attain the maximal secretory level, but some found the maximum level occurring later ${ }^{306}$; however the difference in resulting values was not great. In order to make both tests (histamine and PG test) comparable the PAO was calculated in all tests from the first three portions by multiplying the acid production of the highest portion by four. In all PG tests the "official" $\mathrm{PAO}\left(\mathrm{PAO}^{\circ}=2 \times\right.$ the sum of the two highest consecutive 15 minute productions from all 6 portions) was 
calculated as well and could be compared with $\mathrm{PAO}$. The relation was $\mathrm{PAO} \mathrm{O}^{\circ}$ : $\mathrm{PAO}$ $=95: 100$, which means that values in this study are about $5 \%$ higher than the official ones. A third PAO $\left(\mathrm{PAO}^{x}\right)$ was also investigated. $\mathrm{PAO}^{\mathrm{x}}: 2 \mathrm{x}$ the two highest consecutive acid productions from the first three 15 minute periods. This resulted in a different relation: $\mathrm{PAO}^{\circ}: \mathrm{PAO}^{\circ}=84: 100 ; \mathrm{PAO}^{*}: \mathrm{PAO}=80: 100$. Since the first value was closer to the official one that value was chosen. Moreover the maximum acid output was calculated, defined here as $4 / 3 \mathrm{x}$ the sum of acid productions of portion 1,2 and 3 after stimulation.

In all chapters, with PAO is meant PAO as defined here:

the highest acid output derived from one of the first three portions after stimulation, multiplied by four.

\subsection{Performance of the test}

After an overnight fast a $14 \mathrm{~F}$ Levin tube was introduced through the mouth/nose by an experienced nurse especially assigned to gastric function examinations ${ }^{306}$. The position of the tube was not checked fluoroscopically; the only test done for the correctness of the position of the tube was the introduction of air via the tube through a syringe. With a stethoscope this air was heard bubbling through the gastric juice. The position of the lube was manoeuvred so that an easy collection of fluid could be obtained; usually the patient was on his left side but often the position was changed during the test to obtain the best collection.

Attention was paid at the same time to the length of the tube introduced.

Through combination of these factors: an experienced nurse, the "feeling" of the tube, attention to length of tube, air bubbling and a good recovery of fluid we were confident that in the majority of cases the position of the tube was correct or nearly so. Fluoroscopic control would not have been feasible as a routine but was done on special occasions ${ }^{121,131}$.

The tube was connected to an intermittent suction pump (pump Egnell, Ameda A. G. , Zug, Switzerland) and portions of 15 minutes were collected separately in bottles; the volumes were measured and acidity titrated in the laboratory. The results were expressed in volume of the sample $(\mathrm{ml}), \mathrm{pH}$ and totall acidity of the sample $(\mathrm{mmol} / \mathrm{l})$.

Acidity was defined as titrable $\mathrm{mmol} \mathrm{H}^{+}$per liter of gastric juice, which gives the same results as the former, now obsolete, definition as $\mathrm{ml} 0.1 \mathrm{~N} \mathrm{NaOH}$ needed to neutralise $100 \mathrm{ml}$ of gastric juice. The quantity of acid per separate portion of gastric juice was easily obtained by multiplication of volume and acidity. E.g. in a sample of gastric juice, volume $80 \mathrm{ml}$, acidity $120 \mathrm{mmol} \mathrm{H}^{+}$per liter, the quantity of acid present would be $0.080 \times 120=9.6 \mathrm{mmol} / \mathrm{sample}$.

\subsection{Results}

\subsubsection{Introduction to results}

There are several points of interest concerning the acid secretion data.

First: what happens to the acid secretion after HSV?

Second: is there a difference in results between the patients who develop a recurrence and those who do not? 
Third: $\quad$ is there any difference in acid secretion between male and female patients?

Fourth: which component determining acid secretion is affected most?

In an attempt to unravel possible factors of influence all patients were subdivided into 4 groups: men with and without a recurrence, and women with and without a recurrence. From these data other categories of interest could be composed:

all men opposed to all women, and all patients with a recurrence opposed to those without.

Since there were only two women with a recurrence their comparison as a separate group with any other group is statistically not very valuable. The best way of stating anything about the difference between patients with a recurrence as opposed to those without is to compare the male patients with a recurrence against those without a recurrence.

Similarly any statement about the difference between male and female patients could be biased if the patients with a recurrence are not excluded. Since in many reports only overall figures are given (all patients together, men compared to women, and patients with a recurrence compared to those without) these data are given as well.

Abbreviations: in the tables and figures some symbols have been used for brevity.

all:

o:

Q:

rec:

non-rec:

sd:

n:

post:

pre:

post/pre: all patients, male \& female, including recurrences

men women

patient(s) with a recurrence

patient(s) without a recurrence

standard deviation

number of values or patients

postoperative

preoperative

postoperative value divided by preoperative value, expressed in percent

BAO: basal acid outpul

PAO:

100-post/pre: reduction in percent.

\subsubsection{Basal Acid Output (BAO) results}

$B A O$ results are illustrated in table $\mathrm{I}$ and figure 1 . In this table the average values are shown of all available tests in each period. As explained before, the values obtained after 2,3 or 4 years after operation have been grouped together. In few cases was more than one test of the same patient available within this period; those values have been averaged and this average has been used as one single value. The same is held for values obtained 5,6 or 7 years after operation. The percentual fractions related to the preoperative value are indicated as well (post/pre). The reduction is the value obtained by subtraction of this figure from $100 \%$.

There is a significant decrease of $\mathrm{BAO}$ of about $60 \%$ after operation. A slight increase in the course of years is apparent, but the differences between the postoperative 
values are not significant as calculated with the paired t-test. In table II and figure 2 the data of the patients who did not develop a recurrence (non-rec) are compared to the data of the patients with a recurrence (rec).

Very similar data result if only male patients with and without a recurrence are compared (Table III, figure 3). The differences in postoperative reduction between the two groups were significant, but the difference in preoperative values was not. The distinction between the groups is clear, the recurrences showing a slight reduction followed by an increase ending at a higher level than before operation. The group without a recurrence so far demonstrated a reduction staying constant over the years. However, it is more correct to use for comparison coupled values: i.e. only those postoperative values when there is a corresponding preoperative value present; but all available preoperative values have been used. If all postoperative tests in each patient are averaged resulting in one value, the mean preoperative and mean postoperative values can be compared. The result hereof is shown in table IV for all possible categories.

Preoperatively there were no significant differences. The postoperatively resulting fraction of the preoperative value (post/pre in $\%$ ) showed a clear and significant difference for each group comparing recurrences and non-recurrences. Since there were only two women with a recurrence their statistical influence is only minor. Moreover there was no statistical difference between the men and the women. Therefore for practical purposes in some tables and figures men and women have been taken together without offending the outcome. If only recurrent males are opposed to non-recurrent males a slightly more accentuated picture would result, at the expense of the number of cases for statistical evaluation. So either of the two can be chosen whichever seems the most appropriate.

For completeness the data for men and women without a recurrence have been presented in table $\mathrm{V}$ and figure 4 . Although the absolute values of the female patients were expectedly lower then those of the male patients at all time periods, the differences were not significant.

The above mentioned coupled data give a rather rough impression and they do not show any change over the years which could be present. Moreover, there usually is an excess of preoperative data not matched by corresponding postoperative values. This can lead to a distortion of the preoperative mean value.

Therefore, additionally, strictly coupled values have been calculated and tabulated (table VI) and a graphical representation is shown in figure 5. Strictly coupled data are obtained by only using preoperative values if there are corresponding postoperative data in the period of interest (and conversely). This results in changing preoperative values for comparison with the respective periods, since the population of patients with a test after $1 / 2$ year, 1 year, 2/3/4 years and $5 / 6 / 7$ years is not the same (table VI).

To be able to compare the results altogether a proportional value can be calculated for each period if one single preoperative value is constructed by assimilation. The mean of the respective preoperative values was considered to be the most appropriate preoperative value.

Alternatively the postoperative values (table VII) could be expressed as a percentage of the preoperative value, which is assumed to be $100 \%$. The transformation is shown 
in table VII with the resulting values. Figure 5 shows the diagram of these values. If the preoperative values were assumed to be $100 \%$ and the percentages of table VI were plotted, a similar figure would have resulted, the only difference being one or two preoperative referring points in case two categories are compared. As assessed by Student's t-test for paired observations there was no statistical difference between any of two postoperative values; in other words: the postoperative reduced $\mathrm{BAO}$ remained constant.

In table VIII and figure 6 the strictly coupled values are shown of all patients subdivided into recurrences (recAll) and non-recurrences (non-recAll).

For comparison the graph with the "normal mean" values for the same categories can be represented next to it (figure $7=2$ ). For accuracy the same has been done (table IX and figure 8) for two more properly comparable groups (rec $\sigma^{7}$ and non-rec $\sigma^{\prime}$ ) showing that there is not much difference, compared with table VIII and figure 7 . Again Student's paired t-test did not reveal changes in the postoperative secretory levels which means that the men with a recurrence did not show any change in relation to the preoperative values, whereas the men without a recurrence remained constant at the reduced level.

A study was made of the two factors determining the $\mathrm{BAO}$, being the acid production per time unit.

The factors were: the volume of gastric juice recovered in a certain time period, and the concentration of acid ("acidity" see definition in this chapter) of the specimen. Which of the two was influenced by HSV and to what extent?

The results are shown in the next figures, expressed as percentages of the preoperative values, and in the tables, expressed as their absolute values with their standard deviations (sd), the number of values ( $n$ ) and the percentages as used in the figures (post/pre).

All available values have been used and the data have not been coupled.

In figures $9 \& 10$ and in tables $X \&$ XI the results are given for all patients, including the patients with a recurrence; the reduced volume did not appear to change, whereas the acidity rose in the course of time. The rise after $5 / 6 / 7$ years was significant compared to the value $1 / 2$ year after operation $(0.02 \times p \times 0.05)$, but not compared to the value obtained 2/3/4 years after operation (paired t-test).

When men and women (without a recurrence) were compared (fig. $11 \& 12$, tables XII \& XIII) there was no significant difference, but the rise in acidity in the male group was evident, in comparison with early postoperative values. This rise was, however, not significant. The comparison between patients with and without a recurrence (figure $13 \& 14$, tables XIV \& XV) showed a clearly smaller reduction for the patients with a recurrence in both volume and, even more, in acidity. The differences were often not significant.

The increase in acidity in figure 10 was partially due to the similar increase in the male group (without recurrence) but for another part by the higher values of patients with a recurrence, the influence of whom was proportionally greater at later periods as can be seen from table XV.

The overall postoperative reduction of the volume in patients without a recurrence was $37 \%$; the reduction percentage of the acidity was $45 \%$. 
For patients with a recurrence the mean overall reduction in wolume was $12 \%$ and there was no reduction at all in acidity.

Was there any difference between men and women without a recurrence? The reduction in volume and acidity for men was 37 and $43 \%$ respectively. For women the percentages were: 38 and 51 respectively (no significant difference). The results (see table XVI) were of course similar to the output (BAO) data.

table I

BAO of all patients, mmol/h

\begin{tabular}{|c|c|c|c|c|c|c|c|c|c|c|}
\hline & preop & $1 / 2$ & $\frac{\text { post }}{\text { pre }}$ & 1 & $\frac{\text { post }}{\text { pre }}$ & $2 / 3 / 4$ & $\frac{\text { post }}{\text { pre }}$ & 5617 & $\frac{p o s t}{p r e}$ & yrpostop \\
\hline mean & 6.16 & 2.07 & $34 \%$ & 2.3 & $638 \%$ & 2.69 & $44 \%$ & 3.09 & $50 \%$ & \\
\hline median & 4.30 & 1.10 & & 1.6 & & 1.80 & & 2.20 & & \\
\hline$s d$ & 6.90 & 2.64 & & 2.7 & & 3.47 & & 3.04 & & \\
\hline$n$ & 207 & 143 & & 127 & & 73 & & 51 & & \\
\hline
\end{tabular}

figure 1

$\mathrm{BAO}$ of all patients

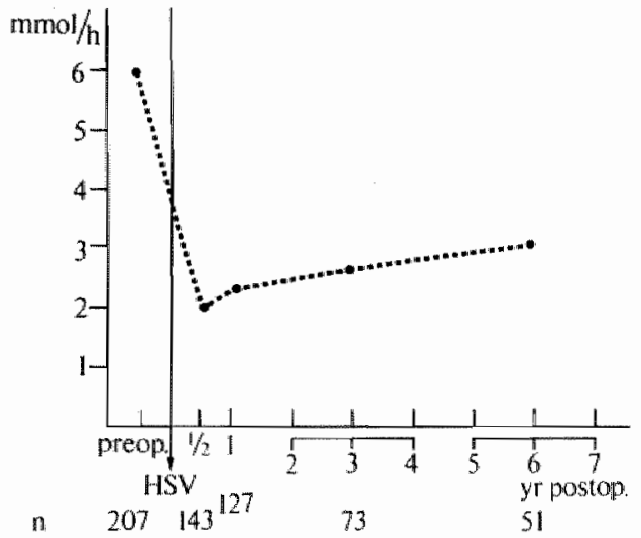

figure 2

BAO of all patients whth and withour a recurtence

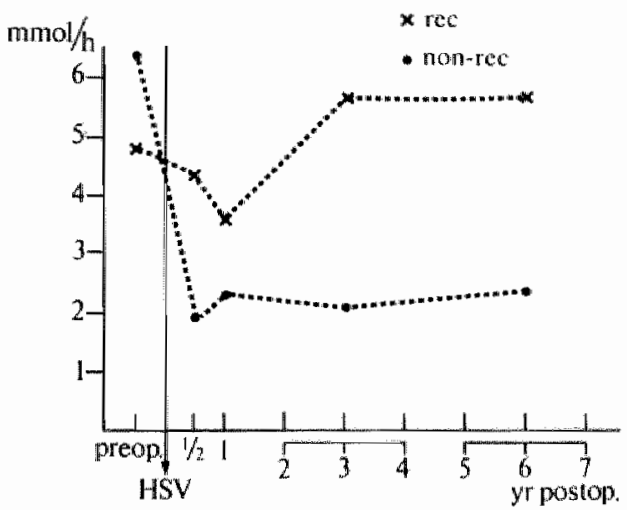

table II

$\mathrm{BAO}$ of all patients with and without a recurrence, mmol/h

\begin{tabular}{|c|c|c|c|c|c|c|c|c|c|c|}
\hline & preop & $t / 2$ & $\frac{\text { post }}{\text { pre }}$ & $l$ & $\frac{\text { post }}{\text { pre }}$ & $2 / 3 / 4$ & $\frac{\text { post }}{\text { pre }}$ & $5 / 617$ & $\frac{\text { post }}{\text { pre }}$ & yr postop \\
\hline rec. mean & 4.72 & 4.26 & $90 \%$ & 3.50 & $74 \%$ & 5.65 & $120 \%$ & 5.65 & $120 \%$ & \\
\hline $\mathrm{sd}$ & 4.01 & 3.60 & & 4.26 & & 6.18 & & 4.59 & & \\
\hline$n$ & 22 & 14 & & 15 & & 13 & & 12 & & \\
\hline $\mathrm{p}$ & ns & $P_{n}(0.00)$ & $*$ & $\mathrm{~ns}$ & * & \multicolumn{2}{|c|}{$p .001$ * } & \multicolumn{2}{|c|}{$p d 0$} & \\
\hline noth-rec me & 06.33 & 1.80 & $28 \%$ & 2.20 & $35 \%$ & 2.04 & $32 \%$ & 2.30 & $36 \%$ & \\
\hline $\mathrm{sd}$ & 7.22 & 2.40 & & 2.43 & & 2.88 & & 2.56 & & \\
\hline $\mathrm{n}$ & 185 & 129 & & 112 & & 60 & & 39 & & \\
\hline
\end{tabular}


table III

$\mathrm{BAO}$ of all men with and without a recurrence, mmol/h

\begin{tabular}{|c|c|c|c|c|c|c|c|}
\hline & & preop & $d / z$ & $l$ & $2 / 3 / 4$ & $516 / 7$ & yrpostop \\
\hline \multirow[t]{4}{*}{$\operatorname{rec} \sigma^{\prime \prime}$} & nuean & 4.52 & 4.47 & 3.60 & 6.02 & 586 & \\
\hline & $\%$ & 100 & 99 & 80 & 133 & 129 & \\
\hline & $\mathrm{sd}$ & 3.88 & 3.65 & 4.43 & 6.18 & 4.54 & \\
\hline & $\mathrm{n}$ & 20 & 13 & 14 & 12 & 10 & \\
\hline $\mathrm{p}$ & & n.s. & $p \cdot 0.001$ & n.s. & porocon & p.o.col & \\
\hline \multirow[t]{4}{*}{ non rec $0^{n}$} & mean & 6.57 & 1.94 & 2.43 & 2.15 & 2.49 & \\
\hline & $\%$ & 100 & 29 & 37 & 33 & 38 & \\
\hline & sd & 7.79 & 2.49 & 2.63 & 2.27 & 1.85 & \\
\hline & $\mathbf{n}$ & 149 & 103 & 89 & 51 & 31 & \\
\hline
\end{tabular}

figure 3

$\mathrm{BAO}$ of all men with and without a recurrence.

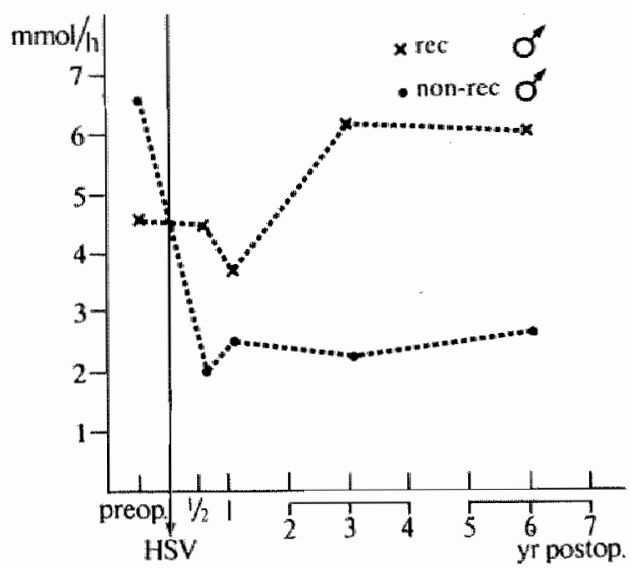

table IV

BAO coupled values, mmol/h

\begin{tabular}{|c|c|c|c|c|c|c|c|c|}
\hline & $\begin{array}{l}\text { mean } \\
\text { preope } \\
\text { value }\end{array}$ & $\begin{array}{l}\text { rative } \\
\text { sd }\end{array}$ & (n) & $\begin{array}{l}\text { mean } \\
\text { postop } \\
\text { wallee }\end{array}$ & $\begin{array}{l}\text { sative } \\
\text { sd }\end{array}$ & $(n)$ & $\frac{\text { post }}{\text { pre }}$ & reduction \\
\hline all & 6.16 & 6.96 & $(207)$ & 2.69 & 2.79 & $(147)$ & $44 \%$ & $56 \%$ \\
\hline $\begin{array}{l}0^{\prime \prime} \\
9\end{array}$ & $\begin{array}{l}6.32 \\
5.42\end{array}$ & $\begin{array}{l}7.46 \\
4.10\end{array}$ & $\begin{array}{l}(169) \\
(38)\end{array}$ & $\begin{array}{l}2.90 \\
1.84\end{array}$ & $\begin{array}{l}2.93 \\
1.91\end{array}$ & $\begin{array}{l}(118) \\
(29)\end{array}$ & $\begin{array}{l}46 \% \\
34 \%\end{array}$ & $\begin{array}{l}54 \% \\
66 \%\end{array}$ \\
\hline $\begin{array}{l}\text { rec } \\
\text { non-rec }\end{array}$ & $\begin{array}{l}4.72 \\
6.33\end{array}$ & $\begin{array}{l}4.01 \\
7.22\end{array}$ & $\begin{array}{l}(22) \\
(185)\end{array}$ & $\begin{array}{l}5.46 \\
2.30\end{array}$ & $\begin{array}{l}5.18 \\
2.02\end{array}$ & $\begin{array}{l}(18) \\
(129)\end{array}$ & $\begin{array}{l}116 \% \\
36 \%\end{array}$ & $\begin{array}{c}0 \\
64 \%\end{array}$ \\
\hline $\begin{array}{l}\text { reco o } \\
\text { non-rec o }\end{array}$ & $\begin{array}{l}4.52 \\
6.57\end{array}$ & $\begin{array}{l}3.84 \\
5.04\end{array}$ & $\begin{array}{l}(20) \\
(149)\end{array}$ & $\begin{array}{l}5.65 \\
2.46\end{array}$ & $\begin{array}{l}5.42 \\
2.06\end{array}$ & $\begin{array}{l}(16) \\
(102)\end{array}$ & $\begin{array}{l}125 \% \\
37 \%\end{array}$ & $\begin{array}{c}0 \\
63 \%\end{array}$ \\
\hline $\begin{array}{l}\text { rec } q \\
\text { non-tec } q\end{array}$ & $\begin{array}{l}6.75 \\
5.35\end{array}$ & $\begin{array}{l}6.57 \\
4.06\end{array}$ & $\begin{array}{l}(2) \\
(36)\end{array}$ & $\begin{array}{l}3.88 \\
1.69\end{array}$ & $\begin{array}{l}3.08 \\
1.80\end{array}$ & $\begin{array}{l}(2) \\
(27)\end{array}$ & $\begin{array}{l}57 \% \\
32 \%\end{array}$ & $\begin{array}{l}43 \% \\
68 \%\end{array}$ \\
\hline
\end{tabular}


table V

BAO of men and women without a recurrence. mmolh

\begin{tabular}{|c|c|c|c|c|c|c|}
\hline & preop & $y / z$ & 1 & $2 / 3 / 4$ & 5,677 & yrpostop \\
\hline \multicolumn{7}{|l|}{ non-ree $0^{7}$} \\
\hline mesn & 6.57 & 1.94 & 2.43 & 2.15 & 2.49 & \\
\hline$\%$ & 100 & 29 & 37 & 33 & 38 & \\
\hline $\mathrm{sdl}$ & 7.99 & 2.49 & 2.63 & 2.27 & 1.85 & \\
\hline $\mathrm{n}$ & 149 & 103 & 89 & 51 & 31 & \\
\hline p & $\mathrm{m} . \mathrm{s}$ & n.s. & an.s. & n.s. & n.s. & \\
\hline \multicolumn{7}{|l|}{ non-rece } \\
\hline mean & 5.35 & 1.41 & 1.32 & 1.86 & 1.53 & \\
\hline$\%$ & 100 & 26 & 25 & 35 & 29 & \\
\hline $\mathrm{sd}$ & 4.06 & 2.16 & 1.31 & 1.75 & 1.67 & \\
\hline $\mathrm{n}$ & 36 & 27 & 23 & 13 & 9 & \\
\hline
\end{tabular}

figure 4

$\mathrm{BAO}$ of men and wornen without a rectirrence.

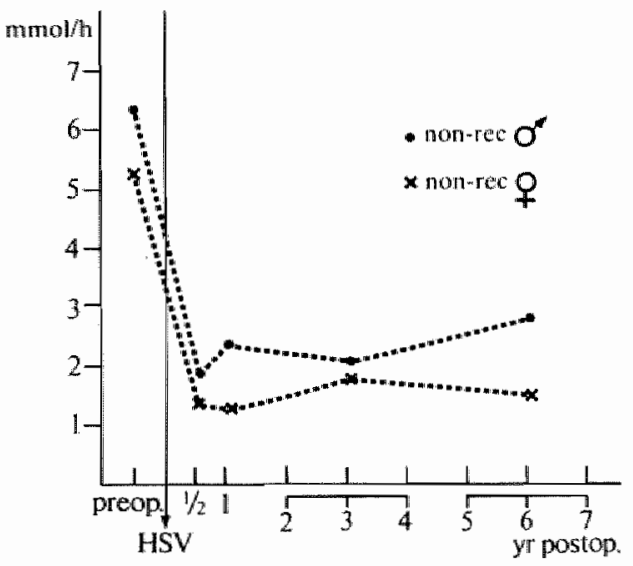

table VI

BAO of all patients, strictly coupled values, mol/h

\begin{tabular}{|c|c|c|c|c|c|c|}
\hline & preop & $1 / 2$ & l & $2 / 3 / 4$ & $5 / 617$ & yr postop \\
\hline $\begin{array}{l}\text { mean } \\
\text { postipre } \\
\text { sd(n) }\end{array}$ & $\begin{array}{l}5.89 \\
5.75(112)\end{array}$ & $\begin{array}{l}2.25 \\
38 \% \\
2.73(112)\end{array}$ & & & & \\
\hline $\begin{array}{l}\text { mean } \\
\text { post/pre } \\
\text { sd }(n)\end{array}$ & $\begin{array}{l}5.59 \\
5.4(99)\end{array}$ & & $\begin{array}{l}2.49 \\
44 \% \\
3.10(99)\end{array}$ & & & \\
\hline $\begin{array}{l}\text { nean } \\
\text { post/pre } \\
\text { sd (n) }\end{array}$ & $\begin{array}{l}7.46 \\
7.97(64)\end{array}$ & & & $\begin{array}{l}2.77 \\
37 \% \\
2.94(64)\end{array}$ & & \\
\hline $\begin{array}{l}\text { mean } \\
\text { post/pre } \\
\text { so }(n)\end{array}$ & $\begin{array}{l}5.115 \\
4.48(44)\end{array}$ & & & & $\begin{array}{l}3.38 \\
66 \% \\
2.54(44)\end{array}$ & \\
\hline
\end{tabular}


figure 5

$\mathrm{A} A \mathrm{O}$ of all patients, strictly coupled wallus

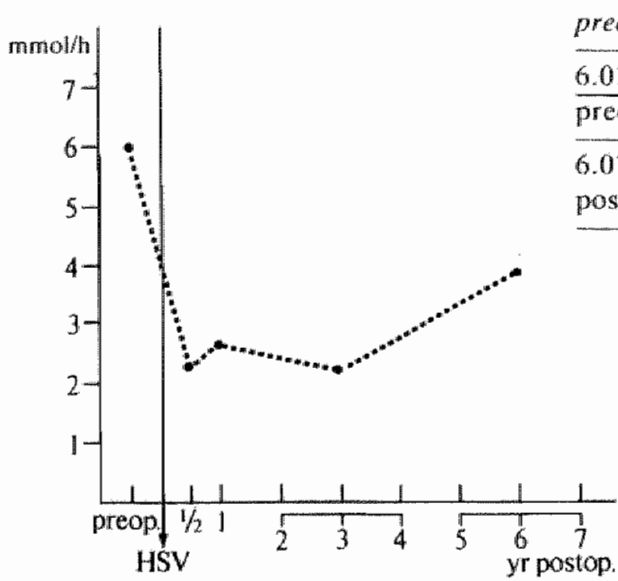

table VII

BA O transformation to one preoperative average (6.01), $\mathrm{mmol} / \mathrm{h}$

\begin{tabular}{|c|c|c|c|c|c|}
\hline preop & $s / z$ & $l$ & $2 / 3 / 4$ & $5 / 6 / 7$ & yr posslop \\
\hline$\frac{6.01}{\text { preop preop }}$ & $\frac{6.01}{5.89} \times 2.25$ & $\frac{6.01}{5.59} \times 2.49$ & $\frac{6.01}{7.46} \times 2.77$ & $\frac{6.01}{5.15} \times 3.38$ & \\
\hline 6.01 & 2.30 & 2.68 & 2.23 & 3.94 & \\
\hline postpre & $38 \%$ & $44 \%$ & $37 \%$ & $66 \%$ & \\
\hline
\end{tabular}

\section{table VIII}

BAO of all patients with and without a recurdence, strictly coupled values, $\mathrm{mmol} / \mathrm{h}$

\begin{tabular}{|c|c|c|c|c|c|c|}
\hline & preop & $1 / 2$ & $I$ & $2 / 3 / 4$ & $5 / 6 / 7$ & yrpostop \\
\hline rec all mean & 5.90 & 3.91 & 3.41 & 6.01 & 6.39 & \\
\hline postipre & & $66 \%$ & $58 \%$ & $102 \%$ & $108 \%$ & \\
\hline n & & 13 & 13 & 13 & 11 & \\
\hline non-rec all mean & 6.04 & 2.07 & 2.55 & 1.54 & 2.99 & \\
\hline postpre & & $34 \%$ & $42 \%$ & $25 \%$ & $49 \%$ & \\
\hline $\mathrm{n}$ & & 99 & 86 & 51 & 33 & \\
\hline
\end{tabular}

\section{rigures of}

MAO of all patiches with and without a recurrence strictly coupled values.

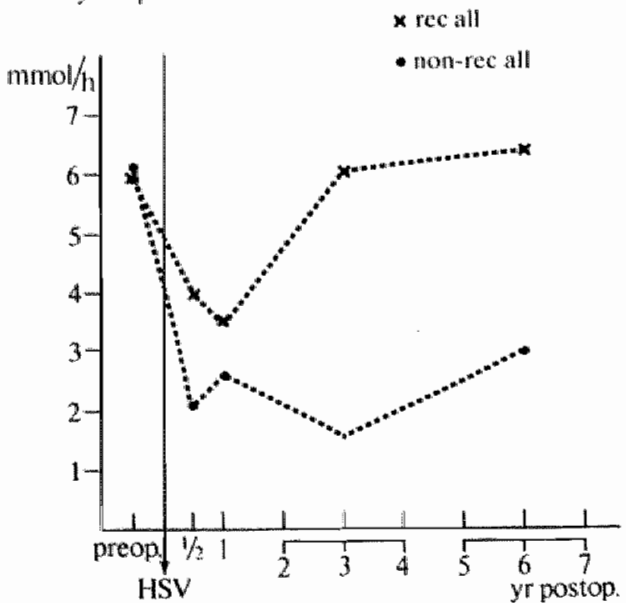

figure? 7

$(=2)$ BAO of all pailents with and without a recurrence

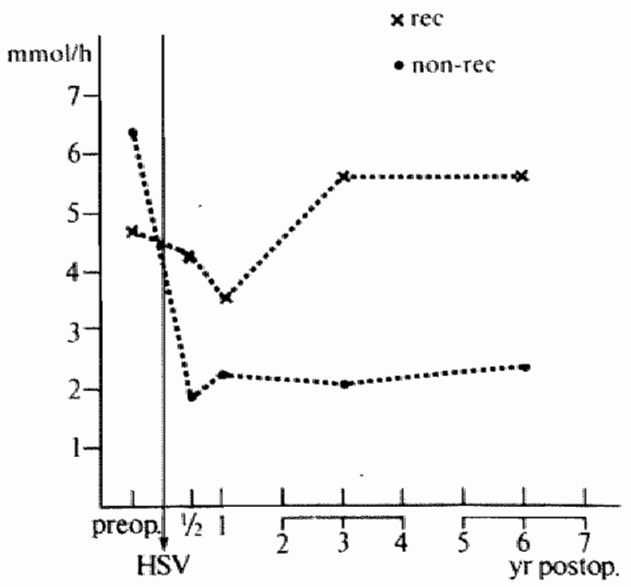


figure 8

$\mathrm{BAO}$ of men with and without a recurrence strictly compled walues

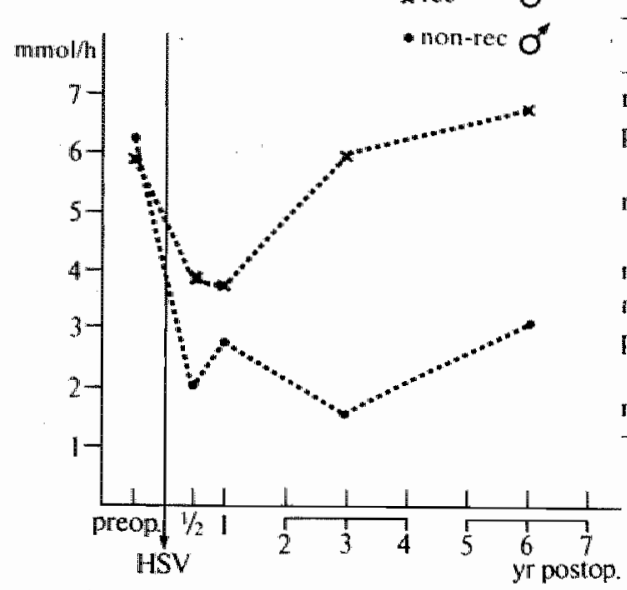

figure 9

BAO, volmene, all:

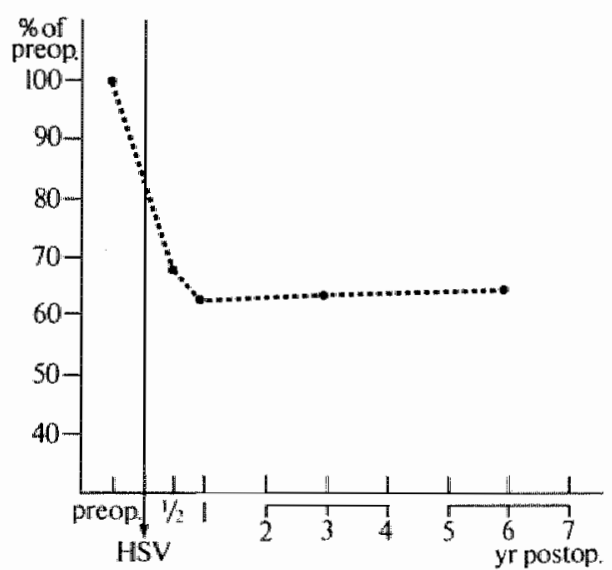

figure 10

$B A O$, acidity, all

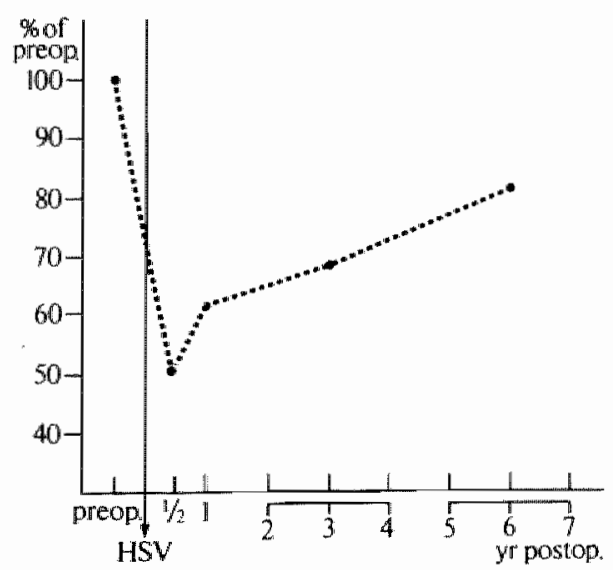

table IX

$\mathrm{BAO}$ of men with and without a rectrence.

strictly coupled values, mmolh

\begin{tabular}{|c|c|c|c|c|c|c|}
\hline & preop & $1 / 2$ & i & $2 / 3 / 4$ & 5617 & yrpostop \\
\hline $\begin{array}{l}\text { reco mean } \\
\text { post/pre }\end{array}$ & 5.91 & $\begin{array}{l}3.90 \\
66 \%\end{array}$ & $\begin{array}{l}3.80 \\
64 \%\end{array}$ & $\begin{array}{l}6.09 \\
103 \%\end{array}$ & $\begin{array}{l}6.98 \\
116 \%\end{array}$ & \\
\hline$n$ & & 12 & 12 & 12 & 9 & \\
\hline \multicolumn{7}{|l|}{ non-rec $O^{\circ}$} \\
\hline mean & 6.30 & 2.12 & 2.85 & 1.65 & 3.26 & \\
\hline post/pre & & $34 \%$ & $45 \%$ & $26 \%$ & $52 \%$ & \\
\hline $\mathrm{n}$ & & 81 & 68 & 40 & 26 & \\
\hline
\end{tabular}

table $X$

$\mathrm{BAO}$, wolumie, $\mathrm{ml} / \mathrm{h}$

\begin{tabular}{lllllll}
\hline & preop & $\%$ & $I$ & $2 / 3 / 4$ & $5 / 6 / 7$ & yr posiop \\
\hline maan & 126.3 & 86.7 & 80.2 & 80.7 & 82.7 \\
$\%$ & $100 \%$ & $69 \%$ & $63 \%$ & $64 \%$ & $65 \%$ & \\
sd & 91.9 & 47.2 & 46.3 & 44.3 & 39.0 \\
n & 209 & 143 & 127 & 79 & 57 \\
\hline
\end{tabular}

table XI

BAO, acidity, all, mmol/l

\begin{tabular}{lllllll}
\hline & preop & $1 / 2$ & $l$ & 23,4 & $56 \% 7$ & yrposiop \\
mean & 42.9 & 21.8 & 26.6 & 29.4 & 35.7 & \\
$\%$ & $100 \%$ & $51 \%$ & $62 \%$ & $69 \%$ & $\mathbf{8 3 \%}$ & \\
sd & 23.7 & 19.2 & 21.5 & 23.6 & 26.9 & \\
$\mathrm{n}$ & 209 & 143 & 127 & 79 & 57 &
\end{tabular}


tigure 1

BAO, valume, men and women withoul at recurrence

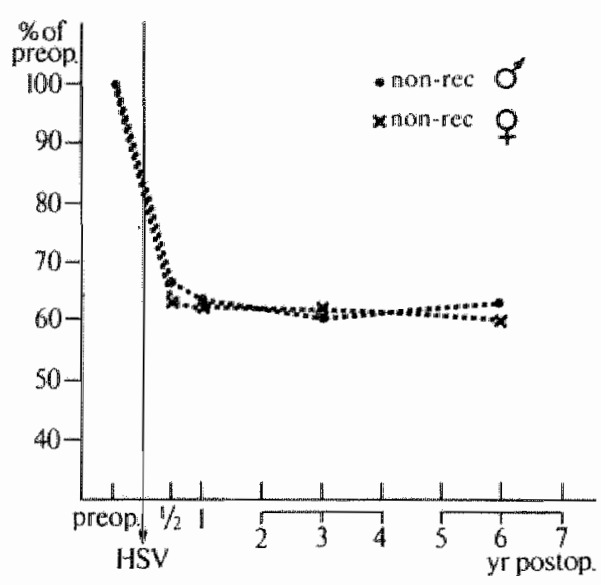

Nigure 12

BAO, acidity, men and women without a recurrence

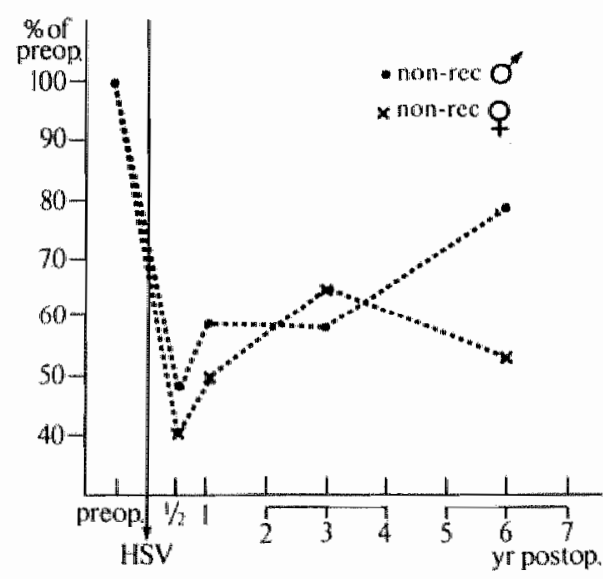

\section{Iable XII}

BAO, volume, ml/h, men with and without a recurrence

\begin{tabular}{|c|c|c|c|c|c|c|}
\hline & preop & $1 / 2$ & 1 & 21314 & $5 / 617$ & yi postop \\
\hline \multicolumn{7}{|c|}{ non-rec $\sigma^{2}$} \\
\hline mearn & 131.4 & 86.8 & 82.2 & 79.4 & 82.9 & \\
\hline$\%$ & $100 \%$ & $66 \%$ & $63 \%$ & $60.4 \%$ & $63 \%$ & \\
\hline $\mathrm{sd}$ & 98.9 & 44.7 & 49.3 & 44.1 & 35.0 & \\
\hline I) & 151 & 102 & 89 & 51 & 32 & \\
\hline $\mathrm{p}$ & n. s. & $\mathrm{n} . \mathrm{s}$ & n.s. & n.s. & n.s. & \\
\hline \multicolumn{7}{|c|}{ non-rec? } \\
\hline mean & 117.7 & $7 A 4.5$ & 73.2 & 71.6 & 71.1 & \\
\hline$\%$ & $100 \%$ & $63 \%$ & $62 \%$ & $61 \%$ & 600 & \\
\hline $\mathrm{sd}$ & 64.6 & 49.9 & 33.2 & 35.9 & 25.1 & \\
\hline D) & 36 & 27 & 23 & 13 & 9 & \\
\hline
\end{tabular}

table XIII

$\mathrm{BAO}$, acidity, mmol/l, men with and without a recurrence

\begin{tabular}{|c|c|c|c|c|c|c|}
\hline & preop & $1 / 2$ & 1 & $2 / 3 / 4$ & $5 / 617$ & yrpostop \\
\hline \multicolumn{7}{|c|}{ mon-itec $\sigma^{*}$} \\
\hline mean & 43.4 & 20.7 & 25.7 & 254 & 34.0 & \\
\hline$\%$ & $100 \%$ & $48 \%$ & $59 \%$ & $58 \%$ & $78 \%$ & \\
\hline $\mathrm{sct}$ & 23.5 & 18.5 & 20,3 & 21.4 & 22.1 & \\
\hline$n$ & 151 & 102 & 89 & 51 & 32 & \\
\hline$p$ & ns.s. & n.s. & n.s. & n.s. & n.s. & \\
\hline \multicolumn{7}{|c|}{ non-rec 9} \\
\hline mean & 42.1 & 10.9 & 21.1 & 27.3 & 21.8 & \\
\hline$\%$ & $100 \%$ & $40 \%$ & $50 \%$ & $65 \%$ & $52 \%$ & \\
\hline $\mathrm{sd}$ & 22.5 & 19.0 & 16.3 & 19.6 & 21.9 & \\
\hline$n$ & 36 & 27 & 23 & 13 & 9 & \\
\hline
\end{tabular}


Figure 13

BAO, volume, men with and without a recurtence

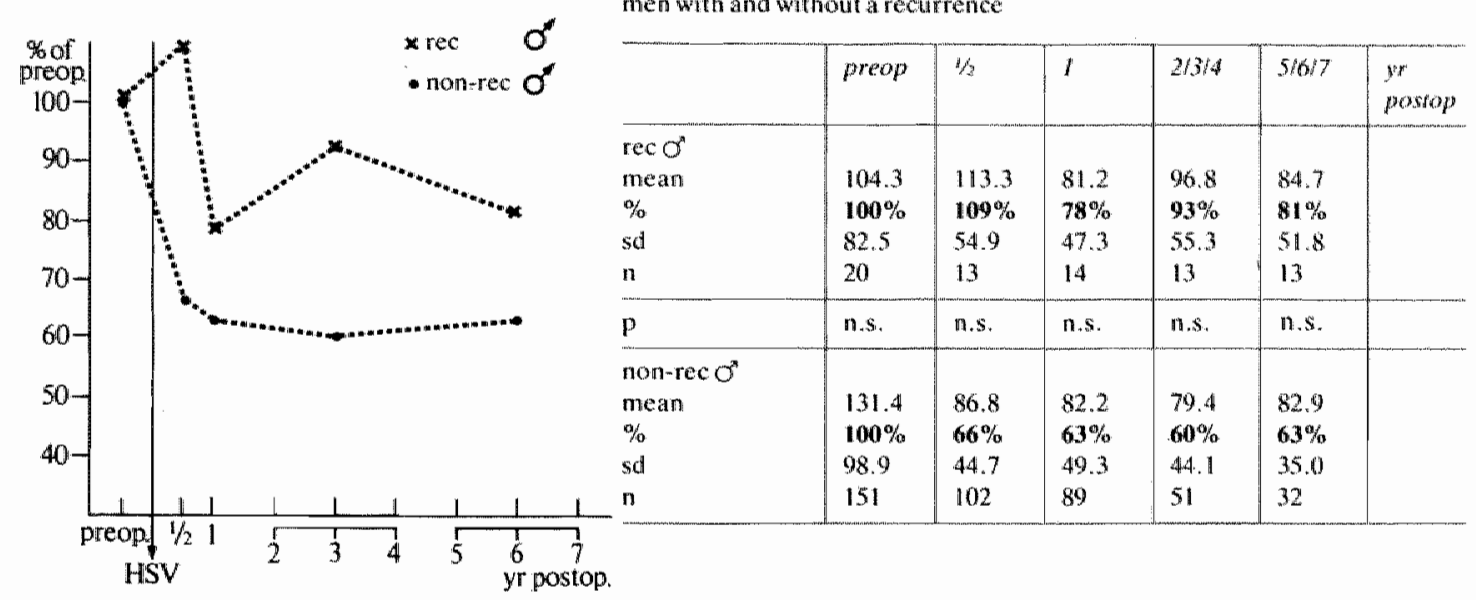

table XIV

BAO, volume, mlih

A

\begin{tabular}{|c|c|c|c|c|c|c|}
\hline & preop & $1 / 3$ & 1 & $213 / 4$ & 5867 & $\begin{array}{l}\text { pr } \\
\text { porrop }\end{array}$ \\
\hline $\begin{array}{l}\text { rec o } \\
\text { mean } \\
\text { \% } \\
\text { sd } \\
n\end{array}$ & $\begin{array}{l}104.3 \\
100 \% \\
82.5 \\
20\end{array}$ & $\begin{array}{l}113.3 \\
109 \% \\
54.9 \\
13\end{array}$ & $\begin{array}{l}81.2 \\
78 \% \\
47.3 \\
14\end{array}$ & $\begin{array}{l}96.8 \\
93 \% \\
5.5 .3 \\
13\end{array}$ & $\begin{array}{l}64.7 \\
81 \% \\
51.8 \\
13\end{array}$ & \\
\hline $\mathrm{P}$ & n.s. & n.s. & $\mathrm{n} . \mathrm{s}$ & M.s. & $\mathrm{n}, \mathrm{s}$ & \\
\hline $\begin{array}{l}\text { non-rec } 0^{3} \\
\text { mean } \\
\alpha \\
\text { sid } \\
n\end{array}$ & $\begin{array}{l}131.4 \\
100 \% \\
98.9 \\
151\end{array}$ & $\begin{array}{l}86.8 \\
66 \% \\
44.7 \\
102\end{array}$ & $\begin{array}{l}82.2 \\
63 \% \\
49.3 \\
89\end{array}$ & $\begin{array}{l}7 \% .41 \\
60 \% \\
44.1 \\
51\end{array}$ & $\begin{array}{l}82.9 \\
6.3 \% \\
3.5 .0 \\
32\end{array}$ & \\
\hline
\end{tabular}

flgure 14

$\mathrm{BAO}$, acidity, men with and without at recurrence

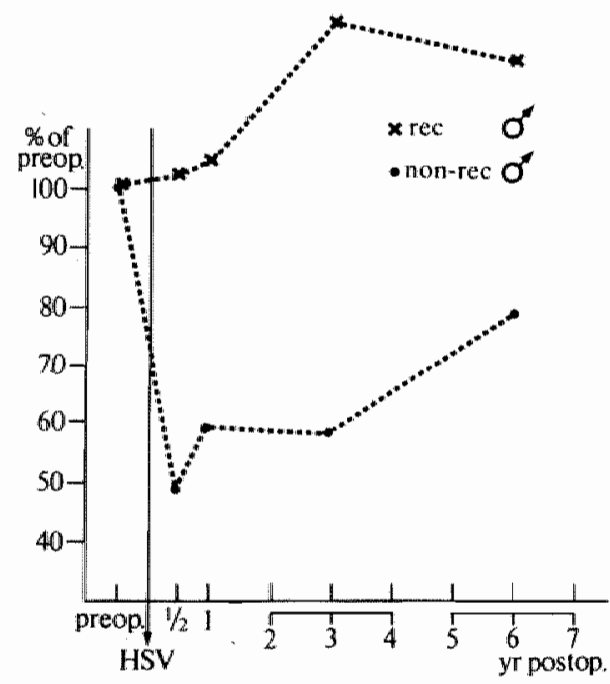

\section{table XV}

$B A O$, acidity, mmolll

men with and without a recurtence

\begin{tabular}{|c|c|c|c|c|c|c|}
\hline & preop & $1 / y$ & 1 & $2 / 3 / 4$ & $5 / 617$ & $\begin{array}{l}y r \\
\text { postop }\end{array}$ \\
\hline $\begin{array}{l}\text { reco } 0^{m} \\
\text { mean } \\
\% \\
\text { sd } \\
n\end{array}$ & $\begin{array}{l}38.5 \\
100 \% \\
24.4 \\
20\end{array}$ & $\begin{array}{l}39.1 \\
102 \% \\
18.0 \\
13\end{array}$ & $\begin{array}{l}39.9 \\
104 \% \\
31.5 \\
14\end{array}$ & $\begin{array}{l}49.2 \\
128 \% \\
311.8 \\
13\end{array}$ & $\begin{array}{l}46.8 \\
122 \% \\
37.2 \\
13\end{array}$ & \\
\hline$p$ & n.s. & ${ }^{*} \mathrm{p} 0.001$ & $n_{1}=\mathrm{s}$ & $* 00.02$ & at.s. & \\
\hline $\begin{array}{l}\text { non-rec or } \\
\text { mean } \\
\text { so } \\
\text { so } \\
\text { n }\end{array}$ & $\begin{array}{l}43.4 \\
100 \% \\
23.5 \\
1.51\end{array}$ & $\begin{array}{l}20.8 \\
48 \% \\
18.5 \\
102\end{array}$ & $\begin{array}{l}25.7 \\
59 \% \\
20.3 \\
89\end{array}$ & $\begin{array}{l}25.40 \\
58 \% \\
21.4 \\
51\end{array}$ & $\begin{array}{l}3 \% 1 \\
79 \% \\
22.1 \\
32\end{array}$ & \\
\hline
\end{tabular}


$B A O$ overall reduction, wolume and acidity

\begin{tabular}{|c|c|c|c|c|c|c|}
\hline & \multicolumn{3}{|c|}{ volume $(m / h)$} & \multicolumn{3}{|c|}{ acidily (mmollo) } \\
\hline & $\begin{array}{l}\text { preop } \rightarrow \text { postop } \\
\text { mmolil }\end{array}$ & postipre & reduction & $\begin{array}{l}\text { preop } \rightarrow \text { postop } \\
\text { mmoll }\end{array}$ & postlpre & reduction \\
\hline all & $126.3 \rightarrow 82.9$ & $66 \%$ & $34 \%$ & $42.9 \rightarrow 26.7$ & $62 \%$ & $38 \%$ \\
\hline O' all & $128.2-85.1$ & $66 \%$ & $34 \%$ & $42.8 \longrightarrow 27.8$ & $65 \%$ & $35 \%$ \\
\hline Q all & $117.5-73.8$ & $63 \%$ & $37 \%$ & $43.1 \rightarrow 22.1$ & $51 \%$ & $49 \%$ \\
\hline recall & $105.0 \rightarrow 92.3$ & $88 \%$ & $12 \%$ & $40.7-42.8$ & $105 \%$ & $0 \%$ \\
\hline non-recall & $129.1 \rightarrow 81.2$ & $63 \%$ & $37 \%$ & $43.2 \rightarrow 23.9$ & $55 \%$ & $45 \%$ \\
\hline $\operatorname{rec} \sigma^{\prime \prime}$ & $104.3 \rightarrow 93.8$ & $100 \%$ & $10 \%$ & $38.5 \rightarrow 43.7$ & $113 \%$ & $0 \%$ \\
\hline non-rec $\sigma^{*}$ & $131.8 \rightarrow 83.3$ & $63 \%$ & $37 \%$ & $4.3 .5 \rightarrow 24.7$ & $57 \%$ & $43 \%$ \\
\hline $\operatorname{rec} 9$ & $112.5 \rightarrow 76.3$ & $68 \%$ & $32 \%$ & $62.0-34.8$ & $56 \%$ & $44 \%$ \\
\hline non-rec? & $117.7 \rightarrow 73.1$ & $62 \%$ & $38 \%$ & $42.1 \rightarrow 20.7$ & $49 \%$ & $51 \%$ \\
\hline
\end{tabular}

\subsubsection{PAO results}

PAO data have been worked out in a similar way as with BAO.

The PAO results of the whole group have been presented in table XVII and figure 15 . There was a significant reduction of about $50 \%$ remaining constant over the years.

The results for patients with and without a recurrence (table XVIII and figure 16) showed a significant difference at $1 / 2$ and 1 year after operation, the reduction in the patients with a recurrence being less. The difference at $2 / 3 / 4$ years after operation was below the $5 \%$ level of significance and the values after $5 / 6 / 7$ years postoperatively showed no difference at all.

If only the data of the male patients with and without a recurrence were used there appeared to be hardly any difference (table XIX and figure 17).

The overall coupled data, comparing the mean preoperative and mean postoperative values of all relevant categories, are listed in table XX. The trends in difference are simillar to the BAO coupled values but much less pronounced. The reduction in the two women who developed a recurrence was less then in the women who did not, although not significantly so, but was in the same range as the men without a recurrence and much better than the male patients with a recurrence.

In table XXI and figure 18 the data concerning men and women without a recurrence are shown, representing the best way of demonstrating a possible difference in PAO between men and women after HSV. There was at all periods a difference between men and women only reaching significance at $5 / 6 / 7$ years after operation. However, relatively few women had a test performed in that period.

Using strictly coupled data worked out as described under BAO results the postoperative reduction of the PAO of about $50 \%$ was confirmed (table XXII, XXIII and fig. 19).

Comparing men with and without a recurrence revealed a slight difference at all periods but only once almost significant (table XXIV and fig. 20). The reduction in 
the men without a recurrence was nevertheless better, being $49 \%, 53 \%, 62 \%$ and $48 \%$ respectively $1 / 2,1,2 / 3 / 4$ and $5 / 6 / 7$ years after operation; the figures for patients with a recurrence were $38 \%, 45 \%, 39 \%$ and $49 \%$ respectively.

However, in patients without a recurrence there was a significant increase $(\mathrm{p}=$ 0.027 ) of the $5 / 6 / 7$ year value un comparison with the $2 / 3 / 4$ year value. In patients with a recurrence there was a continuing decrease of $\mathrm{PAO}$ after $1 / 2$ year postoperatively, only being significant $(p=0.01)$ in comparison with the value $5 / 6 / 7$ years after operation (paired $t$-test).

The PAO results in men and women (table XXV and fig. 21) showed slightly lower values for the women at all periods, including preoperatively, but this was not significant in spite of a considerable graphical difference at 5/6/7 years after operation. Possibly the number of female patients was too small to attain sufficient statistical accuracy.

The same analysis with volume and acidity was performed as was done with the BAO data. The volume figures have been expressed in milliliters per 15 minutes.

The overall data of the volume and the acidity (table XXVI, XXVII and fig. 22, 23) showed a postoperative reduction of the volume of about $57 \%$ and a reduction of the acidity of around $18 \%$.

The differences between men with and without a recurrence was not very clear; neither the volume nor the acidity was clearly deviating. The only significant difference was found in the acidity $1 / 2$ year after operation (table XXVIII, XXIX and fig. 24 , 25).

Men and women (without a recurrence) did not always show a statistically significant difference, although in general the values of the female patients were lower both relatively and absolutely. The acidity in the men, however, increased significantly between $2 / 3 / 4$ and $5 / 6 / 7$ years (paired t-test, $0.02<\mathrm{p}<0.01$ ) as did the acid output (table XXX, XXXI and fig. 26,27).

Table XXXII shows the overall reduction results for all categories. There was a slight difference between patients with a recurrence as compared to those without; also there was a difference between men and women. Both differences however were not significant. 
table XVII

PAO of all paticnts, mmol/h

\begin{tabular}{|c|c|c|c|c|c|c|c|c|c|c|}
\hline & preop & $1 / 2$ & $\frac{p o s t}{p r e}$ & I & $\frac{\text { post }}{\text { pre }}$ & 21314 & $\frac{p o s t}{\text { pre }}$ & $5 / 617$ & $\frac{\text { post }}{\text { pre }}$ & $\begin{array}{l}\text { yr } \\
\text { postop }\end{array}$ \\
\hline mean & 56.1 & 28.2 & $59 \%$ & 25.9 & $46 \%$ & 25.7 & $46 \%$ & 28.3 & $50 \%$ & \\
\hline median & 53.5 & 248 & & 24.0 & & 25.6 & & 28.1 & & \\
\hline $\mathrm{sd}$ & 24.2 & 16.1 & & 13.6 & & 13.0 & & 12.6 & & \\
\hline$(n)$ & 212 & 144 & & 127 & & 73 & & 51 & & \\
\hline
\end{tabular}

figure. 15

$\mathrm{PAO}$, all patients

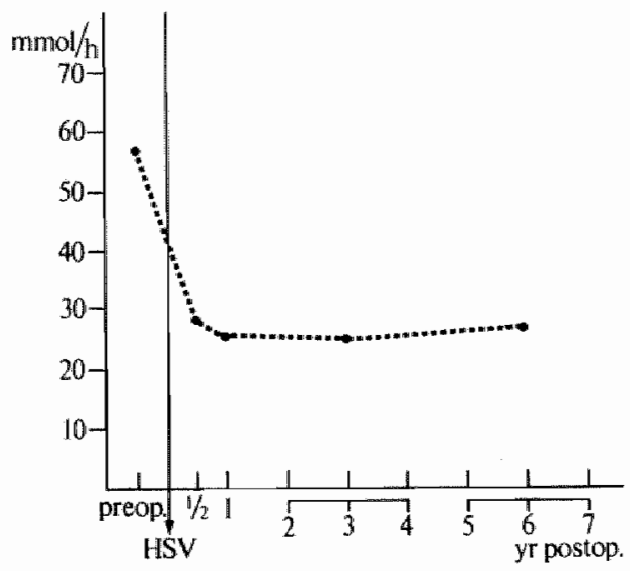

figure 16

PAO, all patients with and without a recurrence

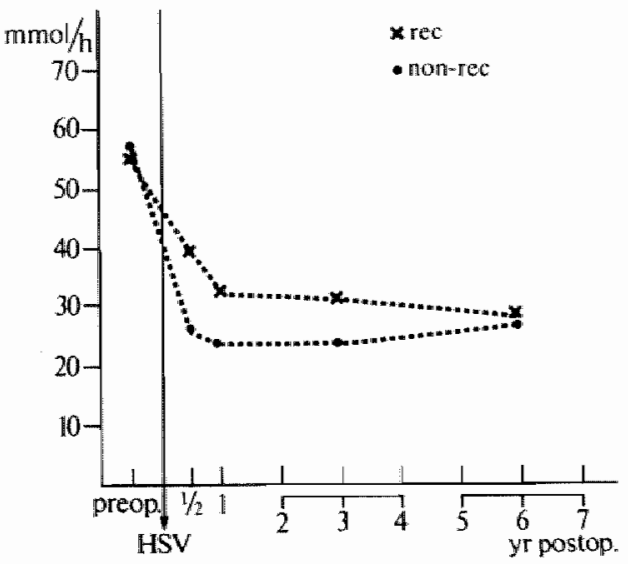

Lable XVIII

PAO ol all patients with and without a recurrence, mmol/h

\begin{tabular}{|c|c|c|c|c|c|c|c|c|c|c|c|}
\hline & & preop & $1 / z$ & $\frac{\text { post }}{\text { pre }}$ & 1 & $\frac{p o s t}{p r e}$ & $2 / 3 / 4$ & $\frac{\text { post }}{\text { pre }}$ & $5 / 677$ & $\frac{\text { post }}{\text { pre }}$ & $\begin{array}{l}y r \\
\text { postop }\end{array}$ \\
\hline \multirow[t]{2}{*}{ recall } & $\begin{array}{l}\text { mean } \\
\text { sd } \\
n\end{array}$ & $\begin{array}{l}56.3 \\
25.9 \\
22\end{array}$ & $\begin{array}{l}39.8 \\
20.3 \\
14\end{array}$ & $71 \%$ & $\begin{array}{l}3.3 .2 \\
17.1 \\
15\end{array}$ & $59 \%$ & $\begin{array}{l}32.3 \\
12.7 \\
12\end{array}$ & $57 \%$ & $\begin{array}{l}28.9 \\
12.6 \\
12\end{array}$ & $51 \%$ & \\
\hline & $\mathrm{p}$ & n.s. & $* p<$ & 0.01 & $p<$ & 0.05 & ins.s. & & n.s. & & \\
\hline non-rec sll & $\begin{array}{l}\text { mean } \\
\text { sell } \\
\text { n) }\end{array}$ & $\begin{array}{l}56.1 \\
24.1 \\
199\end{array}$ & $\begin{array}{l}26.9 \\
5.3 \\
130\end{array}$ & $48 \%$ & $\begin{array}{l}24.9 \\
12.8 \\
112\end{array}$ & $44 \%$ & $\begin{array}{l}24.4 \\
13.0 \\
6 !\end{array}$ & $43 \%$ & $\begin{array}{l}28.2 \\
12.6 \\
40\end{array}$ & $50 \%$ & \\
\hline
\end{tabular}


table XIX

PAO, men with and without a recurrence, mmol/h

\begin{tabular}{|c|c|c|c|c|c|c|c|}
\hline & & preop & $/ / 2$ & I & $2 / 3 / 4$ & 51677 & yr posstop \\
\hline reco ${ }^{\prime \prime}$ & mean & 57.4 & 41.6 & 33.6 & 33.4 & 29.5 & \\
\hline & $\%$ & $100 \%$ & $72 \%$ & $58 \%$ & $58 \%$ & $51 \%$ & \\
\hline & $\mathrm{sd}$ & 27.0 & 20.0 & 17.7 & 11.4 & 14.1 & \\
\hline & $n$ & 20 & 13 & 14 & 11 & 10 & \\
\hline & $\mathrm{p}$ & n.s. & $p p<0.02$ & ${ }^{2} p<0.05$ & n.s. & n.s. & \\
\hline non $-\mathrm{rec}$ & mean & 57.4 & 28.2 & 25.6 & 25.8 & 31.5 & \\
\hline$\sigma^{m}$ & $\%$ & $100 \%$ & $40 \%$ & $45 \%$ & $45 \%$ & $55 \%$ & \\
\hline & $\mathrm{sd}$ & 24.4 & 16.1 & 12.1 & 13,0 & 13.4 & \\
\hline & $\mathrm{n}$ & 154 & 103 & 89 & 48 & 31 & \\
\hline
\end{tabular}

figure 17
PAO, men with and without a recurrence mmol/ $/ \mathrm{h}$

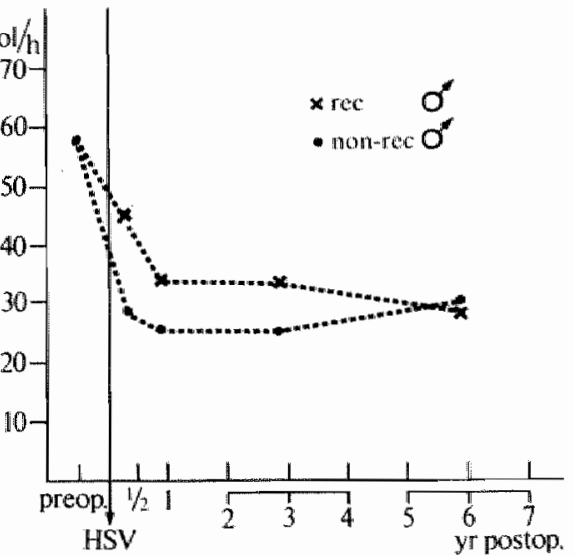

\section{table XX}

PAO, coupled values, mmol/h

\begin{tabular}{|c|c|c|c|c|c|c|c|c|}
\hline & \multicolumn{3}{|c|}{$\begin{array}{l}\text { mean } \\
\text { preoperative }\end{array}$} & \multicolumn{3}{|c|}{$\begin{array}{l}\text { mean } \\
\text { postoperative }\end{array}$} & $\frac{\text { post }}{\text { pre }}$ & reduction \\
\hline all & 56.1 & 24.2 & $(212)$ & 27.3 & 12.9 & $(162)$ & $49 \%$ & $51 \%$ \\
\hline$\infty$ & 57.4 & 24.7 & $(174)$ & 28.9 & 13.3 & $(130)$ & $50 \%$ & $50 \%$ \\
\hline 9 & 50.2 & 21.3 & (38) & 21.0 & 9.3 & (32) & $42 \%$ & $58 \%$ \\
\hline $\mathrm{rec}$ & 56.3 & 25.9 & (22) & 33.7 & 13.7 & (19) & $60 \%$ & $40 \%$ \\
\hline non-rec & 56.1 & 24.1 & $(190)$ & 26.5 & 12.7 & (143) & $47 \%$ & $53 \%$ \\
\hline $\operatorname{rec} \phi^{n}$ & 57.4 & 27.0 & $(20)$ & 35.1 & 13.7 & (17) & $61 \%$ & $39 \%$ \\
\hline non-rec on & 57.4 & 24.4 & $(154)$ & 27.9 & 13.0 & $(113)$ & $49 \%$ & $51 \%$ \\
\hline $\operatorname{mec} ?$ & 44.8 & 10.6 & (2) & 21.4 & 3.4 & (2) & $48 \%$ & $52 \%$ \\
\hline non-rec? & 50.5 & 21.9 & (36) & 21.0 & 9.6 & (30) & $42 \%$ & $58 \%$ \\
\hline
\end{tabular}


table XXI

$P A O$, men and women without a recurrence, mmolh

\begin{tabular}{|c|c|c|c|c|c|c|}
\hline & preop & $/ / 2$ & 1 & $2 / 3 / 4$ & $5 / 617$ & yrpostop \\
\hline \multicolumn{7}{|l|}{ non-reco } \\
\hline mean & 57.4 & 28.2 & 25.6 & 25.7 & 31,4 & \\
\hline$\%$ & $100 \%$ & $49 \%$ & $45 \%$ & $45 \%$ & $55 \%$ & \\
\hline$s d$ & 24.4 & 16.1 & 12.1 & $12 \ldots$ & 11.4 & \\
\hline $\mathrm{n}$ & 154 & 103 & 89 & 51 & 31 & \\
\hline$p$ & n.s. & $\pi . s$. & n.s. & n.s. & ${ }^{*} p<0.01$ & \\
\hline \multicolumn{7}{|l|}{ non-ree? } \\
\hline mean & 50.5 & 22.1 & 22.1 & 19.5 & 16.6 & \\
\hline$\%$ & $100 \%$ & $44 \%$ & $44 \%$ & $39 \%$ & $33 \%$ & \\
\hline so & 21.9 & 9.9 & 15.3 & 13.2 & 9.6 & \\
\hline n & 36 & 27 & 23 & 13 & 9 & \\
\hline
\end{tabular}

figure 18

$\mathrm{PAO}$, men and women without a

recurrence

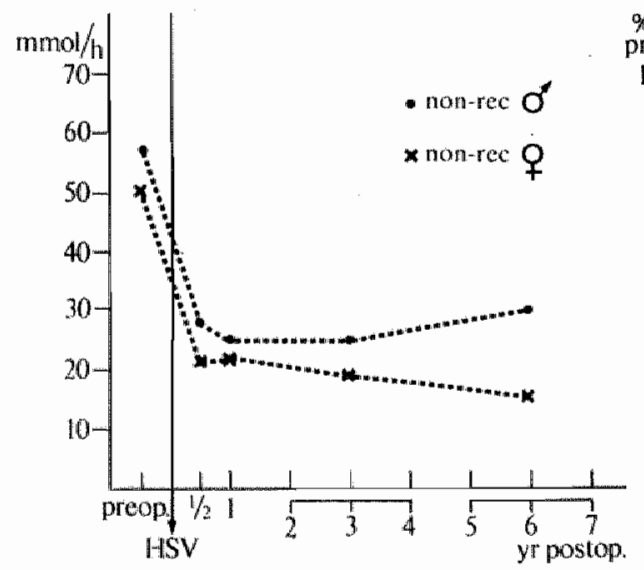

PAO in of of preoperative value, then and wonnen without a recurrence

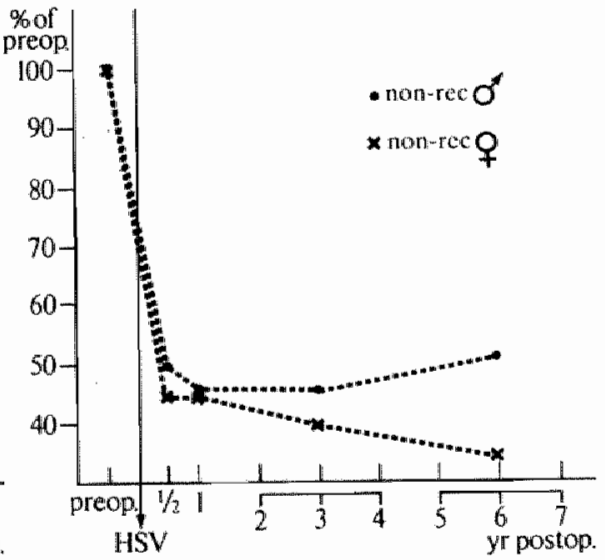




\section{table XXII}

PAO of all patients, strictly coupled values, mmolh

\begin{tabular}{|c|c|c|c|c|c|c|c|c|c|c|}
\hline & preop & $1 / 2$ & $\frac{\text { post }}{\text { pre }}$ & 1 & $\frac{\text { post }}{\text { pre }}$ & $2 / 3 / 4$ & $\frac{\text { post }}{\text { pre }}$ & $5 / 6 / 7$ & $\begin{array}{l}\text { post } \\
\text { pre }\end{array}$ & yt postop \\
\hline $\begin{array}{l}\text { mean } \\
\text { sd }(n)\end{array}$ & $23.6^{57.2}(116)$ & $\begin{array}{c}29.2 \\
16.4(116) \\
\end{array}$ & $51 \%$ & & & & & & & \\
\hline $\begin{array}{l}\text { mean } \\
\text { sd (n) }\end{array}$ & $22.6^{56.2}(100)$ & & & $\begin{array}{c}26.8 \\
14.2(100)\end{array}$ & $48 \%$ & & & & & \\
\hline $\begin{array}{l}\text { mean } \\
\text { set (n) }\end{array}$ & $27.3^{62.6}(64)$ & & & & & $\begin{array}{c}26.1 \\
13.2(64)\end{array}$ & $42 \%$ & & & \\
\hline $\begin{array}{l}\text { mean } \\
\text { sd (n) }\end{array}$ & $\begin{array}{c}59.4 \\
20.4(44)\end{array}$ & & & & & & & $\begin{array}{c}29.9 \\
12.6(44)\end{array}$ & $50 \%$ & \\
\hline
\end{tabular}

\section{table XXIII}

$\mathrm{PAO}$ transformation to one preoperative average $(58.2)$, mmol/h

\begin{tabular}{llllll}
\hline preop & $1 / 2$ & 1 & $2 / 3 / 4$ & $5 / 6 / 7$ & yrposiop \\
\hline$\frac{58.2}{\text { preop }}$ preop & $\frac{58.2}{57.2} \times 29.2$ & $\frac{58.2}{56.2} \times 26.8$ & $\frac{58.2}{62.6} \times 26.1$ & $\frac{58.2}{59.4} \times 29.9$ & \\
58.2 & 29.7 & 27.7 & 24.3 & 29.2
\end{tabular}

\section{figure 19}

PAO of all patients, strictly coupled values

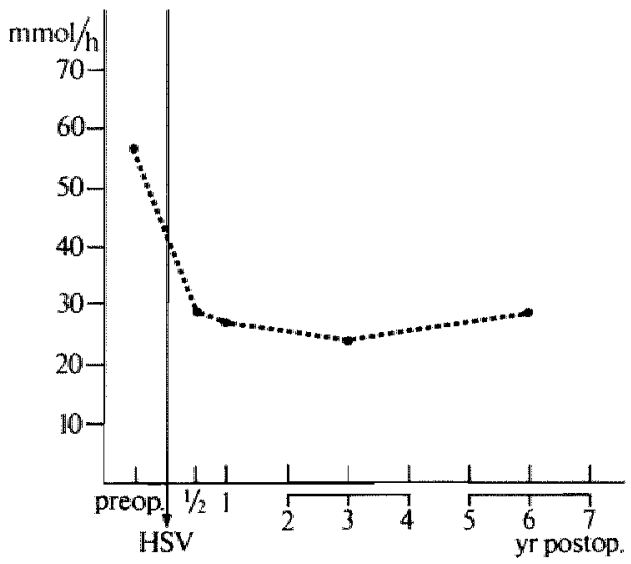


table XXIV

$\mathrm{PAO}$, men with and withou a recurrence, strictly coupled values, $\mathrm{m}$ mol/h

\begin{tabular}{|c|c|c|c|c|c|c|}
\hline & preopp & $1 / x$ & $l$ & $213 / 4$ & $5 / 677$ & yr postop \\
\hline $\begin{array}{c}\operatorname{recco} \sigma^{\prime \prime} \\
\% \\
\mathrm{n}\end{array}$ & $\begin{array}{l}60.6 \\
100 \%\end{array}$ & $\begin{array}{l}37.8 \\
62 \% \\
12\end{array}$ & $\begin{array}{l}33.2 \\
55 \% \\
12\end{array}$ & $\begin{array}{l}36.7 \\
61 \% \\
12\end{array}$ & $\begin{array}{l}31.0 \\
51 \% \\
9\end{array}$ & \\
\hline $\begin{array}{c}\text { non-rec } \sigma^{n} \\
\% \\
n\end{array}$ & $\begin{array}{l}59.3 \\
100 \%\end{array}$ & $\begin{array}{l}30.1 \\
\mathbf{5 1 \%} \% \\
84\end{array}$ & $\begin{array}{l}28.1 \\
47 \% \\
69\end{array}$ & $\begin{array}{l}22.5 \\
38 \% \\
40\end{array}$ & $\begin{array}{l}309 \\
52 \% \\
26\end{array}$ & \\
\hline
\end{tabular}

rigure 20

PAO, men whth and without is recurrence, strictly onpled values

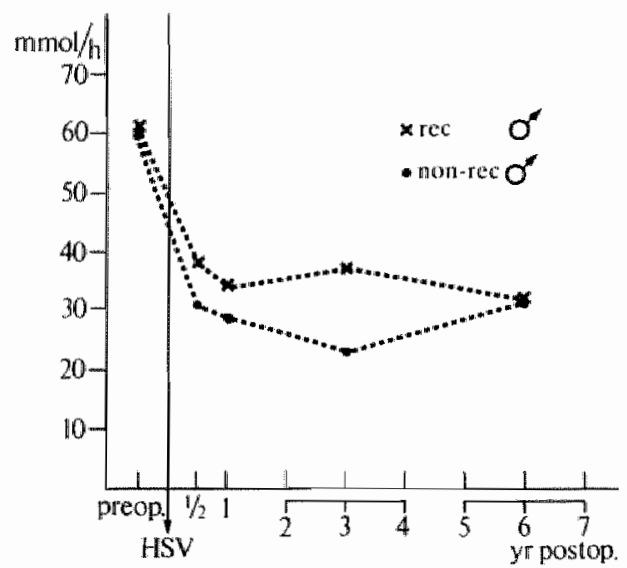

figure 21

PAO, men and women without a recurrence strictly coupled values

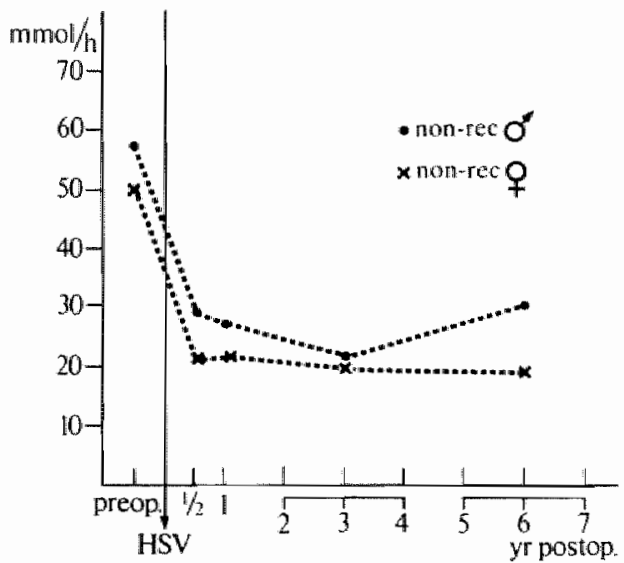

\section{table XXV}

PAO, men and women without a recurrence, stricily coupled values, mmoth

\begin{tabular}{|c|c|c|c|c|c|c|c|c|c|c|c|c|c|c|}
\hline & presp & $1 / x$ & (n) & $\frac{p o s t}{p^{2} z^{2}}$ & $l$ & $(n)$ & $\frac{\text { post }}{\text { pre }}$ & 2134 & $(n)$ & $\frac{\text { post }}{\text { pre }}$ & 51617 & $(n)$ & $\frac{p o s t}{p r e}$ & yr postop \\
\hline non rec on & 57.4 & 291 & (84) & $51 \%$ & 27.7 & $(69)$ & $48 \%$ & 21.7 & $(40)$ & $38 \%$ & 30.0 & (26) & $52 \%$ & \\
\hline non ree? & 50.2 & 21.4 & $(19)$ & $43 \%$ & 21.9 & $(18)$ & $44 \%$ & 19.1 & (11) & $38 \%$ & 18.7 & $(7)$ & $37 \%$ & \\
\hline
\end{tabular}


figuine: 22

PAO. wolume, all patients, \% of preoperative walue

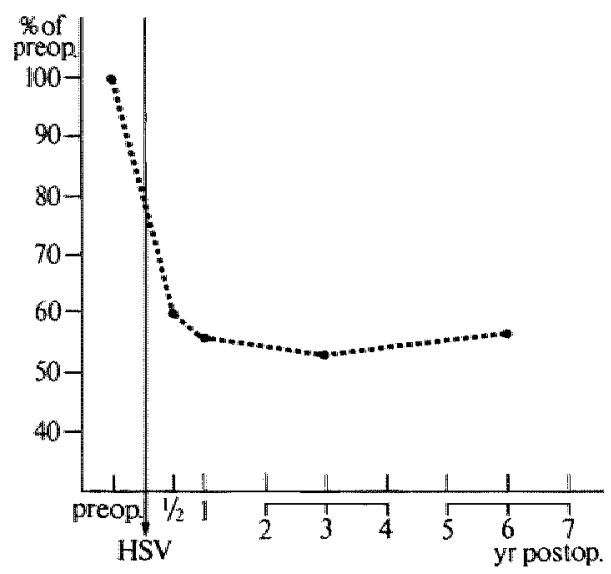

figure 23

PAO, acidity, all patients, of of preoperative valte

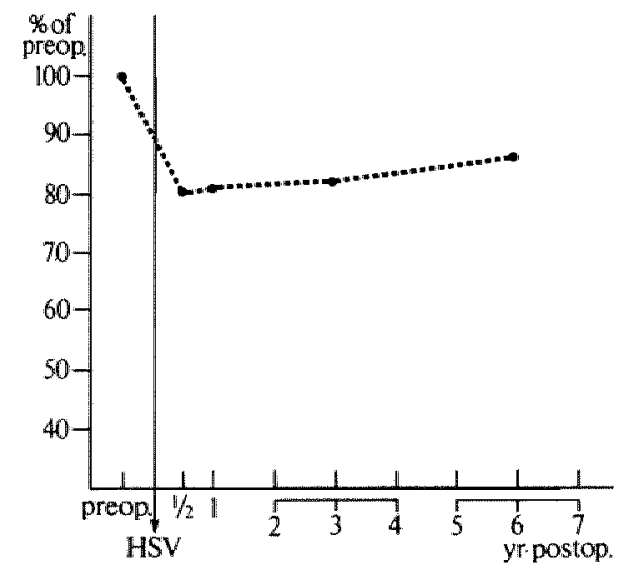

table XXVI

PAO, volume, all patients, ml/15 min

\begin{tabular}{|c|c|c|c|c|c|c|}
\hline & preop & $t_{2}$ & $l$ & $2 / 3 / 4$ & $\$ 617$ & $\begin{array}{l}\text { yor } \\
\text { posiop }\end{array}$ \\
\hline mean & 131.2 & 78.2 & 736 & 70.2 & 75.3 & \\
\hline$\%$ & $100 \%$ & $60 \%$ & $56 \%$ & $53 \%$ & $57 \%$ & \\
\hline$s d$ & 51.0 & 34.4 & 30.1 & 27.4 & 27.7 & \\
\hline$n$ & 208 & 143 & 127 & 79 & 57 & \\
\hline
\end{tabular}

\section{table XXVII}

PAO, acidity, all pationts, mmol/h

\begin{tabular}{|c|c|c|c|c|c|c|}
\hline & preap & $\sqrt{1 / 2}$ & 1 & $2 / 3 / 4$ & 51617 & $\begin{array}{l}y r \\
\text { posilop }\end{array}$ \\
\hline mean & 108.6 & 87.1 & 87.7 & 85.6 & 93.9 & \\
\hline$\%$ & $1000_{0} \%$ & $80 \%$ & $81 \%$ & $82 \%$ & $86 \%$ & \\
\hline sd & 18.5 & 27.1 & 25.9 & 26.0 & 25.8 & \\
\hline$n$ & 208 & 143 & 127 & $70)$ & 5.7 & \\
\hline
\end{tabular}


figure 24

$\mathrm{PAO}$, wolume, men with and whow at

recurence, $\%$ of preoperat ve value

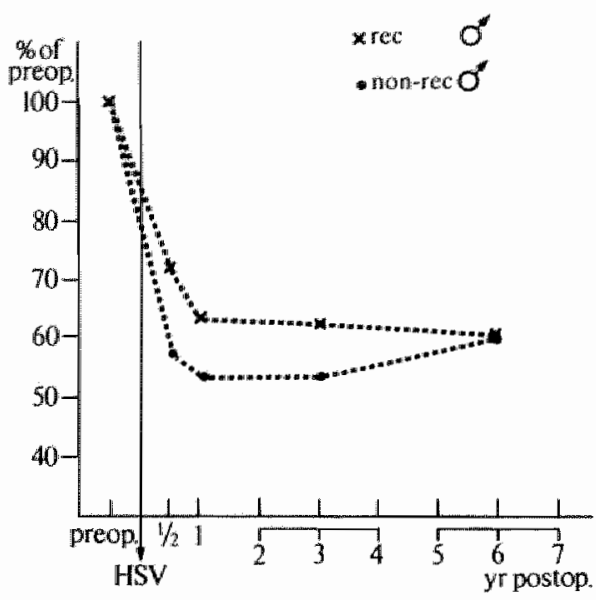

table XXWII

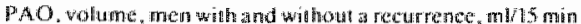

\begin{tabular}{|c|c|c|c|c|c|c|c|}
\hline & & progos & $t_{2}$ & 1 & 21,104 & $5 / 6,7$ & yopentap \\
\hline \multirow[t]{5}{*}{$\operatorname{mec} \mathrm{O}^{2}$} & mean & 131.8 & 94.9 & 83.6 & 820 & 78.2 & \\
\hline & $\%$ & $100 \%$ & 729 & $67 \%$ & $62 \%$ & $59 \%$ & \\
\hline & $\mathrm{sd}$ & 50.0 & 35.3 & 327 & 286 & 30.7 & \\
\hline & $n$ & 20 & 13 & 14 & 13 & 13 & \\
\hline & $p$ & $n \cdot s$ & H.s. & $n_{5} 5$ & n.s. & ก. 5. & \\
\hline \multirow[t]{4}{*}{ mom-neco $0^{\pi}$} & mองก & 136.9 & 72.8 & 72.5 & 721 & 91.0 & \\
\hline & $\%$ & lowns & $58 \%$ & $53 \%$ & $53 \%$ & $59 \%$ & \\
\hline & $s \mathrm{~d}$ & 51.6 & 35.3 & 26.7 & 26.0 & 26.2 & \\
\hline & $n$ & 150 & 102 & 89 & 51 & 32 & \\
\hline
\end{tabular}

figure 25

$P A O$, acidity, ane in with and without a recurrence, \% of preoperative value

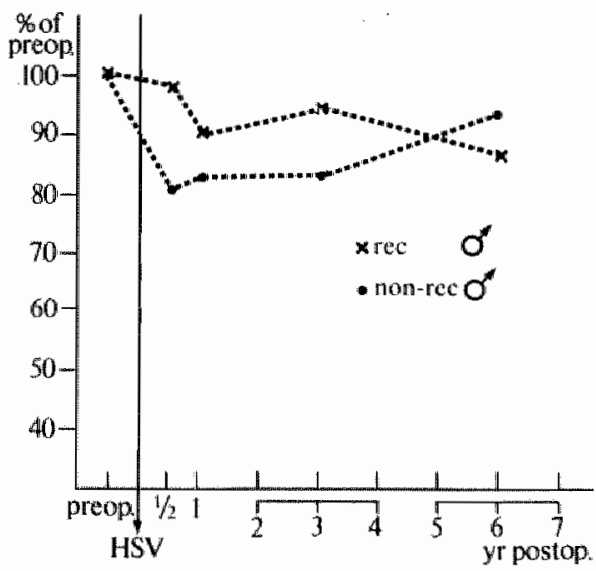

table XXIX

PAO. acidty, men with and without a recurrence, myoll

\begin{tabular}{|c|c|c|c|c|c|c|c|}
\hline & & preop & By & 1 & 2734 & $5 / 6 / 7$ & $y$ postog? \\
\hline \multirow[t]{5}{*}{$\sec 0^{\prime \prime}$} & metiln & 108.2 & 104.7 & 98.0 & 102.1 & 919 & \\
\hline & $\%$ & $10 \% \%$ & $98 \%$ & $40 \%$ & $94 \%$ & $85 \%$ & \\
\hline & $s d$ & 22.5 & 24.2 & 27.4 & 24.3 & 30.7 & \\
\hline & $\mathrm{n}$ & 20 & 13 & 14 & 13 & 13 & \\
\hline & $p$ & $n . \$$ & $" p<6,12$ & n.s. & m.s. & $n . s$. & \\
\hline \multirow[t]{4}{*}{ nen-recos } & meass & 107.5 & 858 & 87.9 & 88.1 & 987 & \\
\hline & 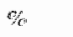 & $100 \%$ & $80 \%$ & $82 \%$ & $82 \%$ & $92 \%$ & \\
\hline & sd & 19.0 & 27.8 & 24.5 & 27.3 & 238 & \\
\hline & $n$ & 150 & $\mathbb{1 0} 12$ & 89 & $5 \%$ & 32 & \\
\hline
\end{tabular}


PAO, wolume, men and women without a recurrence, m/15 min

\begin{tabular}{|c|c|c|c|c|c|c|c|}
\hline & & preop & $1 / x$ & 1 & $213 / 4$ & 5617 & yrposrop \\
\hline \multirow[t]{6}{*}{ non-rec of } & & & & & & * & \\
\hline & mean & 136.9 & 78.8 & 72.5 & 72.1 & 81.0 & \\
\hline & \% & $100 \%$ & $58 \%$ & $53 \%$ & $53 \%$ & $59 \%$ & \\
\hline & sd & 51.6 & 35.3 & 26.7 & 26.0 & 26.2 & \\
\hline & $\mathrm{n}$ & 150 & 102 & 89 & 51 & 32 & \\
\hline & $\mathrm{p}$ & $* p<0.01$ & n.s. & n.s. & ${ }^{*} p<0.05$ & $p<0,0$ & \\
\hline \multirow[t]{5}{*}{ nonmrec? } & & & & & & & \\
\hline & mean & 110.8 & 68.5 & 71.8 & 54.6 & 51.8 & \\
\hline & $\%$ & $100 \%$ & $62 \%$ & $65 \%$ & $49 \%$ & $47 \%$ & \\
\hline & $\mathrm{sd}$ & 42.1 & 28.5 & 40.7 & 26.8 & 21.3 & \\
\hline & $\mathrm{n}$ & 36 & 27 & 23 & 13 & 9 & \\
\hline
\end{tabular}

figure 26

PAO, volume, men and women without a recurrence. \% of preoperative value

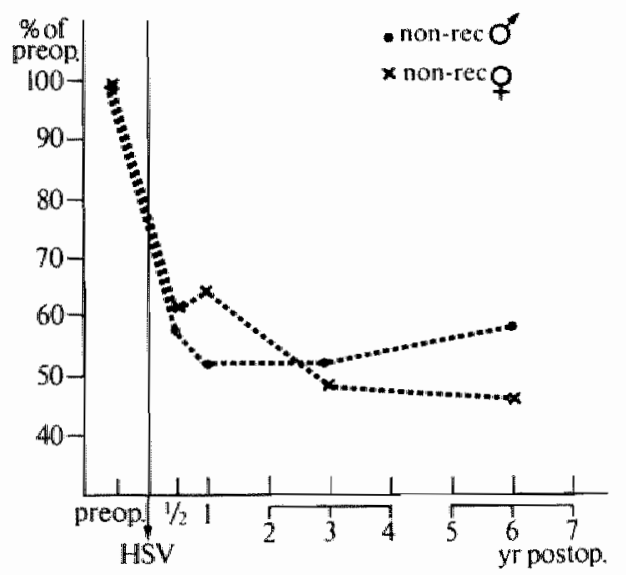

figure 27

PAO, acidity, men and women without recurrence, \% of preoperative value:

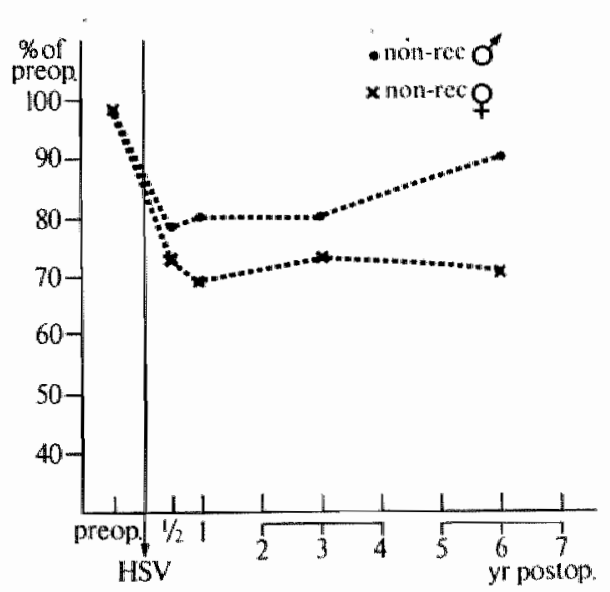

\section{table XXXI}

$P A O$, acidity, men and women without a recurrence, mmol $/ \mathrm{h}$

\begin{tabular}{|c|c|c|c|c|c|c|}
\hline & preop & $1 / 2$ & $I$ & $2 / 3 / 4$ & $5 / 6 / 7$ & yrposfop \\
\hline \multicolumn{7}{|l|}{ non $4 \mathrm{rec} \mathrm{o}^{\mathrm{n}}$} \\
\hline mean & 107.5 & 82.8 & 87.9 & 88.1 & 98.7 & \\
\hline$\%$ & $100 \%$ & $80 \%$ & $82 \%$ & $82 \%$ & $92 \%$ & \\
\hline sd & 190 & 27.8 & 24.5 & 27.3 & 23.8 & \\
\hline $\mathrm{n}$ & 150 & 192 & 89 & 51 & 32 & \\
\hline$p$ & $\mathrm{n}_{n} \mathrm{~s}$ & n.S. & $n . s$ & $n .5$ & $n . s$ & \\
\hline \multicolumn{7}{|l|}{ mon-rec $Q$} \\
\hline mean & 112.4 & 82.9 & 80.3 & 84.8 & 82.1 & \\
\hline m & $100 \%$ & $74 \%$ & $71 \%$ & $75 \%$ & $73 \%$ & \\
\hline sd & 12.1 & 22.9 & 29.6 & 21.5 & 25.5 & \\
\hline n & 36 & 27 & 23 & 13 & 9 & \\
\hline
\end{tabular}


PAO, overall postoperative reduction, volume and acidity

\begin{tabular}{|c|c|c|c|c|c|c|}
\hline & \multicolumn{3}{|c|}{ volume (mull 15 miny) } & \multicolumn{3}{|c|}{ acidny (mmoll) } \\
\hline & preop $\rightarrow$ postop & $\frac{\text { post }}{\text { pre }}$ & reduction & preop-posilop & $\frac{\text { post }}{\text { pre }}$ & reduction \\
\hline at & $131.2 \rightarrow 74.8$ & $57 \%$ & $43 \%$ & $108.6 \rightarrow 88.6$ & $82 \%$ & $18 \%$ \\
\hline$\varnothing^{7}$ & $135.9 \rightarrow 77.2$ & $57 \%$ & $43 \%$ & $197.6 \rightarrow 90.3$ & $84 \%$ & $16 \%$ \\
\hline 9 & $1100.0 \rightarrow 64.8$ & $59 \%$ & $41 \%$ & $\| 12.9 \rightarrow 82.3$ & $73 \%$ & $27 \%$ \\
\hline rec & $128.5 \rightarrow 82.2$ & $64 \%$ & $36 \%$ & $109.4 \rightarrow 97.9$ & $89 \%$ & $11 \%$ \\
\hline non-rec & $131.9 \rightarrow 73.5$ & $56 \%$ & $44 \%$ & $108.5 \rightarrow 87.2$ & $80 \%$ & $20 \%$ \\
\hline $\operatorname{rec} 0^{\prime}$ & $131.8 \rightarrow 84.7$ & $64 \%$ & $36 \%$ & $108.2 \rightarrow-99.6$ & $92 \%$ & $8 \%$ \\
\hline non-reco & $136.9 \rightarrow 75.7$ & $55 \%$ & $45 \%$ & $107.5 \rightarrow 88.5$ & $82 \%$ & $18 \%$ \\
\hline $\operatorname{rec} \sigma^{\prime \prime}$ & $95.0 \rightarrow 63.8$ & $67 \%$ & $33 \%$ & $121,0 \rightarrow 84.4$ & $70 \%$ & $30 \%$ \\
\hline non-rec? & $110.8 \rightarrow 73.8$ & $67 \%$ & $33 \%$ & $112.4 \rightarrow 82.3$ & $73 \%$ & $27 \%$ \\
\hline
\end{tabular}

\subsection{Conclusions}

Conclusions which can be drawn from these acid secretion studies are:

for BAO:

1. BAO decreases as a result of the operation; the average reduction appears to be $65 \%$ in successfully operated patients and this reduction probably remains stable.

2. There is a very clear distinction between patients who develop a recurrence and those who do not. The former do not show on average any reduction at all, the latter show a reduction of $65 \%$.

3. There is no significant difference in results between male and female patients, but in general the results in women are slightly more pronounced. The overall reduction percentage in men without a recurrence is $63 \%$, in women without a recurrence $68 \%$.

4. Both volume and acidity are reduced by the operation by $37 \%$ and $45 \%$ respectively in patients who do not develop a recurrence. In patients with a recurrence however the percentages are $12 \%$ and $0 \%$ respectively. The acidity appears to be the most sensitive constituent.

for PAO:

1. PAO decreases as a result of the operation by $50 \%$, remaining constant over the years. 
2. There is a difference in PAO reduction between patients who later develop a recurrence and those who do not (40\% as compared to $50 \%$ ). The difference between both categories gradually later disappears, partly because a further significant decrease takes place in the patients with a recurrence, partly because of a significant rise after 5 years in the patients without a recurrence ${ }^{14}$.

3. There is hardly a significant difference between men and women, but again the results in the female patients are slightly better in the long term.

4 . Both volume and acidity are reduced by $56 \%$ and $20 \%$ respectively and these figures are about $10 \%$ less in patients with a recurrence.

\subsection{Discussion}

As found by several authors $48,123,142,184,332$ the postoperative $\mathrm{BAO}$ is the most sensitive discriminative parameter of acid secretion between patients who later develop a recurrence and those who do not. From the figures obtained some more recurrences might be feared but they have not yet appeared, since the BAO figures (and especially the acidity) have a tendency to rise again after 5 years.

However, the $5 / 6 / 7$ year figures show no significant differences at all in comparison with the preceeding postoperative values (paired $t$-test). Nevertheless the suspicion is confirmed by a slight but significant rise in the PAO after 5 years.

PAO secretion data have been found by several authors to be of equal or better

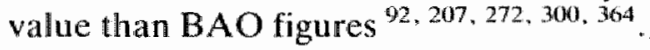

The discriminative ability of any parameter of acid secretion has been excellently and extensively described by Kronborg ${ }^{204,207}$, who by his own discriminative analysis has demonstrated not only that the Hollander criterion is not the best one in assessing completeness of a vagotomy by means of the insulin test but also that parameters derived from the histamine or pentagastrin tests are as good as those from the insulin test.

\subsubsection{Discriminative analysis} definitions:

sensitivity: percentage of patients with a recurrence having a positive criterion specificity: percentage of patients without a recurrence having a negative criterion $\mathrm{PV}+=\quad$ predictive value of a positive criterion: percentage of patients with a positive criterion, having a recurrence

$\mathrm{PV}-=\quad$ predictive value of a negative criterion: percentage of patients with a negative criterion, not having a recurrence

According to Kronborg"s description the critical level was defined for BAO and PAO, separating maximally the patients with and without a recurrence. This critical level is found by placing the highest possible percentage of non-recurrences below, and the highest possible percentage of recurrences above the level, the sum of the percentages being maximum ${ }^{204}$; in other words the highest sum of sensitivity and specificity is to be obtained.

The statistical significance of the thus separated groups was tested according to the $\mathrm{X}^{2}$ test.

Applied on the BAO data the best separation on the base of the reduction percentage 
(calculated from the average postoperative value and the preoperative value) appeared to be a reduction of less than $50 \%$ (being the positive criterion): $X^{2}=9.93$; $0.01 \times p<0.001$ resulting in a sensitivity of $79 \%$ ( 15 out of 19 patients) and a specificity of $62 \%$ ( 87 out of 140 patients). The predictive value of the presence of this criterion $(\mathrm{PV}+)$ is $15 /(53+1.5)=22 \%$; the predictive value of the absence of the criterion $(\mathrm{PV}-)$ is $87 /(87+4)=96 \%$.

The best absolute postoperative value ( $1 / 2$ year after operation) was $\geqslant 3.5 \mathrm{mmol} / \mathrm{h}$ $\left(\mathrm{X}^{2}=9.05,0.01 \times \mathrm{p} \times 0.001\right)$, with a sensitivity of $54 \%$ ( 7 out of 13 patients) and a specificity of $85 \%$ (110 out of 130 patients); PV +: $26 \%$, PV-: $95 \%$.

According to Bayes rule the PV- and PV + also depend on the prevalence of a recurrence in the population ${ }^{307}$; this prevalence is $9.2 \%$.

In formula: $\mathrm{PV}+=\frac{\text { sensitivity } \mathrm{x} \text { prevalence }}{\text { sensitivity } \mathrm{x} \text { prevalence }+(1-\text { specificity) (1-prevalence) }}$

The thus corrected $\mathrm{PV}+$ for the criterion of $\mathrm{BAO} \geqslant 3.5 \mathrm{mmol} / \mathrm{h}$ :

$\mathrm{PV}+=\frac{0.54 \times 0.092}{0.54 \times 0.092+(1-0.85)(1-0.092)}=27 \%$

Similarly the corrected PV- $=95 \%$. When applied to the criterion BAO reduction < $50 \%$ the corrected PV $+=17 \%$ and the corrected PV- $=97 \%$.

If a separation is attempted on the base of PAO data no critical level can be found by which the groups are separated significantly as assessed by the $X^{2}$ test, neither for reduction percentage data (maximum $\mathrm{X}^{2}=3.17,0.05<\mathrm{p}<0.1$ ) obtained in a similar way as with $\mathrm{BAO}$, nor for any absolute postoperative level ( $1 / 2$ year after operation): maximum $\mathrm{X}^{2}=1.69,0.5<\mathrm{p} \times 0.1$.

The results of this analysis mean that only the postoperative $B A O$ has any predictive value with respect to a recurrence. The results of the application are better than the results with a positive Hollander response as described by Kronborg ${ }^{207}$ : in his series the sensitivity was $45 \%$, the specificity $81 \%$, the PV $+26 \%$ and the PV $-93 \%$. In our material $19 \%$ of the patients with a known BAO $1 / 2$ year after operation (27 out of 143 ) had such a positive criterion.

Assuming - as several authors did $21,61,92,207,272,275,304$ - that the histamine or pentagastrin test is as suitable as the insulin test in assessing the completeness of the vagotomy (see also chapter 6 ) one is tempted to speculate that $19 \%$ of the patients are at risk for a recurrence on the base of incompleteness, and that $26 \%$ of this $19 \%$ $=$ about $5 \%$ of the patients actually developed a recurrence because of incompleteness.

The other recurrences could possibly be explained by other reasons. (chapter 1, chapter 15).

\subsubsection{Acid secretion in the course of time after HSV.}

"There is an abundance of data describing the behaviour of acid output (both BAO and $\mathrm{PAO}$ ) in the course of time but the opinions are not uniform. Generally however a tendency to increase in the course of time is found to be predominant after all kinds of vagotomy. Several factors could be of influence: 
1. the time interval after operation seems to be important

2. many series contain an unidentified proportion of patients with a (eventual) recurrence, constituting part of the figures. Most authors describe a higher postoperative acid output in patients with a recurrence $21,50,142,152,207.272 .300$, 303,364

3. it is not certain that the acid output behaviour after HSV is the same as after other forms of vagotomy

4. the progressively increasing basal serum gastrin level (see chapter 11)

5. revascularisation of the stomach. It was demonstrated that partial devascularisation of the stomach resulted in a decreased acid output, which could recover partially. Since HSV is also a devascularisation procedure a comparable effect could take place $^{223,236,349}$

6. reinnervation/sprouting of nerve endings is the classical idea about conversion of the insulin test and the development of a recurrence because of increasing acid output ${ }^{155}$. It is however doubted by most authors ${ }^{105,369}$.

The use of intra-operative control tests relies on the presence of a refractory state of the parietal cell mass just after the completion of the vagotomy. This is true both under basal and stimulated conditions; in other words the BAO and PAO are $=0$ just after vagotomy. Evidently one week after operation there is a considerable output again ${ }^{105}$ which decreases however within the next three months (both BAO and PAO) ${ }^{105,301}$. Thereafter again an increase is apparent ${ }^{105,301}$ which comes to a plateau within 1 year ${ }^{105}$ or 2 years ${ }^{301}$. In the present material both BAO and PAO remain constant from 6 months after operation onward.

It is not clear whether there is a further increase thereafter; the increase in PAO reported by Greenall et al ${ }^{105}$ was just below significance; in the present material a late increase of PAO was significant as commented on below. The BAO in Greenall's report ${ }^{105}$ showed a slight but insignificant decrease. Several other authors reported an increase $126,127,275,313,345,349$, whereas some did not find this $30,92,144$. Liavag ${ }^{226}$ found that the PAO had stabilised after one year, but that the BAO had not. He demonstrated an increasing BAO up to 5 years after operation in all available and comparable tests as well as in 113 patients who underwent serial testing.

In the present series $\mathrm{BAO}$ in men without a recurrence showed a tendency to increase after more than 5 years following operation, since the reduction was lowest at that time, compared to preoperative values. After $1 / 2,1,2 / 3 / 4$ and $5 / 6 / 7$ years the reduction percentages were $68,60,74$ and $49 \%$ respectively (paired observations), but the re was no significant change between any of the postoperative time periods.

If all available $\mathrm{BAO}$ values (including those of patients with a recurrence) are used, the reduction percentages were (at the same postoperative time periods) 63, 59,63 and $33 \%$, but only once was there a near increase demonstrated postoperatively (between $1 / 2$ year and $5 / 6 / 7$ years: $p=0.07$, paired $t$-test, $n=31$ ).

As for PAO data: in men without a recurrence the reduction percentages were 49 , 53,62 and 48 respectively, but there was a just significant increase ( $p=0.027$, paired t-test, $\mathbf{n}=11$ ) between the values of $2 / 3 / 4$ and $5 / 6 / 7$ years after operation. It might well be accidental since the number of patients was small and the significance not pronounced. 
If all patients are considered (including recurrences) the $\mathrm{PAO}$ reduction percentages were $49,52,58$ and 50 respectively without any significant difference between any two periods.

Resuming: from $6-12$ months after highly selective vagotomy onward the basal and stimulated secretory levels remain probably stable. However there could be a late rise both in $\mathrm{BAO}$ and $\mathrm{PAO}$, but its meaning is not yet clear; perhaps it is comparable to the conversion of negative insulin tests into positive.

The amount of reduction found by various authors is different both for BAO and PAO. Possible factors of influence have been outlined above, but even with consideration of those factors differences remain.

Several authors demonstrated a lower reduction level after HSV as compared to truncal vagotomy ${ }^{50}$, others found the reduction of the same order ${ }^{160,}, 172,286$. Generally the reduction of BAO is between 60 and $80 \%$; the PAO reduction between 45 and $60 \%$.

An overview of figures extracted from the literature is presented in the next table, demonstrating the difficulty of proper comparison. The choice of the authors was arbitrary; completeness was not attempted.

Legend to the table:

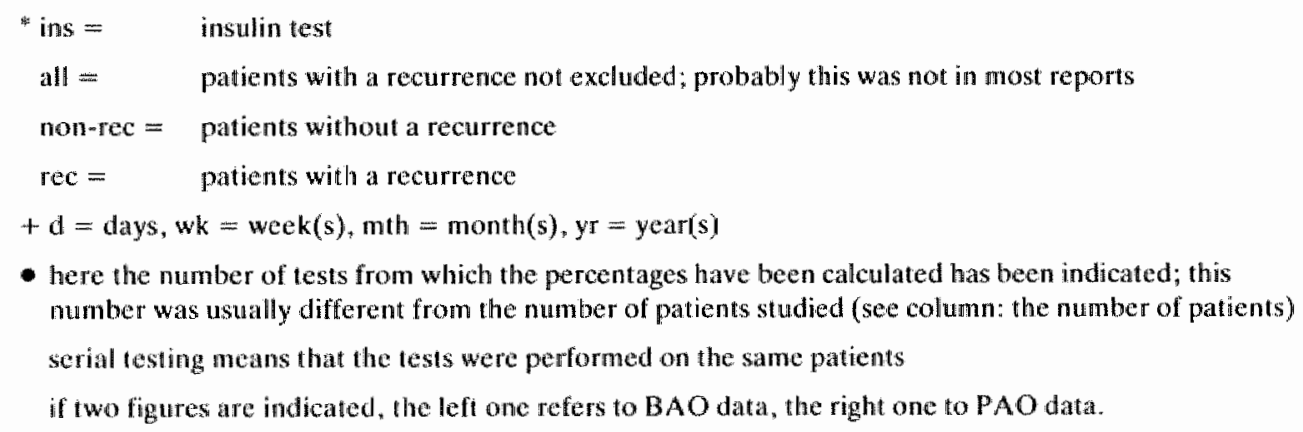


$\mathrm{BAO} \& \mathrm{PAO}$ reduction percentages in the literature

\begin{tabular}{|c|c|c|c|c|c|c|c|c|}
\hline author & $\begin{array}{l}\text { ref. } \\
\text { no. }\end{array}$ & $\begin{array}{l}\text { year of } \\
\text { publication }\end{array}$ & $\begin{array}{l}\text { no. of } \\
\text { paibents: }\end{array}$ & stontus" & $\begin{array}{l}\text { limet } \\
\text { postop }\end{array}$ & $\begin{array}{l}B A O \\
\text { in } \%\end{array}$ & $\begin{array}{l}\text { PAO } \\
\text { ins }\end{array}$ & comment \\
\hline $\begin{array}{l}\text { Amdrup } \\
\text { Kronborg } \\
\text { Johnston }\end{array}$ & $\begin{array}{r}8 \\
206 \\
164\end{array}$ & $\begin{array}{l}1970 \\
1972 \\
1973\end{array}$ & $\begin{array}{l}17 \\
30 \\
63\end{array}$ & & $\begin{array}{l}2 \mathrm{mih} \\
10 \mathrm{~d} \\
1 \mathrm{wk} \\
2-3 \mathrm{mth} \\
6-12 \mathrm{mth} \\
1-2 \mathrm{yr}\end{array}$ & $\begin{array}{l}92 \\
86 \\
87 \\
80\end{array}$ & $\begin{array}{l}60 \\
57 \\
51 \\
68 \\
55 \\
55\end{array}$ & $\begin{array}{l}n=30 \\
n=26 \\
n=43 \\
n=30 \\
n=31\end{array}$ \\
\hline Clark & 52 & 1973 & 16 & $\begin{array}{l}\text { inst } \\
\text { ins - }\end{array}$ & $2 w k$ & $\begin{array}{l}35 \\
0\end{array}$ & $\begin{array}{l}24 \\
56\end{array}$ & $\begin{array}{l}n=8 \\
n=8\end{array}$ \\
\hline $\begin{array}{l}\text { Jaffe } \\
\text { Greenall }\end{array}$ & $\begin{array}{l}150 \\
105\end{array}$ & $\begin{array}{l}1974 \\
1975\end{array}$ & $\begin{array}{l}10 \\
21\end{array}$ & & $\begin{array}{l}3 \mathrm{mth} \\
1 \mathrm{yr} \\
5 \mathrm{yr}\end{array}$ & $\begin{array}{l}77 \\
75 \\
79 \\
\end{array}$ & $\begin{array}{l}69 \\
51 \\
48\end{array}$ & $\begin{array}{l}\text { serial } \\
\text { lesting }(n=21)\end{array}$ \\
\hline Roland & 301 & 1975 & 16 & & $\begin{array}{l}10 \mathrm{~d} \\
3 \mathrm{mth}\end{array}$ & & $\begin{array}{l}48 \\
64 \\
\end{array}$ & \\
\hline $\begin{array}{l}\text { Hedenstedt } \\
\text { Saüberli } \\
\text { Thompson }\end{array}$ & $\begin{array}{l}126 \\
312 \\
345\end{array}$ & $\begin{array}{l}1975 \\
1975 \\
1976\end{array}$ & $\begin{array}{l}25 \\
11\end{array}$ & & $\begin{array}{l}1 \text { mith } \\
6 \text { mth } \\
<6 \text { mith } \\
<4 \mathrm{yr} \\
\end{array}$ & $\begin{array}{l}80 \\
77 \\
68 \\
95 \\
\end{array}$ & $\begin{array}{l}75 \\
63 \\
41 \\
38 \\
\end{array}$ & $n=116$ \\
\hline $\begin{array}{l}\text { Rosati } \\
\text { Dozois } \\
\text { Geurts }\end{array}$ & $\begin{array}{r}303 \\
74 \\
89\end{array}$ & $\begin{array}{l}1976 \\
1976 \\
1977\end{array}$ & $\begin{array}{r}25 \\
191 \\
60\end{array}$ & $\sigma^{\prime \prime}$ & $\begin{array}{l}1 \mathrm{yr} \\
? \\
2 \mathrm{wk} \\
6 \mathrm{mth}\end{array}$ & $\begin{array}{l}87 \\
81 \\
60 \\
72 \\
\end{array}$ & $\begin{array}{l}71 \\
58 \\
64 \\
50 \\
\end{array}$ & $\begin{array}{l}\text { collected data } \\
n=48 / 47 \\
n=34\end{array}$ \\
\hline $\begin{array}{l}\text { Meikle } \\
\text { Solhaug }\end{array}$ & $\begin{array}{l}251 \\
330\end{array}$ & $\begin{array}{l}1977 \\
1977\end{array}$ & $\begin{array}{r}7 \\
85\end{array}$ & & $\begin{array}{l}3 \mathrm{mth} \\
1 \mathrm{yr} \\
2 \mathrm{yr}\end{array}$ & $\begin{array}{l}62 \\
61 \\
56 \\
\end{array}$ & $\begin{array}{l}50 \\
32 \\
41\end{array}$ & $\begin{array}{l}n=36 \\
n=27\end{array}$ \\
\hline Andersen & 16 & 1978 & 273 & all & $\begin{array}{l}3 \mathrm{mth} \\
1 \mathrm{yr}\end{array}$ & $\begin{array}{l}75 \\
66 \\
\end{array}$ & $\begin{array}{l}54 \\
44 \\
\end{array}$ & $\begin{array}{ll}n=131 & \text { serial } \\
n=131 & \text { testing }\end{array}$ \\
\hline Jensen & 152 & 1978 & 100 & & $\begin{array}{l}3 \mathrm{mth} \\
5 \mathrm{yr} \\
3 \mathrm{mth} \\
5 \mathrm{yr}\end{array}$ & $\begin{array}{l}81 \\
71 \\
81 \\
71\end{array}$ & $\begin{array}{l}60 \\
56 \\
59 \\
53\end{array}$ & $\begin{array}{l}n=90 / 86 \\
n=48 / 43 \\
\text { serial testing } \\
n=46 / 40\end{array}$ \\
\hline $\begin{array}{l}\text { Poppen } \\
\text { Liavag }\end{array}$ & $\begin{array}{l}288 \\
226\end{array}$ & $\begin{array}{l}1978 \\
1979\end{array}$ & $\begin{array}{r}45 \\
481\end{array}$ & $\begin{array}{l}0^{\prime \prime} \\
\text { all }\end{array}$ & $\begin{array}{l}8 \mathrm{mth} \\
2 \mathrm{mth} \\
1 \mathrm{yr} \\
5 \mathrm{yr}\end{array}$ & $\begin{array}{l}71 \\
81 \\
70 \\
59 \\
\end{array}$ & $\begin{array}{l}49 \\
60 \\
54 \\
53 \\
\end{array}$ & $\begin{array}{l}n=37 \\
n=236 \\
n=225 \\
n=166\end{array}$ \\
\hline & & & & & $\begin{array}{l}2 \mathrm{mth} \\
1 \mathrm{yr} \\
5 \mathrm{yr}\end{array}$ & $\begin{array}{l}81 \\
67 \\
57 \\
\end{array}$ & $\begin{array}{l}61 \\
55 \\
54 \\
\end{array}$ & $\begin{array}{l}\text { serial } \\
\text { testing } \\
n=113\end{array}$ \\
\hline $\begin{array}{l}\text { Marceau } \\
\text { Makey }\end{array}$ & $\begin{array}{l}241 \\
238\end{array}$ & $\begin{array}{l}1979 \\
1979\end{array}$ & $\begin{array}{r}98 \\
173\end{array}$ & $\begin{array}{r}\text { non-rec } \\
\text { rec }\end{array}$ & $\begin{array}{l}? \\
\geqslant 3 \mathrm{muth} \\
\geqslant 3 \mathrm{mth}\end{array}$ & $\begin{array}{l}63 \\
78 \\
36 \\
\end{array}$ & $\begin{array}{l}47 \\
60 \\
42\end{array}$ & $\begin{array}{l}n=49 \\
n=42 \\
n=4\end{array}$ \\
\hline $\begin{array}{l}\text { Cabrera } \\
\text { Bank }\end{array}$ & $\begin{array}{l}46 \\
22\end{array}$ & $\begin{array}{l}1980 \\
1980\end{array}$ & $\begin{array}{r}60 \\
937\end{array}$ & & $\begin{array}{l}6 \mathrm{wk}-6 \mathrm{mih} \\
2 \mathrm{mth} \\
1 \mathrm{yr}\end{array}$ & $\begin{array}{l}83 \\
79 \\
64 \\
\end{array}$ & $\begin{array}{l}48 \\
62 \\
55\end{array}$ & $\begin{array}{l}n=121 \\
\text { collected } \\
\text { dalla }\end{array}$ \\
\hline Hedenstedt & 127 & 1980 & 78 & & $\begin{array}{l}3 \mathrm{mth} \\
5 \mathrm{yr}\end{array}$ & $\begin{array}{l}86 \\
61\end{array}$ & $\begin{array}{l}67 \\
48\end{array}$ & $\begin{array}{l}n=43 \\
n=43\end{array}$ \\
\hline
\end{tabular}




\begin{tabular}{|c|c|c|c|c|c|c|c|c|}
\hline awhor & $\begin{array}{l}\text { ref. } \\
\text { no. }\end{array}$ & $\begin{array}{l}\text { year of } \\
\text { publicanion }\end{array}$ & $\begin{array}{l}\text { no. of } \\
\text { patients }\end{array}$ & starus & $\begin{array}{l}\text { imet } \\
\text { postop }\end{array}$ & $\begin{array}{l}B A O \\
i n \%\end{array}$ & $\begin{array}{l}P A O \\
\text { in } \%\end{array}$ & comment \\
\hline Hater-Jensen & 123 & 1980 & 72 & & $2 m$ th & 68 & 45 & $\mathrm{n}=37$ \\
\hline \multirow[t]{4}{*}{ Blackett } & 37 & 1981 & 433 & non-rec & l wk & 90 & 50 & $\mathrm{n}=100 \quad$ serial \\
\hline & & & & nion-rec & $>1 \mathrm{yr}$ & 80 & 46 & $\mathrm{n}=100$ testing \\
\hline & & & & rec & $\| w k$ & 74 & 44 & $\mathrm{n}=24$ serial \\
\hline & & & & $\mathrm{rec}$ & $>1$ yr & 36 & 40 & $n=24$ testing \\
\hline \multirow[t]{6}{*}{ Selking } & 320 & 1981 & 56 & all & $6 \mathrm{wk}$ & 60 & 47 & $n=50$ \\
\hline & & & & all & $1 y r$ & 45 & 31 & $n=39$ \\
\hline & & & & non-rec & $6 w k$ & 71 & 52 & \\
\hline & & & & non-rec & $1 \mathrm{yr}$ & 49 & 31 & \\
\hline & & & & rec & $6 \mathrm{wk}$ & 0 & 37 & \\
\hline & & & & rec & $1 y r$ & 0 & 40 & \\
\hline \multirow[t]{2}{*}{ Romeo } & 302 & 1981 & 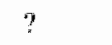 & & $6 \mathrm{mth}$ & 80 & 75 & \\
\hline & & & & & $3 \mathrm{yr}$ & 70 & 65 & \\
\hline \multirow{7}{*}{$\begin{array}{l}\text { Christiansen } \\
\text { Nylamo }\end{array}$} & 50 & 198.1 & 83 & & $3 \mathrm{mth}$ & 60 & 49 & $n=68$ \\
\hline & 275 & 1982 & 73 & non-rec & $2 \mathrm{mth}$ & 93 & 74 & $n=46$ \\
\hline & & & & & $1 y r$ & 74 & 66 & $n=40$ \\
\hline & & & & & $3 y r$ & 64 & 48 & $\mathrm{n}=35$ \\
\hline & & & & rec & $2 \mathrm{mih}$ & 72 & 57 & $n=5$ \\
\hline & & & & & $1 \mathrm{yr}$ & 57 & 53 & $n=5$ \\
\hline & & & & & $3 y r$ & 41 & 27 & $n=2$ \\
\hline Mollinshead & $14 \|$ & 1982 & 114 & & ? & 74 & 56 & $n=16$ \\
\hline \multirow{2}{*}{ Horton } & 144 & 1982 & 19 & & $<3$ mith & 79 & 64 & $n=11$ \\
\hline & & & & & $>\| \mathrm{yr}$ & 90 & 75 & \\
\hline \multirow[t]{12}{*}{ Busman } & & 1983 & 262 & all & WyT & 63 & 49 & $\mathrm{n}=111 / 114$ \\
\hline & & & & & $1 \mathrm{yr}$ & 59 & 52 & $\mathrm{n}=97 / 99$ \\
\hline & & & & & $2 / 3 / 4$ yr & 63 & 58 & $n=64$ \\
\hline & & & & & $5 / 6 / 7 \mathrm{yr}$ & 33 & 50 & $n=44$ \\
\hline & & & & non-rec & yyr & 68 & 49 & $n=79$ \\
\hline & & & & $\sigma^{\prime}$ & $1 \mathrm{yr}$ & 60 & 53 & $n=66$ \\
\hline & & & & & $2 / 3 / 4 \mathrm{yr}$ & 74 & 62 & $n=40$ \\
\hline & & & & & $5 / 6 / 7 \mathrm{yr}^{\mathrm{r}}$ & 49 & 48 & $n=26$ \\
\hline & & & & $\mathrm{res}$ & $1 / 2 y r$ & 34 & 38 & $n=12$ \\
\hline & & & & $\sigma^{*}$ & $1 \mathrm{yr}$ & 36 & 45 & $n=12$ \\
\hline & & & & & $2 / 3 / 4 \mathrm{yr}$ & 0 & 39 & $n=12$ \\
\hline & & & & & $5 / 6 / 7$ yr & 0 & 49 & $\mathrm{n}=9$ \\
\hline
\end{tabular}




\section{Chapter 11.}

\section{Gastrin}

\subsection{Introduction}

The physiological role of gastrin is reported to be, among others, the increase of the acid- and pepsin production of the parietal cells. Under the influence of certain stimuli such as food (aminoacids, polypeptides, alcohol) distension of the antrum and vagal stimulation (demonstrable for example by sham feeding) gastrin release is increased ${ }^{45,81,86,112,193,246,297 .}$

Gastrin release is inhibited by the very acid it stimulates (negative feed-back mechanism).

There seems to be an intricate relationship between the vagus and gastrin, each needing the other for its action ${ }^{62}$.

Gastrin action is blocked by atropine (known to block the presumed acetylcholine receptors on the parietal cells) and by $\mathrm{H}_{2}$ receptor blockers. It is possible that histamine is the final common pathway for acid secretion and that both gastrin and acetylcholine need the last step, mediated by histamine, for their action ${ }^{81}$.

The role of gastrin in DU disease is unclear ${ }^{219}$. Contrary to expectation DU patients with higher acid secretion than normal usually have a normal or even higher than normal basal gastrin level in their serum (preoperatively) which may be an indication that the feedback mechanism is defective in DU disease 178,367 .

Postprandial increase of gastrin is higher in DU patients than in normal subjects, as is the rise after insulin hypoglycaemia. This rise proved to be vagus-independant, since it was not abolished after vagotomy $62,150,217,308,335$. Further actions of gastrin under physiological conditions are improvement of the gastric mucosal blood flow and a trophic action on the mucosa and parietal cells ${ }^{119,217}$.

There are conflicting reports about what happens to gastrin after vagotomy, whether truncal, selective or highly selective. Several reports could not demonstrate any significant change $42,52,144,233,250$ whereas most authors report an elevation of basal and postprandial gastrin levels $20.28,40,72,81,150,478,215,224,232,286,297,308,334,335$, 338 .

\subsection{Methods}

An important technical difficulty is that there are many gastrins circulating with different potentiall stimulatory power, half-life time and sensitivity to radioimmunoassay (R.I.A.) detection ${ }^{81}$.

In this study gastrin determination was carried out by means of a commercially available R.I.A. kit (Becton-Dickinson), which has not been changed over the years studied. Regular control checks have been carried out by other laboratories by the same method and other methods; these revealed minor fluctuations (about $10 \%$ ) or proportional differences as compared with other assay methods. Each month a separate quality control was carried out with a standard consisting of pooled blood from the blood transfusion service. This revealed the normal value to remain constant 
over the years. The normal value in our laboratory is $66-174 \mathrm{ng} / \mathrm{l}$.

Often abnormal values were only accepted if they could be reconfirmed; the average of those values was used, thus increasing the reliability of the value, but this second or third determination was not used for significance statistics. Only one resulting value for each patient and each period was used for calculations. Probably this means that the reliability of the results is higher than appears from the statistical calculations, which is nevertheless accepted here.

\subsection{Results}

Preoperative basal serum gastrin was determined in 190 patients. Details of the figures are assembled in table I and figure 1. There appeared to be no difference before operation between the patients who later developed a recurrence and the ones who did not, nor between men and women. Furthermore there was no difference in gastrin levels between the patients with a high and those with a low acid output, whether basal or after stimulation.

tabel I

basal serum gastrin, ng/l

normal tange: $66-174 \mathrm{ng} /$

\begin{tabular}{|c|c|c|c|c|c|c|c|c|c|c|}
\hline & & preop & $w$ & 1 & 2 & 3 & 4 & 5 & 6178 & yr posstop \\
\hline all & $\begin{array}{l}\text { mean } \\
\text { sd }(n) \\
\text { mediann } \\
\text { range }\end{array}$ & $\begin{array}{l}120.3 \\
64.5(190) \\
107.0 \\
26-560\end{array}$ & $\begin{array}{l}203.5 \\
147.4(155) \\
161.0 \\
55-1000\end{array}$ & $\begin{array}{l}205.2 \\
127.7(176) \\
176.0 \\
57.1000\end{array}$ & $\begin{array}{l}213.3 \\
165.3(51) \\
168.0 \\
61-855\end{array}$ & $\begin{array}{l}200.1 \\
114.2(36) \\
162.0 \\
77.571\end{array}$ & $\begin{array}{l}199.4 \\
146.3(30) \\
172.5 \\
67.818\end{array}$ & $\begin{array}{l}238.3 \\
155.9(48) \\
203.5 \\
99-1000\end{array}$ & $\begin{array}{l}233.6 \\
131.4(24) \\
186.5 \\
106-704\end{array}$ & \\
\hline all $\sigma^{*}$ & $\begin{array}{l}\text { mean } \\
\text { sd(n) }\end{array}$ & $\begin{array}{l}122.0 \\
66.5(159)\end{array}$ & $\begin{array}{l}205.1 \\
144.8(128)\end{array}$ & $\begin{array}{l}207.3 \\
131,2(103)\end{array}$ & $\begin{array}{l}210.2 \\
154.2(36)\end{array}$ & $\begin{array}{l}206.2 \\
121.7(30)\end{array}$ & $\begin{array}{l}206.4 \\
157.2(25)\end{array}$ & $\begin{array}{l}248.6 \\
162.2(36)\end{array}$ & $\begin{array}{l}249.7 \\
170.6(15)\end{array}$ & \\
\hline all? & $\begin{array}{l}\text { metan } \\
\text { sil }(n)\end{array}$ & $\begin{array}{l}114.3 \\
53.3(31)\end{array}$ & $\begin{array}{l}196.4 \\
161,7(27)\end{array}$ & $\begin{array}{l}197.8 \\
116.6(301)\end{array}$ & $\begin{array}{l}220.9 \\
195.1(15)\end{array}$ & $\begin{array}{l}169.7 \\
62.5 .(6)\end{array}$ & $\begin{array}{l}164.4 \\
70.6(5)\end{array}$ & $\begin{array}{l}237.5 \\
141.9(12)\end{array}$ & $\begin{array}{l}206.8 \\
66.19 y\end{array}$ & \\
\hline recall & $\begin{array}{l}\text { mean } \\
\text { sdi(n) }\end{array}$ & $\begin{array}{l}111.2 \\
55.5(14)\end{array}$ & $\begin{array}{l}124.9 \\
30.7(10)\end{array}$ & $\begin{array}{l}183.6 \\
141.8(12)\end{array}$ & $\begin{array}{l}214.0 \\
195.9(4)\end{array}$ & $\begin{array}{l}196.9 \\
134.2(8)\end{array}$ & $\begin{array}{l}136.3 \\
67.6(3)\end{array}$ & $\begin{array}{l}221.3 \\
63.3(7)\end{array}$ & $\left\{\begin{array}{l}232.4 \\
116.6(7)\end{array}\right.$ & \\
\hline non-rec alll & $\begin{array}{l}\text { mean } \\
\text { sd (n) }\end{array}$ & $\begin{array}{l}121.0 \\
65.2(176)\end{array}$ & $\begin{array}{l}208.9 \\
155.4(145)\end{array}$ & $\begin{array}{l}206.7 \\
127.0(120)\end{array}$ & $\begin{array}{l}213.3 \\
164.9(47)\end{array}$ & $\begin{array}{l}201.0 \\
110.5(28)\end{array}$ & $\begin{array}{l}206.4 \\
151.7(27)\end{array}$ & $\begin{array}{l}241.3 \\
167.1(41)\end{array}$ & $\begin{array}{l}234.0 \\
137.5(17)\end{array}$ & \\
\hline
\end{tabular}

figure I

basal serung gastrith, all patients

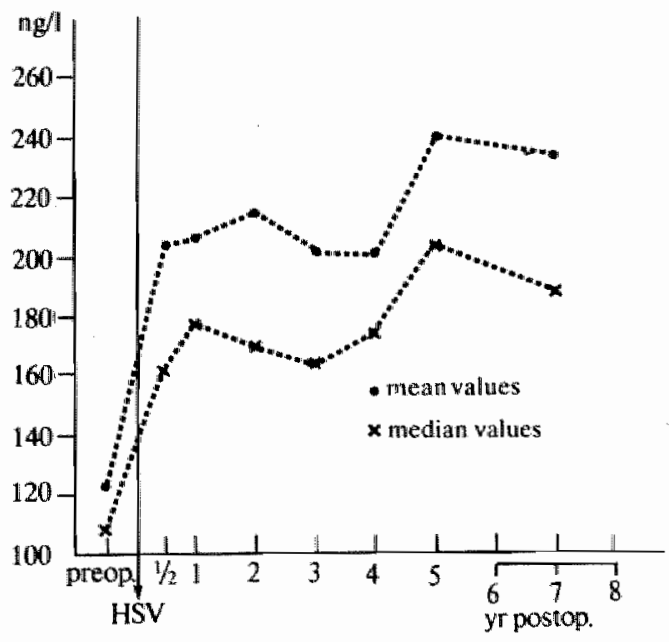


Correlation coefficient of preoperative gastrin/preoperative $\mathrm{BAO}(\mathrm{n}=101) \mathrm{r}=$ 0.169 . In those patients who had both preoperative and postoperative values of gastrin as well as BAO and PAO measured, a subdivision was made between those who had used cimetidine prior to operation and those who had not; there was no difference in the $\mathrm{BAO}$ data.

Equally there was no correlation found between preoperative gastrin and preoperative PAO $(n=113): r=-0.074$. Again cimetidine had no detectable influence. No correlation was found either between the preoperative gastrin level and the BAO/PAO ratio $(r=-0.0742)$.

\section{Postoperative basal serum gastrin.}

For all follow-up periods it is held that the values in the tables and figures are the mean values of all available determinations (table I, figure 1). In the combined groups $(2 / 3 / 4$ and $5 / 6 / 7 / 8$ years after operation) each patient contributed maximally one value. If there were more values for one patient within such a period the averaged value has been used.

There is a significant increase of serum gastrin after HSV in all subdivided groups ol about $60 \%$ over the preoperative value. This increase remains stable up to 5 years after operation when a further rise seems to take place. This rise is, however, strongly significant ( $\mathrm{p}=0.000$ ) in comparison to all preceding time periods.

Again there is no difference between men and women, or between patients with and without a recurrence.

When all postoperative values of each individual patient were averaged and the mean of all these averaged values was compared with the mean preoperative value, the figures were 120.3 (sd 64.6, $\mathrm{n}=190$ ) preoperatively and 215.7 (sd $120.3, \mathrm{n}=$ $160)$ postoperatively, an increase of $79 \%$. In this comparison only postoperative values have been used whenever there was a preoperative value (coupled values). The values collected in table I were not necessarily from the same patients in each period. Therefore also a separate comparison was made where only those postoperative values were used if there was a preoperative value avallable and conversely (strictly coupled values). Since the patients al each postoperative follow-up period were not exactly the same the preoperative values varied slightly for each comparison (table II).

There was a significant increase for all periods compared with the preoperative value. The second increase later (which is also significant in relation to the previous postoperative values) was very clear in these strictly coupled data; at the various interval dates this increase grew from 69 to $158 \%$ (table II).

In table III the strictly coupled values are shown in the patients with and without a recurrence. The number of comparable basal serum gastrin values of patients with a recurrence was low. This is a reflection of the fact that many recurrences were operated upon early in the series at the time serum gastrin could not yet be determined.

No correlation was found between the average postoperative gastrin levells and the average postoperative acid secretion (BAO and PAO). There was no difference in this respect between patients who had never used cimetidine before operation and 
table II

basal serum gastrin, all patients.

strictly coupled values, ng/l

\begin{tabular}{|c|c|c|c|c|c|c|c|c|c|}
\hline preop & $1 / z$ & $\frac{\text { post }}{\text { pre }}$ & \multirow[t]{2}{*}{1} & \multirow[b]{2}{*}{$\frac{\text { post }}{\text { pre }}$} & \multirow{3}{*}{\multicolumn{2}{|c|}{$\begin{array}{l}2 / 3 / 4 \\
\frac{\text { post }}{\text { pre }}\end{array}$}} & \multicolumn{2}{|c|}{$56 / 7$ yrpostop } & statisrical \\
\hline $\begin{array}{r}121.8 \\
s 0159.9 \\
n=125\end{array}$ & $\begin{array}{r}206.2 \\
150.4 \\
\mathrm{n}=125 \\
\end{array}$ & $169 \%$ & & & & & & & $\mathrm{p}=0.000$ \\
\hline $\begin{array}{r}118.6 \\
\mathrm{sd} 53.8 \\
n=108\end{array}$ & & & $\begin{array}{r}205.3 \\
138.1 \\
\mathrm{n}=108 \\
\end{array}$ & $173 \%$ & & & & & $p=0.000$ \\
\hline $\begin{array}{r}106.3 \\
s d 65.1 \\
n=72\end{array}$ & & & & & $\begin{array}{r}210.9 \\
150.7 \\
n=72\end{array}$ & $198 \%$ & & $\frac{\text { post }}{\text { pre }}$ & $p=0.000$ \\
\hline $\begin{array}{r}90.8 \\
\text { sd } 31.6 \\
n=33\end{array}$ & & & & & & & $\begin{array}{r}234.5 \\
109.5 \\
n=33\end{array}$ & $258 \%$ & $\mathrm{p}=0.000$ \\
\hline
\end{tabular}

table III

Basal se rum gastrin, all patients with and without a recurrence strictly coupled values, $n g / l$

\begin{tabular}{|c|c|c|c|c|c|c|c|c|}
\hline & preop & $\begin{array}{l}1 / 2 y r \\
\text { postop }\end{array}$ & preop & $\begin{array}{l}\text { Iyr } \\
\text { postop }\end{array}$ & preop & $\begin{array}{l}2 / 3 / 4 y r \\
\text { posiop }\end{array}$ & preop & $\begin{array}{l}5 / 6 / 7 \mathrm{yr} \\
\text { postop }\end{array}$ \\
\hline non-rec mean & 124.3 & 211.7 & 120.6 & 206.0 & 107.9 & 213.8 & 88.6 & 237.0 \\
\hline sul & 60.6 & 156.1 & 54.6 & 135.8 & 66.7 & 151.9 & 29.5 & $11: 4,8$ \\
\hline$n$ & 117 & 117 & 100 & 100 & 65 & 65 & 28 & 28 \\
\hline $\mathrm{p}$ & n.s. & n.s. & v.s. & $\mathrm{n} . \mathrm{s}$ & n.s. & n.s. & nn.s. & $\mathrm{ns}$. \\
\hline recmenn & 85.4 & 124.6 & 93.7 & 199.9 & 91.6 & 183.7 & $\$ 03.4$ & 220.6 \\
\hline sil & 33.8 & 34.1 & 35.9 & 175.3 & 49.1 & 147.4 & 43.7 & 82.1 \\
\hline$n$ & 8 & 8 & 8 & 8 & 7 & 7 & 5 & 5 \\
\hline
\end{tabular}

those who had. The correlation was not present irrespective of whether the absolute values or the percentages of increase or decrease in relation to the preoperative values were used.

\subsection{Discussion}

The results showed a significant increase of basal serum gastrin values after HSV. Within two years after operation the increase was about $60 \%$, further increasing thereafter. After 5 years the increase had grown to $100 \%$ irrespective of the presence of a recurrence. Largiader found a constant elevation of more then $100 \%$ after HSV 214 
This suggests that the gastrin level pre-or postoperatively is not contributing to a recurrence, nor can a postoperative increase be regarded as a sign of completeness or adequacy of the vagotomy.

As an explanation it has been suggested that vagotomy of the whole stomach or only of the parietal cell mass reduces the responsiveness to gastrin (and to histamine ${ }^{246}$ ).

The increase after operation could theoretically be due to ${ }^{224:}$

- decreased acid production, which affects the feed-back

- distension of the antrum due to a relative obstruction

- decreased vagal inhibition of gastrin release

- development of Zollinger-Ellison syndrome, renal insufficiency, pernicious anaemia.

Thompson $\left(76^{345}\right)$ postulates that vagotomy has two effects of opposed direction on the serum gastrin level:

- a rise due to decreased acid inhibition

- a decrease due to decreased vagal release of gastrin.

The first principle seems to dominate in man over the second, which dominates in dogs ${ }^{338}$.

Further proof hereof can be derived from the comparison of the effect of HSV and selective vagotomy on serum gastrin, both having the same effect qualitatively and quantitatively, demonstrating that the antral vagal innervation does not play a significant role in gastrin release ${ }^{74,150,308,334,335}$.

In contrast Ahonen (19796), Malmström (1979 239 ) and Lam (1978 $\left.{ }^{215}\right)$ have postulated that the antral nerve supply suppresses the release of gastrin, contrary to the earlier concept of the opposite.

However, no correlation between the gastrin levels and the measured gastric acid secretion was found, either before or after operation ${ }^{62,87}$.

It is improbable that the rise could be explained wholly or partially by obstruction ${ }^{8}$, since few patients had symptoms of nausea, vorniting and foul eructation. Moreover in about $35 \%$ of the patients at some time after operation a X-ray was made and in no case there was evidence of delayed emptying or obstruction except in the two cases described elsewhere, who were clearly symptomatic.

This was found also by Largiader $\left(1976^{219}\right)$.

It is difficult to explain the further rise in gastrin more than 2 years after operation. This fact has not been reported before to the author's knowledge. The majority of authors find a constant elevation 40,178 .

However there was a striking shift to higher gastrin values in patients operated upon more recently; this was found both before and after operation at all interval dates whenever the serum gastrin level was determined. One could speculate that the preoperative use of cimetidine is to be held responsible, as the longstanding use of cimetidine is known to increase the basal gastrin values ${ }^{45,119}$ but this was also denied 22. It is not certain whether these values should be normalised after cessation of cimetidine.

Therefore the gastrin values before and after operation were compared separately in the group of patients who had never used cimetidine with those who did (table IV). The results show a significant difference between the two groups at all time periods. In both groups of patients there is a postoperative increase similar to that already 
lable IV

busal serum gastrin and preoperative cimetidiue use, all pathents, ngh

\begin{tabular}{|c|c|c|c|c|c|}
\hline $\begin{array}{l}\text { o }^{4} \& \\
\text { including rec }\end{array}$ & props & $\begin{array}{l}\text { wyear } \\
\text { postop }\end{array}$ & $\begin{array}{l}1 \text { year } \\
\text { postop }\end{array}$ & $\begin{array}{l}2 / 3 / 4 \text { years } \\
\text { postop }\end{array}$ & $\begin{array}{l}567 / 6 \text { years } \\
\text { postop }\end{array}$ \\
\hline $\begin{array}{l}\text { no cimetidine } \\
\text { wse preoperatively }\end{array}$ & $\begin{array}{l}105.3 \\
5000.3 \\
n=107\end{array}$ & $\begin{array}{l}167.6 \\
5 d 99.0 \\
n=91\end{array}$ & $\begin{array}{l}178.9 \\
\mathrm{sd} 94.9 \\
\mathrm{n}=8 \mathrm{l}\end{array}$ & $\begin{array}{l}175.0 \\
s d 97.5 \\
n=76\end{array}$ & $\begin{array}{l}229.9 \\
s d 128.6 \\
n=64\end{array}$ \\
\hline $\begin{array}{l}\text { cimetidine } \\
\text { whe preoperatively }\end{array}$ & $\begin{array}{l}139.6 \\
\text { s.d } 65.1 \\
n=83\end{array}$ & $\begin{array}{l}254.6 \\
s d 186.0 \\
n=64\end{array}$ & $\begin{array}{l}246.01 \\
\mathrm{sd} 159.0 \\
\mathrm{n}=52\end{array}$ & $\begin{array}{l}288.5 \\
s d 213.9 \\
n=20\end{array}$ & \\
\hline
\end{tabular}

described. In both, there seems also to be a secondary rise, starting earlier in the group who used cimetidine. The secondary rise in the group who never used cimetidine is significant in relation to the preceding period, but this rise in the cimetidine group is not, possibly due to too small a number of patients and too large a spreading. The significance of the rise in gastrin is not well understood. The author can find no explanation why the serum gastrin stays at a higher level in patients who used cimetidine before operation compared to those who did not.

The use of cimetidine cannot explain all phenomena since the group who never used this drug showed a similar rise. In fact the values $5,6,7$ and 8 years after operation were all obtained from patients operated upon before the introduction of cimetidine. Cimetidine just seems to amplify the effect of HSV on serum gastrin.

Another explanation, although only valid for the postoperative state is that in the latter half of the series a more extensive denervation took place in the region of the corpus-antrum border. It has been demonstrated by Poppen ${ }^{288}$ and Ahonen ${ }^{6}$ that a more distal dissection leads to higher gastrin values. However this is at variance with the finding, that after a selective vagotomy gastrin levels increase to the same extent as after HSV.

No evidence was found of the Zollinger-Ellison syndrome in the HSV patients norin the patients treated with any other method during the 8 years of study, although statistically it should have occurred. Not a single HSV patient showed a BAO/PAO ratio over 0.60 . There were no cases of renal insufficiency or of pernicious anaemia detected.

It has been suggested (Fritsch ${ }^{86}$ ) that duodenal ulcer patients with normal acid secretion have higher gastrin levels in their blood than patients with hypersecretion; this hypersecretion could be the consequence of a past hypergastrinaemia causing a hyperplasia of parietal cells (trophic effect).

If so, one would expect higher secretion levels with increasing length of ulcer history. In the material studied there was no difference between the gastrin levels in hyperand normosecretors. Furthermore there was no difference in preoperative acid secretion data between patients with a long and with a short history (see table V). These data do not suggest the consequences of the increasing gastrin values. So far, no increasing acid secretion has been found and there was no relation with the development of recurrences $\left({ }^{178.246}\right)$.

Is there an increased risk of gastric cancer due to hypergastrinaemia? (Wieman ${ }^{368}$ ). There is no evidence at present in support of this contention. No cases of gastric 
table $\mathrm{V}$

length of history and mean basal gastrin, BAO \& PAO in the course of time. all patients

\begin{tabular}{|c|c|c|c|c|c|}
\hline \multicolumn{2}{|c|}{$\sigma^{7} Q$ (including rec) } & preop & Wyrpostop & Iyrpostop & Syrposrop \\
\hline \multirow{3}{*}{$\begin{array}{l}\text { length of } \\
\text { history } \\
\leqslant 10 \text { years }\end{array}$} & $\begin{array}{l}\text { gastrion mf } \\
\text { mests } \pm \text { sd: } \\
\text { (n) }\end{array}$ & $\begin{array}{c}115 \pm 50 \\
(53)\end{array}$ & $\begin{array}{c}200 \pm 119 \\
(75)\end{array}$ & $\begin{array}{c}198.4 \pm 95 \\
(82)\end{array}$ & $\begin{array}{c}243 \pm 174 \\
(32)\end{array}$ \\
\hline & $\begin{array}{l}\text { BAO ramodih } \\
\text { mean } \pm \text { sd } \\
\text { (n) }\end{array}$ & $\begin{array}{c}6.3 \pm 7.3 \\
(135)\end{array}$ & $\begin{array}{c}2.2 \pm 2.8 \\
(95)\end{array}$ & $\begin{array}{c}2.6 \pm 3.0 \\
(81)\end{array}$ & $\begin{array}{c}3.3 \pm 3.7 \\
(32)\end{array}$ \\
\hline & $\begin{array}{c}\text { PAO namol/h } \\
\text { mean } \& \text { sd } \\
\text { (n) }\end{array}$ & $\begin{array}{c}55.6 \pm 23.2 \\
(139)\end{array}$ & $\begin{array}{c}28.5 \pm 17.4 \\
(95)\end{array}$ & $\begin{array}{c}27.5 \pm 13.4 \\
(81)\end{array}$ & $\begin{array}{c}29.4 \pm 12.9 \\
(32)\end{array}$ \\
\hline \multirow{3}{*}{$\begin{array}{l}\text { length of } \\
\text { history } \\
>10 \text { years }\end{array}$} & $\begin{array}{c}\text { gastrin ngt } \\
\text { mean } \pm \text { sd } \\
(m)\end{array}$ & $\begin{array}{c}128 \pm 83 \\
(70)\end{array}$ & $\begin{array}{c}209 \pm 187 \\
(58)\end{array}$ & $\begin{array}{c}206 \pm 155 \\
(50)\end{array}$ & $\begin{array}{c}236 \pm 115 \\
(15)\end{array}$ \\
\hline & $\begin{array}{c}\text { BAO mmol/ht } \\
\text { meand se } \\
\text { (in) }\end{array}$ & $\begin{array}{c}6.0 \pm 6.3 \\
(70)\end{array}$ & $\begin{array}{c}1.9 \pm 2.4 \\
(48)\end{array}$ & $\begin{array}{c}2.0 \pm 2.3 \\
(44)\end{array}$ & $\begin{array}{c}2.8 \pm 2.3 \\
(10)\end{array}$ \\
\hline & $\begin{array}{l}\text { PAO mnubl/h } \\
\text { mean w sdl } \\
\text { (n) }\end{array}$ & $\begin{array}{c}57.7 \pm 26.3 \\
(71)\end{array}$ & $\begin{array}{c}27.5 \pm 13.6 \\
(48)\end{array}$ & $\begin{array}{c}23.2 \pm 13.8 \\
(44)\end{array}$ & $\begin{array}{c}26.6 \pm 9.1 \\
(10)\end{array}$ \\
\hline & & n.s & n.s. & n.s. & n.s.s. \\
\hline
\end{tabular}

carcinoma have been reported so far after HSV, but they might take longer than the present study period ( 8 years) to develop.

However the incidence of carcinoma of the stomach after truncal vagotomy has not been reported to be higher than the incidence expected in the whole population. Moreover the drainage procedure should more probably be incriminated for those cases ${ }^{172,315}$.

\subsection{Conclusion}

The conclusion of this study on gastrin must be that its role is not understood ${ }^{367}$. There is no correlation with acid production either preoperatively or postoperatively. Gastrin appears to behave quite independently.

Even patients with no acid reduction at all more often than not showed a rise in serum gastrin. Conversely, there were patients without any gastrin rise postoperatively "in spite of" a substantial reduction is acid production.

Fritsch and Hengels ${ }^{87}$ postulated that HSV causes a disinhibition of an oxyntopyloric reflex or (in easier words) that by the operation not only vagal fibres are severed which stimulate the parietal cells to acid production, but that aiso fibres are cut which cause an inhibition of the production or release of gastrin by the G cells of the antrum. 


\section{Chapter 12}

\section{Serum Vitamin $\mathrm{B}_{12}$}

\subsection{Introduction}

One of the effects to be expected from denervation such as vagotomy expectedly is a reduction of the activity of the organ or cells denervated.

In HSV the parietal cells are intentionally denervated, resulting in reduced spontaneous and stimulated production of acid and pepsin 19, $114,301,333$; this has been demonstrated also in this study with regard to acid secretion.

Little is known however about parietal cell dependant intrinsic factor (IF) ${ }^{4}$. One of the metabolic sequelae which can follow gastric resections is pernicious anaemia and neurological disorders on the basis of vitamin $B_{12}$ deficiency $201,317,352$. In such cases evidently the remaining parietal cells were not able to keep up production of enough IF to enable the body to absorb sufficient vitamin $\mathbf{B}_{12}$. Other intestinal disturbances caused by the same operation may also contribute to a decreased absorption leading to the deficiency; therefore many patients need regular suppletion to prevent vitamin $\mathbf{B}_{12}$ deficiency. Nevertheless only a minority develop this and even Visick did not see any cases of pernicious anaemia following his measured radical gastrectomy whereby about $95 \%$ of the stomach was removed.

Meikle et al. $\left(1977^{251}\right)$ demonstrated a reduction of IF in the stomach juice 3 months after HSV and TV \& PP, compared with the preoperative production in the same patients. He expressed the view that this reduction might be permanent or even progressive and proved that the vagotomy was responsible. He demonstrated also $\left(1976^{250}\right)$ an increasing gastritis of the proximal stomach after operation, which was found by Poppen as well ${ }^{287}$.

This might explain a decreased IF production and vitamin $B_{12}$ absorption. It is not known whether this leads to clinically detectable deficiency in the long term.

The vitamin $B_{12}$ levels in the serum were studied regularly in a substantial number of patients who underwent a HSV, both before and after operation.

\subsection{Materials and methods}

From November 1976 the laboratory was able to determine the vitamin $\mathbb{B}_{12}$ content of the blood (R.I.A., Becton \& Dickinson). Preoperative values were obtained from 110 patients. Postoperatively a differing number of values were available from each follow-up period, not necessarily being from the same patients.

The average and median values for each period were calculated as were the values of pre-and postoperatively corresponding determinations (as was done with the gastrin values, chapter 11 ).

The method of measuring vitamin $B_{12}$ was changed in May " 79 from total into the more accurate true cobalamine determination. A correction factor, derived from the laboratory standards was used to adjust total into true cobalamine data. Although averages of the old and the new determination do have a constant relationship, the difference, however, can vary from sample to sample depending on the contents of non-specific impurities in the old determination procedure. Individual values are 
therefore not strictly comparable to each other.

For convenience of comparison the entire cobalamine data have been presented in their adjusted values (the correction factor was 0.65 ).

\subsection{Results}

In table I the average and median vallues have been presented for all follow-up periods. The course of these values has been illustrated in figure 1 . There were few values $1 / 2$ year after operation since this determination was not intended in the follow-up protocol. There was a slight tendency to decrease which was, however, not significant.

table I

serum vitamin $B_{12}$ all paticnts

nmolll

normal raroge: $\$ 150 \mathrm{nmol} /$

\begin{tabular}{|c|c|c|c|c|c|c|c|c|c|c|}
\hline & preop & $R_{/ 2}$ & $y$ & 2 & 3 & 4 & 5 & 6 & $7 / 8$ & yr postop \\
\hline median & 311.0 & 2650 & 265.5 & 255.5 & 275.0 & 260.5 & 280.5 & 245.5 & 240.0 & \\
\hline mean & 311.0 & 2805 & 271.7 & 282.8 & 289.7 & 299.1 & 280.0 & 269.9 & 264.1 & \\
\hline $\mathrm{sd}$ & 90.7 & 62.1 & 83.4 & 110.7 & 113.2 & 122.3 & 112.3 & 130.1 & 108.9 & \\
\hline$n$ & $\mathbb{1 1 0}$ & 19 & 76 & 68 & 48 & 48 & 45 & 24 & 11 & \\
\hline range & $144-725$ & $200-438$ & 97.560 & $70-680$ & $90-754$ & $120-624$ & $111-635$ & $90-540$ & 100.510 & \\
\hline & & & & \multicolumn{3}{|c|}{ 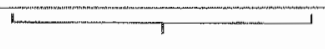 } & \multicolumn{3}{|c|}{ 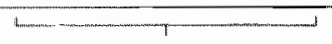 } & \\
\hline & & & & \multicolumn{3}{|c|}{ if combined } & \multicolumn{3}{|c|}{ if combined } & \\
\hline & & & & \multicolumn{3}{|c|}{ median $\quad 270.0$} & \multirow{2}{*}{\multicolumn{2}{|c|}{ median }} & 260,0 & \\
\hline & & & & \multicolumn{2}{|c|}{ meary } & 289.3 & & & mean & \\
\hline & & & & \multicolumn{2}{|c|}{ sd } & & \multicolumn{2}{|c|}{ sd } & & \\
\hline & & & & \multicolumn{2}{|c|}{$\mathrm{n}$} & & \multicolumn{2}{|c|}{$\mathrm{n}$} & & \\
\hline
\end{tabular}

figure 1

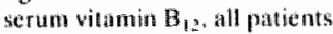

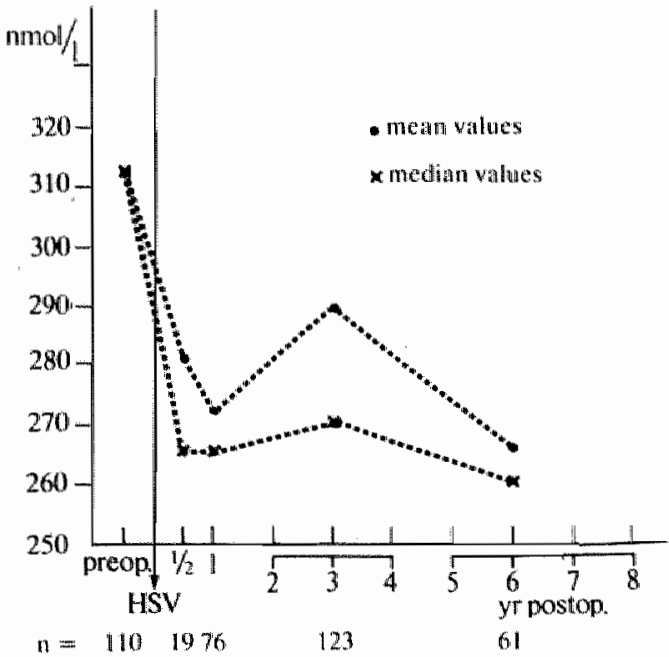


Table II shows the results of coupled data: only those postoperative values were used if a preoperative value was present. All postoperative values were averaged in each patient to one value; the mean of these values has been compared to the mean preoperative data for men with and without a recurrence and women with and without a recurrence. There were, however, no suitable values in the two women with a recurrence. Although the overall data again suggest a minimal decrease, the differences were not significant for the women and the men with a recurrence but were just significant for the whole group and significant for the men without a recurrence.

table II

serum vitamin $B_{12}$, coupled values

nmol/1

\begin{tabular}{|c|c|c|c|c|c|c|}
\hline & & $\operatorname{rec} \sigma^{n}$ & non-reco" & reces & nom-res? & $a l l$ \\
\hline preop & $\begin{array}{l}\text { mean } \\
\text { sd } \\
n\end{array}$ & $\begin{array}{l}260.9 \\
76.6 \\
8\end{array}$ & $\begin{array}{l}320.7 \\
92.9 \\
87\end{array}$ & - & $\begin{array}{l}281.7 \\
71.8 \\
15\end{array}$ & $\begin{array}{l}311.0 \\
90.7 \\
110\end{array}$ \\
\hline postop & $\begin{array}{l}\text { mean } \\
\text { sid } \\
n\end{array}$ & $\begin{array}{l}283.9 \\
101.7 \\
6\end{array}$ & $\begin{array}{l}277.1 \\
96.8 \\
54\end{array}$ & . & $\begin{array}{l}292.1 \\
97.4 \\
11\end{array}$ & $\begin{array}{l}280.0 \\
96.0 \\
71\end{array}$ \\
\hline
\end{tabular}

Using strictly coupled data (table III) the only significant decrease was between preoperative values and values 1 year postoperatively. The increases at $2 / 3 / 4$ and $5 / 6 /$ $7 / 8$ years after operation were not significant.

If only data of men without a recurrence had been used the picture would have been the same, showing no difference after 2 or more years.

table III

serum witamin $\mathrm{B}_{12}$, all patients

strictly couplod values, nmoll

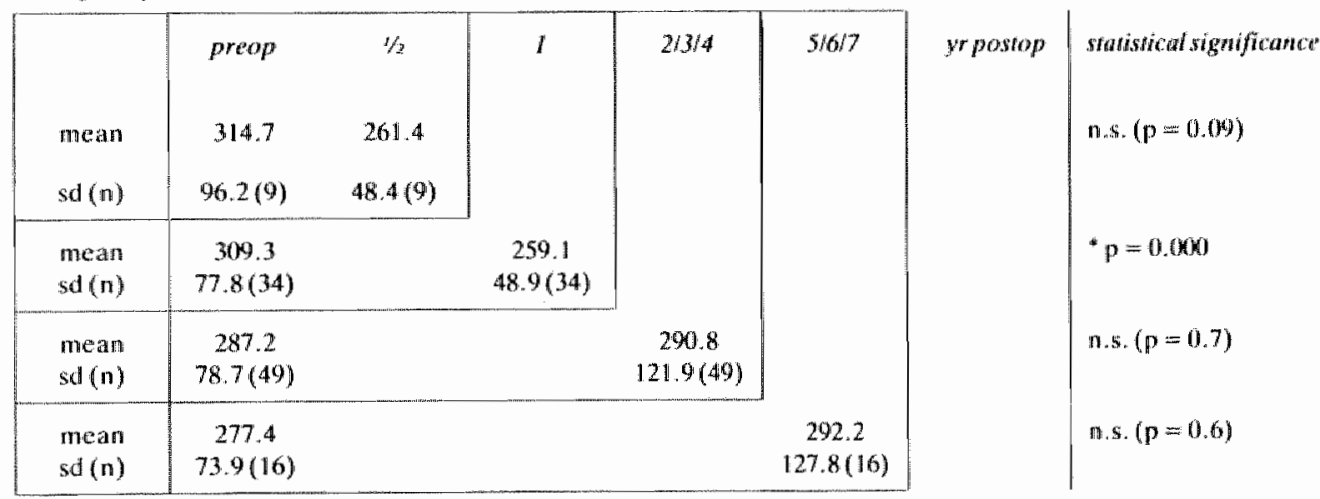


Table IV shows a comparison of all determinations with the old and with the new method. The old method (total cobalamine determination) resulted in slightly lower values after correction into true cobalamine values than the new and the spreading was smaller. Both methods demonstrated the tendency to decrease but not significantly so. The preoperative mean values differed just significantly. If - separately for both determinations - all postoperative values were averaged and compared to the mean preoperative value the difference with the old determination method was below the statistical significance level, but this was significant with the new determination.

table IV

comparison of serum vitamin $B_{12}$ data obtained from old and new determination

\begin{tabular}{|c|c|c|c|c|c|c|c|}
\hline \multicolumn{4}{|c|}{ old determination } & \multicolumn{4}{|c|}{ new determination } \\
\hline & mean & $s d$ & $n$ & & mhean & $s d$ & $n$ \\
\hline preop & 290.1 & 75.0 & 60 & preop & 336.2 & 101.8 & 50 \\
\hline $1 / 2$ & 270.4 & 24.3 & 8 & $1 / 2$ & 287.9 & 79.9 & 11 \\
\hline 1 & 272.7 & 79.2 & 36 & 1 & 270.9 & 88.1 & 40 \\
\hline 2 & 261.1 & 85.4 & 22 & 2 & 293.2 & 120.4 & 46 \\
\hline 3 & 246.6 & 63.7 & 9 & 3 & 299.6 & 120.3 & 39 \\
\hline 4 & 281.5 & 40.3 & 2 & 4 & 299.9 & 124.9 & 46 \\
\hline 5 & & & & 5 & 280.0 & 112.3 & 45 \\
\hline 6 & & & & 6 & 269.9 & 130.1 & 24 \\
\hline 7 & & & & 7 & 257.5 & 118.3 & 8 \\
\hline 8 & & & & 8 & 285.0 & 80.6 & 4 \\
\hline $\begin{array}{c}y r \\
00 s t a n\end{array}$ & & & & yr & & & \\
\hline postop & & & & postop & & & \\
\hline
\end{tabular}

\section{$12.4 \quad$ Discussion}

The results show a stightly decreasing tendency in the vitamin $B_{12}$ level in the blood in the patients up to 8 years following HSV. Several calculations have been made to exclude the biasing influences of data obtained from differing populations of patients and from two different methods of determination.

The decrease was, comparing the strictly coupled data, only significant at 1 year after operation but no difference at all was apparent $2 / 3 / 4$ and $5 / 6 / 7 / 8$ years after operation.

Nevertheless several patients showed a surprisingly low true cobalamine level in their blood at some time after HSV, whereas they did not do so before operation.

Preoperatively there were $1 \mathbb{1}$ patients in the lower range $(.200 \mathrm{nmol} / \mathrm{l})$ of normal values; postoperatively this number grew to 41 and 18 were below the normal range $(\alpha 150 \mathrm{nmol} / \mathrm{l})$ in contrast to 2 before operation. Of few patients it was known that they received a vitamin $B_{12}$ in jection from their family doctor or from us at some time after operation; the values obtained thereafter were excluded.

It is possible, however, that some others received a similar injection without our 
knowledge since vitamin $B_{12}$ injections are readily given for non-specific complaints like tiredness. These patients would evidently show a higher vitamin $B_{12}$ level, but have not been excluded. This may have obscured a more significant decrease than was demonstrated in the figures. The categories of patients most likely to undergo this treatment with vitamin injections were the women and the patients with a recurrence. Both categories showed a slight and non-significant increase in the strictly coupled data.

Using coupled data (table II) both groups again showed no decrease whereas the men without a recurrence did and significantly so (from 320.7 - 277.1 nmol/l). Another bias examined could be the slight difference in values resulting from either method of determination. The patients with the longest follow-up had the old method used for determining their preoperative values, but the new one was used for the data more than two years after operation. It was demonstrated that the difference between the two methods was just significant. This worked against a decreasing tendency which nevertheless was apparent, although not significantly so. When the average of all postoperative new determinations was compared to the preoperative average the difference was highly significant (336.2 nmol// ( $\mathrm{sd} 101.8$, n $=50)-286.1 \mathrm{nmol} / 1$ (sd 113.4, $\mathrm{n}=263$ ), $\mathrm{p}$ <0.01).

Surprisingly, the strictly coupled data are the only ones not in favour of a decrease except at 1 year after operation, but the number of patients for comparison later are relatively small and the figures are biased by a comparison between preoperative old determinations and postoperative new determinations in all cases.

Meikle ${ }^{250,251}$ has shown in two studies that intrinsic factor production decreases after HSV and that atrophic gastritis of the proximal stomach occurs. He suggested that this might lead to vitamin $B_{12}$ deficiency just as partial gastrectomy did. Muller $\left(1980^{266}\right)$ did not find any reduction in serum vitamin $\mathbb{B}_{12}$ levels up to 5 years after operation. In this series there were no patients developing signs of pernicious anaemia and the average haemoglobin content in the blood remained unchanged (see chapter 13).

More prolonged studies will be needed to clarify this phenomenon but a certain degree of suspicion seems justified.

However, it should not be forgotten that ageing of the patients could contribute to any change, especially to a decrease. 


\section{Chapter 13 \\ Metabolic parameters}

\subsection{Introduction}

Partial gastrectomy was the former operation of choice in the Netherlands for duodenal ulcer. Apart from being a more mutilating procedure than HSV with other sequelae, the possible metabolic consequences of this operation in the long term were great disadvantages.

Among them were described: loss of weight, bone disease, diminished uptake of iron and consequently iron-deficiency anaemia $53,57,94,172,201,294,317$.

Therefore patients who had undergone a partial gastrectomy were screened regularly for metabolic changes.

This practice was continued when HSV was introduced. At each yearly follow-up examination haemoglobin, ESR, alkaline phosphatase, iron, total iron binding capacity, calcium and phosphate in the blood were determined and the body-weight measured.

The results of these examinations are reported here.

\subsection{Results}

\subsubsection{Weight}

In order to prevent groups and subgroups with too few data the values at $2 / 3 / 4$ years and $5 / 6 / 7 / 8$ years after operation have been taken together (after averaging more than one value in each patient in each period).

As shown before (chapter 4), and as was expected, there was a significant difference in the mean weight between men and women. Therefore they are considered separately.

About $20 \%$ of the patients stated that they had lost weight prior to operation.

Although their original weight was not objectivated they were examined as at separate group as far as their weight was concerned.

\section{Results}

The results for all men and all women are illustrated in table $I$ and figure 1.

table I

\begin{tabular}{|c|c|c|c|c|c|c|c|}
\hline & & preop & $1 / x$ & 1 & $213 / 4$ & $5 / 617$ & yrpasrop \\
\hline $0^{A}$ & $\begin{array}{l}\text { mean } \\
\text { sd (n) }\end{array}$ & $\begin{array}{c}73.1 \\
11.1(162)\end{array}$ & $\begin{array}{c}74.9 \\
11.1(106)\end{array}$ & $\begin{array}{c}75.3 \\
10.6(79)\end{array}$ & $\begin{array}{c}75.8 \\
11.0(\| 10)\end{array}$ & $\begin{array}{c}74.6 \\
11.1(36)\end{array}$ & \\
\hline 9 & $\begin{array}{l}\text { mean } \\
\text { sd }(n)\end{array}$ & $\begin{array}{c}61.7 \\
9.7(41)\end{array}$ & $\begin{array}{c}62.5 \\
11.1(26)\end{array}$ & $\begin{array}{c}64.3 \\
9.4(19)\end{array}$ & $\begin{array}{c}66.7 \\
11.9(28)\end{array}$ & $\begin{array}{c}65.5 \\
10.8(17)\end{array}$ & \\
\hline
\end{tabular}




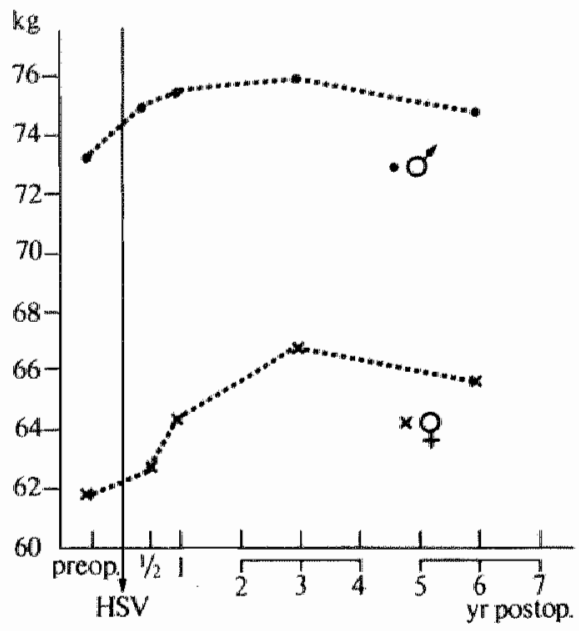

Both men and women showed a steady increase in weight after operation, followed by a slight decrease after more than 5 years. If the men with reported preoperative weight loss were considered separately a similar increase was observed.

Their preoperative mean weight did not differ from that of the other men. Considering the women with preoperative loss of weight, roughly there appeared to be an increase as well, but their numbers were so small (less than 10 in all periods) that nothing could be said with accuracy and strictly coupled values had to be looked for. To obtain a general overview between patients with and without a recurrence, subdivided into men and women, coupled values appeared useful: all postoperative values in each patient were averaged and the mean value of the averages was compared to the mean preoperative value (no postoperative values were used if there was no corresponding preoperative value). The results are shown in table II.

table III

weight, coupled valucs, $\mathrm{kg}$

\begin{tabular}{|c|c|c|c|c|}
\hline & $\sec 0^{\pi}$ & non-recon & $\operatorname{rec} q$ & non-ree? \\
\hline proop neatu & 67.8 & 73.6 & 72 & 61.4 \\
\hline $\mathrm{sdl}(\mathrm{n})$ & $9.9(1.3)$ & $11.1(149)$ & (i) & $9.7(40)$ \\
\hline postopmean & 70.4 & 77.3 & 68.3 & 63.9 \\
\hline $\mathrm{sd}(\mathrm{n})$ & $11.5(11)$ & $10.8(111)$ & (1) & $9.7(33)$ \\
\hline
\end{tabular}

In all categories except one there wase gain of weight. The woman with a recurrence did not show this gain, but she was overweight at the time of operation.

If strictly coupled values were used in men and women with reported weight loss before operation, there was a gain at all periods for both categories. The maximum 
gain for men was $6 \%$ of their preoperative weight, for the women $17 \%$, but these women showed a lower preoperative weight than the women without prior weight loss.

The maximal gain in weight for the men and women without prior weight loss amounted to $8 \%$ and $5 \%$ respectively.

The values of the paired data (table III) for men and women with and without preoperative weight loss (in the figure: $+w .1$. and $-w .1$.) have been transformed suitably to be plotted graphically in figure 2 . The transformation procedure has been extensively explained in chapter 10 dealing with $\mathrm{BAO}$ data. For comparison, the paired data of weight of all men and all women have been plotted as well (figure 3 ).

\section{table III}

weight of men and women with $(+$ wl) and without $(-$ wl)preoperative weight loss,

strictly coupled values, $k g$

\begin{tabular}{|c|c|c|c|c|c|c|c|c|}
\hline & \multicolumn{4}{|c|}{$\sigma^{\prime \prime}$} & \multicolumn{4}{|c|}{9} \\
\hline $\begin{array}{l}\text { wetgt } \\
m \mathrm{~kg}\end{array}$ & & & & & $-n$ & & H. & \\
\hline$H / z$ & $\begin{array}{l}\text { preop } \\
74.2 \\
11.4(65)\end{array}$ & $\begin{array}{l}\text { postop } \\
76.7 \\
12.3(65)\end{array}$ & $\begin{array}{l}\text { preop } \\
73.1 \\
9.1(8)\end{array}$ & $\begin{array}{l}\text { postop } \\
74.6 \\
7.3(8)\end{array}$ & $\begin{array}{l}\text { preop } \\
61.4 \\
10.3(15)\end{array}$ & $\begin{array}{l}\text { postop } \\
63.1 \\
10.3(15)\end{array}$ & $\begin{array}{l}\text { preop } \\
59.8 \\
11.1(6)\end{array}$ & $\begin{array}{l}\text { postop } \\
62.7 \\
12.1(6)\end{array}$ \\
\hline 1 & $\begin{array}{l}74.9 \\
13.2(47)\end{array}$ & $\begin{array}{l}76.1 \\
12.1(47)\end{array}$ & $\begin{array}{l}74.3 \\
7.6(7)\end{array}$ & $\begin{array}{l}78.3 \\
5.9(7)\end{array}$ & $\begin{array}{l}62.5 \\
9.5(15)\end{array}$ & $\begin{array}{l}64.4 \\
8.3(15)\end{array}$ & & \\
\hline $2 / 3 / 4$ & $\begin{array}{l}74.4 \\
12.5(68)\end{array}$ & $\begin{array}{l}77.4 \\
12.2(68)\end{array}$ & $\begin{array}{l}71.1 \\
10.5(11)\end{array}$ & $\begin{array}{l}74.8 \\
8.5(11)\end{array}$ & $\begin{array}{l}62.4 \\
10.3(18)\end{array}$ & $\begin{array}{l}65.8 \\
10.5(18)\end{array}$ & $\begin{array}{l}56.6 \\
12.1(5)\end{array}$ & $\begin{array}{l}66.2 \\
15.1(5)\end{array}$ \\
\hline $\begin{array}{l}5 / 67 \\
\text { yr postop }\end{array}$ & 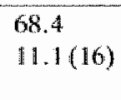 & $\begin{array}{l}73.7 \\
14.3(16)\end{array}$ & $\begin{array}{l}75.7 \\
11 . \|(4)\end{array}$ & $\begin{array}{l}77.7 \\
9.4(4)\end{array}$ & $\begin{array}{l}62.5 \\
6.9(8)\end{array}$ & $\begin{array}{l}62.2 \\
7.7(8)\end{array}$ & $\begin{array}{l}58.0 \\
11.6(6)\end{array}$ & $\begin{array}{l}65.2 \\
8.9(6)\end{array}$ \\
\hline
\end{tabular}

figure 2

weghth, men and women, with $(+$ wil) and without (-wi) preoperative weight loss, strictly coupled walues

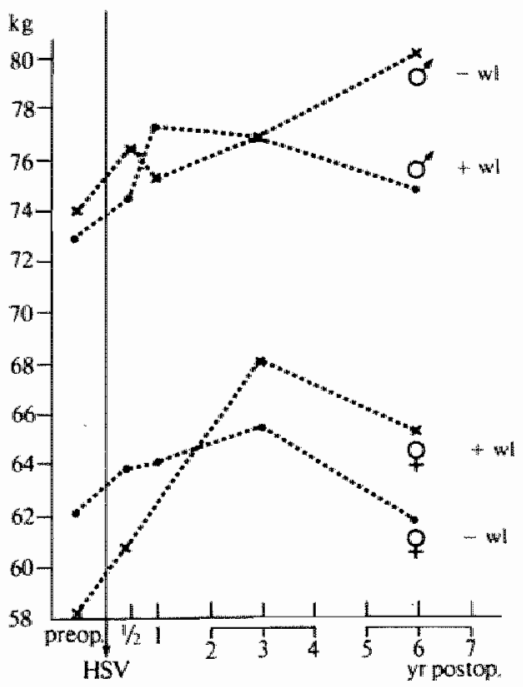

figure 3

weight, men and women, strictly coupled wathes

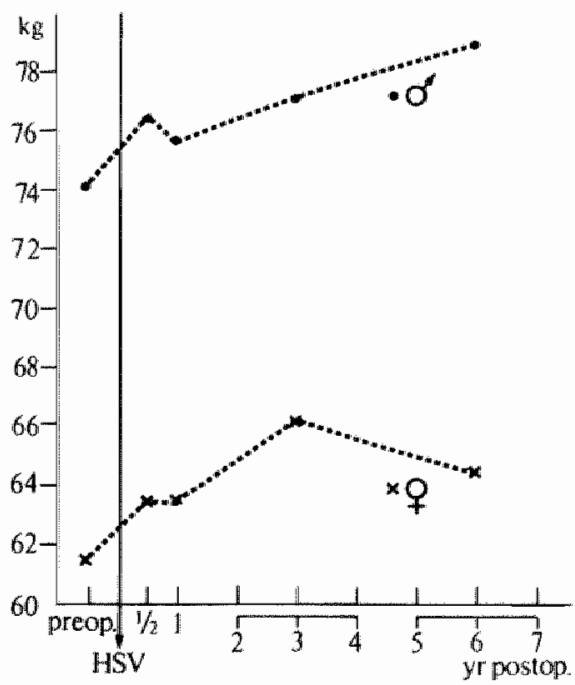




\section{Discussion}

The difference between patients who claimed to have lost weight and those who did not was not remarkable; in men the mean preoperative weights were 71.2 and 73.5 $\mathrm{kg}$ and in women 56.3 and $63.2 \mathrm{~kg}$ respectively. Both differences were not statistically significant.

All categories of patients gained some weight on average after operation, which generally meant that their condition did not become worse as a consequence of operation.

Sometimes the weight gain was excessive and a considerable number (predominantly women) claimed to be on a regimen to lose weight again.

This was probably the reason for the decline of the slope after some years of followup.

There was no striking difference with the patients who developed a recurrence. Although they weighted less at the time of operation this difference was just not significant $(p=0.07)$. The average gain in weight was of the same order as in the other patients.

\section{Conclusion}

The conclusion of this study is that in general there is an increase in weight after operation, although most patients were not underweight at the time of operation.

\subsubsection{Haemoglobin (Hb)}

The haemoglobin content of the blood was measured before operation and at yearly intervals thereafter. It was not intended to be determined $1 / 2$ year after operation, but on many occasions it was done, as with other parameters.

Any change of the haemoglobin content could reflect a change in iron absorption or vitamin $\mathrm{B}_{12}$ depletion.

The iron content of the blood will be described later in this chapter; vitamin $B_{12}$ has been discussed in a separate chapter (chapter 12). Since a significant difference between men and women was expected the figures have been subdivided into data for men and women separately.

The normal values for haemoglobin are:

for men:8.5- $11.9 \mathrm{mmol} / \mathrm{l}$

and for women: $7.5-10.0 \mathrm{mmol} / \mathrm{l}$.

\section{Resulls and discussion}

The results are indicated in table IV and figure 4.

The average haemoglobin level in the blood did not appear to change at all in the course of years. The difference between men and women remains highly significant, as it is in the normal population. If the results between patients with and without a recurrence are compared there is no significant difference at any time period. If the average haemoglobin is compared between men with and without a recurrence - which is more appropriate - there is no difference either. 
hatemoglobine, men and women, mmol/

normal range: men: $8.5-11.0$ mimol/1

women: $7.5-10.0 \mathrm{mmoll}$

\begin{tabular}{|c|c|c|c|c|c|c|c|c|c|c|}
\hline & preop & $w_{2}$ & 1 & 2 & 3 & 4 & 5 & 6 & $7 / 8$ & yrposop? \\
\hline omean & 9.7 & 9.7 & 9.7 & 9.7 & 9.6 & 9.6 & 9.7 & 9.6 & 9.5 & \\
\hline $\mathrm{sd}$ & 0.7 & 0.6 & 0.6 & 0.6 & 0.6 & 0.5 & 0.5 & 0.5 & 0.5 & \\
\hline$n$ & 199 & 45 & 95 & 83 & 63 & 49 & 42 & 18 & 10 & \\
\hline & $\approx$ & * & 踏 & * & 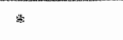 & 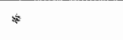 & $*$ & क & n.s. & \\
\hline $\mathrm{p}$ & \multicolumn{6}{|c|}{$p=0.000 p=0.001 p$} & \multicolumn{3}{|c|}{$p=0.000 p=0.007$} & \\
\hline Gmean & 8.8 & 8.9 & 8.8 & 8.9 & 8.7 & 8.9 & 8.9 & 9.0 & 9.4 & \\
\hline$s d$ & 0.8 & 0.9 & 0.5 & 0.5 & 0.4 & 0.5 & 0.5 & 0.5 & 0.8 & \\
\hline$n$ & 43 & 12 & 25 & 26 & 16 & 15 & 15 & 7 & 3 & \\
\hline
\end{tabular}

figntire 4

thacmoglobine, men and women

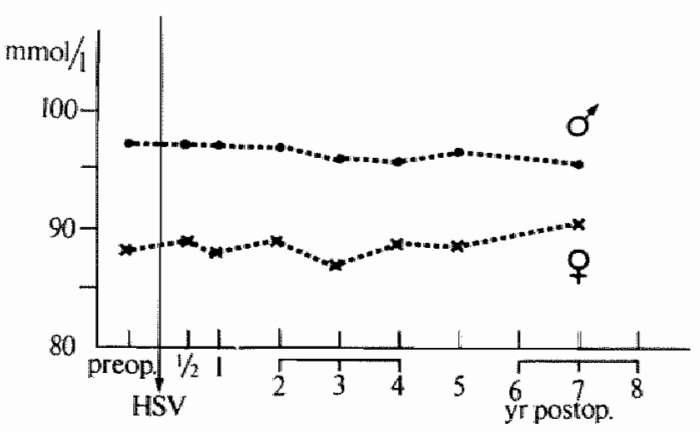

The conclusion is that the haemoglobin level in the blood is not affected by or after the operation.

\subsubsection{Sedimentation Rate of the Erythrocytes (ESR)}

ESR is a general, non-specific parameter, not specially related to stomach diseases. The normal values for men and women are $7 \mathrm{~mm}$ and $12 \mathrm{~mm}$ respectively.

\section{Resuls and discussion}

The results are illustrated in table $\mathrm{V}$ and figure 5.

There was no important change in the period studied.

Surprisingly, however, there appeared to be at several time periods a highly significant difference between men and women (at $1 / 2,1$ and 5 years after operation). Moreover at two time periods (preoperatively and 3 years after operation) the p value was just below statistical significance at the $5 \%$ level.

Probably these differences were due to the difference in normal values. No other explanation appeared satisfactory. The apparent rise in the curve of the men was not significant (t-test for paired data). The ESR values of patients (and, separately: men) 
table V

e rythrocyle sedimentation rate, men and women. mm/st hour mormal range: men: $7 \mathrm{~mm}$

Wonnen: $12 \mathrm{~mm}$

\begin{tabular}{|c|c|c|c|c|c|c|c|c|c|c|}
\hline & preop & $1 / 2$ & 1 & 2 & 3 & 4 & 5 & 6 & $7 / 8$ & yrposiop \\
\hline Ormean & 5.7 & 5.4 & 5.6 & 7.1 & 6.7 & 7.7 & 7.6 & 9.4 & 6.8 & \\
\hline sd & 6.7 & 3.9 & 6.1 & 7.9 & 6.5 & 5.6 & 6.7 & 7.5 & 2.3 & \\
\hline in & 186 & 37 & 87 & 82 & 62 & 48 & 39 & 15 & 6 & \\
\hline p & $\begin{array}{l}\text { n.s. } \\
p=0.06\end{array}$ & $p=0.005$ & $p=0.007$ & nis. & $\begin{array}{l}\text { n.s. } \\
p=0.059\end{array}$ & n.s. & $p=0,004$ & n.s. & nl.s. & \\
\hline 9 mean & 7.9 & 11.4 & 9.7 & 8.8 & 10.2 & 10.5 & 15.3 & 11.8 & 5.5 & \\
\hline sd & 5,9 & 9.3 & 7.9 & 4.8 & 6.6 & 6.5 & 11.7 & 7.8 & 3.5 & \\
\hline ติ & 41 & 7 & 24 & 22 & 17 & 17 & 14 & 7 & 2 & \\
\hline
\end{tabular}

figure 5

erythrocyte sedimentation rate, men and

wornen

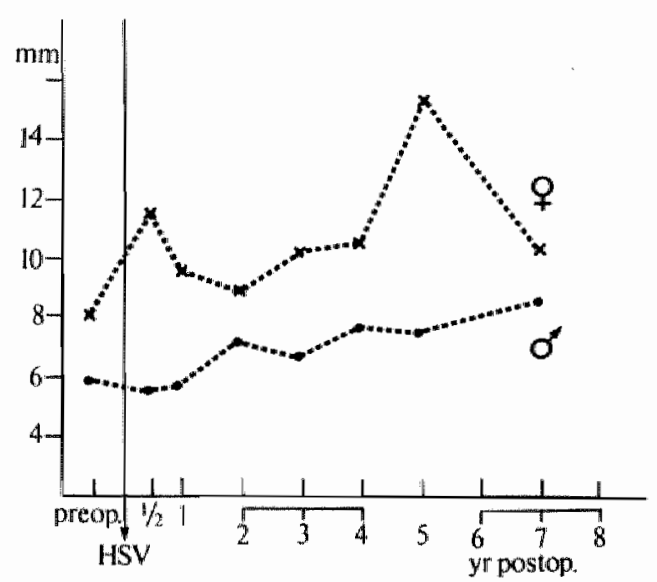

with and without a recurrence were compared as well. At no time period was there a significant difference, which was not expected either.

Conclusion: ESR does not change after HSV and is not indicative for a recurrence.

\subsubsection{Alkaline Phosphatase (AP)}

Serum alkaline phosphatase was determined before operation and at yearly intervals thereafter. It does not have any direct relation with stomach pathology, but it was used as a parameter for bone metabolism ${ }^{201}$.

The normal values are: $30-125 \mathrm{U} / \mathrm{l}$.

\section{Results and discussion}

There was no significant difference between men and women. Therefore all values have been taken together. The results are illustrated in table VI and figure 6. 
serum alkaline phosphatase, all patients $U / 4$

normall range: $30-125 \mathrm{U} / \mathrm{H}$

\begin{tabular}{|c|c|c|c|c|c|c|c|c|c|c|}
\hline & preop & $1 / 2$ & $l$ & 2 & 3 & 4 & 5 & 6 & 718 & yr positop \\
\hline mean & 84.4 & 77.1 & 80.7 & 82.1 & 83.6 & 81.9 & 83.5 & 85.9 & 78.1 & \\
\hline $\mathrm{sd}$ & 27.6 & 32.7 & 25.9 & 23.4 & 23.9 & 19.9 & 18.7 & 20.3 & 28.3 & \\
\hline$n$ & 181 & 36 & 100 & 100 & 76 & 63 & 50 & 27 & 12 & \\
\hline
\end{tabular}

figure 6

serum alkaline phosphatase, all patients

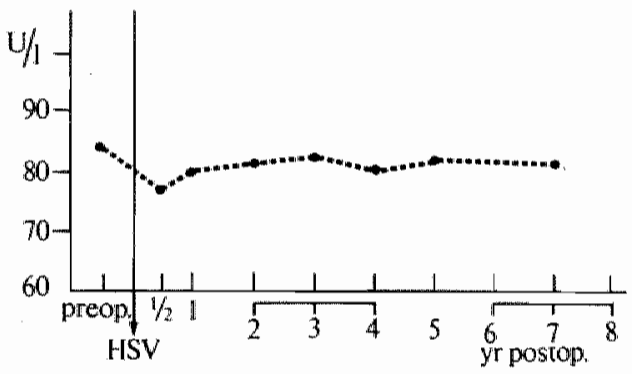

There appeared to be no important changes in the course of time. There were no significant differences either between all patients with and without a recurrence or between men with and without a recurrence.

Conclusion: serum alkaline phosphatase remains stable after HSV and does not have any relation with the development of a recurrence.

\subsubsection{Serum Calcium and Phosphate ( $\mathrm{Ca}$ and $\mathrm{P}$ )}

Calcium and Phosphate were both determined before operation and once yearly thereafter to screen for evidence of bone disease or for suspicion of hyperparathyroidism ${ }^{143,261,332}$. No such cases were diagnosed before or after operation.

Normal values: $\mathrm{Ca}: 2.20-2.60 \mathrm{mmol} / 1$

$$
P: 1.00-1.40 \mathrm{mmol} / 1
$$

\section{Results}

The course of the mean Calcium and Phosphate in the serum of all patients is illustrated in table VII and figure 7. Both fluctuated slightly within narrow limits.

There was neither a significant difference between male and female patients nor between patients (or men only) with or without a recurrence.

Conclusion: the course of serum calcium and phosphate is not changed by or after HSV.

No cases of bone disease or hyperparathyroidism were discovered. Several patients had a further screening for the latter, with negative result ${ }^{265}$. 
lable VII

serum calcium and phosplibate, all patients. mmoll

nomal tange: Cat 2, 20-2.60 mranol/

$P: 1.60-1.40 \mathrm{mmon}$

\begin{tabular}{|c|c|c|c|c|c|c|c|c|c|c|}
\hline & preop & $/ y$ & $\jmath$ & 2 & 3 & 4 & 5 & 6 & $7 / 8$ & yr postop \\
\hline \multicolumn{11}{|l|}{ calciumm } \\
\hline men & 2.42 & 2.42 & 2.41 & 2.43 & 2.45 & 241 & 2.45 & 2.47 & 2.42 & \\
\hline$s d$ & 0.1 & 0.14 & 0.10 & $0 . \|$ & 0.13 & 0.10 & 0.10 & 0.13 & 0.08 & \\
\hline$n$ & 159 & 27 & 105 & 1010 & 76 & 65 & 53 & 26 & 13 & \\
\hline \multicolumn{11}{|l|}{ phosphate } \\
\hline mean & 1.13 & 1.07 & 1.04 & 1.05 & 1,01 & 1. 10 & 1.06 & 1.13 & 1.15 & \\
\hline$s t$ & 0.20 & 0.22 & 0.16 & 0.16 & 0.17 & 0.16 & (0.17 & 0.22 & 0.21 & \\
\hline m & 159 & 27 & 105 & $10 \mathrm{~g}$ & 76 & 65 & 53 & 26 & 13 & \\
\hline
\end{tabular}

[ifgura 7

scrum caldium and phosphate, all patients
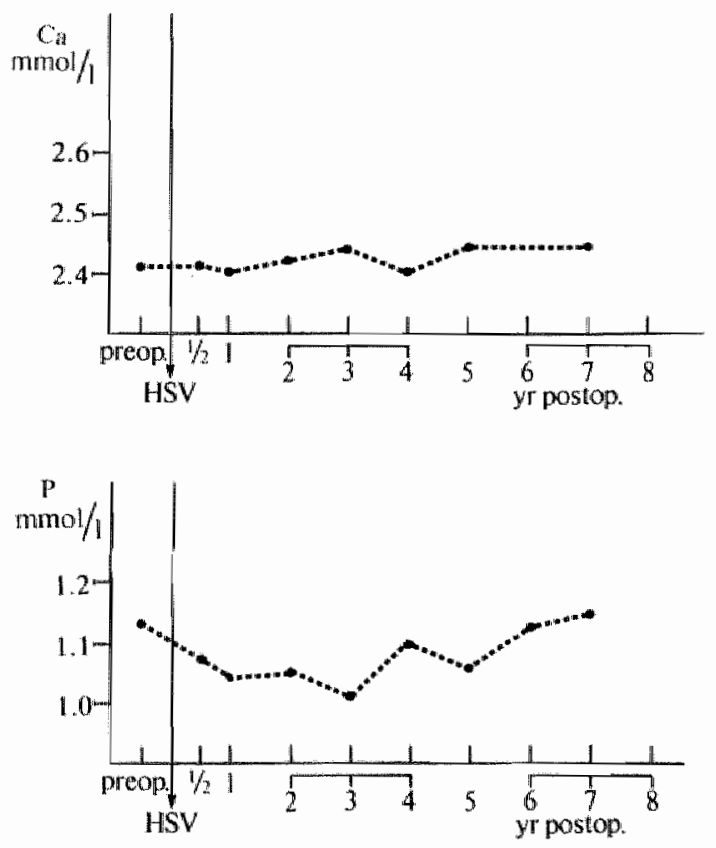

\subsubsection{Serum Iron and Total Iron Binding Capacity (Fe and TIBC)}

Both serum Fe and TIBC were determined before operation and yearly thereafter. The uptake of iron could theoretically be influenced by a diminished acid production of the stomach, brought about by the operation.

Normal values: $\mathrm{Fe} \quad: 14-30 \mu \mathrm{mol} / \mathrm{l}$

$$
\text { TIBC : } 45-75 \mu \mathrm{mol} / 1
$$




\section{Results and discussion}

The results are represented in table VIII and figure 8 . The data of men and women have been taken together since there was generally no difference between them, except for Fe at 1 year after operation, when the men had an average of $19.6 \mu$ molil. (sd $6.8, \mathrm{n}=79$ ) and the women $15.8 \mu \mathrm{mol} / 1(\mathrm{sd} 3.8, \mathrm{n}=26)$ and at 3 years after operation: men: $20.5 \mu \mathrm{mol} / 1$ (sd $6.5, \mathrm{n}=54$ ) and women: $17.1 \mu \mathrm{mol} / / \mathrm{l}(\mathrm{sd} 4.2, \mathrm{n}=$ 18). These differences were probably due to menstrual blood loss.

Between patients with and without a recurrence there were no significant differences at any period, neither with men only.

\section{table VIII}

serum iromand total ir on binding capacity, all patients, 4 mol/

normal range: Fe: $14-30$ pumoll

$\mathrm{TIBC} 45-75 \mu \mathrm{mol} / \mathrm{t}$

\begin{tabular}{|c|c|c|c|c|c|c|c|c|c|c|}
\hline & preop & $1 / 2$ & 1 & 2 & 3 & 4 & 5 & 6 & $7 / 6$ & yr postop \\
\hline \multicolumn{11}{|l|}{ Fe! } \\
\hline mean & 19.1 & 19.8 & 18.7 & 19.1 & 19.7 & 19.9 & 20.5 & 118.7 & 17.8 & \\
\hline $\mathrm{sd}$ & 6.5 & 6.9 & 6.4 & 6.4 & 6.1 & 5.6 & 5.7 & 6.3 & 6.2 & \\
\hline $\mathbf{I}^{n}$ & 144 & 43 & 105 & 93 & 72 & 62 & 52 & 26 & 13 & \\
\hline \multicolumn{11}{|l|}{ TIBC } \\
\hline mean & 60.7 & 59.1 & 60.2 & 59.2 & 59.9 & 60.4 & 61.3 & $\$ 7.5$ & 56.5 & \\
\hline$s d$ & 9.7 & 8.4 & 7.8 & 8.2 & 8.7 & 9.6 & 8.2 & 6.2 & 7.1 & \\
\hline$n$ & 144 & 43 & 104 & 93 & 72 & 62 & 52 & 26 & 13 & \\
\hline
\end{tabular}

figure 8

serum iron and total iron binding capacity

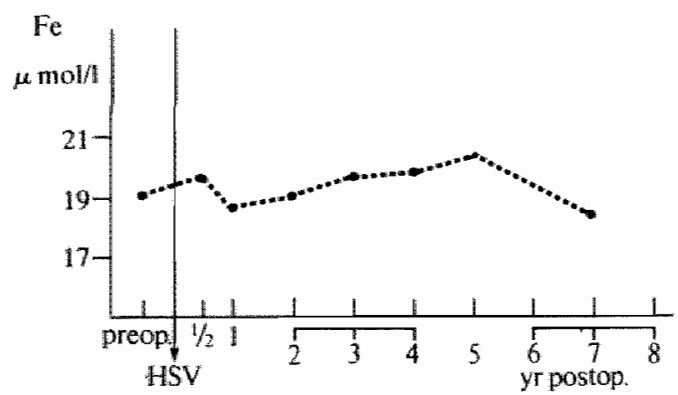

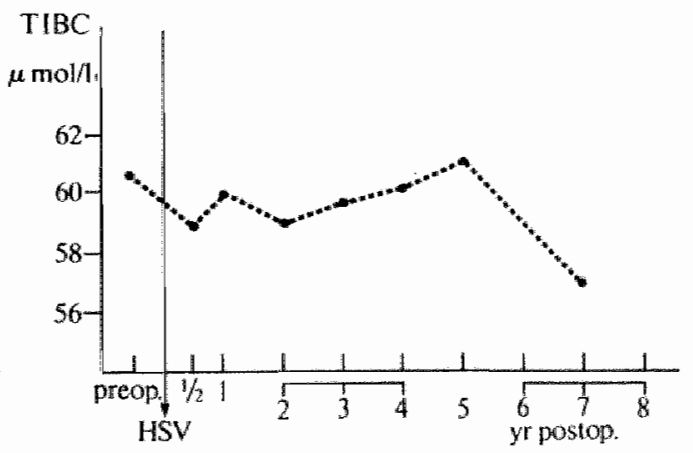

\section{Conclusion}

There is no change after HSV in the serum Fe and TIBC. There was no difference in pattern between men and women and the patients who developed a recurrence did not differ from patients who did not. 


\section{Chapter 14}

\section{Blood group and family history}

\subsection{Introduction}

Although the aetiology of duodenal ulcer still is obscure hereditary factors seem to play a role but probably not in all cases ${ }^{32,59,}, 98$. In some patients hereditary predisposition appears to be severe. In one of the patients in this series all his family members had been suffering from the disease and 7 of his 8 brothers were operated upon.

In 208 of the 262 patients in this study the family history was noted; in $122(59 \%)$ it was positive and in $86(41 \%)$ negative. In 54 no information was recorded; in this last group there will probably be a preponderance of negative family histories since negative data stand a higher chance of not being recorded than positive ones. Although exact figures cannot be given from these data it seems justified to conclude that more than half of the patients had a positive family history.

Another appearance of hereditary influence in duodenal ulcer has been reported to be a difference in the distribution of blood groups among the patients suffering from duodenal ulcer compared to the normal population.

Blood group $O$ is associated almost universally with a higher frequency of duodenal ulcer $59,213,260,264,270,363$, especially in non-secretors (secretors are persons who secrete blood group substances in several body fluids, among them saliva and possibly gastric mucus, offering a better resistance of duodenal mucosa to aggressive ulcerogenic factors). Secretor substances were not measured in this study but the blood group was determined in all patients.

In 17 patients the blood group result could not be found because it had not been recorded. This kind of "secretor status" has a completely different meaning than elsewhere in this thesis. In this significance it was used only in this paragraph.

Lam \& Sircus in 1975 postulated 2 types of duodenal ulcer patients with differing properties $^{213}$.

Type I

were normosecretors, had a negative family history, blood group $O$ was predominant, had more complications, had a shorter length of history (less than 10 years) and the onset of the disease was generally later than in type II. They speculated that these patients had a weaker defence against ulcerogenic factors and that the aetiology of duodenal ulcer was more gastrin (antrum) dependant in this group.

Type II

patients were hypersecretors, had a positive family history, a predominance of bloodgroup $A, B$, and $A B$, the ulcer history should be longer and the onset of the disease earlier.

Type II patients should have a normal defence and the aetiology should depend more on hyperplasia of the parietal cell mass.

Later they failed to prove the existence of these two groups ${ }^{202}$ although their theory was quite attractive and could give grounds for different medical and operative treatment according to the characteristics. 
In 1976 Lam \& Ong subdivided their patients in early and late onset groups differing in blood group pattern, family history, and rate of complications ${ }^{214}$.

In the patients of this series the correlations and theories outlined above were tested. Moreover it was investigated whether there was any detectable relation between blood group and the development of a recurrence after HSV and between blood group and the existence of preoperative hypersecretion.

\subsection{Materials and methods}

245 Blood groups have been recorded and 17 were missing or lost. The method of blood group determination was according to Ortho ${ }^{\circledR}$ diagnostics.

As control group were used the data of all donors in 1981 obtained from the referral area of the hospital. This is probably more reliable than the blood group distribution of the whole Dutch population since the donors were recruited from the same area as the duodenal ulcer patients studied.

Nevertheless the reported distribution of the whole population is not very different 283 . In the patients with a recurrent ulcer 1 blood group was missing.

\subsection{Results}

In table I the blood group distribution is shown of the normal population (blood bank donors) and of the patients in this study separated into those who developed a recurrent ulcer and those who did not. Table II shows the distribution of the rhesus factor. There was a slight but significant preponderance of blood group $\mathrm{O}$ in the patients in this series compared to the controls. There was, however, no difference in blood group distribution between the patients with or without a recurrence. No difference in the distribution of the rhesus factor could be detected at all.

table I

distribution of blood groups

\begin{tabular}{|c|c|c|c|c|c|c|c|c|}
\hline & \multicolumn{2}{|c|}{ donors } & \multicolumn{2}{|c|}{ patients (all) } & \multicolumn{2}{|c|}{$\begin{array}{l}\text { patients } \\
\text { withour a } \\
\text { recurrence }\end{array}$} & \multicolumn{2}{|c|}{$\begin{array}{l}\text { patiens } \\
\text { wish a } \\
\text { recurrence }\end{array}$} \\
\hline & $n$ & $\%$ & $n$ & $\%$ & $n$ & $\%$ & $n$ & $\%$ \\
\hline A & 2049 & 41.8 & 95 & 38.8 & 86 & 38.7 & 9 & 39.2 \\
\hline B & $5 \| 3$ & 11.4 & 17 & 6.9 & 15 & 6.8 & 2 & 8.7 \\
\hline$A B$ & 260 & 5.3 & 8 & 3.3 & 7 & 3.2 & 1 & 4.3 \\
\hline 0 & 2081 & 42.5 & 125 & 51.0 & 114 & 51.3 & $\| 1$ & 47.8 \\
\hline total & 4903 & 100 & 245 & 100 & 222 & 100 & 23 & 100 \\
\hline
\end{tabular}


table II

astribution of thesus factor

\begin{tabular}{|c|c|c|c|c|c|c|c|c|}
\hline & \multicolumn{2}{|c|}{ domors } & \multicolumn{2}{|c|}{$\begin{array}{l}\text { parierus } \\
(a l l)\end{array}$} & \multicolumn{2}{|c|}{ 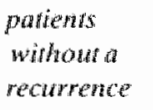 } & \multicolumn{2}{|c|}{ 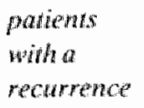 } \\
\hline & $n$ & $\%$ & 11 & $\%$ & $n$ & $\%$ & $n$ & $\%$ \\
\hline rhat & 4013 & 81.8 & 196 & 80.0 & 179 & 80.6 & 17 & 81.0 \\
\hline rh - & 890 & 18.2 & 49 & 20.0 & 43 & 19.4 & 4 & 19.0 \\
\hline total & 4003 & 100 & 245 & 100 & 222 & 100 & 21 & 100 \\
\hline
\end{tabular}

Gastric Acid secretion related to blood groups.

The average $\mathrm{PAO}$ and $\mathrm{PAO} / \mathrm{kg}$ body weight have been calculated for all patients with the same blood group. The blood groups A, B and AB have been taken together (Lam \& Sircus ${ }^{213}$ ). The results are indicated in table III. In this table the results of a further analysis on the base of the blood groups are shown.

The recurrences were equally distributed over both groups and there was no significant difference in family history, age at operation, age at the onset of the disease or in the number of hypersecretors. Neither was there a difference in preoperative PAO, nor in $\mathrm{PAO} / \mathrm{kg}$. The only significant difference found was the preoperative complication rate: $25.8 \%$ in the $\mathrm{A} / \mathrm{B} / \mathrm{AB}$ group and $40.0 \%$ in blood group $\mathrm{O}$.

\section{table III}

subdivision in blood groups ( $\mathrm{A} / \mathrm{B} / \mathrm{AB} / \mathrm{O})$

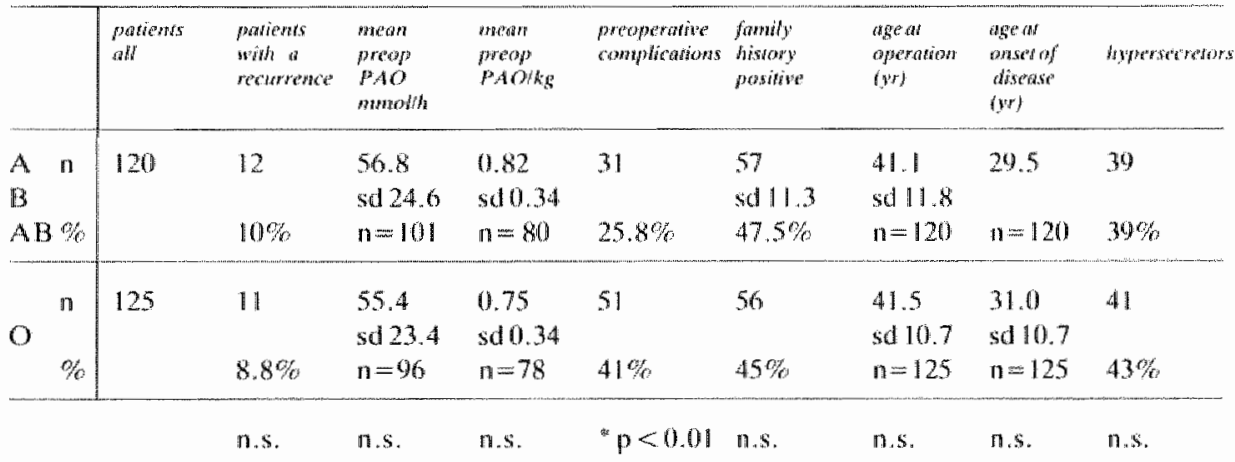

\section{Hypersecretion}

If hypersecretion is defined in this study as : for men: a preoperative $\mathrm{PAO} \geqslant 60$ mmol $/ \mathrm{h}$, and for women: $\mathrm{PAO} \geqslant 50 \mathrm{mmol} / \mathrm{h}$, then 82 patients $(38.7 \%$ of 212 with a known preoperative $\mathrm{PAO}$ ) were hypersecretors. Patients with a $\mathrm{PAO}$ below these levels were called normosecretors.

The blood group distribution of these groups is shown in table IV.

In the group of patients with a recurrent ulcer 10 met the definition of hypersecretor, 
resulting in a recurrence rate of $12.2 \%$ among hypersecretors as compared to $9.2 \%$ in the normosecretor group. The difference was, however, not significant.

There was no appreciable difference in the number of preoperative complications, the length of ulcer history before operation or the age at the onset of the disease between normosecretors and hypersecretors.

When the patients were divided into type I and type II (see introduction) on the base of MAO per $\mathrm{kg}$ body weight below or abowe $0.50 \mathrm{mmol} / \mathrm{hr} / \mathrm{kg}$ (Lam \& Sircus) the results were not very different from the foregoing comparison (table V). The only exception was the age at operation, which was just significantly lower in the patients with a high acid output per $\mathrm{kg}$.

trable IV

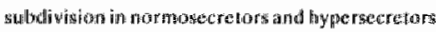

\begin{tabular}{|c|c|c|c|c|c|c|c|c|c|c|c|c|c|c|c|c|c|}
\hline \multirow{5}{*}{ 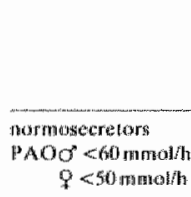 } & \multirow{5}{*}{ 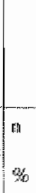 } & \multirow[t]{2}{*}{$\begin{array}{l}\text { now of } \\
\text { pexteress }\end{array}$} & & \multicolumn{2}{|c|}{$\begin{array}{l}\text { fonnily } \\
\text { history }\end{array}$} & \multicolumn{4}{|c|}{ b3ood group } & \multirow[t]{2}{*}{ 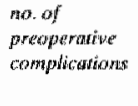 } & \multicolumn{2}{|c|}{$\begin{array}{l}\text { age at } \\
\text { aperation } \\
\text { ori }\end{array}$} & \multirow{2}{*}{\multicolumn{2}{|c|}{$\begin{array}{l}\text { lengith } \\
\text { of hishory } \\
\text { oyrs }\end{array}$}} & \multirow{2}{*}{\multicolumn{2}{|c|}{$\begin{array}{l}\text { agre ar } \\
\text { onsee of } \\
\text { drsease } \\
(y p)\end{array}$}} & \multirow[t]{2}{*}{$\begin{array}{l}\text { no. } \\
\text { of } \\
\text { recuryences }\end{array}$} \\
\hline & & & & \# & - & $A$ & $\theta$ & $A B$ & 0 & & & & & & & & \\
\hline & & 130 & & 66 & $4 \|$ & 51 & 8 & 4 & 57 & 40 & & 40.5 & & 10,9 & & 29,6 & 12 \\
\hline & & $1050^{4}$ & $25 ?$ & & & 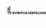 & 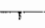 & & & & $\mathrm{sd}$ & 11.2 & sid & 19,4 & sd: & 15.7 & \\
\hline & & & & 620 & $38 \%$ & & $52 \%$ & & $48 \%$ & $31 \%$ & $n$ & 130 & $\mathrm{n}$ & 130 & $n$ & 130 & $9.2 \%$ \\
\hline & p & & & $\mathrm{n}, \mathrm{s}$ & & & m.S & & & m.s. & & N.s.s. & & n.s. & & n.s. & n.s. \\
\hline lypor reecrebors & $n$ & 82 & & 37 & 25 & 32 & 3 & 3 & 39 & 22 & & $40: 1$ & & 10.5 & & 29.6 & 10 \\
\hline $\begin{aligned} \text { PMOO } & \geqslant 60 \mathrm{mmol} / \mathrm{h} \\
& =50 \mathrm{mmolh}\end{aligned}$ & $\%$ & 690 & 139 & $60 \%$ & $40 \%$ & & $4(x) y$ & & $51 \%$ & $27 \%$ & $\mathrm{sd}$ & $\begin{array}{l}100 \\
82\end{array}$ & $\begin{array}{l}\text { sill } \\
n\end{array}$ & $\begin{array}{l}8.0 \\
82\end{array}$ & $\begin{array}{l}\mathrm{sd} \\
\mathrm{n}\end{array}$ & 10.6 & $12.2 \%$ \\
\hline
\end{tabular}

Mable V

sulbdivision according 60 PAO secretion per kg bady weingh

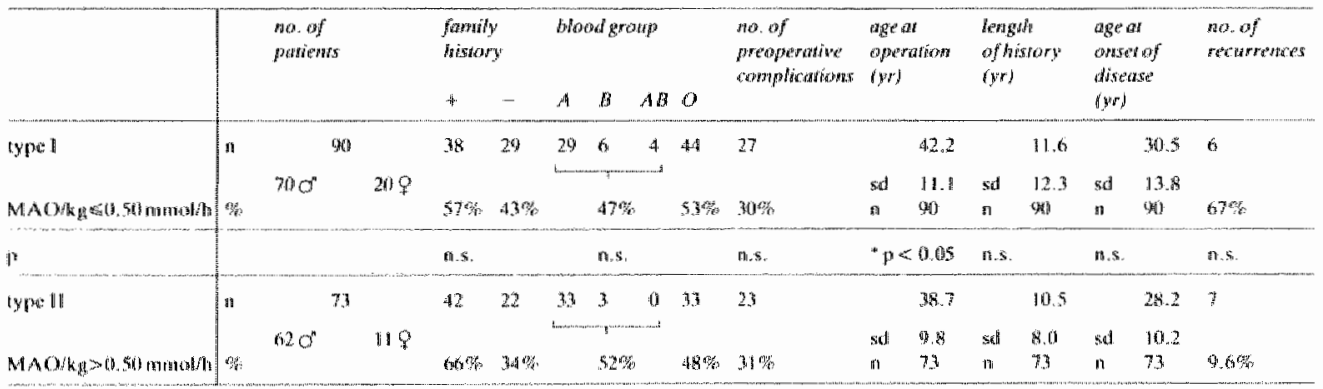

The age at the onset of disease

The age at the onset of the disease was calculated by subtracting the length of ulcer history from the age of each patient. The average age at the onset of the disease for the differing blood groups is indicated in table III. The patients were separated in two ways, into early and late onset groups. In table VI the patients are divided into those with the onset of disease below 30 years and those above.

The only differences between the two groups were a significantly shorter duration of history and a higher proportion of positive family histories in the late onset group. In table VII the two extreme groups are compared: those with the onset of disease 
below 20 years of age with those with the onset above 40 years (as was done by Lam \& Ong).

There was a significant difference in family history and a much more pronounced difference in length of ulcer history. Moreover between the extreme groups there was a clear difference in preoperative complication rate and in the number of hypersecretors. This was mirrored as well in a significanly higher PAO.

table VI

subdivision in early and late onset of disease

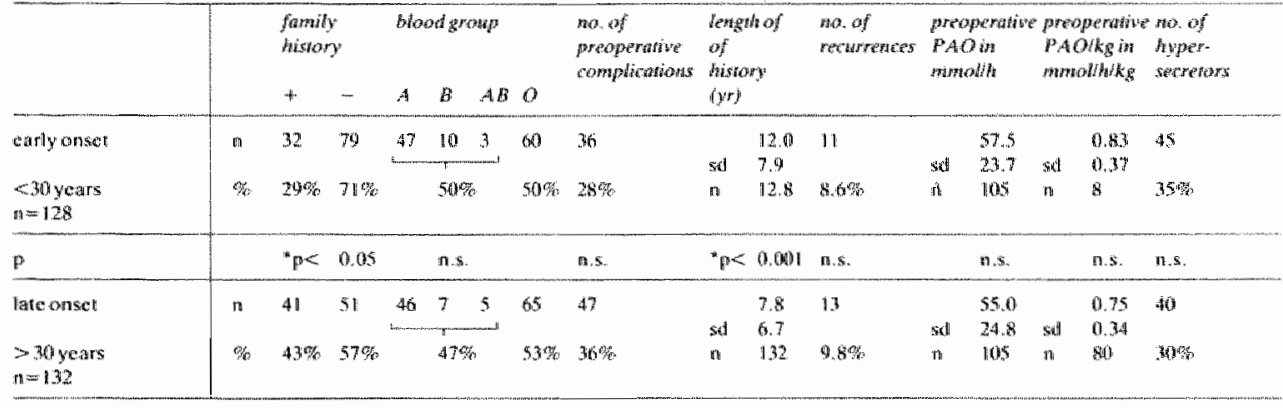

tablle VII

subdiw sion in early and late onset of disease

\begin{tabular}{|c|c|c|c|c|c|c|c|c|c|c|c|c|c|c|c|c|c|}
\hline \multirow{4}{*}{$\begin{array}{l}\text { early anset } \\
20 \text { years } \\
n=54\end{array}$} & \multirow{4}{*}{$n$} & \multicolumn{2}{|c|}{$\begin{array}{l}\text { favnity } \\
\text { history }\end{array}$} & \multicolumn{3}{|c|}{ bood group } & \multicolumn{3}{|c|}{ 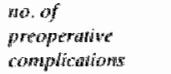 } & \multirow[t]{2}{*}{$\begin{array}{c}\text { dength } \\
\text { of } \\
\text { kisiporys } \\
(h r)\end{array}$} & \multirow{2}{*}{\multicolumn{2}{|c|}{ 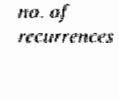 }} & \multirow{2}{*}{\multicolumn{2}{|c|}{$\begin{array}{l}\text { prespeprative } \\
\text { PAO in } \\
\text { mplish }\end{array}$}} & \multirow{2}{*}{\multicolumn{2}{|c|}{ 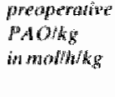 }} & \multirow[t]{2}{*}{ 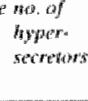 } \\
\hline & & + & - & $A$ & $A B$ & 0 & perf bl & $s i$ & wll & & & & & & & & \\
\hline & & 39 & 13 & $2^{23}$ & $\begin{array}{ll}3 & 2 \\
-7 & 3\end{array}$ & 24 & 49 & 0 & 13 & & 13.8 & 3 & & 61.9 & & 0.98 & 21 \\
\hline & & $75 \%$ & $25 \%$ & & $53.8 \%$ & $46.2 \%$ & $7.4 \quad 16.7$ & & $24 \%$ & $\mathrm{sad}$ & 7.9 & $5.5 \%$ & 3il & $\begin{array}{l}22.6 \\
46\end{array}$ & $\begin{array}{l}3 d \\
11\end{array}$ & (1) 34 & $38.8 \%$ \\
\hline & $n$ & 17 & 21 & 24 & $\begin{array}{ll}2 & 1 \\
-1 & 1\end{array}$ & 26 & $110 \quad 13$ & 6 & 29 & & 4.9 & 5 & & 50.1 & & 0.39 & 12 \\
\hline $\begin{array}{l}\text { listeonset } \\
>40 \text { years } \\
n=57\end{array}$ & $\%$ & $45 \%$ & $55 \%$ & & $51.0 \%$ & $49.0 \%$ & 117.522 .8 & 10.5 & $51 \%$ & sold & 3.9 & $8.8 \%$ & $\begin{array}{l}\text { ind } \\
0\end{array}$ & $\begin{array}{l}20.4 \\
40\end{array}$ & $\mathbf{s d}_{n}$ & $\begin{array}{l}0,31 \\
30\end{array}$ & $21.0 \%$ \\
\hline
\end{tabular}

Family history.

Patients with a negative family history have been compared with those having a positive history.

In table VIII the body weight, serum gastrin, BAO and PAO have been studied both preoperatively and $1 / 2$ year after operation. No differences of statistical significance were found between the groups.

In table IX the $\mathrm{PAO} / \mathrm{kg}, \mathrm{MAO} / \mathrm{kg}$, length of history, the age at operation, the age at the onset of the disease, the number of preoperative complications, the number of recurrences and the blood group distribution have been compared between patients with a positive and a negative family history.

Patients with a positive history were on average younger at operation and their onset of disease was earlier.

Those with a negative family history had a higher recurrence rate (14.3\%) as compared to $6.6 \%$ in patients with a positive family history but the difference was not significant; moreover in 4 patients with a recurrence the family history was not known. 
family history and weight, gastrin, $\mathrm{BAO}, \mathrm{PAO}$

\begin{tabular}{|c|c|c|c|c|c|c|c|c|c|}
\hline & \multirow[b]{2}{*}{$n$} & \multicolumn{2}{|c|}{$\begin{array}{c}\text { mean } \\
\text { weight }(\mathrm{kg})\end{array}$} & \multicolumn{2}{|c|}{$\begin{array}{c}\text { mean } \\
\text { gastrin (ng/l) }\end{array}$} & \multicolumn{2}{|c|}{$\begin{array}{c}\text { mean } \\
B A O(n m a l h)\end{array}$} & \multicolumn{2}{|c|}{$\begin{array}{c}\text { mean } \\
\text { PAO (mmol/h) }\end{array}$} \\
\hline & & preop & postop & preop & postop & preop & postop & preop & postop \\
\hline \multicolumn{10}{|l|}{$\begin{array}{l}\text { family } \\
\text { history }\end{array}$} \\
\hline negative & $86(41,3 \%)$ & & & & 196.8 & & 1.72 & & 25.8 \\
\hline $\mathrm{sd}$ & & 11.6 & 13.6 & 63.4 & 111.9 & 5.99 & 2.13 & 24.6 & 15.9 \\
\hline $\mathrm{n}$ & & 67 & 42 & 63 & 56 & 66 & 49 & 66 & 49 \\
\hline positive & $122(58.7 \%)$ & 69.8 & 72.0 & 123.8 & 213.8 & 6.33 & 2.39 & 56.7 & 30.2 \\
\hline sd & & 10.9 & 12.2 & 72.2 & 183.9 & 6.65 & 3.10 & 24.7 & 14.5 \\
\hline $\mathrm{n}$ & & 95 & 62 & 88 & 64 & 101 & 63 & 103 & 63 \\
\hline & & n.s. & & n.s & & nu. & & & \\
\hline
\end{tabular}

table IX

subdivision in negative and positive family history

\begin{tabular}{|c|c|c|c|c|c|c|c|c|c|c|}
\hline & $\begin{array}{l}\text { no of } \\
\text { patienss } \\
0^{x}+9\end{array}$ & $\begin{array}{l}\text { blood group } \\
\text { A/B/AB }\end{array}$ & $O$ & $\begin{array}{l}\text { no. of } \\
\text { recorrencess }\end{array}$ & $\begin{array}{l}P A O F \\
\mathrm{~kg}\end{array}$ & $\begin{array}{l}M A O H \\
\mathrm{~kg}\end{array}$ & $\begin{array}{l}\text { lengh } \\
\text { of } \\
\text { thistory } \\
\text { (yr) }\end{array}$ & $\begin{array}{l}\text { ange at } \\
\text { operation } \\
\text { (yr) }\end{array}$ & $\begin{array}{l}\text { ager an ansert } \\
\text { of discetise } \\
\text { fyrl }\end{array}$ & $\begin{array}{l}\text { so. of } \\
\text { Preoperative } \\
\text { complicarions } \\
\qquad \begin{array}{l}\text { n } \%\end{array}\end{array}$ \\
\hline $\begin{array}{l}\text { lamily } \\
\text { knistory }\end{array}$ & & & & & & & & & & \\
\hline $\begin{array}{r}\text { megarivo: } \\
\text { sd } \\
n\end{array}$ & 86 & $39(-17 \%)$ & $44(53 \%)$ & $12(14 \%)$ & $\begin{array}{l}0.76 \\
0.37 \\
53\end{array}$ & $\begin{array}{l}0.48 \\
0.21 \\
51\end{array}$ & $\begin{array}{l}10.4 \\
8.0 \\
86\end{array}$ & $\begin{array}{l}43.8 \\
11.1 \\
86\end{array}$ & $\begin{array}{l}33.4 \\
11.9 \\
86\end{array}$ & 2731 \\
\hline $\begin{array}{r}\text { positive } \\
\text { sid } \\
0\end{array}$ & 122 & $57(50.4 \%)$ & $56(49.6 \%)$ & $8(66) \%$ & $\begin{array}{l}0.81 \\
0.35 \\
82\end{array}$ & $\begin{array}{l}0.51 \\
0.21 \\
80\end{array}$ & $\begin{array}{l}10.0 \\
7.2 \\
120\end{array}$ & $\begin{array}{l}37.4 \\
10.0 \\
122\end{array}$ & $\begin{array}{l}27.3 \\
10.3 \\
120\end{array}$ & $38 \quad 31$ \\
\hline$n$ & & n. & an.s. & n.s. & (x.s. & $\mathrm{n} \mathrm{s}_{\mathrm{s}}$ & 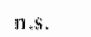 & p.00001 & poolat & n.s \\
\hline
\end{tabular}

\subsection{Discussion}

There was a slight preponderance of blood group $O$ in the patients in this series compared to the controls ( $51.0 \%$ compared to $42.5 \%$ ). No difference in distribution of the rhesus factor could be detected. This has been described by most authors ${ }^{190}$, $260,270,283$

The blood group distribution of the patients who developed a recurrence was not significantly different from the whole group.

Several characteristics of the patients were studied from several points of view such as blood group distribution, preoperative stimulated secretory level, age at onset of disease and family history.

Special attention was paid to the liability of developing a recurrent ulcer after HSV. 


\section{Influence of blood group}

There appeared to be no difference in stimulated acid secretion between the blood group $\mathrm{O}$ and $\mathrm{A} / \mathrm{B} / \mathrm{AB}$. Similarly the proportion of hypersecretors in the two groups was the same.

However, the number of preoperative complications was greater in blood group $\mathrm{O}$ patients. This confirmed the statement of Lam \& Sircus (1975) that the complications of duodenal ulcer were more connected with blood group $O$ than with hypersecretion 251

Several other authors found that blood group $\mathrm{O}$ was associated with a higher complication rate. It can be speculated that the preponderance of blood group $\mathrm{O}$ in a duodenal ulcer population is caused by a higher number of complications, forcing patients into the hospital and enhancing the liability to be operated on ${ }^{264}$.

\section{Influence of hypersecretion}

If patients are divided into a hypersecretor and a normosecretor group (on an arbitrary base which was defined here for men as: $\mathrm{PAO} \geqslant 60 \mathrm{mmol} / \mathrm{h}$, and for women as :PAO $\geqslant 50 \mathrm{mmol} / \mathrm{h}$ ) no significant differences were found, although there seemed to be a tendency to a higher recurrence rate in the hypersecretor group (12.2 versus $9.2 \%$, not significant).

\section{Influence of the age at onset of disease}

Early onset of disease appeared to be associated with a higher proportion of positive family histories, with a longer history of ulcer disease before operation and with a higher preoperative PAO; the proportion of hypersecretors was correspondingly higher.

The late onset group of patients showed more complications than those with an early onset. This may be the reason why these patients had a shorter history since they stood a higher chance of being operated on earlier.

The same result was found when the patients were divided on the basis of their acid output per $\mathrm{kg}$, which was attempted by Lam \& Sircus in order to abolish the difference in body weight and acid secretion between men and women. The theory that two different populations could thus be separated was not confirmed, although there was a slight difference in the length of history, being shorter in the group with the higher acid secretion.

According to Lam \& Ong ${ }^{214}$ early onset of disease ( 20 years) should be associated with a higher proportion of blood group $\mathrm{A} / \mathrm{B} / \mathrm{AB}$, more positive family histories and hypersecretion compared with late onset. Bleeding was reported to be the predominant complication in the early onset patients, whereas the late onsef patients were said to be more prone to perforation and stenosis.

These findings could be confirmed grosso modo with a few exceptions. The preponderance of blood group $\mathrm{O}$ in the late onset group was not significant in this series, but the number of patients was considerably smaller (262 vs. 1042). Lam \& Ong did not find a difference in duration of history, which was, however, highly significant in this series. 
Moreover they found a much higher proportion of bleedings in both groups, but they did not mention a higher complication rate for the late onset patients. It should be noted, however, that the present series consists only of patients already operated upon, whereas Lam \& Ong studied patients who were admitted for duodenal ulcer disease; only a part of them were to be operated on.

\section{Influence of family history}

The patients with a positive family history were on average younger when the disease started and were younger at operation. This was found before by Artemiev et al 1970 214 


\section{Chapter 15}

\section{Recurrences: an analysis}

\subsection{Introduction}

As mentioned before, at some time $1 / 2$ - 8 years after operation 24 patients out of 262 had developed a recurrence: $9.16 \%$. Since no new recurrences were discovered at the end of 1982, the end of that year has been used as well for convenience instead of the conclusion date (1-7-1982).

Why did HSV fail or appear to fail in these patients?

The details known about the recurrent ulcer patients will be discussed in order to look for any discriminant factors.

Many details have already been mentioned and discussed in the foregoing chapters but for clarity and completeness these are repeated here.

15.2 Characteristics of patients with a recurrence in comparison with patients without a recurrence (table $B$ ).

\section{Introduction to table $B(p .143-146)$}

As already explained in chapter 10 (acid secretion studies) for some parameters there appeared to be a difference between men and women and also between patients with and without a recurrence.

Therefore originally for all parameters all patients were divided into 9 groups: all, rec $O^{\prime \prime}$, non-rec $O^{\prime}$, rec,+ , non-rec $q$, all $\varnothing^{*}$, all $q$, all rec, all non-rec, but in order to prevent completely unreadable tables only the figures of patients with and without a recurrence have been tabulated here.

If there was no significant or otherwise appreciable difference between men and women (without a recurrence) the data have been taken together to enhance the reliability of statistical testing. If, however, there was such a difference, only data of the male patients have been compared as they were by far the largest subgroup. The women with a recurrence (two) were considered too small in number to be useful for comparison with the women without a recurrence.

Although there was a clearly lower recurrence rate in the women (4.2 versus $10.3 \%$ ) the difference in the sex distribution was just below significance ${ }^{15,} 142$. There was no significant difference in preoperative height, weight (see chapter 13), blood group, rhesus factor (see chapter 14), mean age at onset of disease or at operation, or duration of ulcer history, but the length of follow-up was significantly longer in patients with a recurrence.

The proportion of patients with a positive family history, the presence of periodicity or nervousness was not different in both groups, but a history of psychiatric treatment was found in $23 \%$ of the male patients with a recurrence in contrast $103.7 \%$ in the male patients without a recurrence.

The proportion of smoking and drinking alcohol was roughly the same, as was the influence of employment. It was remarkable, however, that unemployment did not 
seem to predispose to duodenal ulcer or to a recurrence.

The influence of preoperative complications has been discussed extensively in chapter 9 as well as the emergency and additional operations (chapter 8 ).

In chapter 8 the influence of the surgeon and assistant has been dealt with.

The presence of a considerable activity of the ulcer was more frequent in the patients with a recurrence, but not significantly so.

The use of clips (chapter 5 ) had no influence.

There was no striking or significant difference in the length of oesophagus laid bare, either when divided in groups per distance, or as an average, but there was a difference in the centimeters of antrum dissected.

Equally there was a significant difference for skeletonising the greater curvature.

The latter data should however be considered with care (see discussion).

The preoperative laboratory parameters have been added for completeness; they are all discussed in the separate chapters.

There were no significant differences to be derived from these parameters, however.

\subsection{Recurrence rate}

There are a number of ways of showing the recurrence rate.

1. Indicating the recurrences in the year in which the operation took place, expressed as absolute figures and as percentage of the total number of operations in that year. See table $\mathbf{I}$.

table I

recurrence rate

\begin{tabular}{|c|c|c|c|c|c|c|c|}
\hline \multirow[t]{3}{*}{$\begin{array}{l}\text { yearof } \\
\text { operation }\end{array}$} & \multirow[t]{3}{*}{$\begin{array}{l}\text { no: of } \\
H S V^{\prime} s\end{array}$} & $\begin{array}{l}\text { wo. of } \\
\text { recurrences }\end{array}$ & $\begin{array}{l}\text { \% of } \\
\text { reciurences }\end{array}$ & \multicolumn{2}{|c|}{$\begin{array}{l}\text { cumularine } \\
\text { no of } \\
\text { operanons } \\
\text { de recurrences }\end{array}$} & \multirow[t]{2}{*}{$\begin{array}{l}\text { cumbulative } \% \\
\text { of recurrences }\end{array}$} & \multirow[t]{2}{*}{$\begin{array}{l}\text { appearance of } \\
\text { recurrences in } \\
\text { months afier } \\
\text { operawon }\end{array}$} \\
\hline & & known at 31 & 11211982. & & & & \\
\hline & & & & $\mathrm{HSV}^{*} \mathrm{~s}$ & rec. & & \\
\hline 1974 & 17 & 5 & 29 & 16 & 5 & 29 & $19 / 26 / 46 / 82 / 85$ \\
\hline 1975 & 21 & 4 & 19 & 38 & 9 & 23 & $39 / 46 / 48 / 69$ \\
\hline 1976 & 43 & 5 & 11 & 81 & 14 & 17 & $13 / 21 / 25 / 35 / 56$ \\
\hline 1977 & 45 & 3 & 7 & 126 & 17 & 13 & $4 / 6 / 49$ \\
\hline 1978 & 41 & 5 & 12 & 167 & 22 & 13 & $7 / 8 / 18 / 28 / 35$ \\
\hline 1979 & 28 & 1 & 3 & 195 & 23 & 11.8 & 30 \\
\hline 1980 & 35 & 0 & 0 & 230 & 23 & 10 & \\
\hline 1981 & 32 & 1 & 3 & 262 & 24 & 9.2 & 4 \\
\hline
\end{tabular}

These are disquieting figures!

Each percentage would have been the recurrence rate if the series had been stopped after that moment and no more cases added. This is not the way the recurrence rate is usually published!

The only figure which is usually reported is the last one $9.2 \%$ which seems acceptable. Sometimes however one excludes the patients operated upon recently: 
for example on 31-12-1982 the results of all patients who had completed at that time 5 years or more follow-up in the present series would have been: $13 \%$ recurrence rate ( 17 recurrences in 126 patients). All unfavourable cases have been included in these calculations. However this is not the way the retrospective, static Visick grading works: this means that these figures are not comparable to the figures quoted in published series.

2. In the next table data have been accumulated at the end of each year (31-12) as they would be known at that moment. The number of HSV's, and the number of recurrences known at that moment have been listed. See table II. This table

table II

recurrence rate

follow-up cumulative cumulative cumulative appearance of

inyears no. of no. of \%of recurrencesinmonths

HSV's recurrences recurrences after operation:

date of

assessment

\begin{tabular}{llllll}
\hline $31-12-74$ & $0-1$ & 16 & 0 & 0 & \\
$31-12-75$ & $0-2$ & 38 & 1 & 2.6 & 19 \\
$31-12-76$ & $0-3$ & 81 & 2 & 2.4 & 26 \\
$31-12-77$ & $0-4$ & 126 & 5 & 3.9 & $4 / 6 / 13$ \\
$31-12-78$ & $0-5$ & 167 & 10 & 5.9 & $7 / 21 / 25 / 39 / 46$ \\
$31-12-79$ & $0-6$ & 195 & 14 & 7.1 & $8 / 35 / 46 / 48$ \\
$31-12-80$ & $0-7$ & 230 & 16 & 6.9 & $18 / 28$ \\
$31-12-81$ & $0-8$ & 262 & 23 & 8.7 & $30 / 35 / 49 / 56 / 69 / 82 / 85$ \\
$31-12-82$ & $1-8$ & 262 & 24 & 9.2 & 4 \\
\hline
\end{tabular}

presents the recurrence rate comparable to the way the usual Visick grading is indicated.

3. The time from operation to appearance of the recurrence in our patients was respectively $4,4,6,7,8,13,18,19,21,25,26,28,30,35,35,39,46,46,48,49$, $56,69,82$ and 85 months.

The average time to appearance of the recurrent ulcer was 33.3 months, the median 29 months.

Within 48 months after operation 19 of 24 recurrences had appeared ( $79 \%$ ). The ultimate recurrence rate can be approached by calculating the recurrence rate in patients operated upon 4 or more years ago. This means 22 of $167 \mathrm{HSV}$ 's $=13 \%$. By extrapolation, the recurrence rate could be estimated at $16 \% \frac{(100 \times 13 \%)}{79}$, table I.

However in these calculations all unfavourable cases have been included. If the figures are corrected for the introduction period (25 HSV's) and the operations performed by the "occasional surgeon", the outcome is slightly more favourable. 
The same data have been collected omitting the first 25 patients and the 10 patients operated on by the "occasional surgeon". See table III.

table III

recurrence rate after correction

\begin{tabular}{|c|c|c|c|c|c|c|c|}
\hline \multirow[t]{3}{*}{$\begin{array}{l}\text { yearof } \\
\text { operation }\end{array}$} & \multirow{3}{*}{$\begin{array}{l}\text { no. of } \\
H S V^{\prime} s\end{array}$} & \multirow{3}{*}{$\begin{array}{l}\text { no. of } \\
\text { reculrences } \\
\text { known at } 31\end{array}$} & \multirow{3}{*}{$\begin{array}{l}\text { to of } \\
\text { recturences } \\
1-12-82\end{array}$} & \multicolumn{2}{|c|}{$\begin{array}{l}\text { cumulative } \\
\text { no. of } \\
\text { HSV's } \\
\text { \& recurrences }\end{array}$} & \multirow[t]{2}{*}{$\begin{array}{l}\text { cumulative } \\
\text { \% of } \\
\text { recurrences }\end{array}$} & \multirow[t]{3}{*}{$\begin{array}{l}\text { appearance } \\
\text { of recurrences } \\
\text { in months } \\
\text { afier operation }\end{array}$} \\
\hline & & & & & & & \\
\hline & & & & HSV's & rec & & \\
\hline 1975 & 13 & 2 & 15 & 3 & 2 & 15 & $39 / 69$ \\
\hline 1976 & 43 & 5 & 11.6 & 56 & 7 & 12.5 & $13 / 21 / 25 / 35 / 56$ \\
\hline 1977 & 37 & 0 & 0 & 93 & 7 & 7.5 & \\
\hline 1978 & 40 & 4 & 10 & 133 & $\| 1$ & 8.2 & $7 / 18 / 28 / 35$ \\
\hline 1979 & 27 & 1 & 3.7 & 160 & 12 & 7.5 & 30 \\
\hline 1980 & 35 & 0 & 0 & 195 & 12 & 6.1 & \\
\hline 1981 & 32 & 1 & 3 & 227 & 13 & 5.7 & 4 \\
\hline
\end{tabular}

Again each percentage in the 6th column would have been the recurrence rate if the series had been stopped at that moment and no more cases added. The recurrence rate of patients operated upon more than 5 years ago (at 31-12-1982) would have been $7 \frac{1}{2} \%$ ( 7 recurrences from 93 patients). This again is not the traditional Visick grading.

In table IV the data are presented as assessed on 31-12 of each year.

table IV

recurrence rate after correction

follow-up camulative cumulatve cumulative appearance of

inyears no. of no. of \%of recurrencesinmonths

HSV's recurrences recurrences after operation

date of

assessinent

\begin{tabular}{llllll}
\hline $31-12-75$ & $0-1$ & 13 & 0 & 0 & \\
$31-12-76$ & $0-2$ & 56 & 0 & 0 & \\
$31-12-77$ & $0-3$ & 93 & 1 & 1 & 13 \\
$31-12-78$ & $0-4$ & 133 & 5 & 3.7 & $7 / 21 / 25 / 39$ \\
$31-12-79$ & $0-5$ & 161 & 6 & 3.7 & 35 \\
$31-12-80$ & $0-6$ & 196 & 8 & 4.1 & $18 / 28$ \\
$31-12-81$ & $0-7$ & 228 & 12 & 5.2 & $30 / 35 / 56 / 69$ \\
$31-12-82$ & $1-8$ & 228 & 13 & 5.7 & 4 \\
\hline
\end{tabular}


The mean time interval since operation for the recurrences was $4,7,13,18,21$, $25,28,30,35,35,39,56$, and 69 months. The average time was 29.2 months, the median time 28 months. Within 36 months, 10 of 13 recurrences had appeared $(77 \%)$. The ultimate recurrence rate can be approached by calculating the recurrence rate of patients operated upon 3 years or more ago: 12 recurrences of $161=7.4 \%$ (table III), by extrapolation $9.6 \%$. This selection may be too favourable. The other figure was $16 \%$, however, definitely too unfavourable. Probably the truth will be somewhere between: about $12 \%$.

4. From the foregoing analyses one is tempted to conclude that the number of recurrences decreases with time. However this impression may be false since the number of patients who have completed the follow-up as far as the late recurrences occurred also decreases. Moreover the patients who had already a recurrence must be accounted for. These factors must be balanced and the best way to do so is the life table method as applied on similar material by Andersen et al ${ }^{15.17}$. By this method a cumulative recurrence hazard related to the remaining ("surviving") patients can be estimated. This method was applied twice on the present material: first for all patients and, secondly, for the patients remaining after correction for inexperience, as was done as well in the foregoing analysis and in chapter 8 . The cumulative recurrence hazard (CRH) is defined as the integral of the recurrence hazard ( $\mathrm{RH}$ ) over the time interval $\mathrm{O}-\mathrm{t}(\mathrm{t}$ is the time of consideration). The $\mathrm{RH}$ is the mathematical expression for the instantaneous recurrence hazard at time $t$ provided there has been no recurrence up to time $t$. The CRH is useful as a statistical tool, but is difficult to interpret.

The CRH's estimated on the base of the observed recurrences and the time intervals after operation have been indicated in figure 1 . The graph suggests that the $\mathrm{CRH}$ is a linear function of the time: $\mathrm{CRH}=\lambda \mathrm{t}$; this results in a straight line in the graph; from the observations the slope of this line has been estimated: for all patients $\lambda=0.0019 \pm 0.0004,95 \%$ confidence interval: $0.0011,0.0027$.
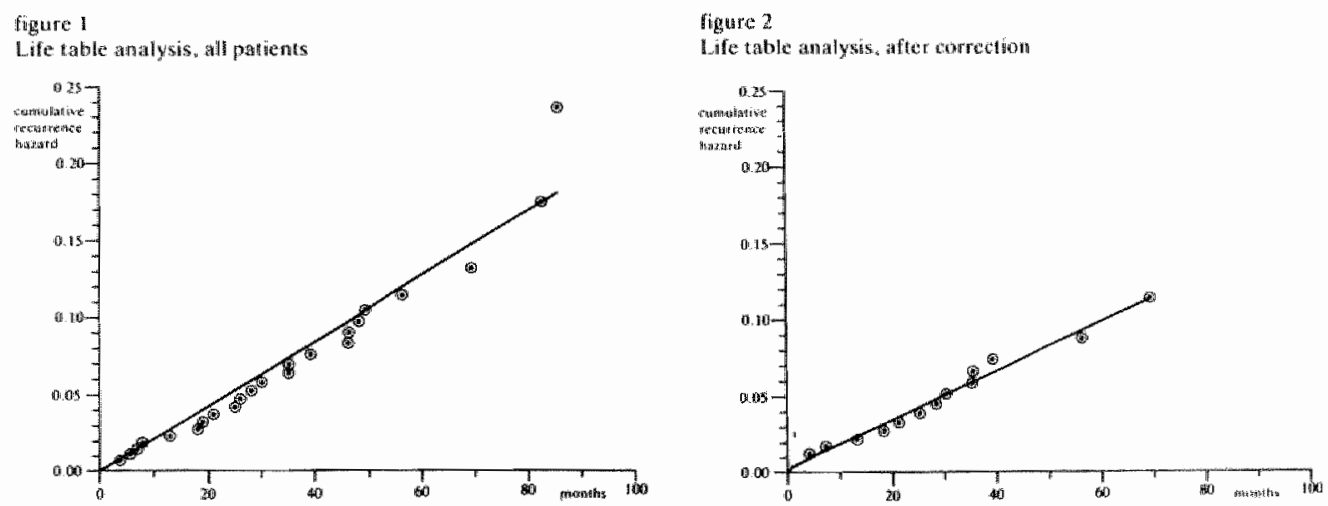

If the same estimation is performed for the corrected material (figure 2) this results in an equally linear relationship between CRH and time; the recurrence hazard is lower (the line is less steep): $\lambda=0.0012 \pm 0.0003 ; 95 \%$ confidence interval: $0.0006,0.0018$. The fact that the $\mathrm{CRH}$ is a linear function of time implies 
that the $\mathrm{RH}=\lambda$, the slope of the line. This again would imply that the recurrence hazard remains constant i.e. equal to $\lambda$, and is as great 5 years after operation as after 2 years.

Whether this comes to an end is not yet clear, and probably the follow-up should be longer in order to know. A similar conclusion was drawn by Andersen $e t$ al ${ }^{15}$ and is in contrast to the generally held belief that the highest risk for a recurrence lies within 2 to 3 years after operation ${ }^{50,}, 106,167,199,266$.

On the condition that the RH remains constant, the percentage (Q) of recurrence after $n$ months ( $n=$ average follow-up) can be predicted by the formula

$100-Q=100(1-\lambda)^{n}$ and consequently $n=\log \left(\frac{100-Q}{100}\right) / \log (1-\lambda)$.

This means, for all patients, that $20 \%, 50 \%$ and $80 \%$ of them will have developed a recurrence after respectively 10,30 and 69 years. After correction the figures would refer to the same percentages after 15,48 and 103 years respectivelly.

\subsection{Peak Acid Output (PAO) and recurrence}

The patients with a recurrence can be subdivided according to their reaction of PAO after operation. Arbitrarily a reduction of, $45 \%$ is considered adequate here. Group I:

Patients with a supposed adequate reduction of PAO due to the operation (more than $45 \%$ reduction). In the 24 recurrences in this series there were 8 patients in this group, 6 men and 2 women. It is striking that all the men were hypersecretors. Their average $\mathrm{PAO}$ was $78.7 \mathrm{mmol} / \mathrm{h}$. This could mean that the reduced postoperative PAO level does not safeguard hypersecretors against getting a recurrence. Moreover 5 of the 6 men had blood group $\mathrm{A}$ antigen. This could be held responsible as well or could be the basis for hypersecretion.

Nevertheless it is also possible that these patients had incomplete vagotomies. Insulin tests after operation were not performed and, if performed now, would be of almost no value ( $90 \%$ turn out to be positive after some years). All these patients except two were operated on by the consultant who taught the technique to the others. One patient was operated on by another consultant also involved in teaching.

Group II:

No reduction at all or a too small reduction (less than $45 \%$ of preoperative PAO). This group comprised of 9 patients. Probably they represent surgeon failures. 5 patients were operated on by consultants ( 3 by teaching consultants) and 4 by residents.

Group III:

Due to missing data nothing can be said about reduction of PAO in 5 patients. In 2 patients no preoperative data were available. One of these was operated upon for perforation and understandably no preoperative test was done. However two postoperative values showed a high PAO. Probably this means that no or insufficient reduction was obtained by the operation. Moreover the surgeon was not satisfied about his performance of HSV on the day after (the operation took place in the middle of the night). In 3 patients no postoperative tests were done due to refusal of the patients. 


\section{Group IV:}

Comprising 2 patients: little can be stated: due to unknown reasons the reduction of PAO measured postoperatively was so different and changing that not hing can be said with confidence: at some time there appeared to be a sufficient reduction but at other times before or after there was insulficient reduction on no reduction at all. The data obtained in these patients were considered unreliable for consideration.

The above subdivision could suggest that there were in the recurrent ulcer group some method failures (6) as well as some surgeon failures (9).

\subsection{Hypersecretion and recurrence}

Many authors have found that patients with a hypersecretion (preop. stimulated acid output above a certain level) run a higher risk for a recurrence. Some of them proposed a different operation for patients with hypersecretion. This matter was investigated in this series as well. Hypersecretion was defined here as having a preoperative PAO $\geqslant 60 \mathrm{mmol} / \mathrm{h}$ for $\mathrm{men}$ and $\geqslant 50 \mathrm{mmol} / \mathrm{h}$ for women. Several other levels have been tried, but this arbitrary definition - also used elsewhere in this thesis - gave the best separation. Moreover the proportion of bypersecretors in relation to the total ( $38 \%$ ) is similar to literature data.

As shown before, the average preoperative $\mathrm{PAO}$ of the non recurrent group was about the same as the PAO of the patients who later developed a recurrence. However there could be an unequal distribution in the population. Therefore a subdivision was made of all patients according to the level of their preoperative $\mathrm{PAO}$. All were divided in classes of $10 \mathrm{mmol} / \mathrm{h}$; in each class the percentage of patients with a recurrence has been compared with the whole group. The outcome (for men and women) is shown in table IX which has been drafted in a cumulative way.

\section{Table V}

Hypersecretion and recurrence rate

\begin{tabular}{ccccc}
$\begin{array}{c}\text { Levelof } \\
\text { PAO }\end{array}$ & $\begin{array}{c}\text { No. of } \\
\text { porienis }\end{array}$ & $\begin{array}{c}\text { \%of } \\
\text { patients }\end{array}$ & $\begin{array}{c}\text { No. of } \\
\text { recurrences }\end{array}$ & $\begin{array}{c}\text { \%of } \\
\text { recurrences }\end{array}$ \\
\hline 20 & 10 & 4.6 & 1 & 4.5 \\
.30 & 27 & 12.5 & 4 & 18.1 \\
40 & 57 & 26.3 & 5 & 22.7 \\
450 & 109 & 50.4 & 11 & 50 \\
460 & 137 & 63.4 & 12 & 54.5 \\
40 & 162 & 75.0 & 16 & 72.7 \\
80 & 182 & 84.2 & 18 & 81.8 \\
90 & 193 & 89.3 & 20 & 90.9 \\
All & 216 & 100 & 22 & 100 \\
\hline
\end{tabular}

This table demonstrates that there is an equal distribution of the recurrences among all secretory levels: in other words, there is no tendency for recurrences to occur preferentially in the classes with a high PAO. The same was done only for the male patients with a similar outcome (see table VI). 
hypersectetion and recurtence rate, men

\begin{tabular}{|c|c|c|c|c|}
\hline level of PAO & no ofo & $\%$ of $0^{*}$ & no. of $\sigma^{x}$ recurrences & \% of ơ recurrences \\
\hline$<20$ & 7 & 3.9 & 1 & 5 \\
\hline$<30$ & 22 & 12.5 & 4 & 20 \\
\hline$<40$ & 46 & 26.1 & 5 & 25 \\
\hline$<50$ & 82 & 46.5 & 9 & 45 \\
\hline$<60$ & 105 & 59.6 & 10 & 50 \\
\hline$<70$ & 128 & 72.7 & 14 & 70 \\
\hline$<80$ & 145 & 82.3 & 16 & 80 \\
\hline$<90$ & 155 & 88.0 & 18 & 90 \\
\hline all & 176 & 100 & 20 & 100 \\
\hline
\end{tabular}

The conclusion appears to be that a high PAO does not predispose to a higher risk of recurrence and, conversely, a low PAO does not decrease that risk.

However if the patients who had a recurrence in spite of an adequate reduction are considered ("method failures") it is remarkable that all the men (there were 6 men and 2 women in this category) were hypersecretors with a PAO of $60.1,73.1,74.8$, $81.9,84.2$, and $98.2 \mathrm{mmol} / \mathrm{h}$. respectively. As stated before all but one were operated on by the consultant who taught the technique in our hospital which makes it likely that the HSV technique was correct.

At the other end of the scale the patients who had an inadequate reduction ("surgeon failure") and a recurrent ulcer were all normosecretors except two. Preoperative PAO's were respectively: $16.9,23.3,23.9,25.2,33.2,40.3,43.0,64.4$ and $67.0 \mathrm{mmol} /$ h.

One is tempted to state that if these patients had been operated so as to result in an adequate postoperative reduction they would probably not have had their recurrence.

In table VII these comparative figures are tabulated including the percentage of patients without a recurrence, subdivided in adequate and in inadequate reduction of $\mathrm{PAO}$.

Unfortunately in both the non recurrent and in the recurrent group there are a considerable number of patients about whom nothing can be stated in this respect. All patients were subdivided on the base of their secretor state preoperatively. In 50 patients no reliable preoperative $\mathrm{PAO}$ was found. In 52 patients no postoperative test was done at all. In 13 patients the postoperative tests were so variable that nothing could be stated about a reduction after operation.

In 100 patients a good reduction was obtained by the operation resulting in 69 men and 23 women without a recurrence and 6 men and 2 women with a recurrence. In 47 patients no reduction (or a reduction smaller than $45 \%$ ) compared to the preoperative value was obtained, consisting of 35 men and 3 women in the non recurrent group and 9 men but no women in the recurrent group.

When the patients were separated on the base of their preoperative secretor status (table VIII) and were further subdivided into those having a good reduction (52 
gastric secretion tests, reduction and recurrence rate

total number of patients

no preoperative test

262

50

212

$(400,10 \%)$ including $2 \mathrm{rec}$

hypersecretor $85\left(720^{\circ}, 13 q\right) 40 \%$

normosecretor $127\left(102,0^{*}, 259\right) 60 \%$

no comparable

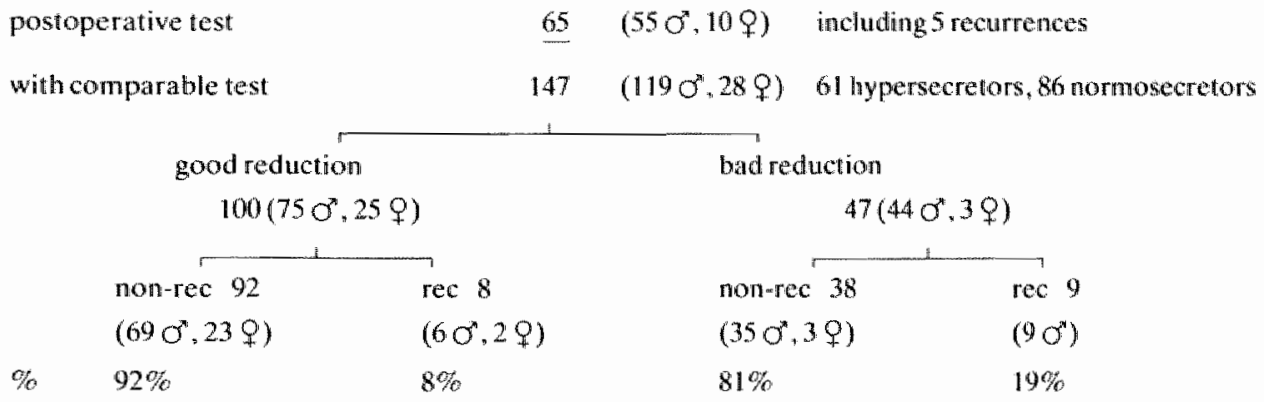

\section{table VIII}

hypersecretion, reduction and recurrence rate, all

hypersecretors

$P A O O=60 . q \geqslant 50 \mathrm{mmol} / \mathrm{h}$

normosecretors

PAO of $<60, q<50 \mathrm{mmol} / \mathrm{h}$

\begin{tabular}{|c|c|c|c|}
\hline & & & rec $\%$ \\
\hline good reduction & 52 & $\begin{array}{l}42 \mathrm{o}^{x}-6 \mathrm{rec} \\
10 \mathrm{q}-0 \mathrm{rec}\end{array}$ & $\| 1.5 \%$ \\
\hline bad reduction & 9 & $\begin{array}{l}9 \sigma-2 \operatorname{rec} \\
0 \%-0 \operatorname{rec}\end{array}$ & $22.2 \%$ \\
\hline
\end{tabular}

$\left[\begin{array}{lll}\text { goodreduction } & 48 & {\left[\begin{array}{c}330^{\circ}-0 \mathrm{rec} \\ 15 \%-2 \mathrm{rec}\end{array}\right.}\end{array}\right.$ 4\%

patients) it appeared that $11 \%$ of the hypersecretors developed a recurrence, in contrast to those with a bad reduction ( 9 patients) resulting in a $22 \%$ recurrence rate. In the normosecretor group with a good reduction (48 patients) $4 \%$ resulted in a recurrence, as compared with $18.4 \%$ in those with a bad reduction ( 38 patients). Disregarding the division on the base of the secretor status it was shown that $8 \%$ of those with a sufficient reduction (100 patients) developed a recurrence in contrast to those with an insufficient reduction ( 47 patients), who had a $19 \%$ recurrence rate (table VII).

If only men were considered the results were about the same (table IX). 
table IX

hypersectetion, reduction and recurrence rate, men

\begin{tabular}{|c|c|c|c|}
\hline only d" & & & $\operatorname{rec} \%$ \\
\hline hypersecretors & good reduction & $42-6$ rec & $14 \%$ \\
\hline $\mathrm{PAO} \geqslant 60 \mathrm{mmol} / \mathrm{h}$ & bad reduction & $9-2 \mathrm{rec}$ & $22 \%$ \\
\hline normosecretors & good reduction & $33-0$ rec & $0 \%$ \\
\hline $\mathrm{PAO}<60 \mathrm{mmol} / \mathrm{h}$ & badreduction & $35-7 \mathrm{rec}$ & $20 \%$ \\
\hline all & good reduction & $75-6 \mathrm{rec}$ & $8 \%$ \\
\hline $\begin{array}{l}\text { hypensecretors } \\
t \\
\text { nombsecretors }\end{array}$ & bad reduction & $44-9$ rec & $20.4 \%$ \\
\hline
\end{tabular}

However, statistically the risk of a recurrence was just significantly greater for "bad" then for "good" reduction, but this was not the case for hypersecretors as a whole as compared to normosecretors.

Nevertheless there was some evidence that the relative risk of a recurrence after bad as opposed to good reduction was not completely independant from the preoperative secretor status of the patients. In other words, the secretor status could have had some additional influence, although this was not significant. This was possibly due to the relatively low number of patients ( $\mathrm{X}^{2}$ test with logistic regression analysis). This result seems to be in contrast to the statement in chapter 10 that no statistically significant separation could be found on the base of PAO data. However, in chapter 10 all test results were used irrespective of their sequential stability.

In the preceding section of this chapter all sequential postoperative tests were "weighted" and on this base the results of 13 patients were excluded since they varied too much postoperatively. This exclusion is responsible for a conversion from insignificance to significance.

\subsection{Discussion}

The only parameters derived from the table with a significant difference between patients who develop a recurrence and those who do not were the length of follow-up, a history of psychiatric treatment, the surgeon who performed the operation, the amount of antrum dissected and the skeletonisation of the greater curvature. However, four of these were biased by one factor: time. As extensively discussed in chapter 8 most recurrences developed from the operations performed early in the series, hence the longer follow-up. At that time predominantly consultants performed the operations, the greater curvature was not then skeletonised and the dissection of the antrum started more proximally (as described in chapter 5).

Although there could be a relationship with the development of a recurrence, it does not appear warranted to blame all of these factors without further comment. If the series is were to be corrected for inexperience, which appears quite reasonable, the significance of the difference between consultants and registrars disappears. 
Moreover, as was suggested in this chapter, consultants seemed to have more "method failures" and the registrars more "surgeon failures".

Caution should be given to the interpretation of the influence of the number of centimeters of antrum dissected and of the skeletonisation of the greater curvature; statistical evaluation is in fact not allowed, since both factors were not randomised among the patients. Nevertheless it is very suggestive that a more extensive dissection of the antrum and skeletonisation of the greater curvature improves the results of HSV, but this cannot be proved in this series.

Several authors have found no difference in clinical results between 6 and 8 or 9 centimeters dissection of the antrum but, in contrast, Poppen ${ }^{288}$ demonstrated a higher chance of residual innervated parietal cells if the dissection was started more proximally.

In an attempt to find a relation between the measured distance to the pylorus and the average reduction of PAO these percentages were compared between patients having $5,6,7$ or $8 \mathrm{~cm}$ of antrum dissected. Contrary to expectation it was found that a better reduction had occurred in the patients with less antrum dissected, but the differences were not significant (table $\mathrm{X}$ ).

table X

influence of amount of antrum dissection

\begin{tabular}{ccccc}
\hline $\begin{array}{c}\text { cmof } \\
\text { antirum } \\
\text { dissected }\end{array}$ & $n$ & $\begin{array}{c}\text { mean PAO } \\
\text { reduction } \\
\% \pm \mathrm{sd}\end{array}$ & $\begin{array}{c}\text { number of } \\
\text { recurrences }\end{array}$ & $\begin{array}{c}\text { number of } \\
\text { hypersecretors }\end{array}$ \\
\hline 8 & 18 & $53 \pm 22$ & 8 & 14 \\
7 & 86 & $48 \pm 26$ & 13 & 52 \\
6 & 50 & $47 \pm 27$ & 3 & 14 \\
5 & 4 & $45 \pm 20$ & 0 & 3 \\
\hline
\end{tabular}

Skeletonisation of the greater curvature probably does have an influence. Both anatomically 144,220 and clinically ${ }^{156,28 i, 303}$ it is reported that skeletonisation interrupts some vagal fibres coming in to the greater curvature side, provided the dissection takes place between the gastroepiploic vessels and the stomach wall. The additional advantage of this kind of skeletonisation in contrast to opening of the gastrocolic ligament at the other side of the vessels, is that the omentum will not be in danger of necrotising. In this series there were no demonstrable deleterious effects on the vascularisation of the stomach.

One factor, independant from the above mentioned four, was proved to influence the number of recurrences: the presence of a history of psychiatric treatment. This appeared to predispose to a disappointing result with HSV, as probably with any other treatment ${ }^{185}$. Visick ${ }^{353}$ expressed it this way: "these patients are badly adapted to life".

As discussed in the introduction some of the patients may represent "patient failures".

Even if this is true, these people exist and evidently develop duodenal ulcers. Although 
many doctors are reluctant, as we were, to accept these patients for operation, they cannot simply be distegarded or excluded, especially since they are probably less suitable candidates than others to be on maintenance treatment with drugs.

A partial gastrectomy could be catastrophic to these patients, causing gastric cripples, but a HSV has the advantage of few side effects: almost no damage is done by the operation.

These data demonstrate that if a good reduction in PAO is accomplished by the operation the recurrence rate is considerably lower than with insufficient reduction. Moreover they favour the theory which suggests that hypersecretors do run a higher risk of recurrence compared with normosecretors in spite of an adequate reduction, possibly in spite of an adequate HSV: about $10 \%$ in this series developed a recurrence.

In contrast normosecretors if operated "correctly" (= resulting in adequate reduction) had only a $4 \%$ incidence of recurrence. If however there was a reduction in PAO of less than $45 \%, 20 \%$ of the recurrences occurred in both hyper and normosecretors. These findings seem to connect different opinions about the role of hypersecretion and its role in developing a recurrence. Johnston ${ }^{167,172}$ has always stated that hypersecretors do not need a different operation, which was confirmed in the Aarhus Vagotomy trial ${ }^{17}$, whereas by others a truncal vagotomy and antrectomy is favoured $154,254,207,361$. Poppen ${ }^{288}$ demonstrated that patients with a high preoperative secretion were denervated less effectively, since their antra were smaller and the parietal cell areas correspondingly greater.

The findings, although not significant, in this study seem to support the latter opinion, if a recurrence rate as low as possible is to be obtained.

However many patients with a recurrence run such a favourable course that they cannot be considered a failure in a real sense and probably one can afford to risk a higher recurrence percentage by performing a HSV on hypersecretors.

Further, the difference in recurrence rate between men and women, which was $10.3 \%$ and $4.2 \%$ respectively, can be understood on the basis of the PAO reduction obtained: only $11 \%$ ( 3 out of 28 ) of the women had a bad reduction in contrast to $37 \%$ (44 out of 119 ) of the men.

This could mean that the women were operated on better than the men or that an adequate HSV is accomplished more easily in women ${ }^{129}$.

The proportion of consultants and registrars operating on male and female patients was about the same (table A, chapter 4).

From the data on acid secretion tests, used in this chapter, one is temped to conclude by extrapolation that $32 \%$ of all patients had an insufficient reduction from the operation ( 47 of 147 patients with comparable preoperative and postoperative testing data). Probably this is not correct, since patients without complaints after operation are understandably less eager to undergo a pentagastrin test than those with complaints, and a higher proportion of patients with an expectedly good reduction is thus suppressed in the figures.

Moreover, it should be stressed that a good PAO reduction does not necessarily 
indicate a good operation and conversely, a bad PAO reduction does not infallibly point at a bad operation (surgeon failure), although one is tempted to think $50.80 \%$ of the patients with a measured "bad" reduction of PAO had no or minor complaints after operation 14 .

In fact there is no absolutely reliable criterion determining the complateness or adequacy of the vagotomy, although many people use the insulin test for this.

\section{Table B}

Characteristics of patients, subdivided in those with and without a recurrence.

The laboratory parameters refer to preoperative values. Either the number of cases and the percentages are indicated or the average value \pm the standard devation (sd) and the number of values ( $n$ ); if the latter is the case the units are given in the second column. The set-up of this table is essentially the same as that of table A (chapter 4), where the data of all patients with a subdivision in men and women are presented.

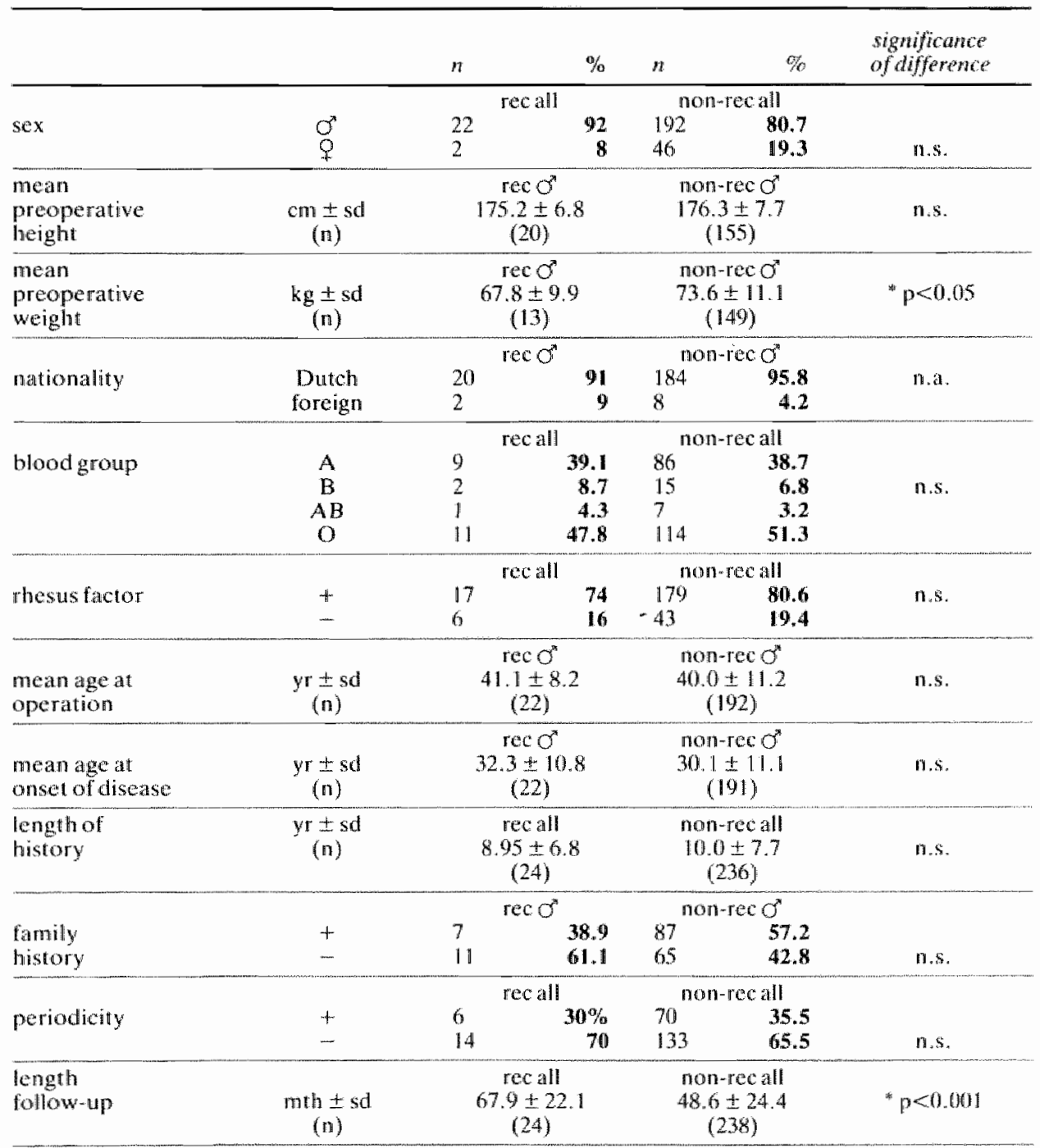




\begin{tabular}{|c|c|c|c|c|c|c|}
\hline & & $n$ & $\%$ & $M$ & $\%$ & $\begin{array}{l}\text { significance } \\
\text { of difference }\end{array}$ \\
\hline patients & & \multicolumn{2}{|c|}{ recall } & \multicolumn{2}{|c|}{ non-recall } & \multirow[b]{2}{*}{ m.s. } \\
\hline vis & $\begin{array}{c}\text { internist } \\
\text { family doctor }\end{array}$ & $\begin{array}{l}21 \\
1\end{array}$ & $\begin{array}{r}95.2 \\
4.8\end{array}$ & $\begin{array}{l}196 \\
25\end{array}$ & $\begin{array}{l}88.7 \\
11.3\end{array}$ & \\
\hline \multirow[t]{3}{*}{ nervousness } & & \multicolumn{2}{|c|}{$\operatorname{rec} 0^{x}$} & \multicolumn{2}{|c|}{ non-rec $0^{x}$} & \multirow{3}{*}{ n.s. } \\
\hline & H & 9 & 41 & 54 & 25.6 & \\
\hline & - & 13 & 59 & 157 & 74.4 & \\
\hline \multirow{3}{*}{$\begin{array}{l}\text { history of } \\
\text { psychiatry }\end{array}$} & & \multicolumn{2}{|c|}{$\operatorname{reco}$} & \multicolumn{2}{|c|}{ non-rec $0^{\prime \prime}$} & \multirow{3}{*}{$* p<0.05$} \\
\hline & + & 5 & 23 & 7 & 3.7 & \\
\hline & - & 17 & 77 & 180 & 96.3 & \\
\hline \multirow{10}{*}{$\begin{array}{l}\text { smoking } \\
\text { of } \\
\text { cigaretes }\end{array}$} & & \multicolumn{2}{|c|}{ recall } & \multicolumn{2}{|c|}{ non-recall } & \multirow{5}{*}{ n.s. } \\
\hline & - & 2 & 9.5 & 32 & 15.9 & \\
\hline & $<10$ & 2 & 9.5 & 29 & 14.4 & \\
\hline & 10.25 & 9 & $\$ 2.8$ & 84 & 41.8 & \\
\hline & $>25$ & 8 & 38.1 & 56 & 28 & \\
\hline & & \multicolumn{2}{|c|}{$\operatorname{rec} 0^{3}$} & \multicolumn{2}{|c|}{ non-rec o } & \\
\hline & - & 7 & 41.11 & 75 & 49 & \\
\hline & moderate & 6 & 35.3 & 62 & 40.5 & n.s. \\
\hline & much & 1 & 5.9 & 13 & 8.4 & \\
\hline & abuse & 3 & 17.6 & 3 & 2 & \\
\hline \multirow{5}{*}{ employment } & & \multicolumn{2}{|c|}{$\operatorname{rec} \sigma^{\prime \prime}$} & \multicolumn{2}{|c|}{ non-rec 0} & \\
\hline & - & 0 & & 7 & 4 & \\
\hline & $\therefore$ & 19 & 90.5 & 143 & 81.7 & n.s. \\
\hline & rejected & 2 & 9.5 & 21 & 12 & \\
\hline & retired & 0 & & & 2.3 & \\
\hline \multirow{3}{*}{$\begin{array}{l}\text { prooperative } \\
\text { complications }\end{array}$} & & & & & & \\
\hline & + & 6 & 25 & 78 & 32.8 & n.s. \\
\hline & - & 18 & 75 & 160 & 67.2 & \\
\hline $\mathrm{HSV}$ & & & & & all & \\
\hline performed by & registrars & 8 & 33 & 159 & 66.8 & $p<<0.001$ \\
\hline & consultants & 16 & 67 & 79 & 32.2 & \\
\hline HSV & & & & & all & \\
\hline assistance by & registrars & 19 & 79.2 & 189 & 79.4 & n.s. \\
\hline & consultants & 5 & 20.8 & 49 & 20.6 & \\
\hline activity of the & & & & & all & \\
\hline ulcer at operition & - & 1 & 4.2 & 22 & 9.2 & \\
\hline & sear & 8 & 33.3 & 131 & 55.5 & n.s. \\
\hline & shight + & 5 & 20.8 & 31 & 13.1 & \\
\hline & + & 10 & 41.6 & 52 & 22.0 & \\
\hline & & & & & all & \\
\hline (semi)entergency & + & 3 & 12.5 & 36 & 18 & n.s. \\
\hline $\mathrm{HSV}$ & - & 21 & 87.5 & 202 & 82 & \\
\hline HSV with additional & + & 3 & 12.5 & 33 & 16.1 & n.s. \\
\hline operation & - & 21 & 87.5 & 205 & 83.9 & \\
\hline & & & & & all & \\
\hline clips & - & 19 & 79.2 & 176 & 80 & n.s. \\
\hline & $1 /$ & 2 & 8.3 & 26 & 11.8 & \\
\hline & + & 3 & 12.5 & 18 & 8.2 & \\
\hline
\end{tabular}




\begin{tabular}{|c|c|c|c|c|}
\hline & & $\%$ & $\%$ & $\begin{array}{l}\text { significance } \\
\text { of difference }\end{array}$ \\
\hline $\begin{array}{l}\text { skeletonising of } \\
\text { greater curve }\end{array}$ & + & $\begin{array}{l}12.5 \\
87.5\end{array}$ & $\begin{array}{l}46.4 \\
53.6\end{array}$ & ${ }^{*} p<0.001$ \\
\hline $\begin{array}{l}\text { cm of } \\
\text { oesophagus } \\
\text { skeletonised }\end{array}$ & $\begin{array}{l}4 \mathrm{~cm} \\
5 \mathrm{~cm} \\
6 \mathrm{~cm} \\
7 \mathrm{~cm}\end{array}$ & $\begin{array}{lr} & \text { recall } \\
1 & 4.3 \\
16 & 69.6 \\
6 & 26.1 \\
0 & \end{array}$ & \begin{tabular}{lr}
\multicolumn{2}{c}{ non-recall } \\
8 & 3.4 \\
128 & 54.7 \\
54 & 40.2 \\
4 & 1.7
\end{tabular} & n.s. \\
\hline $\begin{array}{l}\text { crn of } \\
\text { oesophagus } \\
\text { skeletonised }\end{array}$ & $\underset{\text { (n) }}{\mathrm{cm} \text { 上 }}$ & $5.21(23)^{ \pm 0.53}$ & $5.39 \quad \pm 0.58$ & n.s. \\
\hline $\begin{array}{l}\text { cm of } \\
\text { antrum } \\
\text { skeletonised }\end{array}$ & $\begin{array}{l}5 \mathrm{~cm} \\
6 \mathrm{~cm} \\
7 \mathrm{~cm} \\
8 \mathrm{~cm}\end{array}$ & $\begin{array}{ll} & \text { recall } \\
0 & \\
3 & \mathbf{1 3 . 6} \\
12 & \mathbf{5 4 . 5} \\
7 & \mathbf{3 1 . 8}\end{array}$ & $\begin{array}{lr} & \text { non-recall } \\
7 & \mathbf{3 . 7} \\
68 & \mathbf{3 6 . 2} \\
89 & \mathbf{4 7 . 3} \\
24 & \mathbf{1 2 . 7}\end{array}$ & $" p<0.01$ \\
\hline $\begin{array}{l}\text { Cm of antrum } \\
\text { skeletonised }\end{array}$ & $\begin{array}{c}\mathrm{cm} \pm \mathrm{sd} \\
(\mathrm{n})\end{array}$ & $\begin{array}{c}7.2 \pm 0.7 \\
(22)\end{array}$ & $\begin{array}{c}6.6 \pm 0.8 \\
(188)\end{array}$ & $p<0.001$ \\
\hline $\mathbb{H}-\mathrm{Hb}$ & $\underset{(n)}{\operatorname{mmol}} \pm s d$ & $\begin{array}{c}\operatorname{reco} \\
9.58 \pm 0.77 \\
(20)\end{array}$ & $\begin{array}{c}\text { non-rec } 0 \\
9.73 \pm 0.69 \\
(179)\end{array}$ & n.s. \\
\hline ESR & $\underset{(n)}{\operatorname{mmol} / \mathrm{h}} \pm \mathrm{sd}$ & $\begin{array}{c}\operatorname{rec} 0 \\
9.0 \pm 13.7 \\
(17)\end{array}$ & $\begin{array}{c}\text { non-reco } \\
5.4 \pm 5.5 \\
(169)\end{array}$ & $\mathrm{n} . \mathrm{s}$. \\
\hline serum $\mathrm{AP}$ & $\underset{(n)}{U} 1 \pm s d$ & $\begin{array}{c}\text { recall } \\
86.0 \pm 25.8 \\
(15)\end{array}$ & $\begin{array}{l}\text { non-rec all } \\
84.3 \pm 27.8 \\
(165)\end{array}$ & n.s. \\
\hline serum $\mathrm{Ca}$ & $\underset{(n)}{\mathrm{mmol} / 1 \pm \mathrm{sd}}$ & $\begin{array}{c}\text { recall } \\
2.42 \pm 0.11 \\
(10)\end{array}$ & $\begin{array}{l}\text { nont-recall } \\
2.41 \pm 0.11 \\
(1.48)\end{array}$ & $\mathrm{n} . \mathrm{s}$. \\
\hline serum $\mathbf{P}$ & $\underset{\text { (n) }}{\mathrm{mmol} / \mathrm{s} \pm \mathrm{sd}}$ & $\begin{array}{c}1.13 \pm 0.27 \\
(10)\end{array}$ & $\begin{array}{c}1.12 \pm 0.19 \\
(148)\end{array}$ & n.s. \\
\hline serum Fe & $\underset{(\mathrm{n})}{\mu \mathrm{mol} / \mathrm{s} \mathrm{sd}}$ & $\begin{array}{c}\text { recall } \\
20.3 \pm 10.7 \\
(9)\end{array}$ & $\begin{array}{l}\text { non-recall } \\
19.0 \pm 6.1 \\
(134)\end{array}$ & n.s. \\
\hline serum TIBC & $\underset{(\mathrm{n})}{\mu \mathrm{mol} / \mathrm{sd}}$ & $\begin{array}{c}58.8 \pm 7.6 \\
(9)\end{array}$ & $\begin{array}{c}60.8 \pm 9.8 \\
(134)\end{array}$ & n.s. \\
\hline vitamin $B_{12}$ & $\underset{(n)}{n m o l / l} \pm s d$ & $\begin{array}{c}\text { rec all } \\
260.8 \pm 76.6 \\
(8)\end{array}$ & $\begin{array}{c}\text { non-rec all } \\
281.6 \pm 71.8 \\
\text { (15) }\end{array}$ & n.s. \\
\hline serum gastrin & $n g / 1 \pm s d$ & $\begin{array}{l}\text { rec atl } \\
111.2 \pm 55.5 \\
(14)\end{array}$ & $\begin{array}{c}\text { non-recall } \\
120.0 \pm 65.2 \\
(174)\end{array}$ & n.s. \\
\hline $\mathrm{BAO}$ & $\begin{array}{l}\mathrm{mmol} / \mathrm{h} \\
\pm \mathrm{sd}(\mathrm{m})\end{array}$ & $\begin{array}{c}\operatorname{reco} \\
4.52 \pm 3.88 \\
(20)\end{array}$ & $\begin{array}{l}\text { mon-rec } 0 \\
6.57 \pm 7.79 \\
(149)\end{array}$ & n.s. \\
\hline volume & $\begin{array}{c}m / / h \\
\pm s d(n)\end{array}$ & $\begin{array}{c}104.3 \pm 82.5 \\
(20)\end{array}$ & $\begin{array}{c}13: .4 \pm 98.9 \\
(151)\end{array}$ & n.s. \\
\hline acidity & $\begin{array}{l}\mathrm{mmol} / 1 \\
\pm \mathrm{sd}(\mathrm{n})\end{array}$ & $\begin{array}{c}38.5 \pm 24.4 \\
(20)\end{array}$ & $\begin{array}{c}43.4 \pm 23.5 \\
(151)\end{array}$ & n.s. \\
\hline
\end{tabular}




\begin{tabular}{|c|c|c|c|c|}
\hline & & $\%$ & $\%$ & $\begin{array}{l}\text { significance } \\
\text { of difference }\end{array}$ \\
\hline PAO & $\begin{array}{l}\mathrm{mmol} / \mathrm{h} \\
\pm \mathrm{sd}(\mathrm{n})\end{array}$ & $\begin{array}{c}\text { reco } \\
57.4 \pm 26.9 \\
(20)\end{array}$ & $\begin{array}{c}\text { norn-reco } \\
57.4+24.4 \\
(154)\end{array}$ & $\mathrm{ns}$ \\
\hline vollume & $\begin{array}{l}\text { ml/s min } \\
\pm \text { sd }(n)\end{array}$ & $\begin{array}{c}131.8 \pm 56.0 \\
(20)\end{array}$ & $\begin{array}{c}136.5 \pm 51.6 \\
(150)\end{array}$ & $n .5$ \\
\hline acidily & $\begin{array}{l}\text { menol/L } \\
\pm \mathrm{sd}(\mathrm{i})\end{array}$ & $108.2 \pm 22.5$ & $\begin{array}{c}107.5 \pm 19.0 \\
(150)\end{array}$ & $n, s$ \\
\hline$M A O$ & $\begin{array}{l}\text { molnolin } \\
\pm \operatorname{sd}(n)\end{array}$ & $\begin{array}{c}\text { rec o" } \\
34.9 \pm 17.5 \\
(20)\end{array}$ & $\begin{array}{c}\text { mon-reco } \\
35,1.13 .9 \\
(148)\end{array}$ & n.s. \\
\hline
\end{tabular}




\section{Chapter 16}

\section{Special observations}

\subsection{Anecdotal observations}

In several patients remarkable complaints have been noted, which did not seem directlly related to the operation. But since more patients had similar problems perhaps they did have a relation.

They are mentioned here as anecdotal details. No special investigation was done about these details in other patients.

\section{1. nerwousness}

Nervousness is often associated with duodenal ulcer disease. Moreover it is perhaps an increasing trait in many people and therefore not noted or recorded.

Several patients, however, clearly stated, and volunteered this information that they had become very nervous after their HSV or that the degree had increased remark ably. These patients had all improved after operation as far as their stomach trouble was concerned.

One patient said very resolutely that since operation he felt very nervous in circumstances wherein he felt stomach pain before operation!

In other words his symptoms had shifted from his stomach to his nervous system. A better description of a psychosomatic phenomenon could hardly be clemonstrated. In the literature such descriptions are rarely found, although a relation to stress has been described more often.

Three of the patients had also noted increased sweating. One of them stated that he started sweating very much under his armpits in circumstances which would have led to stomach pain before operation. Moreover he used to be a good shooter before operation, but since his HSV he did not manage to perform anything of that kind. One other patient experienced stomach trouble after operation if he had to relax. At work he never had any trouble, contrary to the situation before operation.

\section{2. left shoulder pain after eating}

After operation many patients complained of epigastric fullness and early satiety. Some, however, volunteered complaints of pain in the left shoulder region after eating evidently too much. From five patients this was recorded. One of these experienced at the same time a band-like feeling inside his left thorax.

Another patient not complaining about pain in his shoulder had a troublesome hiccup after operation.

All these patients suggest an abnormal irritability of the left hemi-diaphragm by operation.

\section{3. immediate freedom of pain after operation}

A striking feature in many patients who still had their characteristic pain before operation was that immediately after operation their pain had completely gone. Of 
course patients do feel pain after awaking from anaesthesia but a completely different "wound-pain", as they say. However, since the introduction of cimetidine patients are usually free of pain on admission for operation and the effect described cannot be noted so clearly any more.

A reason for this quick relief could be:

a) transmission of pain via the vagus nerve fibres, which have been cut,

b) acute cessation of acid production at operation.

concerning $a$ ): this seems improbable since the location of the ulcer is duodenal and the nerve fibres, whether vagal or sympathetic, to the duodenum are preserved. concerning $b$ ): although ten days after $\mathrm{HSV}$ the parietal cell mass can be stimulated again with histamine, gastrin and insulin this is not the case at the moment of operation, after the vagal fibres have been cut. The parietall cells seem to be refractory for some time. This is the reason why $\mathrm{pH}$-metry or Congo-red testing under pentagastrin infusion can be accomplished succesfully for controll of completeness. Possibly in the short time of temporary achlorhydria a quick re-epithelialisation of the ulcer takes place, abolishing the typical pain.

How this refractory state is to be explained is not known.

Another example of a similar phenomenon is the quick disappearance of a "réaction antralle" - a rather seldom found irritable state of the antrum in the presence of an active duodenal ulcer. Five days after operation this had disappeared completely in one patient and the ulcer had healed on X-ray (see picture).
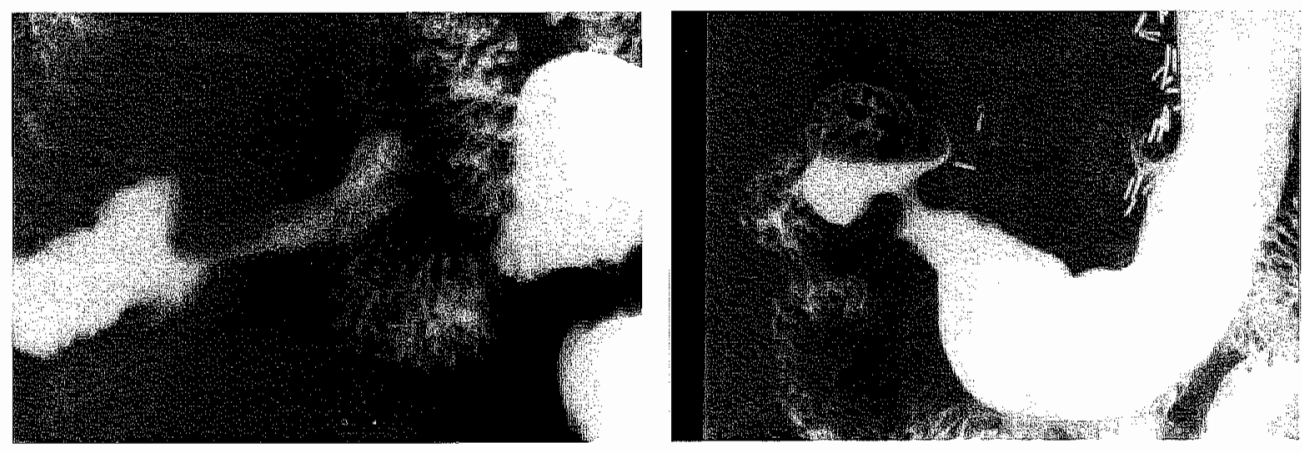

Disappearance of antral reaction. a (left): 1 month before operation: 'réaction antrale'; deformed bulb to the left. no ulcer visible on this picture.

b (righy): 5 days after HSV: antrum and bulb almost normal. Dissection has been performed with clips.

The direction of $X+r a y s$ was different in both pictures, hence the overprojection of jejunum in a.

\section{4. peculiar cimetidine use}

Cimetidine is an effective drug in suppressing symptoms. Many patients are familiar with the use of it and keep a little stock of left over tablets after they have been operated "just in case".

Generally it should be effective if taken continuously for some time, but two patients said they just needed occasionally one single tablet whenever their stomach pain returned after operation. They never used more then one tablet on each occasion. In one of them a cigarette gave the same relief. 


\subsection{Periodicity}

As was introduced in chapter 4 the presence or absence of a periodical character of ulcer symptoms was recorded. In chapter 15 no statistically sigmificant difference of this periodicity was demonstrated (table B) between the patients who developed a recurrence and those who did not. This subject was investigated further with regard to the weight, serum gastrin, BAO and PAO of the patients in the course of time. No statistical difference could be found between the patients with and without periodicity of their complaints in any of these parameters at any time period in relation to the $\mathrm{HSW}$.

The figures are assembled in table $I$. The data of patients whose periodical character of complaints was doubtful or unknown have been neglected.

table I

periodicity and weight, gastrin, $\mathrm{BAO}, \mathrm{PAO}$

\begin{tabular}{lllllllll}
\hline & $\begin{array}{c}\text { mean } \\
\text { weight } \\
(\mathrm{kg})\end{array}$ & $\begin{array}{c}\text { mean basal } \\
\text { serum gastrin } \\
\text { (ng/l) }\end{array}$ & $\begin{array}{c}\text { mean BAO } \\
\text { (mmoll) }\end{array}$ & $\begin{array}{c}\text { mean PAO } \\
\text { (mmolll) }\end{array}$ \\
\hline periodicity & - & + & - & + & - & + & - & + \\
\hline preop & 70.6 & 72.7 & 117.4 & 124.3 & 5.9 & 6.9 & 55.4 & 55.0 \\
sd & 11.5 & 12.5 & 57.4 & 75.8 & 5.9 & 9.4 & 24.9 & 22.8 \\
n & 115 & 62 & 107 & 57 & 118 & 60 & 121 & 61 \\
1/2yr postop & 73.3 & 73.3 & 207.0 & 201.2 & 2.3 & 1.6 & 29.2 & 27.3 \\
sd & 12.2 & 11.4 & 140.5 & 181.9 & 3.0 & 1.8 & 16.5 & 16.9 \\
n & 73 & 33 & 89 & 41 & 82 & 35 & 82 & 35 \\
1 yr postop & 72.3 & 76.1 & 214.2 & 204.5 & 2.3 & 2.9 & 25.4 & 26.3 \\
sd & 11.9 & 12.2 & 119.5 & 161.1 & 2.6 & 3.0 & 12.4 & 14.1 \\
n & 46 & 37 & 73 & 39 & 73 & 33 & 73 & 33 \\
5yr postop & 72.4 & 78.2 & 262.5 & 193.3 & 2.9 & 3.9 & 26.0 & 34.5 \\
sd & 12.3 & 11.6 & 191.7 & 81.1 & 3.3 & 3.7 & 11.7 & 11.1 \\
n & 21 & 10 & 27 & 12 & 24 & 10 & 24 & 10 \\
\hline
\end{tabular}

Conclusion: periodicity of ulcer complaints is not important for the outcome of clinical and some laboratory results.

\subsection{Appendix}

16.3.1 Case histories of patients who developed a recurrent or new ulcer after their HSV

pt.no.2 $\sigma$, born in 1932

$\begin{array}{ll}\text { profession: } & \text { wiler } \\ \text { length of history: } & 4 \text { years } \\ \text { family history: } & \text { negative } \\ \text { blood group: } & \text { A }+ \\ \text { preop PAO: } & 73.6 \mathrm{mmol} / \mathrm{h}\end{array}$

Further relevant details: Italian origin, history of psychiatric treatment in connection with alcohol abuse, nervosity ++ , nicotine abuse ( 60 cigarettes dailly) 
HSV: January 1974

postoperatively: symptomfree untif August 1975. On two separate occasions a recurrent duodenal ulcer was proved, both in connection with great family problems (diworce, illness of mother, daughter ran alway).

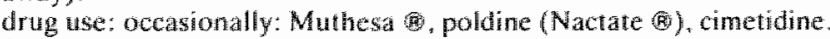

Evident relationship between symptoms and stress.

Reoperation was proposed, but tefused by the patient.

Subjectively: much better than before operation

mean positop PAO

$19.9 \mathrm{mmol} / \mathrm{h}$ (4 values)

pt.no. $60^{\circ}$, born in 1922 reduction $\mathrm{BAO} 92 \%$

reduction PAO73\%

profession: miner

length of history: 11/2 years

family history: positive

blood group: AB -

preop PAO: $\quad 84.2 \mathrm{mmol} / \mathrm{h}$

HSV: May 1974

postoperatively: sporadically heartburn and eructations

$X$-ray in "75 and "79: no ulcer, no reflux.

In "81 endoscopically a slight oesophagitis was proved but $\mathrm{X}$-ray revealed a recurrent duodenal ulcer.

Treatment: cimetidine.

Repeat endoscopy: small sliding hernia, no ulcer.

In March '82: X-ray: duodenal ulcer, while on maintenance treatment. He continues on maintenance treatment with cimetidine; is symptomfree.

nean post op $\mathrm{PAO}$

34. 1 mmol/h (5 values)

pt.no. $12 \sigma^{\prime \prime}$, born in 1934

\begin{tabular}{|c|c|}
\hline profession: & $\begin{array}{l}\text { miner, later labourer } \\
\text { stonefactory }\end{array}$ \\
\hline length of history: & 3 years \\
\hline family history: & unknown \\
\hline blood group: & A - \\
\hline preop PAO: & $74.8 \mathrm{mmol} / \mathrm{h}$ \\
\hline
\end{tabular}

further relevant details: treated for chronic alcoholism, low I.Q.

HSV: September 1974

postoperatively: perfect until abandoning follow-up after being operated on for inguinal hernia...

In 1978 the had stomach trouble again; recurrent duodenal ulcer was demonstrated on two occasions that year, treat ment: cimetidine for a short period by his family doctor. The stomach problems had a close relationship with (irregular) night duties. Later he obtained a more quiet job and had no further problems. Subjectively: even at the time of recurrent stomach problems much better than before operation, now perfect.

mean postop $\mathrm{PAO}$

$23.7 \mathrm{mmol} / \mathrm{h}$ ( 2 values)

pt.no.14 $0^{*}$, born in 1954

HSV: October 1974

postoperatively: minor symptoms, X-ray April 1975: no ulcer.

November 1976: more severe symptoms; $X$-ray: recurrent duodenal ulcer. Treatment: dietary measures only. reduction $\mathrm{BAO} 0 \%$

reduction $\mathrm{PAO} 68 \%$

profession: forester

length of history: 8 years

family history: positive

blood group: $\quad A+$

preop PAO: $\quad 117 \mathrm{mmol} / \mathrm{h}$ 
January 1978: abandoning of follow-up, so far sporadically minor symptoms since then. The family doctor has seen hirn for other problems, but mot for his stomach; no drugs were preseribed.

mean postop $\mathrm{PAO}$

$64.1 \mathrm{nmmol} / \mathrm{h}$ (2 values)

pt.no.16 0', born in 1931

$\begin{array}{ll}\text { reduction } \mathrm{BAO} 0 \% & \\ \text { reduction PAO 45\% } & \\ \text { profession: } & \text { galvanoindustry } \\ \text { length of history: } & 7 \text { years } \\ \text { family history: } & \text { negative } \\ \text { blood group: } & 0+ \\ \text { preop PAO: } & \text { test failed }\end{array}$

further relevant details: a recurrent duodenal ulcer was demonstrated on at least three occasions; al one occaston there was also suspicion of a gastric ulcer.

HSV: November 1974

postoperatively: sporadically minor complaints, no drugs preseribed. He staned to have problems when he lost his job in 1980. In December 1980 no ulcer could be demonstrated by $X$-ray or endoscopy.

Treatment: Muthesa (cimetidine did mot bring any relief at all).

September 1981: again symptoms, related to backache due to hernia; endoscopically a pyloric ulcer was demonstrated; again cimetidine did not bring much relief.

In December 1981 he was operated on for his hernia; he had no further stomach trouble. except for a shont period related to stress (open heart operation on his son).

mean postop $\mathrm{PAO}$

$23.1 \mathrm{mmol} / \mathrm{h}$ (3 3 walues)

pt.no.20 o", born in 1929 reduction $B A O$ n.a.

reduction PAO n.a.

profession:

length of history:

family history:

blood group:

preop PAO: railways controller

26 years

negative

$\mathrm{O}+$

$67.0 \mathrm{mmol} / \mathrm{h}$

HSV: March 1975

postoperatively: no symptoms or problems.

During 1979 again dyspeptic symptoms in connection with irregular work; in February 1979 a recurrent duodenal ulcer was proven endoscopically, but not on X-ray. Treatment: a short course with cimetidine. Temporarily he did lighter work, but soon resumed his old job. Sporadically (a few days per year) he experiences some stomach pain, relieved quickly after some days of cimetidine taking. The drug is then discontinued.

Subjectively: much better than before operation.

mean postop $\mathrm{PAO}$

$51 \mathrm{mmol} / \mathrm{h}$ ( 4 values)

pt.no.22 9 , born in 1931 reduction $\mathrm{BAO} 48 \%$

reduction PAO 23\%

\author{
housewile \\ 20 years \\ negative \\ Bi-
}

$\begin{array}{ll}\text { preop PAO } & 45.6 \mathrm{mmol} / \mathrm{h}\end{array}$

HSV: May 1975

postoperatively: perfect.

In 1979 she had stomach trouble during I week; a recurrent duodenal ulcer was demonstrated with $X$-ray,

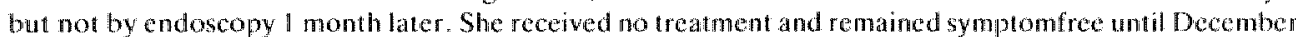
1980. Then renewed symptoms ensued related to stress (her disabled mother was nursed by her for several months); a recurrent duodenal ulcer wats again demonstrated by $X$-ray and proved cured endoscopically 3 months llater. She had been treated for two months with cimetidine. She had no further problems and is symptomfree. Subjectively: satisfied with the result of operation.

mean postop PAO

$18.9 \mathrm{mmol} / \mathrm{h}$ (4 values) reduction BAO $19 \%$

reduction $\mathrm{PAO} 58 \%$ 
HSV: Junc 1975

$\begin{array}{ll}\text { profession: } & \text { driver } \\ \text { length of history: } & \text { loyears } \\ \text { family hisiory: } & \text { positive } \\ \text { blood group: } & O+ \\ \text { preop PAO: } & 40.3 \mathrm{mmol} / \mathrm{h}\end{array}$

postoperatively: no problems.

September 1978: admission for sudden haematemesis; gastroscopy: recurrent duodenal ulcer. Treatment: cimetidine ( 6 wecks). Since then he experiences hearburn for two weeks a year, relieved by cimetidine. Subjectively: very satisfied with the result of operation.

mean postop $\mathrm{PAO}$

53.1 mmolih ( 3 values)

pt.no.31 $0^{*}$, born in $194 \|$

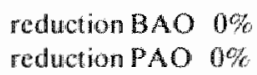

$\begin{array}{ll}\text { profession: } & \text { mason } \\ \text { length of history: } & 18 \text { years } \\ \text { family history: } & \text { positive } \\ \text { blood group: } & \mathrm{A}+ \\ \text { preop PAO: } & 33.2 \mathrm{mmol} / \mathrm{h}\end{array}$

HSV: August 1975

postoperatively: shonly after operation he moved to another town, but appeared later to be symptomfree untill November 1978.

Then he had several periods of dyspeptic symptoms, but no ulcer was demonstrated with $X$-ray or endoscopy. Im May 1981 a recurrent duodenal ulcer was demonstrated, treatment: cimetidine. In August "8I the ulcer was still present and the patient was referred to the surgeon for reoperation. Suddenly, however, he became symptomfree and was not reoperated.

mean postop $\mathrm{PAO}$

$34.0 \mathrm{mmol} / \mathrm{h}(2$ values)

pt. no. 430 , born in 1930

\section{reduction $\mathrm{BAO} \quad 7 \%$}

reduction PAO $0 \%$

$\begin{array}{ll}\text { profession: } & \text { miner } \\ \text { length of history: } & 12 \text { years } \\ \text { family history: } & \text { negative } \\ \text { blood group: } & O+ \\ \text { preop PAO: } & 81.9 \mathrm{mmol} / \mathrm{h}\end{array}$

HSV: April 1976

postoperatively: synaptomfree until June 1976. Recurrent dyspeptic symptoms started and a recurrent duodemal ulcer was demonstrated both on $X$-ray and endoscopy. Treatment cinatidine: in spite of the treatment the pain increased and in August 1978 he was reoperated; a revision of the HSV was attempled and the greater curvature, which was not opened at the time of HSV, was skeletonised. After this reoperation he contimued to have pain and his acid production had not been brought down further. In July 1979 a partial gastrectomy (Billroth i) was performed.

He still experiances symptoms of pain, Tatulence, dumping but is moderately satisfied now.

mein postop $\mathrm{PAO}$

$21.0 \mathrm{mmol} / \mathrm{h}$ (3values)

pt.no.57 9 , born in 1919 reduction BAO $64 \%$

reduction $\mathrm{PAO} 74 \%$

$\begin{array}{ll}\text { profession: } & \text { pension holder } \\ \text { length of history: } & \text { Iyear } \\ \text { family history: } & \text { positive } \\ \text { blood group: } & \mathrm{O}- \\ \text { preop PAO: } & 44.1 \mathrm{mmol} / \mathrm{h}\end{array}$

further relevant detaits: preoperatively a gastric outlet obstruction was demonstrated (dilatation of stomach, narrowed pyloric channd) patient had lost $18 \mathrm{~kg}$ of body weight before operation.

HSV: July 76 , gastrotony was performed, but the pylorus appeared not to be narrowed, admitting 1 finger including the PIP joint.

postoperatively: no problems at all.

Early 1981 again problems; vomiting and flatulence. A prepyloric ullcer was demonstrated by endoscope 
with narrowing of the pylorus.

Treatment with cimetidine; the ulcer healed.

She is without symptoms now; the maintenance dose of cimetid ine has been discontinued.

Subjectively: much better than before operation.

mean postop $\mathrm{PAO}$

$62.5 \mathrm{mmol} / \mathrm{h}$ ( 2 valtues)

pt. no. $59 \sigma^{*}$, born in 1945 reduction $\mathrm{BAO} 47 \%$
reduction $\mathrm{PAO} 46 \%$

profession:

length of history:

family listory:

blood group:

preop PAO: painter

11 years

positive

$\mathrm{O}+$

$16.9 \mathrm{mmol} / \mathrm{h}$

HSV: July 1976

postoperatively: symptomfree.

In May 1979 he developed dyspeptic symptons; endoscopically a recurrent duodenal ulcer was

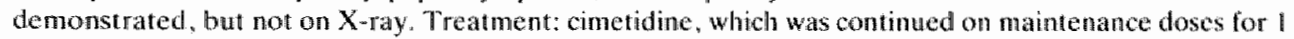
year. No further problems except 1 month in '82: no wlcer was demonstrated but a slight oesophagitis.

Further detail: since operation he suffers from eczema on his legs.

Subjectively: satisfied with result of operation.

mean postop $\mathrm{PAO}$

$16.9 \mathrm{mmol} / \mathrm{h}$ ( 4 values)

pt.no.61 of, born in 1943

\section{reduction $\mathrm{BAO} 49 \%$}

reduction $\mathrm{PAO} 0 \%$

\author{
profession: \\ length of history: \\ family history: \\ blood group: \\ preop PAO
}

truck driver
10 years
positive
B.
$68.2 \mathrm{mmol} / \mathrm{h}$

HSV: Angust 1976

postoperatively: slight occasional heartburn.

In September 1977 a recurrent duodenal ulcer was demonstrated with signs of obstruction. Treatment: Muthesa (\$). There were no symptoms of nausea, vomiting or regurgitation. The ulcer was cured and symptoms subsided. In 1980 again dyspeptic symptoms started (pain) which were related to stressfinl work; again a recurrent duodenal ulcer was demonstrated together with slow emptying of the stomach. He was examined for possible hyperparathyroidism, since higher serum calcium values than normal were found, but this was not demonstrated. He was reoperated in November 1981 (B I partial gastrectomy), because he did not want to use drugs contimuouslly.

He still needs dietary restrictions.

mean postop $P A O$

$38.7 \mathrm{mmol} / \mathrm{h}$ (4 values)

reduction $\mathrm{BAO} 35 \%$

reduction PAO 43\%

pt.no.76 $\mathrm{C}^{\circ}$, borm in 1922

profession:

rejected

length of history:

3 years

family history:

blood group:

unknown

At

$25.2 \mathrm{mmol} / \mathrm{h}$

further relevant details:incapacitated due to accident of his back, history of psychiatric treatment (depression, hysteriform psychopathy. concentration camp syndrome).

HSV: November 1976

postoperatively: no problems.

August 1978 again pain; $X$-ray showed a cascade shape of the stomach but endoscopy revealed a pyloric ulcer. Treatment: cimetidine; no relief experienced.

His behaviour is strange as are his periodical complaints. In 1982 no ulcer was demonstrated by endoscopy or X-ray. 
Subjectively: satisfied with the result of operation.

mean postop $\mathrm{PAO}$
$17.6 \mathrm{mum} / \mathrm{h}$ ( 3 walues)

pt. no. $880^{*}$, born in 1942

\author{
reduction $B A O O \%$ \\ reduction $\mathrm{PAO} 30 \%$
}

\author{
profession: \\ length of history: \\ family history: \\ blood group: \\ preop PAO:
}

waiter

5 years

unknown

A. +

$64.4 \mathrm{mmol} / \mathrm{h}$

further relevant features: Chinese origin, difficult communication.

HSV: February 1977

postoperatively: probably he was not without problems; in August '77 a recurrent duodenal ulcer was suspected by $X-$ ray and proved by endoseopy. Treatment: cimetidine. His complaints are difficult to assess; evidently he was withour symptoms more often, but with increasing stress dyspeptic symptoms recurted. He has been using cimetidine almost continuously and refused reoperation. X-ray examinations in 1980 and 1982 did not show any evidence of ulceration.

\begin{tabular}{|c|c|c|}
\hline $\begin{array}{l}\text { mean postop } \mathrm{PAO} \\
44.3 \mathrm{mmol} / \mathrm{h} \text { ( } 4 \text { values) }\end{array}$ & $\begin{array}{l}\text { reduction } \mathrm{BAO} \\
\text { reduction } \mathrm{PAO} 3\end{array}$ & \\
\hline \multirow[t]{2}{*}{ pt.no.94 $\sigma^{2}$, born in 1936} & profession: & $\begin{array}{l}\text { shopkeeper, } \\
\text { barfholder }\end{array}$ \\
\hline & $\begin{array}{l}\text { length of history: } \\
\text { family history: } \\
\text { blood group: } \\
\text { preop PAO: }\end{array}$ & $\begin{array}{l}8 \text { years } \\
\text { unknown } \\
\text { unk nown } \\
92.8 \text { mmol/h }\end{array}$ \\
\hline
\end{tabular}

further relevant details: history of psychiatric treatment, divored

HSV: May 1977

postoperatively; soon he developed dyspetic symptoms; in September 1977 a recurrent duodenal ulcer was demonstrated by $X$-ray. Treatment: cimetidine, admission was necessary. From 1979 he only had symptoms in relation with stress; he abandoned the follow-up; according to his family doctor he needs cimetidine regularly.

Subjectively: much better than before operation.

\begin{tabular}{|c|c|c|}
\hline mean postop PAO & reduction $\mathrm{BAO}$ & \\
\hline $37.9 \mathrm{mmol} / \mathrm{h}(2$ valtues $)$ & reduction PAO 5 & \\
\hline pt.no.106 o', born in 1935 & $\begin{array}{l}\text { profession: } \\
\text { length of history: } \\
\text { lamily history: } \\
\text { blood group: } \\
\text { preop PAO: }\end{array}$ & $\begin{array}{l}\text { labourer } \\
10 \text { years } \\
\text { negative } \\
0+ \\
41.6 \mathrm{mmol} / \mathrm{h}\end{array}$ \\
\hline
\end{tabular}

HSV: Augusi 1977

postoperatively: without complaints until 1981 : in September " 81 a recurremt duodenal ulcer was seen on $X-r n y$, but not with endoscopy; this was repeated $I$ month later: an ulcer was seen, but the focalisation was nof cortain, due to scarring. Possibly it was pyloric. Treatment: cimetidine.

Hes still is on a maintenance dose.

postop PAO

notests performed

pt.no. $1460^{\circ}$, born in 1928 reduction $\mathrm{BAO}$ n.a.

reduction PAOn.a.

profession:

length of history:

family history:

blood group:

preop PAO: tetired miner
lyear
negative
$O+$
not done

further relevant details: suspected of acute appendicitis he was operated on, but turned out to have a perforated duodenal ulcer. This was oversutured and a HSV performed. 
HSV: April 1978

postoperatively: soon after operation he developed symptoms; in November 1978 a recurrent duodens ulcer was proved both with $X$-ray and endoscopy. He was treated with cirnetidine and continued to use this drug on maintenance dose, although inaccurately, but he was asymptomatic. In April 198 lagain a recurrent duodenal ulcer was demonstrated; the cimetidine dose was increased temporarily. In March 1982 he was admitted for a bleeding; again an ulcer was demonstrated together with reflux oesophagitis. The ulcer heded soon, cimetidine was continued. He refused reoperation.

mean postop $\mathrm{PAO}$

$51.5 \mathrm{mmol} / \mathrm{h}$ ( 2 values)

pt.no. $1450^{*}$, born in 1937

\section{reduction BAOn.a.}

reduction $\mathrm{PAO}$ n.a.

profession:

length of history:

familly history:

blood group:

preop PAO: labourer in shoe

factory

14 years

positive

A -

$23.3 \mathrm{mmol} / \mathrm{h}$

further relevant details: hypochondriac nature.

HSV: March 1978, complicated by pneumonia and septicaemia postoperatively; occasionally stress-related dyspeptic symptoms, drugs rarely needed. Early 1981 a recurrent duodenal ulcer was demonstrated by endoscopy, but not on $X$-ray.

Treatment: cimetidine, the ulcer healed. He still is on maintenance treatment.

mean postop $\mathrm{PAO}$

$27.1 \mathrm{mmol} / \mathrm{h}$ ( 2 values)

pt.no.154 o , born in 1936 reduction $\mathrm{BAO} \quad 0 \%$
reduction $\mathrm{PAO} \quad 0 \%$

profession:

liength of history:

family history:

blood group:

preop PAO: clerk

2 years

negative

A th

$60.1 \mathrm{mmol} / \mathrm{h}$

further relevant details: history of psychiatric treatment

HSV: july 1978, complicated by axillary thrombosis.

postoperatively: free of symptoms.

During 1980: stress-related dyspeptic symptoms (son with severe diabetes mellitus) a recurrent duodenal wilcer was demonst rated endoscopically. Treatment : cimetidine.

In 1982 he angain experienced stomach problems, quickly relieved by cimetidine. Subjectively: satisfied with the result of operation.

$\begin{array}{lll}\text { mean postop PAO } & \text { reduction } \mathrm{BAO} 46 \% \\ 25.8 \mathrm{mmol} / \mathrm{h} \text { (2 values) } & \text { reduction PAO } 57 \% & \\ \text { pt.no.158 } \mathrm{m} \text {. born in } 1930 & \text { profession: } & \text { representative } \\ & \text { length of history: } & 10 \text { years } \\ & \text { family history: } & \text { negative } \\ & \text { blood group: } & \text { O } \\ & \text { preop PAO: } & 23.9 \mathrm{mmol} / \mathrm{h}\end{array}$

further relevant details: history of psychiatric treatment in connection with alcohol abuse.

HSV: August 1978, additional procedure: liver biopsy

postoperatively: symptomfree until February 1980: by X-ray a recurrent duodemal ulcer was demonstrated which healed after antacid treatment. Strikingly strange behaviour, many atypical, vague symptoms not especially related to the stomach. On two further occasions no ulicer could be demonstrated.

postop PAO

$44.6 \mathrm{mmolh}$ reduction $\mathrm{BAO} 0 \%$

reduction $\mathrm{PAO} 0 \%$ 
profession:

length of thistory:

family history:

blood group:

preop PAO: retired legiontaire

5 years

negative

$\mathrm{O}+$

$65.2 \mathrm{mmol} / \mathrm{h}$

further relevant detalls:excessive use of alcohol and nicotine (.65 cigarettes daily).

HSV: October 1978

postoperatively: soon recurrent symptoms; June 1979, a gastric ulcer with signs of obstruction was demonstrated by endoscopy.

He was reoperated 2 months later: a BI partial gastrectomy was performed. Since then he has not complained about his stomach but is still a heavy smoker and drinker.

postop PAO

no test performed

pt.no. $179 \mathrm{~d}^{\mathrm{\prime}}$, born in 1942 reduction BAO n.a.

reduction PAO n.a.

$\begin{array}{ll}\text { profession: } & \text { dental technician } \\ \text { length of history: } & 9 \text { years } \\ \text { family history: } & \text { positive } \\ \text { blood group: } & \text { A }+ \\ \text { preop PAO: } & 98.2 \text { momol/h }\end{array}$

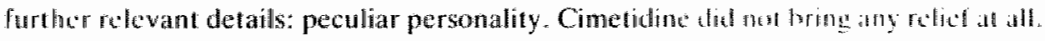

HSV: May 1979

postoperatively: no improvement at all. Periodical return of complaints related with backinche; plyysiotherapy for backache relieves dyspepsia. On several occasions endoscopic and $\mathrm{X}$ ray cxaminations were performed, but only once (November 1981) was at recurrent duodenal ulcer demonstrated endoscopically. It healed quickly with cimetidine. Patient refused reoperation and preferred episodic cimetidine treatment if necessary (scveral weeks a year).

Subjectively: no improvement at all.

mean postop $\mathrm{PAO}$

$49.6 \mathrm{mmol} / \mathrm{h}$ ( 2 values)

pt.mo.262 $0^{\prime}$, born in 1934

\section{reduction $\mathrm{BAO} 61$ \% reduction PAO 59\%}

$\begin{array}{ll}\text { profession: } & \text { painter } \\ \text { length of history: } & 15 \text { years } \\ \text { familly history: } & \text { negative } \\ \text { blood group: } & 0+ \\ \text { preop PAO: } & 47.4 \mathrm{mmol} / \mathrm{h}\end{array}$

HSV: October 1981

postoperatively: initially symptomfree, but in March 1982 again stomach pain. With endoscopy a pyloric ulcer was demonstrated, which healed quickly with cimetidine.

He is all present symptonfree without drugs.

postop PAO

notest performed

reduction $B A O$ n.a.

reduction PAO n.a.

\subsubsection{Localisation of proved ulcers after operation:}

$\begin{array}{lr}\text { duodenal } & 18 \\ \text { pyloric } & 3 \\ \text { prepyloric } & 1 \\ \text { gastric } & 1 \\ \text { duodenal or pyloric } & 1\end{array}$




\subsubsection{Pathology}

In the three patients who underwent a partial gastrectomy aftertheir HSV the resected specimens were examined thoroughly ${ }^{259}$. It is known however that the histological changes generally found are of limited value, since they can occur during the course of operation ${ }^{250}$.

$\begin{array}{lll}\text { pt.no. } 43 & \begin{array}{l}\text { antrum: } \\ \text { corpus: }\end{array} & \begin{array}{l}\text { chronic follicular gastritis }++ \\ \text { normal }\end{array} \\ \text { pt.no. } 61 & \begin{array}{l}\text { duodenum: } \\ \text { antrum: } \\ \text { corpus: }\end{array} & \begin{array}{l}\text { normal } \\ \text { chronic superficial gastritis }+ \\ \text { normal mucosa with abundant parietal cells. }\end{array} \\ \text { pt.no. 164 } & \begin{array}{l}\text { duodenum: } \\ \text { antrum: }\end{array} & \begin{array}{l}\text { normal } \\ \text { chronic follicular gastritis }++ \\ \text { small scar at lesser curvature } \\ \text { follicular gastritis }+++ \text { with partial } \\ \text { atrophy, strongly diminished number of } \\ \text { corpus: }\end{array} \\ & \begin{array}{l}\text { parietal cells, compared to what is } \\ \text { normally found. }\end{array}\end{array}$

comment: it is noteworthy that the gastric ulcer occurred in the patient, who demonstrated the heaviest gastritis. 


\section{Chapter 17}

\section{Summary and conclusions}

\subsection{Summary and conclusions}

In chapter 1 the conditions in which the study took place are outlined and the purpose and design of the study are defined. It is demonstrated that the incidence of the disease (duodenal ulcer - DU) for which HSV was applied has decreased considerably in the area where the study was done compared to 2 decennia before, as measured by the number of patients coming to operation. From 1974 onward HSV was applied increasingly and soon it became the operation of choice. The majority of the operations were performed by residents in training.

The indications for operation are discussed. The most common indication was intractable duodenal ulcer, usually of long standing. Gradualiy HSV was applied also for the complications of duodenal ulcer: haemorrhage, perforation and stenosis. The nomenclature of the operation which is far from uniform is discussed. Highly selective vagotomy is the preferred term, which is used here. Finally a theoretical background is discussed of the components contributing to the exponent of failure: "the" recurrence rate. Discussed are: method failure, surgeon failure and patient failure.

In chapter 2 the natural history of $\mathbb{D U}$ is sketched, and it appears to be unpredictable. The versatility of the disease is even enhanced by epidemiological and historical data, suggesting that the disease is at present on the decline. This was already perceivable before the introduction of greatly improved medical treatment. A concise overview is given of the operations employed for DU.

An outline of surgical anatomy is presented in chapter 3 . The relevant vagal supply to the stomach is sketched on the basis of reports of several renowned authors and relevant surgical details are highlighted. Furthermore, a short and practical physiological background is presented. With this basic knowledge in mind, the scala of operations is memorised with a rationale for their effect.

In chapter 4 the patients are described; many characteristics are mentioned together with the distribution of these characteristics among male and female pationts. The only data significantly differing between men and women were: height, weight, age at operation, family history, periodicity of the complaints, nervousness, alcohol consumption, haemoglobin and some gastric secretion parameters (in chapter 15 a similar comparison has been made between patients with and without a recurrence) Furthermore, the statistical methods employed are mentioned.

In chapter 5 the operative technique is described together with the pre- and postoperative management. The technique in case of operation for a complication of DU is given (haemorrhage, perforation and stenosis). Some possible adaptations to the technique are mentioned and a description is given of a slightly modified teclonique used initially. 
In chapter 6 the principles of quality control tests are described and discussed. Two kinds of test are possible, each with their own advantages and disadvantages: intraoperative tests and postoperative tests. All try to test the vagotomy for completeness, which is a theoretical concept approached by immediately measurable criteria. The most commonly used test (the insulin test) is extensively commented on, with the help of a survey of the literature.

The insulin test was not used in this study for various reasons mentioned. Instead, the safer histamine/pentagastrin test was performed with a similar purpose. The outcome of the analysis on the base of the results of these tests is presented in chapter 10 .

In chapter 7 the qualitative judgement of the results after operation (the Visick grading) is explained. A Visick grading modified according to Goligher was employed with some adaptations. The practice of the follow-up is described as well as the completeness. This was $96 \%$ - or $99 \%$ if the patients who died in the course of the follow-up are not deducted. The average follow-up was 50.4 months $(6-99 \mathrm{~m})$.

Chapter 8 shows the results of the study, first in the classical way by means of the static, retrospective Visick grading, which was given at the conclusion date of the study (1st July 1982). By convention patients with a recurrence are graded Visick 4 (= failure). Secondly, another way of presentation is applied as was done originally by Visick in 1948, which gives a dynamic picture of the results at yearly intervals after operation. The operation is the reference-point for all patients. Patients who have been reoperated on are considered a permanent failure (Visick 4) but otherwise they are regraded at each time period if appropriate. The same dynamic grading has been applied on a fixed group of patients, who have all completed 5 years of follow-up. Both dynamic grading methods show the same picture: a good or excellent result in almost $90 \%$ of the patients and a constant failure rate of 6-7\%. Half of these patients represent temporary failures differing each year, the other half permanent failures. The majority of failures are caused by recurrences.

The recurrence rate is $9.2 \%$ ( 24 out of 262 ) with $4.1 \%$ for women and $10.3 \%$ for men.

Further the mortality and complication rates and the side effects are discussed. The mortality ( 1 patient, $0.4 \%$ ) was low and seemed unrelated to the operation per se. The morbidity was not serious, but two patients needed reoperation for obstruction. Side effects were very minor; almost no cases of dumping and diarrhoea - a common sequel after vagotomy - were observed.

Chapter 9: the application of HSV for complicated DU is described in detail. Both acute complications and those in the past have been considered, separately as well as together. The results in these patients were certainly not worse than the results of the main group.

In chapter 10 the acid secretion studies are dealt with. In the introduction it is explained that some assimilations have taken place in order to compare the histamine and pentagastrin tests from the whole period. The performance of the tests is described. 
The results have been presented for $\mathrm{BAO}$ and $\mathrm{PAO}$ using all available values for several categories of patients: all patients together, patients with and without a recurrence and men and women without a recurrence. Moreover coupled and strictly coupled (paired) values have been calculated, studying the course of acid secretion data after operation. Conclusions are that BAO decreases after operation by about $60 \%$ and remains constant, and that there is no decrease at at in patients who develop a recurrence. For PAO a decrease of $50 \%$ is obtained, but the reduction in patients with a recurrence is smaller shortly after operation; the difference with patients without a recurrence tends to disappear, though.

There was no difference in results between men and women apart from a slightly lower secretion level in women. The most sensitive factor of acid output was the acidity.

Comparing the results of patients with and without a recurrence, the parameter with the highest predictive value for a recurrence turns out to be a $\mathrm{BAO} \geqslant 3.5 \mathrm{mmol} / \mathrm{h}$ (discriminative analysis), but the sensitivity and specificity are rather low as is the experience described in literature.

Finally a literature survey is presented of the reduction percentages of BAO and PAO obtained with HSV.

In chapter 11 the results of basal serum gastrin determinations are represented. As a consequence of the operation gastrin increases by $60 \%$ compared to the preoperative value and rises further significantly later (over $100 \%$ compared to preoperatively). This rise is not understood. It is demonstrated further that patients who have used cimetidine before operation show a higher gastrin level preoperatively than those who have not; this significant difference remains present at all time periods after operation.

No correlation has been found between gastrin and gastric acid secretion either before or after operation. Gastrin appears to behave independently; its role has not yet been elucidated.

In chapter 12 the results of serum vitamin $B_{12}$ are described. Two different methods of determination have been employed ("total cobalamine" and "true cobalamine") and a correction factor was needled for adjustment. A decreasing tendency seems likely - which could be expected as a consequence of the denervation of the parietal cell mass - but this could not be proved conclusively. However, the results can be biased by the difference between the two methods.

Several metabolic parameters are considered in chapter 13: the weight, $\mathrm{Hb}, \mathrm{AP}, \mathrm{Ca}$, $\mathrm{P}, \mathrm{Fe}, \mathrm{TIBC}$. They are known to deteriorate often after partial gastrectomy.

The weight increased significantly, both in patients who had lost weight before operation and in those who had not. So no deterioration of the general condition was concluded, but even preoperatively this was not below the average. Among the parameters in the blood no change was found. The conclusion is that HSV does not confer demonstrable deleterious metabolic effects. 
Chapter 14 is devoted to the possible hereditary influence on DU. Both family history and blood group have been studied, as Lam and Sircus did in 1976. The results show that among the patients studied blood group $\mathrm{O}$ is predominant compared to the standard population, but no differences are demonstrated between patients with and without a recurrence. It is demonstrated further that patients with blood group $\mathrm{O}$ are more likely to develop preoperative complications, than patients with $\mathrm{A}, \mathrm{B}$ or $\mathrm{AB}$. This can explain why blood group $\mathrm{O}$ is predominant in DU patients, since patients with a complication are more likely to ask for treatment than those without. This explanation is at least as plausible for the predominance of blood group $\mathrm{O}$ than the usually held idea that patients with this blood group are more prone to develop DU. It is demonstrated further that early onset of the disease is correlated with a positive family history, a longer history until operation and a higher PAO. Late onset of the disease correlates with a higher complication rate and a shorter history before operation (which means that these patients are operated on earlier). It is not unlikely that their shorter history is a consequence of a higher complication rate.

In chapter 15 an attempt is made to analyse the recurrences. Comparing the same characteristics as mentioned in chapter 4 the differences in patients with and without a recurrence are considered. Women have had fewer recurrences than men (just below significance). Correlated with recurrences are: a longer history - which means that most patients with a recurrence were operated on early in the series and consequently show the characteristics of the early technique - and a history of psychiatric treatment.

The recurrence rate is calculated in several different ways trying to estimate the ultimate recurrence rate: surprisingly different percentages can be estimated, among others a steadily increasing percentage as assessed by life table analysis.

The relation between acid secretion/hypersecretion and recurrences is considered. It appears likely that several recurrences were method failures, others surgeon failures. Hypersecretion alone does not seem to predispose to a recurrence, but hypersecretors having an adequate reduction of acid secretion after operation have more recurrences than normosecretors with an adequate reduction (not significantly so).

In chapter 16 some anecdotal observations have been collected, some of them not earlier described.

The short case histories of all patients who developed a recurrence have been assembled in an appendix.

\subsection{Concluding remarks}

HSV is a safe operation as demonstrated by its low mortality and morbidity, and is almost without disadvantages. Side effects are of minor importance and on average cannot be distinguished from those in a healthy population.

HSV can be taught successfully to residents in training and must be considered at present the operation of choice in the treatment of duodenal ulcer. With ample experience the application of the operation in complicated cases of DU can be recommended.

The only real objection to HSV appears to be a higher recurrence rate compared 
with other operations. This higher rate may be caused by the initial inexperience, but perhaps it is inherent to HSV. However, how severe is a recurrence after HSV?

First: should a recurrence after HSV always be considered a failure? Many recurrent ulcers develop in connection with severe stress. The majority of these recurrences heal quickly with a short course of cimetidine; some heal or become symptomless without any treatment at all. Thus the course of a recurrence after HSV appears to be rather benign and it can be treated easily. In other words: HSV has modified the natural history of disease favourably in many of those patients, for whom the operation was not a complete success.

This benign course of a recurrent ulcer contrasts sharply with the behaviour of a recurrence after other operations, when it is notoriously difficult to treat. It seems justified to conclude that, for HSV, the obligatory link recurrence $=$ Visick 4 should be abolished. In order to judge the results objectively a dynamic Visick grading, as described, can be applied demonstrating the modified natural history continuously.

Second: it is not that simple to indicate the number of recurrences in correct relationship with the whole population and with time.

The statement: "the recurrence rate of an operation applied on $X$ patients with an average follow-up of Y months is $2 \%$ " reveals less than usually thought. Generally the recurrence rate is thought to reach a plateau, which is inherent to the procedure. It is not unlikely, however, that it is more complicated - as has been demonstrated. The relation to time is seldom expressed accurately but this can be achieved by means of the life-table method.

Because of its statistical nature and difficult interpretation this method is seldom applied. If applied on this series the recurrence hazard appears to remain the same. Nevertheless from the same data similar conclusions can be drawn as found in most reports, namely, that most recurrences occur within a few years after operation. If the life table analysis were to be applied on other series it is likely that a similar constant recurrence risk would be found ${ }^{322}$. This probably holds true for other operations as well. In one of Andersen's reports ${ }^{15}$ where he described the application to HSV he has made a comparison with the outcome of partial gastrectomy results, showing that the recurrence hazard in these operations is equally constant, be it at a lower level.

It is not clear whether this risk remains the same or declines after some more years. Therefore the expression: "the recurrence rate of operation $Z$ is $10 \%$ " is not very useful and indicates the recurrence rate after an "average" observation period. This average, however, is not composed uniformly. A comparison of such rates in controlled trials can be useful, but the life table method is more revealing.

Third: as discussed in the introduction and elsewhere, there are most likely qualitative differences among recurrences found: method failures, surgeon failures and patient failures. Method failures are unavoidable but their number should be low for al standard operation. It is difficult to estimate this method failure rate for $\mathrm{HSV}$, since it can be patient dependant (size of the antrum, hypersecretion). 
Surgeon failures should be as low as possible ${ }^{29}{ }^{37}$, but depend on the intrinsic complexity of the operation. In contrast to common belief HSV is not a very easy operation and this has been stressed by several authors ${ }^{127,258,351,354}$. It is a demanding procedure and a very careful and accurate technique is extremely important.

Patient failures are probably hard to avoid but selection of the patients is important. The indications for operation are always difficult to appreciate objectively in judging results. Psychologically labile patients probably stand a higher chance of failure. If they are excluded, the result of a series will undoubtedly be better, but these patients have possibly been neglected. Moreover extreme circumstances of stress can contribute to a recurrence in non-labile persons.

This mixture of qualitatively differing recurrences which cannot be discerned at present is possibly responsible for the poor predictive value of gastric secretion tests with respect to the development of a recurrence and also for the quality control of the surgical performance. Perhaps these tests would be very valuable if only surgeon failures occurred.

On the basis of this poor correlation it is easy to conclude that acid secretion only plays a minor role in the pathogenesis of a recurrence (as confirmed in the literature). It is perhaps better to state that it has an important role in some but a minor role in others, but unfortunately it is not clear to whom this applies. 


\section{Samenvatting en conclusies}

In hoofdstuk 1 worden de opzet en het doel van het onderzoek uiteen gezet, alsmede de omstandigheden waaronder dit onderzoek gerealiseerd werd. Het valt op dat het aantal operaties voor het ulcus duodeni (UD) in de regio waar het onderzoek plaatsvond aanzienlijk is teruggelopen in vergelijking met twee decennia tevoren. Vanaf 1974 werd HSV in toenemende mate toegepast en werd spoedig de operatie der keuze voor het UD. Deze operatie werd dan ook in het opleidingsschema ingepast, hetgeen resulteerde in het feit dat $64 \%$ van de operaties werd verricht door assistenten in opleiding. Wat de indicaties betreft: de meest voorkomende indicatie was een recidiverend UD bij falende interne behandeling. Een klein gedeelte van de patienten werd behandeld woor een complicatie van het UD. De naamgeving van de operatie wordt aan de orde gesteld; gekozen werd voor Highly Selective Vagotomy. Tenslotte wordt getheoretiseerd over de componenten die uiteindelijk "het" recidief percentage uitmaken, exponent van het falen van de behandeling. Deze componenten zijn: factoren inherent aan de methode, factoren bijgedragen door de operateur en factoren van de kant van de patient.

Hoofdstuk 2 geeft een kort overzicht van het natuurlijke beloop van het UD dat nogal onvoorspelbaar blijkt te zijn. Deze wispelturigheid wordt geaccentueerd door epidemiologische en historische gegevens. Tenslotte wordt schetsmatig weergegeven welke de voornaamste operatieve behandelingen zijn geweest in de loop van de tijd.

In hoofdstuk 3 wordt beknopt de chirurgische anatomie besproken; de vagale zenuwvoorziening van de maag met de nadruk op chirurgische knelpunten wordt belicht. Vervolgens komt enige basale fysiologie aan de orde. Op grond van deze gegevens wordt getracht de fundering voor de diverse operaties, die in de loop der jaren zijn toegepast, toe te lichten.

In hoofdstuk 4 worden de patienten beschreven; vele karakteristieken van deze populatie worden hierbij vermeld, met een opsplitsing in mannen en vrouwen. De enige gegevens die hierbij significante verschillen opleveren tussen mannen en vrouwen zijn: lengte, gewicht, leeftijd ten tijde van de operatie, familie-anamnese, periodiciteit van de klachten, nervositas, alcoholgebruik en enkele zuursecretieresultaten (in hoofdstuk 15 zal een soorgelijke tabel gegeven worden, die echter cen onderverdeling geeft in patienten mét en patienten zonder een recidief). Vervolgens worden de gebruikte statistische methoden vermeld en toegelicht.

Hoofdstuk 5 geeft een uitvoerige beschrijving van de operatietechniek, waarbij tevens het beleid voor en na de operatie aan de orde gesteld wordt. Verder wordt de gang van zaken besproken wanneer de operatie wordt uitgevoerd voor een complicatie van het UD: bloeding, perforatie, stenose. Tevens worden enkele mogelijke variaties besproken en wordt de techniek die aan het begin van het onderzoek werd toegepast toegelicht.

Hoofdstuk 6 beschrijft de principes van controletesten; deze zijn bedoeld om de kwaliteit van de operatie te beoordelen. Er zijn twee soorten testen, ieder met eigen voor- en nadelen: peroperatieve en postoperatieve testen. Alle testen pogen de volledigheid van de uitgevoerde vagotomie vast te stellen, hetgeen vóóronderstelt dat hiervoor betrouwbare criteria mogelijk zijn. De meest gebruikte test is de 
insulinetest; de waarde hiervan wordt aan de hand van gegevens wit de literatuur aan een kritisch onderzoek onderworpen. De insulinetest werd in het huidige onderzoek niet gebruikt, de redenen hiervoor worden aangegeven. In plaats hiervan werden zuursecretietesten verricht met histamine, resp. pentagastrine als stimulans. Het resultaat hiervan zal in hoofdstuk 10 worden besproken.

In hoofdstuk 7 wordt de methode van de kwalitatieve beoordeling van de resultaten toegelicht: de gradering volgens Visick. Een naar Goligher gemodificeerde Visick gradering werd bij dit onderzoek toegepast, zij het met enkele kleine aanpassingen. Vervolgens wordt de praktische gang van zaken betreffende de nacontrole besproken: de "follow-up". Uiteindelijk kon van $96 \%$ van de patienten - of $99 \%$, indien de inmiddels overleden patienten hierbij worden gerekend - betrouwbare informatie verkregen worden betreffende hun toestand na de operatie. De gemiddelde follow-up bedroeg 50.4 maanden (6-99).

Hoofdstuk 8 behandelt de resultaten. Allereerst wordt de klassieke retrospectieve Visick gradering gepresenteerd zoals deze werd gegeven op de afsluitingsdatum van het onderzoek: 1-7-82. Per definitie worden hierbij patienten met een recidief ulcus na operatie als een mislukking beschouwd. Tevens wordt een andere manier van presentatie van gegevens aangegeven, zoals deze door Visick zelf in 1948 ook werd uitgevoerd. Dit leidt tot een veel dynamischer beeld van de resultaten: gradering vindt daarbij jaarlijks plaats, waarbij het uitgangspunt voor iedere patient het moment van operatie is. Herwaardering van de gradering is hierbij steeds mogelijk (ook bij recidieven behalve wanneer re-operatie heeft plaatsgehad). Dezelfde dynamische gradering wordt toegepast op een constant blijvende groep patienten die 5 jaar follow-up voltooid hebben. Beide dynamische graderingsmethoden tonen hetzelfde beeld: een constant percentage goede en zeer goede resultaten (iets minder dan $90 \%$ ) en een constant mislukkingspercentage van $6-7 \%$, waarvan de helft als permanente mislukking moet worden beschouwd. Het merendeel van de mislukkingen berust op een recidief. Het recidiefpercentage van de gehele groep bedraagt $9,2 \%$ (24 van 262); voor vrouwen $4,1 \%$ en voor mannen $10,3 \%$. Vervolgens worden de mortaliteit, complicaties en de bijwerkingen besproken. De mortaliteit was laag $(0,4 \%)$, en leek niet gekoppeld aan de aard van de operatie. Er waren geen complicaties met ernstige gevolgen, behoudens twee re-operaties voor een obstructie. De bijwerkingen van de operatie waren zeer gering, met name ontbraken symptomen zoals dumping en diarrhee - berucht na vagotomie - praktisch geheel.

In hoofdstuk 9 worden de resultaten besproken van de toepassing van HSV bij het gecompliceerde UD. Deze resultaten zijn zeker zo goed als die van de groep die zonder voorafgaande complicatie werd geopereerd. Beide groepen worden in meerdere opzichten met elkaar vergeleken. Er deden zich geen ernstige postoperatieve complicaties voor bij de patienten die een HSV ondergingen na een complicatie van hun UD.

Hoofdstuk 10 behandelt de zuursecretietesten en de resultaten hiervan. In de inleiding worden enkele aanpassingen uitgelegd, die nodig waren teneinde de resultaten wan histamine- en pentagastrinetesten met elkaar te kunnen vergelijken. Tevens wordt de uitvoering van de zuursecretietesten besproken. De resultaten van zuursecretietesten onder basale (BAO) en maximaal gestimuleerde omstandigheden 
(PAO) worden gepresenteerd voor diverse categorieën patienten: alle patienten samen, patienten met en zonder recidief, mannen en vrouwen zonder recidief. Verder worden gekoppelde en gepaarde waarnemingen gebruikt die veranderingen van de zuursecretiegegevens in de loop van de tijd laten zien. De conclusie hiervan is dat de $B A O$ na de operatie $\pm 60 \%$ daalt en dan constant blijft. Bij patienten met een recidief treedt geen daling op. Voor de PAO bedraagt de daling $50 \%$. Bij patienten met een recidief is de daling iets minder groot doch later verdwijnt dit verschil weer. Mogelijk neemt de PAO langzaam toe in de loop van de tijd. Er blijkt slechts een gering verschil te bestaan tussen de gegevens verkregen bij mannen en vrouwen. De meest gevoelige parameter die bijdraagt tot de zuurproductie is de aciditeit. Bij vergelijking van de resultaten van patienten met en zonder recidief blijkt de parameter met de hoogste voorspellende waarde voor het krijgen van een recidief te zijn: een postoperatieve $\mathrm{BAO}$ (na $1 / 2 \mathrm{jaar}$ ) van $\geqslant 3.5 \mathrm{mmol} / \mathrm{uur}$, maar de gevoeligheid en de specificiteit hiervan zijn nogal laag, zoals dit ook in de literatuur wordt beschreven. Preoperatief worden geen verschillen gevonden met enige voorspellende waarde ten aanzien van het optreden van het recidief. Tenslotte wordt een literatuuroverzicht gegeven betreffende de verkregen zuurreductiepercentages bij HSV.

In hoofdstuk 11 worden de resultaten weergegeven van gastrine bepalingen in het bloed. Als gevolg van de operatie stijgt het gastrine t.o.v. de preoperatieve waarde. De stijging bedraagt $\pm 60 \%$, doch neemt later significant toe tot meer dan $100 \%$. Een verklaring hiervoor kan niet worden gevonden. Tevens wordt aangetoond dat patienten, die preoperatief cimetidine hebben gebruikt gemiddeld voor de operatie een hoger gastrinegehalte hebben en ook na de operatie op ieder tijdstip significant hogere waarden blijven houden. Er werd geen verband gevonden tussen gastrinegedrag en de resultaten van het zuursecretieonderzoek, noch voor de operatie noch erna. Gastrine blijkt zich onafhankelijk van de zuurproductie te gedragen. De betekenis hiervan is vooralsnog niet duidelijk.

In hoofdstuk 12 worden de resultaten gepresenteerd van de serum vitamine $B_{12}$ bepalingen. Tijdens de periode van onderzoek werden twee verschillende soorten bepalingen verricht, ("total cobalamine "en" true cobalamine" methode), die via cen gestandaardiseerde omrekeningsfactor aan elkaar werden geassimileerd. Hoewel een dalende tendens aanwezig leek te zijn - hetgeen op grond van de denervatie van de parietale celmassa verwacht zou kunnen worden - kon dit toch niet onomstotelijk worden aangetoond. Hierbij speelde ongetwijfeld het lager uitvallen van de "omgerekende" waarden van de vroegere bepalingsmethode (total cobalamine) ten opzichte van de nieuwe methode een rol, waardoor een eventuele echte dalling versluierd zou kunnen worden.

In hoofdstuk 13 worden metabole parameters zoals gewicht en (in het bloed) haemoglobine, alkalische fosfatase, calcium, fosfaat, ijzer en totale ijzerbindingscapaciteit onder de loep genomen. Hiervan is bekend dat ze m.n. na een magresectic in ongunstige zin zouden kunnen veranderen. Voor de bloed-parameters werd geen verandering waargenomen; het gewicht nam significant toe, hetgeen beschouwd mag worden als uiting van het niet achteruitgaan van de voedingstoestand, die overigens ook preoperatief zelden te wensen overliet. Er werd onderscheid gemaakt tussen patienten die voor de operatie ten gevolge van hun ulcusziekte wel of geen gewichtsverlies hadden geleden. Bij beide categorieën nam het gewicht toe, bij de 
eerste iets meer. Geconcludeerd wordt dat HSV geen aantoonbare nadelige metabole gevolgen heeft.

Hoofdstuk 14 is gewijd aan de mogelijke invloed van erfelijke predispositie wat betreft het UD hijden. Zowel familie-anamnese als bloedgroep werden bestudeerd, ten dele aan de hand van een uitgebreid onderzoek, dat Lam \& Sircus hieraan in 1976 hebben gewijd. Als resultaat blijkt, dat onder de patienten van dit onderzoek bloedgroep $\mathrm{O}$ jets vaker voorkomt dan bij de normale bevolking, doch er is geen duidelijk verschil tussen de patienten die wel en die geen recidief ontwikkelden. Tevens wordt aangetoond dat patienten met bloedgroep O duidelijk meer preoperatieve complicaties hebben gehad dan de patienten met bloedgroep A, B of $A B$. Dit kan een verklaring zijn voor het vaker voorkomen van bloedgroep $O$ in elke populatie UD-patienten aangezien door deze complicaties patienten eerder gedwongen worden zich onder behandeling te stellen. Deze verklaring is op zijn minst zo plausibel als de tot nu toe geldende, namelijk dat mensen met bloedgroep $O$ een grotere kans hebben om een UD te krijgen. Verder wordt aangetoond dat een vroeg begin van de ziekte positief geassocieerd is met een positieve familie-anamnese, een langere duur van de anamnese tot aan de operatie en een hogere PAO. Wanneer de ziekte zich op latere leeftijd voor het eerst manifesteert is de kans op complicaties groter en is de duur van de anamnese duidelijk korter, d.w.z. deze patienten worden eerder geopereerd; mogelijk hangt dit weer samen met de toegenomen kans op complicaties.

In hoofdstuk 15 wordt een poging gedaan te achterhalen waarom patienten met een recidief dit ontwikkeld hebben. Allereerst worden alle gegevens, die in hoofdstuk 4 werden gegroepeerd en onderverdeeld in mannen en vrouwen, beschouwd, doch nu onderverdeeld in patienten met en zonder recidief. Vrouwen blijken minder vaak een recidief te hebben dan mannen, doch dit was net niet significant. De factoren die positief geassocieerd zijn met het optreden van een recidief waren: langere follow-up, waaruit blijkt dat de meeste recidieven stammen uit de begintijd en dientengevolge ook de kenmerken dragen van de vroegere operatietechniek, en een psychiatrische anamnese. Vervolgens wordt het recidief percentage nader geanalyseerd. Dit wordt op diverse manieren gedaan met de bedoeling een extrapolatie naar de toekomst te kunnen maken. Dit blijkt verrassende resultaten op te leveren: diverse percentages kunnen aannemelijk gemaakt worden, onder andere een constant toenemend percentage. Dit laatste wordt gevonden bij toepassing van de "life-table" methode. Vervolgens wordt de relatie zuursecretie/ hypersecretie en recidief nagegaan. Op grond hiervan wordt aannemelijk gemaakt dat een aantal recidieven tot stand kwamen op grond van een methodische en een aantal op grond van een chirurgische tekortkoming. Tenslotte blijkt dat het optreden van een recidief niet met hypersecretie gecorreleeerd is, doch wel met de grootte van de PAO reductie. Het is opvallend dat patienten met hypersecretie en een goede reductie een grotere kans op recidief lijken te hebben dan patienten met normosecretie en een goede reductie. Dit verschil is echter niet significant.

In hoofdstuk 16 worden enkele bijzondere waarnemingen vermeld waarvan enkele nog niet eerder werden beschreven na een HSV. In de bijlage worden de ziektegeschiedenissen beschreven van alle patienten, die een recidief ontwikkelden. 


\section{Slotbeschouwing}

HSV is een veilige operatie zoals blijkt uit de geringe mortaliteit en geringe morbiditeit. De operatie heeft praktisch geen nadelen, er zijn slechts geringe bijwerkingen waarbij het verschil met de normale populatie niet significant is. HSV kan uitstekend onderwezen worden aan chirurgen in opleiding en moet beschouwd worden als eerste keuze bij de chirurgische behandeling van het UD. De toepassing ervan bij opgetreden complicaties is aan te bevelen mits voldoende ervaring bestaat. Het enige bezwaar van HSV lijkt het aantal recidieven in vergelijking met de resultaten na andere operaties te zijn. Hoewel dit hogere percentage wellicht samenhangt met onervarenheid in het begin, bestaat de mogelijkheid dat dit verhoogde percentage inherent is aan de HSV in vergelijking met andere operaties. Echter hierbij doet zich het probleem voor van het begrip "mislukking" (recidief = Visick $4=$ mislukking). Hierbij dienen de volgende overwegingen in aanmerking genomen te worden.

Ten eerste: is een recidief na HSV wel gelijk te stellen aan een mislukking? Veel recidief ulcera ontstonden in omstandigheden die ernstige stress met zich meebrachten. De meeste van deze recidieven genazen in het algemeen snel met cimetidine; in enkele gevallen was in het geheel geen behandeling noodzakelijk, aangezien de symptomen reeds verdwenen waren, of het ulcus reeds na korte tijd genezen was. Het lijkt er derhalve op dat het verloop van een recidief na HSV nogal goedaardig is en dat het gemakkelijk kan worden behandeld. Anders gezegd: HSV lijkt het natuurlijke beloop van de ziekte ten gunste te hebben gewijzigd bij een aantal patienten bij wie de operatie niet $100 \%$ succesvol was. Dit goedaardige beloop staat in scherp contrast met het moeilijk behandelbare recidief ulcus na andere operaties. Het lijkt dan ook gerechtvaardigd te concluderen dat bij de toepassing van HSV de verplichte koppeling "recidief = Visick 4" dient te vervallen. Om tot een objectieve beoordeling te komen is het gebruik van de dynamische Visick gradering, zoals beschreven, zeer nuttig, waarbij het door de HSV gewijzigde natuurlijke beloop van het UD veel beter kan worden weergegeven.

Ten tweede: het is niet zo eenwoudig het recidief-percentage in juiste relatie tot de totale groep en met de tijd vast te stellen. De uitdrukking: "deze operatie - bij Xpatienten met een gemiddelde follow-up van $\mathrm{Y}$ manden - heeft $2 \%$ recidieven" zegt veel minder dan men intuitief geneigd is aan te nemen. In het algemeen wordt verondersteld dat dit recidiefpercentage tot een bepaald maximum gaat en dit maximum zou gerelateerd zijn aan de methode. Het lijkt er echter op, en aanwijzingen hiervoor worden hier gegeven, dat dit veel ingewikkelder ligt. Zelden wordt het recidiefpercentage in correct verband gebracht met de tijd. De life table methode geeft hiervoor een goede oplossing. Dat dit tot heden zo weinig toegepast is komt omdat de berekeningen hierbij statistisch van aard zijn en moeilijk tot het voorstellingsvermogen spreken. Indien de life table methode wordt toegepast op deze serie patienten dan blijkt dat de kans op recidief constant blijft. Echter uit dezelfde cijfers lijken eveneens dezelfde conclusies te kunnen worden getrokken als in de literatuur, $\mathrm{nl}$. dat $\mathrm{x} \%$ recidieven te verwachten zijn en dat de meeste recidieven optreden binnen enkele jaren na operatie (hoofdstuk 15). Waarschijnlijk zou er, wanneer een rekenmethode als de life table analyse op andere series zou worden toegepast, eveneens een constante kans op een recidief worden gevonden ${ }^{322}$. 
Dit geldt niet alleen voor de HSV maar waarschijnlijk voor alle operaties. Andersen ${ }^{\text {is }}$ heeft in een van de artikelen, waarin de toepassing van deze methode op de HSV is beschreven, een vergelijking gemaakt met de resultaten van patienten, die in het verleden een BI of BII resectie hebben ondergaan en die eveneens een constante recidief kans hebben, zij het geringer. Het is echter nog niet zeker of deze kans op recidief hetzelfde zal blijven; wellicht is na verloop van jaren toch een afname van deze kans te verwachten. Dit betekent evenwel dat de uitdrukking "operatie $Z$ heeft $10 \%$ recidief" als zodanig niet erg zinvol is en een recidiefpercentage weergeeft na een "gemiddelde" observatie periode. Dit gemiddelde is bij de diverse onderzoeken zeer verschillend van samenstelling. Wel waardevol is de vergelijking van dergelijke percentages in "controlled trials", hoewel ook hier de life table analyse veel meer zegt dan het recidiefpercentage op een bepaald moment.

Ten derde: zoals betoogd in de inleiding en zoals in diverse hoofdstukken aan de orde kwam zijn er na alle waarschijnlijkheid etiologische verschillen onder de recidieven. Het is zeer waarschijnlijk dat zich onder de recidieven zowel methodischeals chirurgische- als patientgebonden mislukkingen bevinden. Mislukkingen inherent aan de methode zijn waarschijnlijk onvermijdelijk, doch het aantal daarvan dient bij een standaardoperatie zo klein mogelijk te zijn. Het is moeilijk vast te stellen hoe hoog dit percentage bij de HSV zal zijn, temeer daar dit samen kan hangen met patient gebonden factoren. (grootte van het antrum, hypersecretie).

Chirurgische mislukkingen zouden zo laag mogeljk moeten zijn ${ }^{29,37}$. Dit is afhankelijk van de intrinsieke moeilijkheidsgraad van de operatie. In tegenstelling tot wat vaak aangenomen wordt is een HSV geen gemakkelijke operatie, zoals ook door diverse auteurs beklemtoond wordt $127,258,35 !, 354$. Het is een operatie waarbij een zeer nauwkeurige en zorgvuldige techniek van het allergrootste belang is.

Patientgebonden mislukkingen zijn waarschijnlijk moeilijk te vermijden; doch selectie van patienten is hierbij wel belangrijk. De indikatiestelling tot operatie zal altijd een moeilijk te beoordelen factor blijven bij evaluatie van de resultaten. Psychisch labiele personen hebben waarschijnlijk een grotere kans op een slecht resultaat. Als men deze categorie niet voor operatie accepteert zullen de resultaten wel beter zijn, maar deze patienten wordt dan (wellicht) tekort gedaan. Ook extreme omstandigheden kunnen mogelijk bij niet labiele personen tot een recidief leiden (stress).

De mengeling van kwalitatief verschillende "soorten" recidief, die voorlopig niet onderscheiden kunnen worden en die warschijnlijk een verschillende pathogenese hebben, is er mogelijk de oorzaak van dat zuursecretietesten van beperkte waarde blijken te zijn, wat betreft het voorspellen van het recidief en derhalve ook voor de $k$ waliteitsbeoordeling van het chirurgisch handelen. Het is mogelijk dat deze testen wel grote waarde zouden kunnen hebben indien er alleen maar chirurgische misluk kingen zouden bestaan. Op grond van de zeer matige correlatie tussen optreden van recidief en resultaat van zuursecretietesten ligt het voor de hand te concluderen dat de zuursecretie slechts een ondergeschikte rol speelt bij de pathogenese van het recidief. Dit is geheel in overeenstemming met de literatuur op dit gebied. Wellicht is het correcter te stellen dat het bij sommigen wel, bij anderen daarentegen geen belangrijke rol speelt. Helaas is het niet uit te maken bij wie dit het geval is. 


\section{List of abbreviations}

Several abbreviations and symbols have been used to keep the text, tables and figures more readible and concise.

S.I. units have been used for all parameters.

symbols

$\begin{array}{ll}0^{*} & \text { man, men, male } \\ \text { q } & \text { woman, women, female } \\ * & \text { statistically significant } \\ + & \text { present } \\ - & \text { absent }\end{array}$

abbreviations (in alphabetical order)

All all patients unless specified otherwise

ant anterior

AP alkaline phosphatase

B I/II Billroth $\mathbb{I} / \mathrm{II}$

BAO basal acid output

$\mathrm{Ca} \quad$ calcium

cig cigarettes

DU duodenal ulcer

ESR erythrocyte sedimentation rate

$\mathrm{Fe} \quad$ iron

GE gastroenterostomy

$\mathrm{Hb}$ haemoglobin

HSV highly selective vagotomy

i.m. intramuscular

i.v. intravenous

MAO maximal acid output

n number of patients or values

n.a. not applicable, not applied

n.s. not significant (statistically)

non-rec patients without a recurrence

p value indicating the level of probability

P phosphate

PCV parietal cell vagotomy (= HSV)

PG pentagastrin

PGV proximal gastric vagotomy

PIP proximal interphalangeal

post(op) postoperative

pre(op) preoperative 


$\begin{array}{ll}\text { pts } & \text { patients } \\ \text { PV } & \text { predictive value } \\ \text { rec } & \text { recurrence }(\mathrm{s}), \text { patients with a recurrence } \\ \text { rh } & \text { rhesus factor } \\ \text { sd } & \text { standard deviation } \\ \text { sem } & \text { standard error of the mean }(\mathrm{sd} / \mathrm{V} \mathrm{n}) \\ \text { TIBC } & \text { total iron binding capacity } \\ \text { TV + D } & \text { truncal vagotomy and drainage procedure } \\ \text { TV + PP } & \text { truncal vagotomy and pyloroplasty } \\ \text { yr }(\mathrm{s}) & \text { year }(\mathrm{s}) \\ \text { Vis. } & \text { Visick }\end{array}$




\section{References}

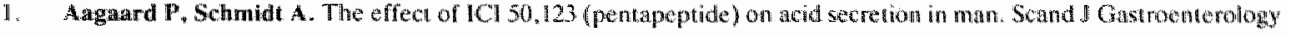
$1967: 2: 265-268$.

2. Aagard P. A comparison between the dfect of peptavon and histamine on gastric acid secretion in man afeer statgical vagotomy. Scand 1 Gastronterology $1968 ; 3: 476-480$.

3. Adami H, Enander L, Ingwar C. Clinical results of 229 patients with duodenal alcer 1.6 years after highty selective vagotomy. Br J Surg 1980; 67: 29-32.

4. Adams JF, Cox AG, Kennedy E.H, Thompson J. Effece of medical and surgical vagotomy on intrinsic factor sectetion. Br Med J 1967; 3: 473 4766 .

5. Aeberthard P, Walther M. Results of a com rolled randomized triat of proximal gastric wagotomy with and without

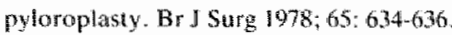

6. Ahonen J, Hoepfrer-Hallikatnen D, Inberg M, Scheinin TM. The wal we of corpus-antrum derarminations in highly selective wagotomy. Br $\mathbb{S}$ Surg 1979; 66:35-38.

7. Alexander-Willams J, Cox AC. After vagotomy. Butterworths London. 1969.

8. Amdrup E, Jensen HE. Selective vagotomy of the partetal cell mass preserving innervation of the undraned antrum. Gastroenterology $1970 ; 59: 522-527$.

9. Andrup E, Jensen HE, Johnstion D. Clinical resulus of parietal cell vengotony. Amm Surg 1974; 180:279-284.

10. Andrup E. Johnston D. Name of the new vagolomy. Gastroenterollogy 1975; 68: 206-207.

11. Amdrup Ex Andersen D, Hestrup H. The Aarhus coun ly wagotomy irial; interim report. Scand J Gastrounterology 1977: 12: supp. 45.

12. Andrup E, Andersen D, Jensen HE. Parietal cell (hightly selective or proximall gastric) wagotomy for peptic uter disease. Womld J Suri $1977 ; 1: 19.27$.

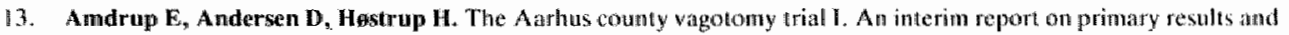
incidence of sequellat following parietal cell vagotomy and selective gastric vagotomy in 748 patients. World $\mathrm{J}$ Surg $1978 ; 2: 85-90$.

14. Andrup E. Recurrent slcer. Br J Sing 1981; 68:679-681.

15. Andersen D, Amdrup E, Hastrup II. The Aarhus connly wagotomy trial: recurrent ulce r after vagotomy, In: Rehteld JF and Amorup E (ed): Gastrins and the vagus. Londont Academic Press 1979; 223-231.

16. Andersen D, Hestrup H, Andrup E. The Aarhus county vagowomy trial II. An interim report on reduction in acid secretion and ulcer recurrence rate following parietal cell vagolomy and selective gastric vagotomy. World J Surg 1978; 2: $91-100$.

17. Andersen $\mathbf{D}$, Amodrup $\mathbf{E}$, Hastrup $\mathbf{H}$, Serensen FH. The Aarhus county vagotomy trial: treads in the problem of recuremt ulcer after parietal cell vagotomy and selective gastric vagotony with drainage. World If Surg 1982; 60 8692.

18. Angorn B, Dimopoulos G, Hegarty MM, Moshal MG. The effect of vagotomy on the lower oesophageal spiniucter: at manometric study. BrJ Surg 1977; 64: 466-46\%.

19. Aubrey DA, Forrest APM. The effect of wagotomy on human gastric secretion. Br J Surg 1970; 57:332-3,38.

20. Ayalon A, Devitt P, Guxman S, Suddith R, Rayford PL. Thempson JC. Relcase of ant nil garstrin in response to an intestinal meal in dogs. An Surg 1982; 399 401.

21. Bank $\mathbf{3}$, Marks IN, Lauw JH. Histamine- and insulin-stimulated gastria acid secretion after select ive and trunctibl vagotomy. Gui 1967; 8: 36-41.

22. Rank S, Marks IN, Louw JW. The long-term effect of vagonony and drainage, parietal cell vagotomy and Hy receptor antagonists on duodenal ulcers and gastric function and structure. S Afr Med J 1980;57:622*627.

23. Baron JH. Sudies of basal and perk acid output with an augnented histamine test. G iat 1963; 4: 136-:44.

24. Daron JH. Dose response to insulin hypoglycaemia of human gastric acid. Br J Surg 1969:56:383-384.

25. Daron JH, Alexander-Whillans J. Gastric secretion tests. In: Taylor S ed: recentadvances insurgery. No 8 Lindizurgh: Churchill Livingstone 1973; 166-195.

26. Baron JH, Spencer J. Facts and heresies about vagotomy. Surg Clin N Am 1976; 56:1247.1311. 


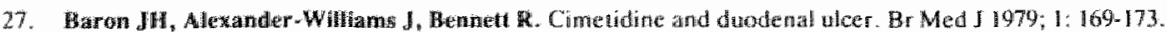

28. Baker HD, Reder DD, Thompson IIC. Effect of truncal vagotomy wh pyloroplasty or with antrectomy on food-

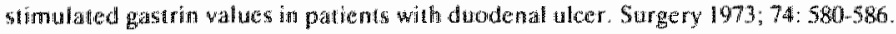

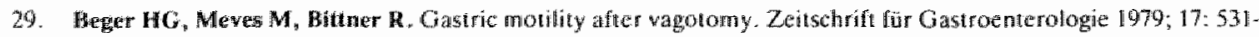
537.

30. Hell PRF. The long-term effect of vagotomy on the maximal acid response to histamine in man. Gastroenterology $1964 ; 46: 387-391$.

31. Heraha N, Sil weira M, Man W, Spencer J. Catecholamines and experimental stress ulcer morphologicat and biochemical changes in the gagtric mucosa. Br J Surg 1990; 67:624-628.

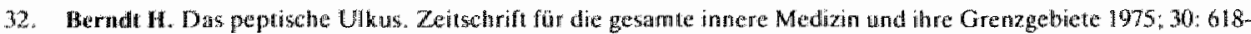
624

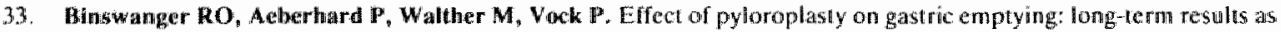
oblained with at labelled test meal 14-43 nonths after operation. Br J Surg 1978; 65: 27-29.

34. Bircher $\mathbf{E}$. Die Resektion von Aesten der Merwus Vagus zur Behand lung gastrischem Affektionen. Schweizerische medizinischuc Wochenschnrift 1920;50:519.528

35. Bituner $\mathbf{R}$, Schnoy $\mathbf{N}$, Zschitedich, Beger HG. Die Nekrose der kleinam Magencurwatur, eine vermeidbare Komplikation der selketiven proximalen Vagolomie. Akuel Chir 1981; 16/5; 175-179.

36. Black JW, Duncan WAM, Durant C.J, Ganellin CR, Parsons EM. Definition and antagonism of histamine H2receptors. Nalure 1972; $236: 385-390$.

37. Blackett RL, Johnston D. Recurrent ulceration after highly selective vagotomy for duodenal ulcer. Br. ISurg 1981 ; 68: $705-710$.

38. Bowey J, Wong J, Ong GB. A prospectiwe study of operative risk factors in perforated duodenal allcers. Ann Surg $1982 ; 195: 265 ; 269$

39. Boey J, Lee NW, Wong J, Ong GB. Perforations in acute duodenal allers. Surg Gynecol Obstet 1982; 155: 193-196.

40. Börger HW, Schafmayer, Becker HD. Der Einfluss der selektiv-proxinnalen Vagotomie auf die Serum-spiegel von Gastrin, GIP and Insulin bei Ukus Duodeni-Patienten. Langeb Arch Chirurg 1978; 346: $25-29$.

41. Braasch JW, Sala LE, Ells FH, Croziter RE. Parietal cell wagotomy. Arch Surg 1980; 115:690-701.

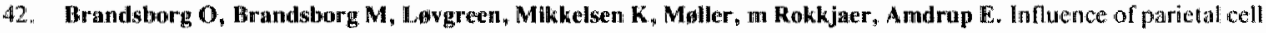
vagotomy and selective gastric vagotony or gastric emptying rate and serum gastrin concentration. Gastroenterology $1977 ; 72 ; 212 \cdot 214$.

43. Bulthuis R. Surgery trends and costs of peptic ulcer disease in the Netherlands before and after the introduction of cimetidine. Netherlands Economic Insitute Rohtendam. Cost benefil symposium, March 1981, Amsterdam.

44. Husman DC, Munting JDK. Results of hughty selective vagotomy in a non-university teaching hospital. Br J Surg 10,$2 ; 69: 620-624$

45. Bufjs PHO. Gastrine. Ned Tijdsctur Geneesikd 1979; 123: 168-172.

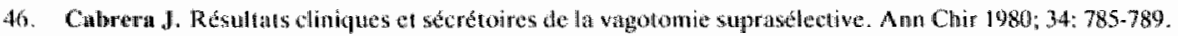

47. Caspary WF, Postvagotomie-diarthoe. Zeitschrift tür Gasuoenterologie 1979; 17:547-554.

4א. Cord WJ, Narks IN. The relationship between the acit output of the stomach following maximal histamine stimulation and the parietal cell mass. Chin Sci 1960\% 19: 147-163.

49. Christensen NJ, Brandsborg O, Lavareen NAn Brandsborg M. Elevated plasma noradrenaline concentrations in duodenal unlcer patients are not nomalized by wagotomy. J Clin Endocrinol Metab 1979; 49*331-334.

50. Christansen J, Jensen HE, Elby*Poulsen P, Bardram L, Henriksen FW. Primary results, sequelae, acid secretion * and recurrence rates, two to five years after operation. Ana Sarg 1981; 193: 49-55.

51. Clark CG. Recovery of gastric Rumction after incomplete wagotomy. Bu J Surg 1964; 51: 539 .542.

\$2. Clark CG, Lewh MR, Stagg BH, Wyllic JH. Effect of proximal gastric vagotomy on gastric acid secretion and plasme gastrin. Gut 1973: 14:293-299.

53. Clark CG. World progress in surgery: progress in the treatment of peptic ulcer. World J Surg 1977; 1 : 1 .

54. Clark CG, Wyllie JH. Drugs for peptic ulce. World I Surg 1977; 1: 3-8. 
55. Chark CG, Boulos PB, Haggie SJ, McDonald AM. H anatagonisus in the ireatment of recuntent alweration after wagotomy. Br J Surg 197\%; 66; $409-41$ I.

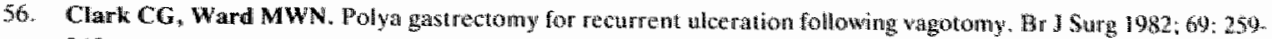
260.

57. Clark CG. Anemie en late complicaties wan magagopraties Modern Medicine 1982; 340.352 .

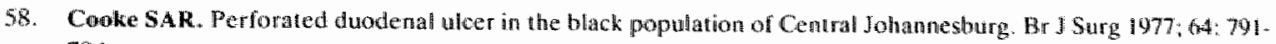
794

59. Cowan WK. Genetios of duodemal and gastric ulcer. Clin Gastroenterology 1973; 2:539,546.

60. Cowley DJ, Vernon P, Jones T, Glass MI, Cox AG. Gist ric enptying of solid mealls after truncal vagotony and Pyloroplasky in human subjects. Gut 1972;13:176.

61. Cowley DJ, Spencer لli, Baron JH. Acid secretion in telation to recurrence of duodenal ulcer after vagotomy and drainage. Br J Surg 1973; 60:517-522.

62. Cowdey DJ, Baron JH. The effect of insulin hypoglycaemia on serum gast tin and gastrite acid in nomal subjects and patterns with duodenal ulcer. Br J Surg 1973;60:438-443.

63. Croft RJ. Reperitonealization and invagination of the lesser curwature of the stomach followimg proximal gastric wagotomy. A reh Surg 1978; 113:206-207.

64. Csendes A, Oster M, Meller JT, fFlynn J, Funch-Jensen P, Overgaard H, Amdrup E. Gastrocsophageal reflux in duodenal ulcer patients befiore and after vagotomy. Ann Surg 1978: 188: 804-808.

65. Csendes $\mathbf{A}$, Oster $\mathbf{M}$, Brandsborg $\mathbf{O}$, e.a. The effect of vagotomy on humar gastroesophageal sphincten pressure in the resting state and following increases in intrabdiominal pressure. Surgery $1979 ; 419-424$.

66. Daly Walker $G$, Stewart JJ, Bass Paul. The effect of parietal cell and tnucal vagotomy on gastric and dunderab contractile activity of the unanesthetized dog. Ann Surg 1974; 179: 853-858.

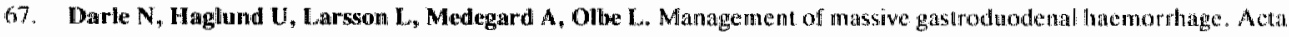
Chir Scand 1980; $146: 277-282$.

68. Delaney P. Preoperative grading of pyloric stenosis: a long term clinical and radiological follow-rap of patients with severe pyloric stenosis by highly selective vagotomy and dilatation of the strictune. Br I Surg 1978; 65:157-160.

69. Dent TL. Evaluation of the bleeding patient. Surg Gynecol Obstet 1980; 151:817-820.

70. Dinstl K. Choice of operations for patients with duodenal ullers. Surg Gyanecol Obstei 1969; 77-80.

71. Donahue PE, Nyhus LM. Exposure of the periousophageal space. Surg Gynecol Obstet 1981; 152:219.

72. Donowan IA, Owens C, Clendinnen, Griffin DW, Harding LK, Alexander -Willams J. Interrelations betwe ch serum gastrin levels, gastric emplying and acial oupu before and afer proximal gastric vagotomy and truncal vagotomy and antrectomy. Br.J Sarg 1979; 66: 149.151.

73. Dorricott JN, McNetsh $\mathrm{R}$, Alexander-Williams J, Rayston CMS, Cooke WM, Spenet J, we Vries MC, Mulker 11. Prospective randomised multicentre trial of proximal gastric vagotomy or truncal vagotomy and antrocony for duodenal ulcer: interim resullis. Br J Surg 1978; 65: 152-154.

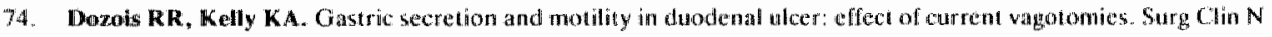
Am 1976:56:1267-1274.

75. Dragstedt LR, Owens M. Supradiaphragmatic section of the vagns nerves for duodenal ulcer. Procectings of the societly for experimental biology and medicine $1943 ; 53: 152-1,54$.

76. Dragstedt LR, Foumier HJ, Woodward ER, Tovee EB, Herper PV. Transabodomitial gastric vagotomy. Surg Gynecol Obstet 19:47; $85: 461-470$.

77. Dunn DC, Thomas, WFg, Hunter JO. Highly selectiwe vagotomy and pyloric dilatition for duodenal ulcer with stenosis. Br J Surg 1981; 68: 194-196.

78. Dunn DC, Thomas WEG, Hunter JO. An evaluation of highly select ive vagotomy in the treat ment of chronic? duodenal ulcer. Am J Surg 1982; 143: 845-849.

79. Dyck WP. Cimelidine in the management of peptic ulcer disease. Surg Clin N Arn 1979; 4: 8653-867.

80. Eberlein TJ, Loremzo FV, Webster MW. Gastric carcinoma following operation for peptic ulcer disease. Ann Surg 1978: $187: 251-256$. 
81. Ebeid AM, Fisether JE. Gastrin and ulcer disease: what is known. Surg Clin N A m 1976; 56: 1249-1260)

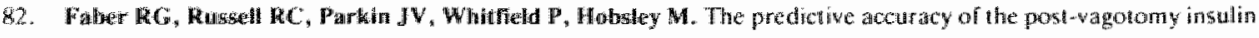
thest: a new interprelation. Gut 1975; $16 ; 3,37-342$.

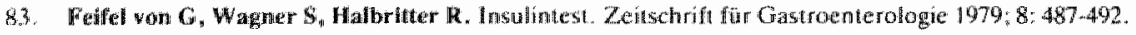

84. Felduan sD, Wise $L_{*}$ Ballinger Wr. Revien of ellectuce surgical treatment of chronic duodenal wicer. World I Surg $1977: 1: 9 \% 17$.

85. Werraz EM, Futho HAF, wacelar TS, Lacerda CM, De Sowza AP, Kelner $S$. Proximal gastric vagotomy in stenosed or perforated duadenal uleer. Br I Surg $1981 ; 68 ; 452-545$

86. Fritsch WP, Hausanen TU, Rok W. Gasic and exagastric gastirin release in normal subjects in durdenal ulcer

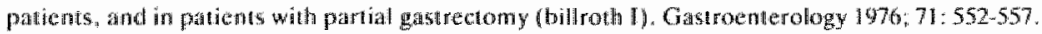

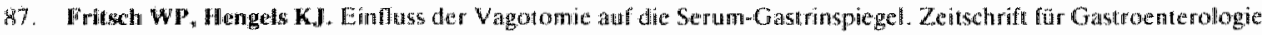
1975; 17: 503.510 .

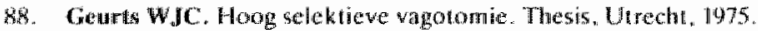

89. Gents W, Winckers EKA, Whttebol P. The effects of highly seledive wagotony on secretion and emptying of the stomach. Surg Gynecol Obstet 1977: 145:826-836.

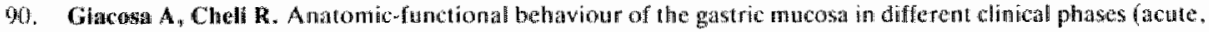
quiescent, relapsing) of duotenal ulcer. Hepato-gastroenteroloy 1982; 29; $124-126$.

91. Gillespie G, Elder JB, Gillespie IE, Kay AW, Campell EHG. Response of insulin to the intact stonach in patterns with dulodenal ulleer. Gut 1969; 10: 744 748.

92. Gillesple G, GHllespie IE, Kay AW. The long-term stability of the insulin test. Crastroenterology 1970; 58:625-632.

93. Gillespie IM, Kay AW. Effect of medical and surgical wagotomy on the augraented histamine test in maru. Br Med J $1961: 5239.5242$

94. Golligher $\mathrm{JC}$, Pulvertaft $\mathrm{CN}$, de Dombal $\mathrm{FT}$, et all. Five to eight years result sof Leeds/York controlled trial of elective surgery for duodenel ulcer. Br Med J 1968; 2: 781-787.

95. Gollgher JC. A technique for highly selectwe (parietal cell or proximal gastric) vagotomy for duodenal ulcer. Br J Surg $1974 ; 61: 337-345$.

96. Goligher JC Fill GL, Kenny TE, Nutter E. Proxinnal gastric vagotony withou drainge for duodenal uhcer: results after 5 - 8 years. Br J Surg 1978; 65: 145-151.

97. Gowgh MJ $J_{4}$ Christopher S, Les H, Les GRG. Does osmotic control of gastric emptying persist after truncal vagotony? Br J Surg 1981; 68:77-80.

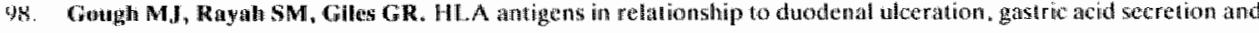
the clivicul result following vagotomy. Bu J Surg 1982; 69: 105-107.

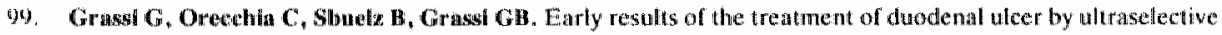
vagolomy withoul drainage. Surg Gynecol Obstet $1973 ; 136 ; 726-728$.

160. Grassi G, Orechin C, Sbuela B, Grassi GB. Vagotomic supersélective en tesi acidomécretoine peropératoire. J Chir 1974; 107: 275-282.

101. Grass G. Highty selective vagotony with intraoperative acid secretive test of completeness of vagal section. Surg Gynecol Obstet 1075; 140:254-264.

102. Grassil G. Orechín C, Cantarent I, Grassi GB. The results of highly seleclive vagotony in our experience (787 cases). Chir Gastroent, 1977; 11:51.

1673, Gray JG, Robert AK. Definitwe emergency hreatment of perforated duodenal ulcer. Surg Gynecol Obstet 1976 : 143: 890 894 .

104. Gray GR, Smith IS, McWhinnie D, Gillespie G. Fue-year study of cimeidine or surgery for severe anodenal uber dyspepsia. Lamcet 1982; 3: 787-788.

105. Greenall MJ, Lyndon PJ, Goligher JC, Johnston D. Long-term effect of highly selective vagotomy on basal and maxinal acid output in mar. Gastroenterology $1975 ; 68: 1421-1425$.

106. Green WER, Kennedy T, Hassard T, Spencer FFA. Management of recument peptic ulceration. Br J Surg 1978; 65: $422-426$ 


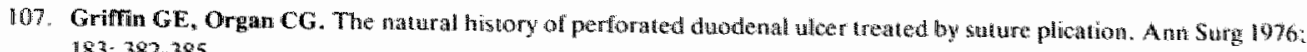
$1 \mathrm{~S} 3=382-385$.

108. Grifth CA, Harkins H. Partial gastric wagotomy: an experimental stuty. Gastroenterology 1957; 32 : 264102.

109. Grossman M. Some ninor heresies about vagotomy. Gastroenterology 1974; 67; 1016-1019.

110. Grossunan M, Guth PH, Isenberg. JI, et al. A new look at pephic ulcer. Ann Interna Med 1976, 84: 57-67.

111. Gurll NJ, Damianos AJ. The role of histamine and histamine receptors in the pathogencsis and treatment of erosive gastritis. World I Surg $1981 ; 5: 18$-187.

112. Guzman S. Chaywialle JA, Banks WA, Rayford PL, Thompson JC. Effect of vagat stirutation on pancrealic secretion and on blood levels of gastrin, cholecystokinin, secretin, vasonctive intestinal peptide and somakostatin. Surgery $1979 ; 329-336$.

113. Haemers S, Hoste P, Elewant A, Barbier WF. Het maagstompearinoom. Ned Tijdschr Geneeskd 1980; 194:4, 636639.

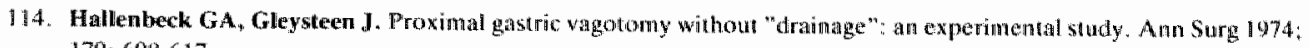
179: $608-617$.

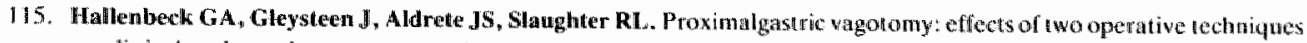
on clinical and gastric secrelory results. Ann Surg 1976; $184: 435.442$.

116. Hallenbeck GA. The natural history of dnodenal ulcer disease, Surg Clin N Am 1976; 56:1235-1242.

117. Hamitton JE, Harbrecht PJ, Robbins RE, Noland JL. The behaviour and management of major actute bleeding lirom peptic ulcers. Surg Gynecol Obstet 1965; $121: 545-550$.

118. Hamsky J, Korman MG. Long-term cimetidine in duodenal ulcer disease. Dig Dis Sci 1979:24: 465:4

119. Hansky J, Stern A1, Korman MG, et al. Eftecis of longwerm cimetidine on serum gastrin in duodenal ulcer. Dig Dis Sci $1979 ; 24: 468-470$.

120. Harmon JW, Trout HH. Effect of proximal gastric wagotomy on feeding stimulated heidenfuain pouch ancid secretion and gastu in release. Ann Surg 1978; $188: 647$.

121. Farmon IW. Verdict on vagotomy. Gastroenterology 1981;81:809-813

122. Hassan MA, Hobsley M. Positioning of subject and of nasogastric tube during a gastric secretion study. B 3 . Med J $1970 ; 1: 458-560$.

123. Hauer-Jansen M, Carisen E, Semb LS. Prognostic value of the pentagastrin and insulin tests after proximal gasuric vagotomy. Scand J Gast roenterology 1980;15:722-729.

124. Hede JE, Temple JG, McFarland J. The piace of transthoracic vagotomy in the management of recurrent peptic ulcenation. Br 1 Surg 1977 ; $64: 332-335$.

12S. Hedenstedt $\mathbf{S}$, Lundquist $\mathbf{G}$, Moberg $\mathbf{S}$. Selecive proximal wagoiony (SPV) in treatment of duodenal ulcer. Act Chir Scind $1972 ; 138: 591-596$.

126. Hedenstedt S. Experiences of selective proximal vagotomy - SPV - 400 cases of uncomplicated and complicated ulcers during 6 years. Chir Gastroenterology $1975 ; 9: 205-213$.

127. Hedenstedt $S$, Schayah N, Moberg S. Selective proximal vagotomy without drainage in the ureatment of altudbenal ulcer. The results after standardization of the surgical technique. Act Chir 5cand 1980; $146: 31-34$.

128. Hermann RE. Obstructing duodenal aller. Surg Clin N Am 1976:56: 1403-1411.

129. Herrington JL, Sawyers JL. Results of elective duodenal ulcer surgery in women. Comparison of trufical vagotomy and antrectomy, gastric selective vagotomy and pyloroplasty, proximal gastric vagotomy. Ann Surg 1978: 187: 576582 .

130. HHat GL. Barker CJ. Anterior highly sefective vagotomy with posterior truncal vagotomy: a simple technique for denervating the parietall cell mass. Br J Surg 1978; 65:702-705.

131. Hobsley M, Silen W. Use of an inert marker to improve accuracy in gastric secretion st.udies. Gut 1969; $16: 787.795$.

132. Holle F, Hart N. Neue Wege der Chirurgie des Gastro-duodenal-ulkus 1967; 62: 441-450,

133. Holle F, Bauer G, Holle GE, Konz B, Lissner J, Wünsch E. Clinical resulls of selective proximat vagolomy in gastroduodenal ulcer. Langenbecks Archiv für klinische Chirurgie 1972; 330; 197-208. 


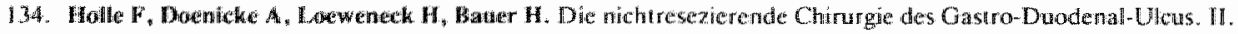
Indikation und Technik, Münch Med Wochensche 1976; 118 : 777-784.

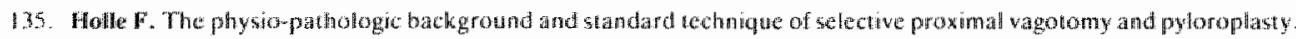

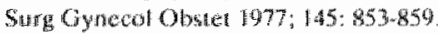

136. Holle Holle GE, Vagolomy and pyloroplasty, advarces 1975-1980. Springer Verlag herlin Heidelberg New York. 1980 .

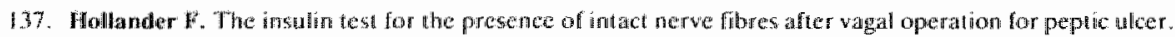
Gestroenterology $1946 ; 7 ; 607-645$.

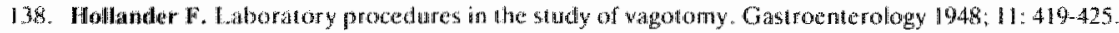

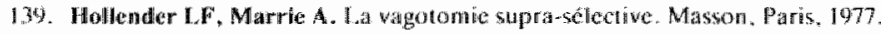

140. Hollender LF, Marre A, Meyer Ch, et al. Anatomical bases of vagolomy. A nat Clin 1980; 22: 169-180

141. Hollnshead JW, Smith RC, Gillet IJJ. Parietal cell vagotomy: experience with 14 patients with prepyloric or duodenal ulcer. World Jisg 1982; 6: 596-602.

142. Holst-Christensem $\mathbf{J}$, Hart Hansen $\mathbf{O}$, Pedersen $\mathbf{T}$, al. Recurrent ulcen after proximal gasiric vagotonay for duodenal and prepyloric ulece. $3 r$ I 5 urg $1977 ; 64: 42-45$

14.3. Horowitz, Werther 1.J. Conserwatieve behandeling van ulous duodeni. Modern Medicine 1979; $971-974$.

14. Horton JW, MeCleland, Weger RV. Effech of parictall cell vagotomy on gastric emptying in duodenal uller disease. Surg Gynecol Obstet 1980: 150: 86-89.

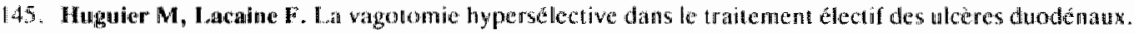
Giatsroenterology Clin Biol 1980; 4: 893-898.

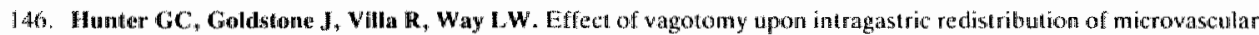
flow. J Surg Res $1979 ; 26: 314319$.

147. Ip politi $\mathbf{A}$, Walsh J. New concepts in the pathogenesis of peptic ulect disease. Surg Clin N Am 1976; 56: 1479.1491.

148. Isenberg J1, Spector H, Hootkin I.A, Pitcher Jlt. An apparert exception to Schwarz's dictum, "no acid - no nicen". N Engl J Med 1971;620.

149. Jackson RG. Anatomic study of vagus nerves with a technic of transabdominal selective gastric vagus resection. Areh Surg 1948; 57: 333-352.

150. Jaffe BM, Clendimen BG, Clarke $\mathbf{R}$, Walliams JA. The effect of selective and proximal gastric vagotony on serumy gastrin. Gastroenterology 1974; 66: 944-984.

151. Jaffe BM. Parietal cell vagotony: surgical technique, gastric acid secration and recurrence. Surgery 1977:82/2: 284286.

152. Jemsen HE, Amdrap E. Follow ap of 100 patients five to eight years after parietal cell vagotomy. World J Surg 1978 : 2. $525-572$

153. Jepson K, Duthe H, Fawett A, et al. Agid and pepsin response to gastrin, pentagastrin tetragastrin. histanaine and periagastrin snult. Lancel $1968: 2: 139-1411$

154. Joffe SN, Primrose. IN. A prospective st de y evaluatimg preoperative gast ric seeretion and choice of an operation for duodenal ulcer. Surg Gynecol Obsted 1981: $152: 421-423$

155. Joffe SN, Crocket A, Doyle D. Morphologie and functional evidenec of reinnervation of the gastric parictal cell matss alter parietal ecti wagotony. Am J Surg 1082;143:80-85.

156. Jolnuswn AG, Baxter HK. Where is your vagotomy incomplete? Obserwations on operative technique. Br I Surg $1977: 64: 583-586$.

157. Johwston D, Goligher JC, Dwithie ML. Medical vigotomy: an assessment, Br Med J 1966; 2: $1481-1485$.

158. Wohuston D, Thomas DG, Checkets RG, Duthic HL. An assessment of postoperative lesting for complete ness of Yagotomy. Br J Surg 1967; $54: 831 \times 833$.

159. Johnston $\mathbf{D}$. Use of pentagast rim in a test of gastric acid sectetion. Lancet $1967 ; 585,588$.

160. Wohnston D, Wilkinson AR. Highly selective vagotomy without a drainage procedure in the treatment of duodenal ulcer. Br J Surg 1970; 57: 289-296. 
161. Johnston D, Goligher JC. The infuence of the individual surgeon and of the type of vagotonty upon the insulin test after vagotomy. Gut $1971 ; 12: 967-967$.

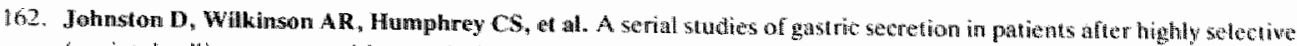

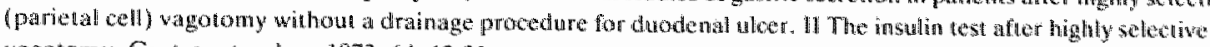
vagotonny. Gastroenterology 1973; b4: 12,21.

163. Johnston D, Lyndon $\mathbb{P J}$, Smith RB, Humphrey CS. Highly selective vagotomy without a dranage procedure in the treatment of hatemorthage, perforation and pyloric stenos is dwe to peptic ulcer. Br J Surg 1973: 60: 790-797.

164. Johnston D, Wilkinson AR, Hamphrey CS. A serial studies of gastric secretion. Effect of HSV on basal and

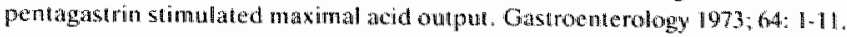

165. Hohnston D. Oastric uleer after highly selectwe vagotomy. Br Med I 1973; 483,

166. Johnston D. Progress report. Highly setective vagotomy. Gut 1974; 15: 748 757.

167. Johnston D, Pickford MR, Wather BE, Goligher JC. Highty selective vagotony for duodenal wleer: do hypersecretors need antrectomy? Br Med $11975 ; 1: 716-718$.

168. Johnston D. Operative mortality and postoperative morbidity of highly selective vagiotomy. Br Med . 1975. 4: 545 . 547

169. Johnston D, Gollgher JC.. Selective, bighly selective or truncal wagotony? In: an clinath appraisal. Surg Clin N Am $1976 ; 56: 1313 \times 1335$.

170. Johnston D. Diwision and repair of the sphineteric mechanism at the gastric outlet in entergency operations for bleeding pephic ulicer. Anr Surg $1977 ; 186: 718-723$.

171. Johnston D. Axon ATR. Highly selective vagotomy for duodenal ulcer: the clinical results after 10 yotrs. Br I Surg $1979 ; 66: 874$.

172. Wohnston D. Treatnent of peptic ulcer and it s complications. Recent advances in surgery. Ediaburgh: Churchil! Livingstone $1980 ; 355-409$.

173. Johnston D. Peptic ulceration: highly selectiwe vagotomy. In: Keery operstive surgery and managenent. Bristol London Boston $1981 ; 68-77$.

174. Jordan GL, Debakey, Duncan JM. Surgical managemen of perfonated peptic alcer. Ann Surg 1974; 179; 628-633.

175. Jordan PH, Korompai FL. Evolvement of a mew treatment for perforated duodenal uleer. Surg Cynecol Obster $1976: 142 ; 391-395$.

176. Jargensen PW, Jensen ME. Leucomethylene blue staining during vagotomy. B J Surg 1981; 68: $81-82$

177. Jubiginger Th, Pichlmaier H. Die postoperatieve Vagotomiekontrolle. Münchener Med Wochensehruft 1978 ; 120 : 955960.

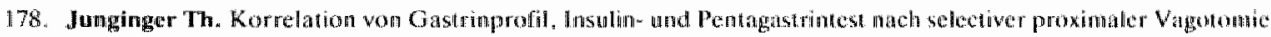
wegen Duoderanlatcus. Therapiewoche $1978 ; 28: 1465$.

179. Kay AW. Bifect of lenge doses of histamine on gastric secretion of HCl. Br Med J 1953; $2: 77,90$.

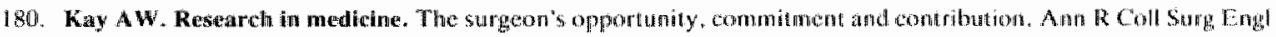
$1970 ; 47: 61: 77$

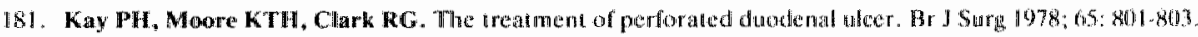

182. Kenredy F, Mackay $\mathrm{C}$, hedi BS, Kay A W. Truncal vagotomy and drainage for chronic duodenal ulter dise ase: a combolled trial. Br Med 1973: 2:71.75.

183. Kennedy $\mathbf{T}$, Johnstom St, Macrae KD, Spencer AF. Proximal gastric wagotomy: incrim results of a 1 andomized controlled triali. Br Med I $1975 ; 1: 301-303$.

184. Kennedy T. Ulket necurrence after parietal cell wagotomy. In: Rehfeld Jf and Amdrup E: Gastrins and ithe vagus. Condon: Academic Press, 1979:281-284

185. Kennedy T. Billrotly symposium: the failures of gastric surgety and their management. Br J Surg $198 \mathrm{~B}:, 68: 677$.

186. Kessler W, Angwerd R. Selektive proximale Wagotomie. Helvetica chirurgicat acta 1986 ; $47,541.545$.

187. Kim U, Rudich Ji, Aufses A. Surgical managementi of acute upper gastrointestial bleeding. Areh Surg 1078; 113: 144414447 
188. Kirkpatrick JW, Bowwman DL. A logical solwion to the perforated alcer controwersy. Surg G yncol Obstet 1980 ; $683-686$.

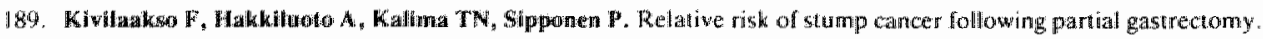
Br ISurg $11977,64: 36-338$.

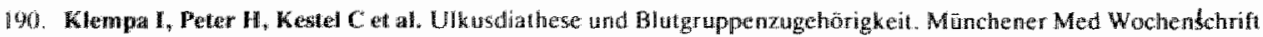
$1974 ; 116: 933,936$.

191. Knight CD, Herden wan JA, Ketly KA. Proximal gastric vagotomy. Ann Surg 1983; 197: 22-26.

192. Knight SE, Mclsace RL Fielling LP. Tha effect of highly setectiwe wagotoniy on the relationship between gast ric mucosal tiood flow and acid secretion in man. Bir Surg 1978; 65: 721-723.

193. Knight NF, Fiddian Green RG, Venik Al. In wivo release of gastmin into human gastric juice. Br J 5 urg 1978 ; 65188 120 .

194. Kaipping d. Beyer I. Selek liw proximale Vagotomie zur Behandlung des unkomplizierten Vlcus Duodeni Bericht aus einem Kreiskankenhass. Arrtsi Forbild 1980; 74: 479-481.

195. Koffman CG, Elder JB, Gillespie 1E al. A prospective randomized trial of vagotomy in chronic duodenal ulcer. Br I Surgig $1979 ; 60: 145-148$.

196. Kokoschka R, Gober I, Gebhart W. Gastric blood flow, mast cell degranulation and micromorphology of gastric mucosa following experimentat hatemorrhagic shock in dogs. Bu J Surg 1982; 69: 328-332.

197. Konturek: S, Effect of medical and surgical vagotomy on gastric vesponse to graded doses of pentagastrin and Tistamine. Gastroemterology $1968 ; 54: 392-400$.

198. Koo J, Lam SK, Ong GB. Cimetidine versus sugery for recurreme ulcer after gastric surgery. Ann Surg 1982: 195: 406.412 .

199. Kow J, Lam SK, Chan P, et all. Proximal gastric vagotomy, truncal vagotomy with drainage, and truncal vagotomy with antrectomy for chronic duodenal uker. Amn Surg 1983; 197: 265-271.

200. Worompal F, Hayward R, Jordan P. Duodenal ulcer. Its treatment by parietal cell vagotomy at the time of cardiowascular operation. Anch Surg 1979; 114: 1004-1005.

201. Korver MF, de Laive LP, Ossentjuk E. De late gevolgen van partiele magresectie. Boom, Meppel, 1975.

202. Krause U. Long-tem results of medical and surgical Ireatment of peptic ulter. Act Chir Scand 1963; $310: 1-107$.

203. Kronborg 0 . Pre and postoperative insulin tests in patients with duodenal ulcer. Comparison with the augmented thistamine test. Scand J Gast roenterology 1970; 5; 687-693.

204. Kromborg 0 . The walue of the insulin test in predicting recurrence affer vagotomy and drainage for duodenal uncer. Scand I Gast roenterology $1971: 6: 471.478$.

205. Kronborg 0 . Influence of the number of parietal cells on risk of recurrence after truncal vagolony and drainage for duodenal wleer. Scand J Gastroenterology $1972 ; 7: 423-431$.

206. Kronborg O, Madsea P. A comparison of gastric acid secretions after highly selective vagotomy without ar anage and selective vagotony with a pyloroplasty. Scand J Gastroenterology 1972; 7:615-621.

207. Kronlmorg 0 . Ginsuric acid secrecion and risk of recurrence of dwodemal ulcer witlin 6-8 years after truncal wagolomy and duratige. Gul 1974; 15:714-719.

208. Kiromborg O, Pedersen $\mathbf{T}$, Stadi $\mathbf{F}$, Rehfeld JF. The effect of beta-adrenergic blockade upon gastric acid secretion and gastrin secretion during hypoglychemia betore and after vagotomy. Scand J Gastioenterology 1974; 9: $173-176$.

209. Kuonborg $\mathbf{O}$, Madsen $\mathbf{P}$. A controlled fandomized trial of highly selective vagotomy versus selective vagotomy and pyloroplasty in the tretaliment of dnodenal ulcer. Gut 1975; 16:268-271.

210. Kronborg O. Assessment of completeness of watgotony. Surg Clin N Am 1976:56:1421-1434.

211. Kusakari K, Nyhus L.M, Gullison EW, Bombelk CT. An endoscopic test for completeness of vagotomy. Arch Surg $1972 ; 105: 386-391$.

212. Kuxtn MJ, Postolow PM. Selective proximal vagotomy the treatment of duodenal alcet. Work J Surg $1980 ; 4$ : 3477.352 .

213. Lam SK, Sircus W. Studies on duodenall ulcer, the climical evidence for the existence of two populations. Quarterly joutrnal of medicine $1975 ; 44: 369-387$.

214. Lam SK, Ong GB. Duodenal nkentsin early and late onset. Gut 1976; 17: 169-179. 
215. Lam SK, Chan PKW, Wong J, Ong GW. Fasing and postprandial serum gastrin levels trefore and after highty selective gastric vagotomy, truncal wagotomy with pyloroplasty and cruncat vagotonth with antrectomy: is there an cholinergic antral gastrin inhbitory and releasing mechavism? Br J Surg 1978, 65:707-800.

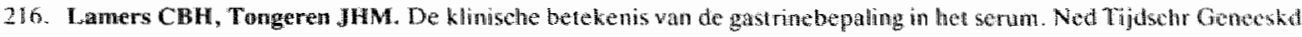
$1975 ; 119: 2024-2030$

217. Lamers CBH. Some aspects of the Z.E. syndrome, and serum-gastrim. Thesis. Nijnegen 1976.

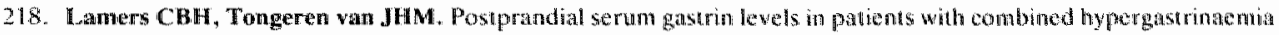
and hyperchlorhydria. Br ISarg $1979 ; 547-549$.

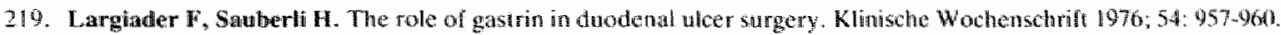

220. Latarjet MA. Résection des nerts de l'estomac. butlen de l'Acadermic (nationale) de Medicine 1922; $87: 681$-691.

221. Lee M. A selective stan ho detect the vagus nerve in the operation of vagotomy. Bir I Surg 1969; 56: 102-115.

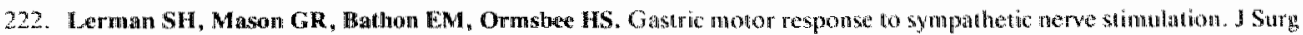
Res 1982: 32:15-23.

223. Levine BA, Gaskill HW, Sirinek KR. Lack of sustanted wagal control of gastric mucosal blood now, Why vagotony is not effective in prewenting fecurrent hemotrhage from stress ulcers. Surgery 198:; 90:631-636.

224. Lezoche E, Marinaccio F, Materia A, Imperati L. Basal and stimulated gastrin in dudenat ulcer patients belore and at different intervats after highly selective wagotomy (HSV), Chir Gastroenterology 1977; 11:83-86.

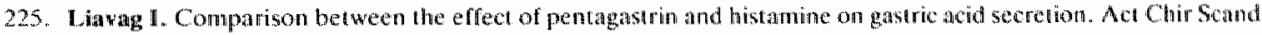
$1969: 135: 719.722$

226. Liawag 1, Roland M. A severy year follow-up of proximal gastric kagotonny. Clinical resulta. Seand J Gistroenterology $1979 ; 14: 409-416$

227. Liavag I, Roland M. Twelve years experience with proxinal gastric vagotomy (POV) for duodenal vleer. World " Surg 1982; 6: 649, abstract.

228. Liedberg $\mathbf{G}$, Oscarson J. Shont time follow-up of 80 patients. Scand J Gastroenterology 1974;8: suppl $20,12$.

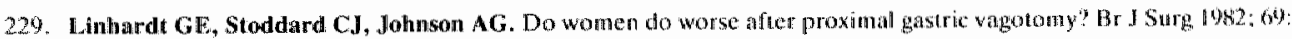
$321-322$.

230. Llanes O, Villar HV, Konturek SJ, Rayford PL., Thompson JC. Release of antrat hind duodtenal gastuin in response to an intestinat meal. Anin surg 1977; 186: 614-618.

231. Loeweneck H, Luedinghausen M, Mempel W. Die vagale Mageninnervation. Mürth Med Wochersshr 1967 : 109 : 1754 .

232. Loud FB, Christiansen J, Holst J., Petersen B, Kirkegard P. Effect of endogencus pancroutic ghtwagon on gastric

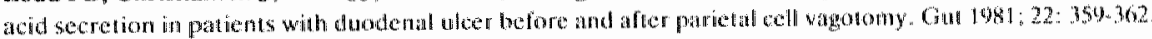

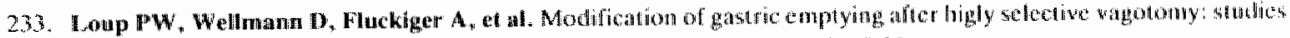
by barium and radio-isotopic meals. Seand \& Gatrotenterology $1981 ; 67: 19.21$.

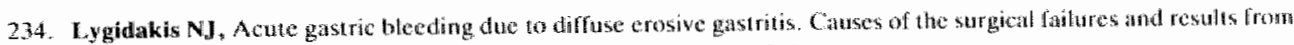
a pollicy after treatment of 115 cases. Ad Chir Beligg $1980 ; 4: 391$. 345

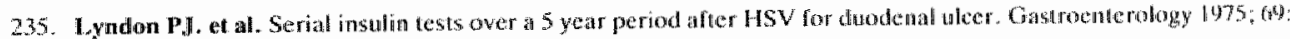
$1188-1195$

236. Mackie DB, Tunner MD. Vagotony and submucosal blood flow Arch Surg 1971: 102: 626-629.

237. Makhlour GM, McManus JPA, Card WI. Action of the pentapeptide (1Cl 50.123) on gastric secretion in man Gastroemterology $1966,51: 455-465$.

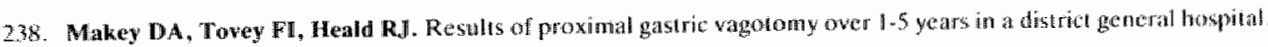
Br J Surg 1979; 66:39-42.

239. Malmstram J, Stadil F, Christensen $\mathrm{KC}$. Erfect of truncal vagotomy on gastroduodemal content of gastrin. Br I Surg $1977 ; 64: 34-38$.

240. Mason MC, Gites GR. The postoperative insulin test failure do detect incomplete vagotomy an patterns whth high acid levells. Br J Surg 1968; 55: 865.

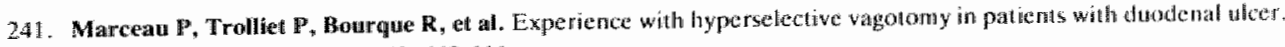
Surg Gynecol Obstet 1979:149:663-666. 


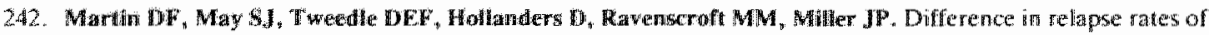

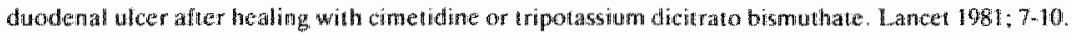

243. Martin JS, Tansy wh. site of alpha bock adte in the demongration of nonvagally mediated gastric acid secretion. Surg Gynecol Obste: 1080: $152: 137-140$.

2a,4. Maybury NK, Russell IRCG, Fabuer RG, Hobsfey M. A new interpretation or the insulin text walidated and then compared with the Burge trest. Br J Surg 1977, 64:673-676.

245. Mc Crea $\mathbb{E l D}$. The abdominal distribution of the vagus. I of A natomy 1924;59:18-40.

246. McGuigan JE, Trudean WL. Serum gastrin levels before and after vagotomy and pyloroplasty or wagotomy and antrectomy. N Engl I Med 1972; no 4, 184m 188.

247. Molsafac RL, Johnston H, Felding LP, Dudley HAF. Basal and dose-response st udies of gasiric mucosal blood flow: comparisom of duodenat ulcer patients before and after highly selectiwe vagotomy with normall volunteers. World I Surg 1982; 6:427-432.

248. McKay A J McArdle CS. Cimetidine and perforated peptic tucer. Br J Surg 1982; 69:319-320.

249. McLean Hoss AH, Smith MA, Anderson JR, Small WP. Late mortality after surgery for peptic ulcer. N Engl J Med $1982 ; 3078: 5199.522$.

250. Meikle DD. Gastritis, duodenitis and citculating levels of gastrin in duodenal ullcer before and after vagotomy. Gut $1976: 17: 719.728$.

251. Meikle DD, Bull J, Callender ST, et al. Intrinsic factor secretion after vagotony. Br J Surg 1977; 64: 795-799.

252. Meiners DJ, Deshpande YG, Kaminski DL. The role of histamine in control of gastric mucosal blood flow in dogs. J Surg Res 1982: $32: 608$-616.

253. Mendeloff A. What has been happening to duodenal ulcer. Gastroenterology $1974 ; 67: 1020-1029$.

254. Menguy R. Le traitement de 1"ufere peptigue. Chirurgie (Paris) 1981; 107/6, 401.

255. De Miguel J. Recurence after proximal gastric vagotomy whout drainage for duodenal uleer: a 3-6 year follow-up. Bir J Surg $1977 ; 64: 473-476$

256. De Migued J. Late results of proximal gastric vagotomy without drainage for duodenal ulcer: 5-9 year follow-ap. Br J Surg $1982: 60 \% 7 \div 10$.

257. Miller TA, Tepperman BL. Effect of prostaglandin E2 on aspirin-induced gastric mucosal injury. J Surg Res $1979 ;$ 26: 10-17.

258. Mitchell GAG. A macroscopic study of the nerve supply of the stomach. I Anat 1940; 75: 50-63.

259. Mitschke H. Morphologische veranderungen der Magenschleimhant nach Vagotomie. Zeitsethrift für Gistroenta:rologie $1979: 17: 493-502$.

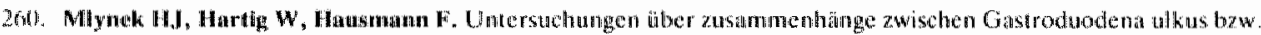

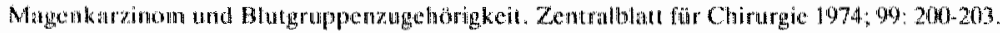

261. Mollerup $C_{4}$ Cartensen HE, Brum $\mathrm{E}_{*}$ Christansem LA, Stage G. Possible antagonists to gastrin in parattyroid adenotnas. Br 5 Sitig 1980; 67:890-892.

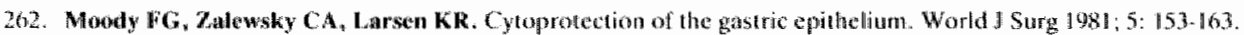

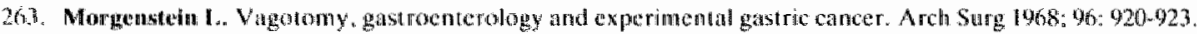

264. Mourant AE. Blood groups and diseases. Fiotest Bull 1976-1-14.

265. Mowat E, Comn A, Paterson CR. Hypenparathyroidism in peptic ulcer patients. Br J Surg 1981; 68:455-458.

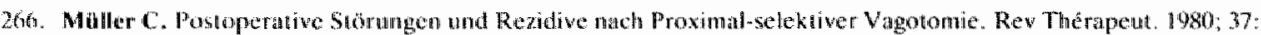
(6) $3 \times 649$.

267. Multer C. How do diniw nesults after proximal gastric wagotony compare with the Visick grade patte of healthy controls" A critical evaluation of the Wask grading. World J Surg 1982: 6: 648.

268. Multer 14. Matagoperate? Z0 ja. welke? Ned Tijdschr Gencesk 1974; 118: 1037-1042.

260. Multicentre Pilot Sudy: pentagastrin as a stimulant of maximal gastric act response in man. Lancet 1967; $1: 291-$ 293.

270. Neukirchen M, Haase W. Untersuchungen über Znsammenhänge zwischen Bhtgruppe und Ulkushäufigkeit des Magens und des Zwöltingerdarms. Medizinische Welt 1960; 31: 394-396. 
271. Nilsell K. Five to nine years results of selective proximal vagotomy with and withoul pyloroplasty for duodenal wher. Act Chir Scand 1979; 145:251:255.

272. Nillsell K., Ewerth $\mathbf{S}$. The acid secratory tesponse to betarole and insul hin hypolycemia after selective proximal wagotomy for dinodenal uleer. Act Chir Scand 1981; 147:431-434.

273. Nyhos L, Donahue P', Krystosek R, et al. Complete wagotomy; the evolution of an efilective technichue. Aroh Surg 1980: 115:264-268.

274. Nylamo EI, Inberg MV, Nelinarkika OL. The insulin test and recurrence of ulcer ffter vagotomy and antral resection or drainage. Act Chir Scand 1980;146:127.132.

275. Nylamo EI, Heinonen R, Inberg MV. Instilin and perut agastrin test and recurrence of ulcer after parietal cell vagotomy. Act Chir Scand 1982; 148: $167-172$.

276. Oomen JPCM, Wittebol P, Geurts WJC, Akkermans LMA. Lower esophageal sphincter function after hightly selective vägotomy. Arch Surg 1979; $114:$ :908-910.

277. Onr 1. Selective surgery for peptic ulcer; a review. Gut 1962; 3:97-105.

278. Papaevangelou EJ, Sapkas AM. A twelve year teview of treat ment of massive gashrodunodenal bleeding. World J Surg 1980; $4: 353 \times 356$.

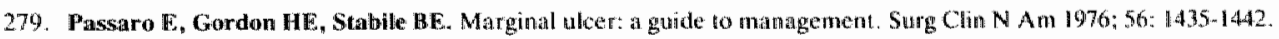

280. Payne RA, Cox AG, Spencer J, Cheng FCY. Effect of wagotomy on gastric acid secretion stimulated by pent and histamine. Br Med J $1967: 4: 456-457$.

281. Pendower JEH. A comparison of the Burge and Grassi intraoperative tests for completeness of nerve section in parictal cell vagotony. Br J Surg 1981; 68: 83-84.

282. Penn I. The declining role of the surgeon in the trewtment af acid-peptic diseaser. Arch Surg 1980; 115: 134-135.

283. Petropoulos PC. Highly selechiwe transgastric vagotomy. Prelimimary report of a new procedure. Arch Surg 1980 : $115: 33-39$

284. Playforth MJ, MeMahon MU.J. The indications for simple closure of perforated duodenal ulcers. Br J 5 urg 1978 : 65 : $699-701$.

285. Polansky DB, Shirazi SS, Coon D. Lack of correlation of gastric acid sectiction and blood low. J Surg Res 1979; 26: $320-325$.

286. Poppen B, Delin A, Sandstedt B. Parietal cell vagotomy. Localisation of the microscopical antral fundic boundary in relation to the macroscopical. Act Chir Scand 1976; 142: 251-255.

287. Poppen B. Delin A, Sandstedt B. Parietal cell vagotomy (II): relation of gastaitis and gastric mucosal antroply to the completeness of denervation at antal-fundic boundary. Act Chir Scand 1978; 144:141-147.

288. Poppen B. Parebal cell wagotomy (III). The contrection between the bealisation of the antral fundic botndary and gastric secrevion pre-and postoperatively. Act Char Scand 1978; 144: 149-158.

289. Poppen B, Deth A. Parietal eell wagotomy for duodenal and pyloric ulcers. I chinical factors leating wa labure of the operation. Am IStrg $1981 ; 141: 323-329$.

290. Poppen B, Dellin A, Sandstedt B. Partetal cell vagotomy for duodenal and pylonic ulcers. If histopathology ant gastric secretion. Am J Surg 1981; $141: 330-333$.

291. Postlethwatt RW. Rehrospective study of operations for peptic ullcer. Surg Gynecol Obstet 1975; 149: 7013-707.

292. Prescont R.J. Sircus W, Lai CL, Lam SK. Failure to confirm evidence for existence of wo populintions with duoderial wheer. Br Med I 1976; 677.

293. Ralphs DNL, Thomson JPS, Haynes S, Lawson-Smith C, Hobstey M, li.e Quesne LP. The relationshipt between the rate of gastric emplying and the dumping syndrome. Br I Surg 1976; 65: 637-641.

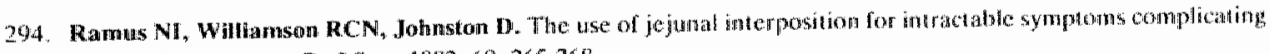
peptic uteer sturgery. Br I Surg. 1982; 69:265\%268.

295. Rauwerd:a IA. Het magsiompcarcinoon. Ned Tijdschr Geneeskd 1980; 124:6.22-635

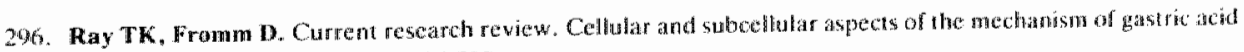
secretion. J Surg Res 1981; $31: 496-505$.

247. Rayford PL, Thompson JC. Gastrin. Surg Gynecol Obsten 1977: 145:257-268. 


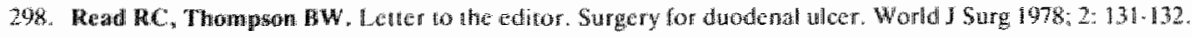

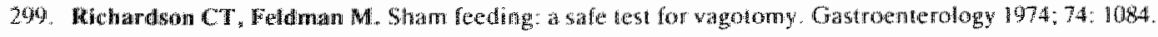

300, Roblys JW. Setection of operation for duodenal ulcer based on acid steretory studies; a reappraisal. Br I Surg 1973 : 60: $(601-605$

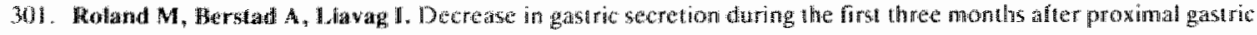
vagolomy in duodenal ulcer patients. Scand I Castroemterology $1975 ; 10: 363-367$.

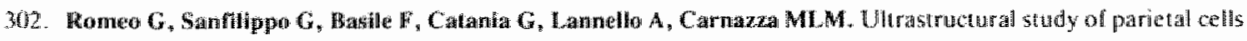

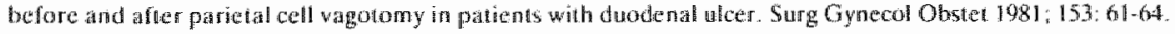

303. Rosati 1 . Extended selectwe proximal vagotomig obserwanions on a variant in tectunique. Chir Gastroenterology $1976 ; 10 ; 3.3 .37$

304. Ross $\mathrm{B}, \mathrm{Kay}, \mathrm{W}$. The insulin test after vagotorny, Gastroenterology $1964,46: 379,386$.

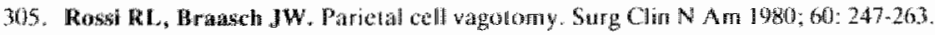

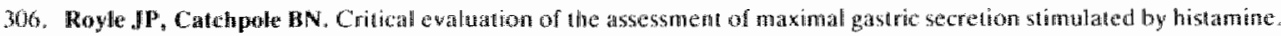
Br.J Surg 1967; 54: 56m63.

307. Rümke Chr $\mathbf{L}$. Kantlekeningen over de gevolightid, de specificile li en de vororpellende waarder wan diagnosische lesis. Ned Thinghr Geneteskd 1983; 127:556-567.

308. Russell ACG, Faber RG, Hobsley M. Plasma gastrin concentration related to acid secretion during insulin hypoglycaemia. Br J Surg 1977; 64: 4704472 .

309. Sagor GR, Ghatei MA, MeGregor GP, Mtitctimere RP, Kirk RM, Btwom Sr. The influence of an intact pylorus on postprathial onteroglucagon and new rotewin release after upper gastric surgery. B I Surg 1981; 68: 190193.

310. Salaman JR. Highy selective vagotomy using tantalum clips. Br J Surg 1978; 65: $155-156$.

311. Salaman JR, Harvey J, Duthie IHL Importance of symptoms after HSV. Br Med I 1981; 283; 1438.

312. Säuberli H, Largader $\mathbf{~}$, Deyhie P, et al. Resultati der proximal selektiven Wagotomie mit und ohme Pyloroplastik Helvelica Chir Acta 1475; 42:543-546.

313. Sawyers JL, Herrington JL., Burney DP. Proxinal gastric vagotomy compared with vagotony and antrechomy and selectiwe gastric wagotomy and pyloroplasty. An Surg 1977; 186: 510-517.

3/4. Sawyers Jl Herrington JL. Perforated duodenal uloer managed by proximal gastric vagotomy and sut ure plication. Ann Surrig 1977; 185:656-660.

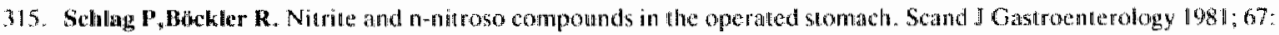
$63 \times 69$.

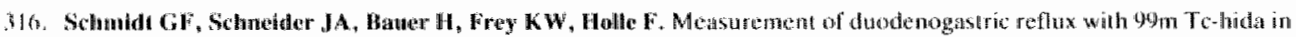

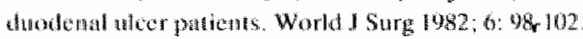

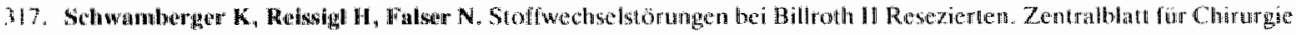
$1973 ; 9811105 \% 1110$.

716. Schwille PO, Schwemule K, Samberger NM, Hegenann G. Serume minerals and alcium regulating hormones following selectiwe proximal vagotomy (SPV) in humans. Soc de Chir 1975; 6: 641-646.

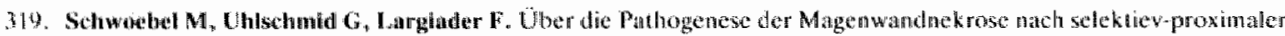
Vagotomie. Chinurg $1981 ; 52: 328-331$.

320. Selking 0 , Krause U, Nilsson 1 , Thoren L. Parietal cel vagotomy and truncal wagotomy as treatment of duodenat wher. An Chir Soand 1981; 147:561-567.

32. Sicwert R. Vagotomic und unterer Osophagussphinkter. Zeitsch fur Gastrocnterologie 1979: 17: $522-530$.

122. Sicwert $\mathbb{R}$, Miller C. Proximal-gasirische Vagotomic. Chirarg 1981; $52: 511-518$.

323. Silen W, Merhav A, Simson JNI. The pathophysiology of stress ulcer disease. World J Surg 1981;5:165-174.

324. Skjennald A. Stadats JO. Syversen SM, Aune S. Dysphagia after proximal gastrie vagotomy. Scand $I$ Ginstrucnterology $1979 ; 14: 609-613$

325. Skoubo Kristensen V. Conservative teatment of 155 cases of perforated peptic ulcer. Aot Chir Seand 1980; 146 ; $189-193$. 


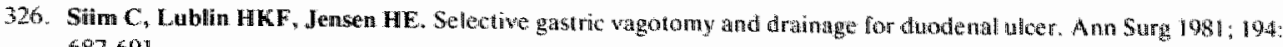
$687-691$

327. Small WP. The results of a policy of selective surgical treatment of duodenal ulcer. Br J Surg 1967; 54: $838-841$.

328. Sumith G, Irving AD. Age an operation and he results of truncal vagotony and gastroenterostomy for chronic duodenal vlcer. Surg Gynecol Obstet $1981 ; 152-153$

329. Smith MP. Decline in duode nal ulcer surgery. JA MA 1977; 237; 987-988.

330. Solhaug $\mathbf{J H}$, Bjerkeset $\mathbf{T}$, Hatvorsen JF. Highly selective vagotomy in the troatmen of duodemat uker in a teathing hospilal. Surgery $1977 ; 82: 248-253$

331. Soll AH, Walsh JH. Regulation of gastric acid secretion. Ann Res Physiol 1979; 41: $15-53$.

332. Stabile BE, Passaro E. Recurrent peptic ulcer. Gastroenterology 1976; $70: 124$.

333. Stabile BE, Passaro EE, Samlof M, Walsh JH. Serum pepsinogen I, serum gastrin, ard gastrin acid output in postoperative recurrent peptic ulcer. Arch Surg 1978; 113:1136-1141.

334. Stadil F, Rehfeld JF, Christiansen PM, Krontworg $O$. Gastrin response to food in duodenal ulcer patients belore and after selective or highly selectiwe vagotomy. Br I Surg 1974;61: $884-888$.

335. Stadth F, Rehfeld JF. Gastrin response to insulin after selective, highly selteclive and trunctal vagotomy. Gastroenterology 1974; 66: 7-1.5.

336. Stening GF, Grossmann MII. Gastric acid response to pentagastrin and thistamine after extragastric wagotomy in dogs. Gastronterology $1970 ; 59: 364-371$.

337. Steiger E, Copperman AM. Considerations in the management of perforated peptic ulcers. Surg Clin N Am 1976 ; 56: $1395-1402$.

338. Stern DH, Walsh JH. Gastrin release in postoperahe ulcer patients: cvidence for release of duodenal gastrin. Gustroenterology $1973 ; 64: 363-369$.

339. Stoddard CJ, Vassilak is JS, Duthie HL. Highly selective vagokony or truncal wagotomy and pyloroplasty for chrohtic duodenal talceration: a randomized, prospective clinical sady. Br J Surg 1978; 65: 793-796.

340. Suleiman ST, Maglad SA, Hobsley M. Dysphagia following selective vagotomy. Br J Surg 1979; 66: 6077608.

341. Susger M, Stein Z. Civilisation and peptic ulicer. Lamcet $1962 ; 115-119$.

342. Suy R. De maagresectie voor het ulcus duodeni en ulcus ventriculi. Tijdschr Gastroenterologie 1962; $5: 5664577$.

343. Taylor TV, Pearson KW, Torrance B. Revagotomy for recurrent peptic ullceration. Br J Surg 1977; 64:477-481.

34t. Temple JG, McFarland J. Gastro-oesophageal reflux complicating highly selective vagotomy. Br Med I1975; 2: $168-169$

345. Thompson JC, Fender HF, Watson LC, villar HV. The effects on gastrin and gastric secretion of 5 wartent aperations for dinodenal ulcer. Ann Surg 1976; $183: 599-608$.

346. Thompson JC. The role of surgeny in peptic uleer. N Engl J Med 1982; 550-551.

347. Thomsen $F$, Kjaergaard $\mathbf{3}$, Jensen HF. Cimetidine freament of recurrent ulcer after wagotomy. Act Chir Scand 1980: $146: 35-39$.

348. Tovey F. Geographical aspects of peptic ulcer sugery. World J Surg 1977; 1: 47-53.

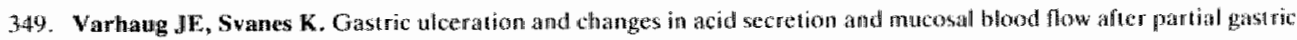
dew wallarization in cats. Act Chir Scand 1979:145:313\%319.

350. Vemables CW, Johnston ID. The use of a combined pentagustrin/insulin test do assess the effectiveness of trincul wagotony. Br I Surg 1969; 56 : 701 .

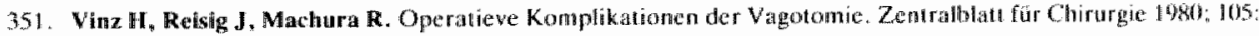
$605-610$

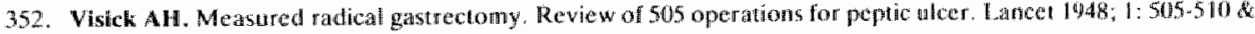
$551-552$.

353. Visick AH. A study of the failures after gastrectomy. Ann R Coll Surg Engl 1948; 3: $266 \% 284$.

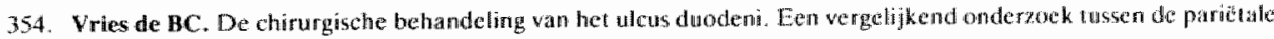

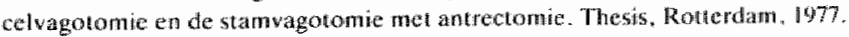




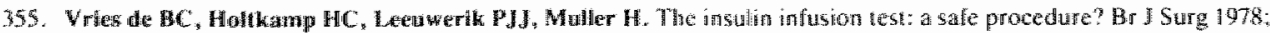
$65: 121-122$.

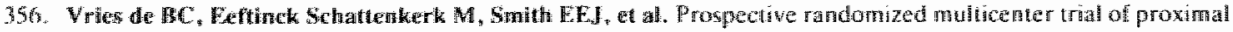
gastric wagotomy ur truncal wgotomy and antreciomy for chronic duotenal alcer: results after 5 -7 years. Wortd 1 Surg: $1982 ; 6: 652$.

357. Wallin 1. The effect of parietal cell vagotony on gestro-besophageal function in duodenal ther pahents. Scand J Gastrocplerology $1981 ; 16: 97.102$.

398. Wangenstuen OH, Wangensten SD. The rise of surgery. Fokkestone. Eageland. Dawson. 1978.

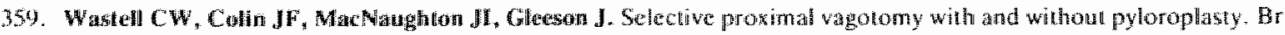
Med J 1972; 1:28-30.

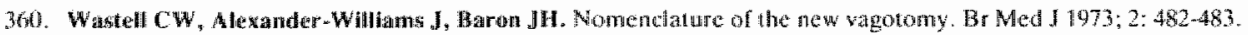

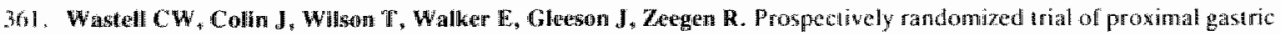
vagotomy either with or without pyloroplasty in treatnent of uncomplicated duodenal ufeer. Br Med I1977;2:851853,

362. Wastelt CW, Millington HT. The chect of hepat ic intepposition on insulin-simulated gastric secretion after proximal gastsic wagotomy. Br J Surg 1978; 65:396-398.

36.3. Wayjen van RGA. Verdeling van de ABO-blocdgrowen bij maagkankerpatemten. Med Tijdschr Geneeskd 1960 ; $104.41149: 24482455$.

364. Weger RV, Meiter DE, Richardson CT, Heldman M, McClelland IRN. Parietal cell vagotomy un a surgical eraining program. An J Surg 1982; 144:6894603.

365. Wefland D, Dunn DH, Humphrey EW, Schwartz ML. Gastric oullet obstruction in peptic ulcer disease: an indication lor surgery. Am J Süg 1982; 143:90193.

366. Weinstein VA, Hollander F, Lauher FU, Colp R. Correlationi of insulin test studies and clinical results in a series of peptic ulcer cases treated by vagotony. Gastroenterology 1950; 14:214-227.

367. Wesdorp RIC. Studies on gasirin. Thesis, Rijksuniversiei Limburg, Maastricht "1977.

368. Wieman J, Max MH, Voyles CR, Darrows GH. Diwersion of duodtenal contents. Arch Surg 1980; 115:959,961.

369. Willims RS, Johngon AG. Residual areas of acid secretion in the cat stomach after inconplete vagotomy. Digestion $1980 ; 20: 420-421$.

370. Witt 'TR, Roseman DL, Banner BF. The role of the gastric antrum in the pathogenesis of reflix gasuritis. I Sutg Res 1979. 26: 220-232.

371. Wormstey KG. Elfects of a gastrin-like pentapeptide (UCI 50, 123) on stomach and pancreas). Lancet 1966 ; May, 9) 34096 .

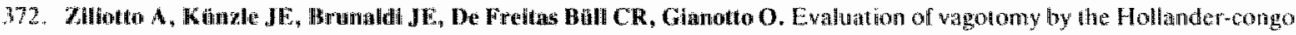
ful text Sung Gynedol Obstet 1982;155;212-220. 


\section{Acknowledgements}

The accomplishment of this thesis is the result of the endeavour and conscientiousness of many people to whom I should like to express my gratitude. Only a few of them can be acknowledged personally.

First I should like to mention those who have contributed to the thesis itself and secondly those connected with the work which constitutes the basis of this book.

David Johnston: I consider you as the guest of honour on this occasion. You were the first to apply highly selective vagotomy in man and you have contributed a huge amount of reliable scientific foundation to this operation, which has conquered the world within ten years.

I am very grateful for having been a guest in your department in 1982 and especially for your commitment towards my scientific attempts, which has contributed greatly to this thesis. Your warm and honest personality has impressed me deeply.

I wish to thank Jaap Munting who introduced the HSV in Heerlen. From you I received the largest part of my surgical training; thanks to your wision and - near neurasthenic - accuracy and personal involvement, the study of the results of HSV has culminated in a thesis.

Prof. Greep: your dynamic and powerful approach is almost proverbial. You accepted my preliminary work for a thesis and consequently shaped it effectively to the end result. I am very grateful for your critical views and wholehearted support as well as those of your co-workers.

Prof. Brombacher: your specialism has a great interface with this thesis. In an almosit silent and self-evident way you have helped me to accomplish this, not fearing to solve many problems, sometimes even without needing to be asked.

Prof. van Houten: you were the one whose thorough judgement I intuitively needed in order to start the work for this thesis and to bring it to completion. I have greatly appreciated your endeavour and judgment.

Prof. Flendrig: in a special way you were connected with the subject; your ideas were thoroughly to the point and have contributed much in enhancing the quality of this work.

Many others have contributed and I want to mention them in gratitude:

- Prof. Drukker and A. Boekelaar who reshaped my anatomical concepts

- Alex Volovics for his assistance in computer elaboration of the data and for his efforts to make a surgeon aware of statistics

- André Naus who - quite voluntarily - was ready, willing and able to solve the most compound and innumerable questions in no time, and had the answers transported by ambulance from Roermond to Heerlen thus illustrating the special character of his help

- Dr. Lustermans for reading the manuscript and commenting on it

- Dr. van Wersch for his revision of the section "blood group and family history"

- Roelof Willighagen for his pathology review

- Chris Voskamp: your skill has impressed me greatly; the final shape of this book is mainly due to your superb performance

- Frans Malschaert: for your "covering" piece of art 
- Dr. Davies, the British enclave in the De Wever-Ziekenhuis: your correction of "my" English was a real performance

- the accurate and intelligent secretarial assistance both in Maastricht, where the definitive text of the manuscript was moulded and its computerisation took place (Maartje Duyzings et $a l$ ) and in Heerlen (Marion Spaans et al).

Furthermore, I feel greatly indebted to many people involved in the original work: the treatment of the patients.

- the surgeons of the De Wever-Ziekentuis: Doctors Pinckaers, Munting, van Houtte, van Duin and Lens, for their cooperation and understanding; in particular Cees van Duin who was always ready to take over my duties for the sake of this thesis

- the residents of the surgical department for their support and their favourable contribution to the results

- all staff of the De Wever-Ziekenhuis involved, especially the operating theatres (head: G. de Esch), the out-patient department (head: P. Lenoir) where in particular Leidy Maahsen did a lot of work, the surgical wards (head: F. Casters), the clinical chemical laboratory (head: Prof. Brombacher), the isotope laboratory (head: Dr. Gijzen), the blood transfusion service, the internal function department, where the gastric secretion tests were carried out conscientiously (Pieternel Hovens and Gonnie Holtus), the library (Miss A. Dessers), the medical archives service (J. Smeets), the X-ray department (head:Dr. Lamers).

Moreover I want to express my gratitude towards those who put their trust in the surgical department, thus enabling this work to be done: the physicians (head: Dr. Zeppenfeldt) of the De Wever-Ziekenhuis, the family doctors and the patients themselves.

Thanks to the "paranimplis" Kees Pons and Tom Schiphorst for their valuable assistance.

Finally, thank you Mariëtte for your tender support and goodwill even in the most discouraging hours. 


\section{Curriculum vitae}

Dick Busman was born on the 25th July 1944 in The Hague, where he graduated from secondary school (gymnasium B, St. Janscollege).

Medical studies were accomplished at the university of Nijmegen and were concluded with qualification in June 1970.

He spent about $2 \frac{1}{2}$ years (1972-1974) in Tanzania (regional hospital of Bukoba) which was preceded by additional training in gynaecology and obstetrics (St. Annadal hospital, Maastricht; J. Specken, G. Kruyver and A.v.d. Kar) and in surgery (St.

Elisabeth hospital, Alkmaar; A. Stoop, P. van Velthoven).

From 1974-1975 he joined the thoracic and cardiovascular department of the

O.L.V.G. (Onze Lieve Vrouwe Gasthuis, Amsterdam; A. Gründemann, B. Zienkowicz).

His surgical training was obtained in the De Wever-Ziekenhuis, Heerlen from F.J.A. Buytendijk and J.D.K. Munting.

Specialist registration took place in July 1981.

From 1st July 1981 he has been senior registrar ("chef de clinique") in this hospital, where all the patients described in this thesis were treated.

the publication of this thesis has been financially supported by:

the surgeons of the De Wever-Ziekenhuis

the 'Stichting Dr. Ir. J.H.J. van de Laar'

the research funds of the De Wever-Ziekenhuis

Laméris Instruments b.v. 
Printed by: Schrijen-Lippertz, Voerendaal Lay-out \& illustrations: Chris Voskamp

Cover: Frans Malschaert 